\title{
Role of arginine in endotoxemia : studies in mice with reduced arginine availability
}

Citation for published version (APA):

Hallemeesch, M. M. (2001). Role of arginine in endotoxemia : studies in mice with reduced arginine availability. [Doctoral Thesis, Maastricht University]. Maastricht University. https://doi.org/10.26481/dis.20011220mh

Document status and date:

Published: 01/01/2001

DOI:

10.26481/dis.20011220mh

Document Version:

Publisher's PDF, also known as Version of record

\section{Please check the document version of this publication:}

- A submitted manuscript is the version of the article upon submission and before peer-review. There can be important differences between the submitted version and the official published version of record.

People interested in the research are advised to contact the author for the final version of the publication, or visit the DOI to the publisher's website.

- The final author version and the galley proof are versions of the publication after peer review.

- The final published version features the final layout of the paper including the volume, issue and page numbers.

Link to publication

\footnotetext{
General rights rights.

- You may freely distribute the URL identifying the publication in the public portal. please follow below link for the End User Agreement:

www.umlib.nl/taverne-license

Take down policy

If you believe that this document breaches copyright please contact us at:

repository@maastrichtuniversity.nl

providing details and we will investigate your claim.
}

Copyright and moral rights for the publications made accessible in the public portal are retained by the authors and/or other copyright owners and it is a condition of accessing publications that users recognise and abide by the legal requirements associated with these

- Users may download and print one copy of any publication from the public portal for the purpose of private study or research.

- You may not further distribute the material or use it for any profit-making activity or commercial gain

If the publication is distributed under the terms of Article $25 \mathrm{fa}$ of the Dutch Copyright Act, indicated by the "Taverne" license above, 


\title{
ROLE OF ARGININE IN ENDOTOXEMIA
}

\author{
Studies in mice \\ with reduced arginine availability
}


Druk: Ponsen en Looijen, Amsterdam

Dit proefschrift is verschenen bij uitgeverij Omen Malum Litterarum te Drachten onder ISBN 90-805415-6-7.

Role of arginine in endotoxemia. Studies in mice with reduced arginine availability/ Marcella M. Hallemeesch
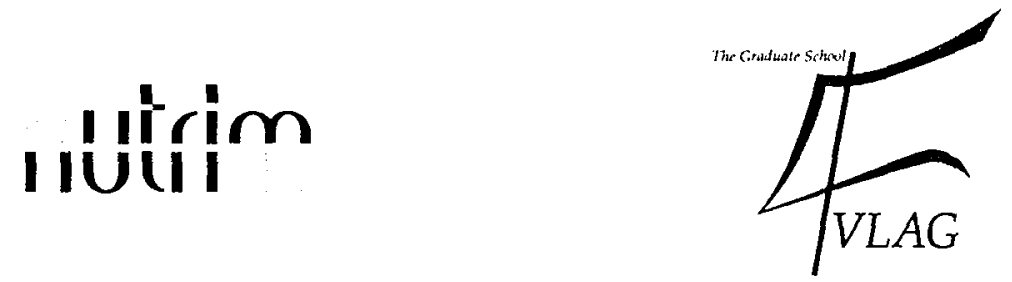

The studies presented in this thesis were performed at the Nutrition and Toxicology Research Institute Maastricht (NUTRIM), which participates in the Graduate School VLAG (Food Technology, Agrobiotechnology, Nutrition and Health Sciences), accredited by the Royal Netherlands Academy of Arts and Sciences (KNAW). 
ROLE OF ARGININE IN ENDOTOXEMIA

Studies in mice with reduced arginine availability

\section{PROEFSCHRIFT}

ter verkrijging van de graad van doctor aan de Universiteit Maastricht,

op gezag van de Rector Magnificus, Prof. dr. A.C. Nieuwenhuijzen Kruseman volgens het besluit van het College van Decanen, in het openbaar te verdedigen

op donderdag 20 december 2001 om 12.00 uur

door

Marcella Madeleine Hallemeesch 
Promotores:

Prof. dr. P.B. Soeters

Prof. dr. W.H. Lamers (Universiteit van Amsterdam)

Co-promotores:

Dr. N.E.P. Deutz

Dr. A.J. Meijer (Universiteit van Amsterdam)

Beoordelingscommissie:

Prof. dr. G. Ramsay (voorzitter)

Dr. A.M. Ajami (Massachusetts Institute of Technology)

Prof. dr. M.H.J.M. Jacobs

Prof. dr. J.G. de Mey

Prof. dr. T.R. Rabelink (Universiteit Utrecht)

The studies described in this thesis were supported by grants 902-23-098 and 90223-239 from the Netherlands Organization for Scientific Research (NWO). Publication of the thesis was financially supported by Xanthus Life Sciences, Inc. 
Aan mijn ouders 


\section{Contents}

page

Chapter 1 General introduction and outline of the thesis

Chapter 2 Methodological studies

2.1 Metabolic flux measurements across portal drained viscera, liver, kidney and hindquarter in mice

2.2 Tracer methodology in whole body and organ balance metabolic studies: plasma sampling is required

Chapter 3

Arginine and NO metabolism during endotoxemia

3.1 In vivo rate of NO synthesis is increased during mouse endotoxemia

3.2 Endotoxemia differentially affects arginine and protein metabolism in intestine and liver of mice

3.3 Renal arginine and protein metabolism are increased during early endotoxemia in mice

3.4 Increased iNOS-mediated and decreased cNOSmediated NO production rates reflect blood pressure changes in LPS-challenged mice

Chapter 4

Reduced arginine availability and nitric oxide production

4.1 Acute reduction of circulating arginine does not compromise cNOS or iNOS-mediated NO production

4.2 Chronic reduction of circulating arginine by ornithine transcarbamylase-deficiency causes a reduction of cNOS-mediated NO production

4.3 Chronic reduction of circulating arginine by transgenic arginase expression causes a reduction of iNOS-mediated NO production

Chapter 5

Summary and discussion

Samenvatting

Publications

Dankwoord 


\section{Chapter 1}

General introduction and outline of the thesis 


\section{Introduction}

Nitric oxide is produced from arginine by nitric oxide synthase (NOS), which is also called arginine deiminase. In this reaction, in which $N^{\omega}$-hydroxyarginine is a stable intermediate (1), molecular oxygen modifies the guanidinogroup to form NO and citrulline (2). NO is then further oxidized to nitrite and nitrate (3). Only arginine, and to a lesser extent homoarginine, are substrates for NOS (4). A number of co-factors are required for $\mathrm{NO}$ production, including $\mathrm{NADPH}_{2}, \mathrm{Ca}^{2+}$ and tetrahydrobiopterin (5). Reduced NO production by NOS may be due to reduced availability of the substrates arginine $(6,7)$ or oxygen $(8,9)$, or to decreased availability of co-factors such as tetrahydrobiopterin (10-14) and $\mathrm{Ca}^{2+}(15,16)$.

The rate of NO production may be critically dependent on the availability of arginine. In physiological conditions, the concentration of circulating arginine is approximately $100 \mu \mathrm{M}$ and the tissue concentration ranges from 100 to $1000 \mu \mathrm{M}$. In healthy volunteers the basal rate of NO production was $1 \mu \mathrm{mol} / \mathrm{kg} / \mathrm{hr}$, and equaled $1.2 \%$ of plasma arginine turnover (17). Although the percentage of arginine turnover involved in NO production was low, the plasma arginine compartment served as a significant precursor pool (54\%) for whole body NO formation (17), suggesting that circulating arginine may determine the rate of NO production.

Three isoforms of NOS exist, endothelial NOS (eNOS, or NOS-3), neuronal NOS (nNOS, or NOS-1) and inducible NOS (iNOS, or NOS-2) $(18,19)$. Of these, eNOS and nNOS are expressed constitutively and are therefore often termed cNOS. These enzymes produce small amounts of NO. The last isoform is inducible by microbial products (including lipopolysaccharide, LPS), and inflammatory cytokines, and is therefore named iNOS (20). cNOS is dependent on $\mathrm{Ca}^{2+}$, whereas iNOS is independent of intracellular $\mathrm{Ca}^{2+}$. The intracellular $\mathrm{Ca}^{2+}$ levels are low and fluctuate, causing cNOS-mediated NO production to be low. The $\mathrm{K}_{\mathrm{m}}$ of the NOS isoforms for arginine lies between 2-20 $\mu \mathrm{M}(21)$.

On basis of enzyme kinetics, the arginine concentration should, in principle, not limit NO production, since the intracellular concentration of arginine is well above the $K_{m}$ values reported for nitric oxide synthases. In the literature, contradicting effects of reduced arginine availability on NO production have been reported. Feeding an arginine-free diet to healthy individuals reduced plasma arginine levels (22-25) but did not change plasma $\mathrm{NO}_{\mathrm{x}}$ levels (25) or in vivo constitutive NO 
synthesis (26). In contrast, in young rats, dietary arginine deficiency decreased plasma arginine concentrations and urinary nitrate excretion before and after LPS, indicating impaired constitutive and inducible NO synthesis (27). In ornithine transcarbamylase deficiency, a condition of decreased circulating arginine, NO production was decreased in the brain (28). In newborns with persistent pulmonary hypertension, plasma arginine utilization for whole body NO synthesis was reduced during the acute vasoconstrictive state (29). Plasma arginine was however not reported. In addition, in vascular smooth muscle cells, induction of NO synthesis by $I L-1 \beta$ depended on external arginine when these cells were arginine-depleted for $24 \mathrm{~h}$ (30). Together these studies indicate that arginine availability is an important factor for NO production.

\section{Postulated mechanisms for the mediation of arginine availability to ensure nitric oxide production}

Reported endogenous adaptations to ensure nitric oxide production despite reduced arginine availability include increased de novo synthesis from citrulline, increased transport across the cell membrane and reduced arginine breakdown by arginase (Figure 1).

\section{Regulation via increased de novo arginine production}

The de novo production of arginine is characterized by the successive action of the small intestine and the kidney (the gut-kidney axis) (31). The small intestine produces citrulline from glutamine (32) and proline (33). Citrulline is released into the circulation and taken up by the kidney, where it is converted to arginine $(34,35)$. The conversion of citrulline to arginine occurs in the renal proximal tubules and is mediated by the enzymes argininosuccinate synthase (ASS) and argininosuccinate lyase (ASL) $(34,36)$, and contributes approximately $10 \%$ to plasma arginine flux (22). The importance of this route was recently illustrated in rats with short bowel syndrome (37). In addition, patients suffering urea cycle deficiencies still require dietary arginine or citrulline supplementation after liver transplantation (38), indicating that the defect in intestinal citrulline synthesis precludes renal arginine synthesis. The reason for this is that only the intestine is capable of net ornithine production. 


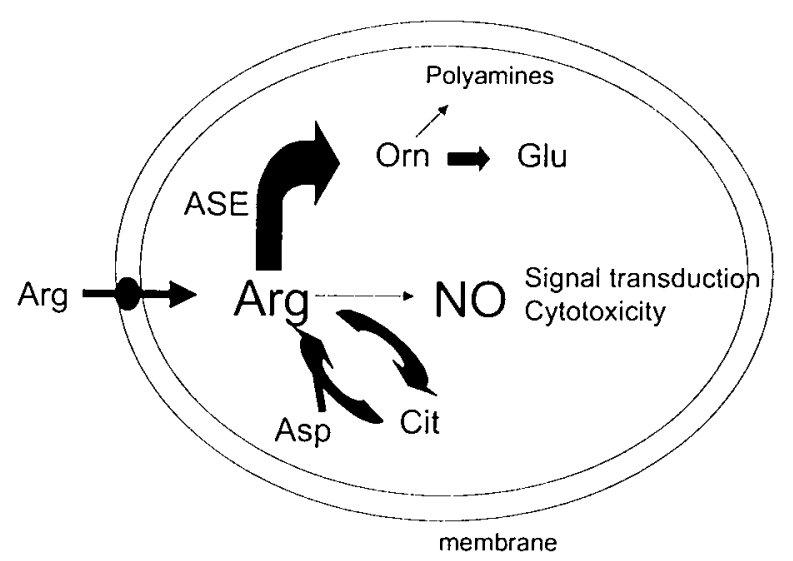

Figure 1. Intracellular arginine availability for NO production is determined by arginine membrane transport, de novo arginine synthesis and arginase activity. Arg = arginine, $N O=$ nitric oxide, Cit $=$ citrulline, Orn $=$ ornithine, $G l u=$ glutamate,$A s p=$ aspartate, $A S E=$ arginase .

Nitric oxide production may be regulated by de novo arginine production. The increase in de novo arginine production may theoretically occur centrally and the arginine that is produced is released into the circulation, as is the case for the kidney. In addition, the production of arginine may occur locally and the arginine produced may be directly used in the synthesis of NO. In this reaction citrulline is formed as a co-product the NOS reaction and is available for recycling to arginine, forming a cycle which could be termed the "citrulline-NO cycle" (39) or the "arginine-citrulline cycle" (40). This cycle can only operate when aspartate synthesis is sufficient, and it thus needs coordinated activity of the TCA cycle and an $\mathrm{NH}_{4}{ }^{+}$donor.

In several organs and tissues, arginine is regenerated from citrulline in the citrulline-NO cycle. This cycle operates in cultured endothelial cells (41), and macrophages (42), and also in the peripheral nervous system including opossum internal anal sphincter (43). In rats injected with bacterial endotoxin, iNOS mRNA and increased ASS and ASL mRNA was detected in lung and spleen $(44,45)$. In this model, iNOS mRNA was induced very rapidly, whereas ASS and ASL MRNA was induced more slowly $(44,45)$. Of these enzymes, ASS is the rate-limiting enzyme, and needs both citrulline and aspartate. A rapid induction of iNOS activity followed by a slower induction of ASS activity was also reported for rat aortic smooth muscle cells stimulated with LPS and IFN-Y (40) and cytokine-stimulated astroglioma cells (46). These data indicate that the induction of iNOS and the arginine synthesizing 
enzymes are partly coordinated and partly dissociated, possibly because of different roles of these enzymes (44). These data clearly suggest recycling of citrulline to arginine in this condition and thus endogenous arginine supplementation in favor of NO production (44). In macrophages, citrulline transport is insensitive to induction by LPS, and adding citrulline in the absence of exogenous arginine only partially restores NO production (47), indicating that arginine biosynthesis from extracellular citrulline is limited.

Several studies have indicated that, despite reduced plasma arginine levels, de novo arginine synthesis rate is not affected by an arginine free diet for 6 days (22, 23). Moreover, net renal arginine synthesis was not affected by dietary arginine uptake (48). Castillo et al. suggested that arginine homeostasis is maintained by regulation of the rate of arginine degradation, rather than the rate of de novo synthesis (24). These data are in contrast to rat data suggesting that renal arginine production increased in response to reduced circulating arginine levels (49). In chronic renal failure induced by $5 / 6$ nephrectomy in rats, arginine production per unit tubular length was increased in proportion to hypertrophy of proximal convoluted tubules, and renal arginine production increased with citrulline concentration (50). The increase in arginine production per unit length was not sufficient to compensate for the reduction in nephron number (50), but in vivo measurements revealed that citrulline uptake and arginine production by the kidney were not different from control values (51).

\section{Regulation via arginine membrane transport}

The transport of cationic amino acids, including arginine, was, for a long time, thought to occur through a single transporter referred to as system $\mathrm{y}^{+}$. Now, four different transport systems $\left(\mathrm{y}^{+}, \mathrm{b}^{0,+}, \mathrm{y}^{+} \mathrm{L}\right.$ and $\left.\mathrm{B}^{0,+}\right)$ have been characterized by their substrate specificity and the $\mathrm{Na}^{+}$dependence of the transport (52). The transport activity of system $\mathrm{y}^{+}$is characterized by a high-affinity for cationic amino acids, sodium independence, and stimulation of transport by substrate on the opposite (trans) site of the membrane (53). The other three systems accept a wider range of substrates, including cationic and neutral amino acids. Systems $\mathrm{b}^{0,+}$ is $\mathrm{Na}^{+}$independent (54) and system $\mathrm{B}^{0,+}$ is $\mathrm{Na}^{+}$-dependent (55). System $\mathrm{y}^{+} \mathrm{L}$ was first described in erythrocytes as a broad scope amino acid exchange system, which in the absence of $\mathrm{Na}^{+}$, mediates the exchange of cationic amino acids, including 
arginine, and, in the presence of $\mathrm{Na}^{+}$, the exchange of intracellular cationic amino

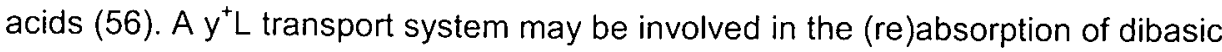
amino acids across the small intestine and kidney proximal tubule epithelia $(57,58)$. In addition, arginine release, for example by the kidney, may be an important function of the $y^{+} L$-like transporter (59).

Transport of arginine is, however, mostly performed via system $\mathrm{y}^{+}(52)$. The affinity for $D$-arginine is 20 times less than for L-arginine $(60)$. The $K_{m}$ of system $y^{+}$ (0.1-0.25 mM) lies within the physiological concentration range of arginine. At the molecular level the transport properties of system $\mathrm{y}^{+}$could be ascribed to a family of cationic amino acid transporters (CATs) $(52,61)$. At present, three related CAT proteins have been identified and referred to as CAT-1, CAT-2B and CAT-3 $(61,62)$. A fourth related carrier, CAT-2A, exhibits the same $\mathrm{Na}^{+}$-independent transport activity specific for cationic amino acids but has at least 10 -fold lower substrate affinity $\left(K_{m}\right.$ : 2.1-5.2 mM) $(60,62,63)$. The low expression of CAT-2A explains the low transport rate of arginine by the liver $(60)$.

The CAT arginine transporters differ in their tissue distribution. Whereas CAT1 is expressed nearly ubiquitously, CAT-2A and CAT-2B expression is restricted to a number of tissues and cell types (52). CAT-2A is found in liver, skeletal muscle, skin, ovary, and stomach, and is absent from brain, large and small intestine, kidney and splenocytes. CAT-2B is expressed in lung, brain, activated macrophages, splenocytes, ovary, skeletal muscle and testis, and is absent from small intestine, kidney, liver and resting macrophages. CAT-3 is brain specific.

Changes in arginine transport regulate intracellular arginine availability. Although the relevance of arginine uptake to NO synthesis may depend on the status of intracellular arginine pools (30), evidence exists indicating a role for arginine transporters in the supply of arginine to NOS. Extracellular arginine is critical to NO synthesis by endothelial cells (64), activated macrophages (65) and liver, lung, spleen and kidney of lipopolysaccharide-treated male rats (6), suggesting the involvement of arginine transport. Arginine transport could be induced by cytokines in hepatocytes (66), myocytes (67) and macrophages (68), and correlated with iNOS induction in macrophages and vascular smooth muscle cells (69-71). The LPS and IFN-y-mediated induction of NO synthesis and the activation of arginine transport occurred in the same time and concentration dependent manner, and were mediated 
by the same signal transduction pathways (72). In the absence of extracellular arginine uptake, iNOS activity was reduced to almost zero (70).

Most studies regarding the regulating effect of arginine transport on NO synthesis focus on system $y^{+}$. CAT2 mediates the L-arginine transport that is required for the raised NO production in activated J774 macrophages (73) and rat alveolar macrophages (72). In lung, heart and kidney, CAT-1 and CAT-2B expression were increased after stimulation with LPS (70). In contrast, CAT-1 expression was not increased after LPS treatment of alveolar macrophages (74). CAT-2A was abundantly expressed in the liver independent of LPS treatment (70), although increased $\mathrm{y}^{+}$activity, possibly mainly reflecting CAT-1 activity, was reported in the liver upon stimulation (66). Further evidence regarding the role of arginine transport in increased NO production arises from studies using inhibitors of arginine transport. Pre-incubation of activated macrophages in $2 \mathrm{mM}$ lysine, a competitive inhibitor of $\mathrm{y}^{+}$ mediated arginine transport, reduced the intracellular arginine concentration from 2 $\mathrm{mM}$ to $160 \mu \mathrm{M}(75)$. At that time iNOS activity was completely abolished, but could be restored by adding extracellular arginine (75). In addition, the administration of lysine to stimulated cardiac myocytes in vitro (67), or to LPS-treated rats in vivo (76) reduced nitrite accumulation by $70 \%$ and plasma nitrate by $20 \%$, respectively. Certain arginine analogues are inhibitors of NOS activity. In order to inhibit NOS, these inhibitors need to pass the cell membrane, often using the arginine transporters (77). Some of their NOS inhibiting action may arise from their ability to competitively inhibit arginine transport (78-80).

Recently, McDonald et al. reported the existence of a caveolar complex between eNOS and the arginine transporter CAT1, suggesting direct delivery of extracellular arginine to eNOS (81). Such mechanisms may explain the arginine paradox. It has long seemed paradoxical that NO production could be increased by increasing arginine availability, when the $K_{m}$ of NOS for arginine is as low as 2-20 $\mu \mathrm{M}$. The existence of an arginine transporter-NOS complex suggests that the $K_{m}$ of the arginine transporter may be more important than the $\mathrm{K}_{\mathrm{m}}$ of NOS. Indeed, the $\mathrm{K}_{\mathrm{m}}$ of NO production by endothelial cells was approximately $73-150 \mu \mathrm{M}(82)$, which is in the range of physiological arginine concentrations and the $K_{m}$ values of the CAT1 and CAT2A transporters. 


\section{Regulation via changes in arginase activity}

Arginase catalyzes the formation of urea and ornithine from arginine. Arginase is known to exist in two isoforms. Arginase I is a cytosolic enzyme that is highly expressed in the liver as part of the urea cycle, and highly regulated. In contrast, type II arginase is a mitochondrial enzyme that is expressed at lower levels in many tissues outside the liver, including kidney, brain, small intestine, prostate, lung and leukocytes (83-85). The $K_{m}$ of arginase is generally accepted to be above $1 \mathrm{mM}$ (4). According to the local enzymatic equipment, generated ornithine is then metabolized to polyamines through ornithine decarboxylase, to glutamate through ornithine aminotransferase, or to citrulline through ornithine transcarbamylase. The importance of arginase I for the maintenance of normal arginine concentrations can be deducted from the fact that arginase I deficiency leads to high plasma arginine levels (as high as $1500 \mu \mathrm{M})(85)$, whereas arginase II deficiency in mice leads to a much milder elevation of circulating arginine (86).

Arginase activity is inhibited by ornithine, lysine, and the branched chain amino acids (valine, leucine and isoleucine) (87). The effect of lysine on arginase activity results from competition between lysine and arginine for cellular uptake via a common membrane carrier (87). In contrast, the inhibition induced by BCAA corresponds to an effect on the enzyme itself (87).

Because the substrate arginine is used by both NOS and arginase, the activity of one of these enzymes may have a regulating effect on the other. The 1000-fold difference in $\mathrm{K}_{m}$ between arginase and NOS for arginine suggests that arginase can not compete with NOS for arginine. Depending on the local concentration of arginase, the enzyme can limit the availability of arginine for NO synthesis (82).

Upon stimulation with LPS, coinduction of arginase II and iNOS was reported in murine macrophage-like RAW 264.7 cells. In an independent study, arginase II was induced in rat aortic endothelial cells exposed to LPS, doubling the previous arginase level, composed of arginase I entirely (88). In addition, arginase I (89) or arginase I and II (83) have been reported to be induced in immuno-stimulated macrophages. These activities could be shown to divert arginine from nitric oxide synthesis, demonstrating that arginase induction might play a role in modulating NO synthesis. Conversely, inhibition of arginase in LPS-treated rodent macrophages resulted in enhanced conversion of arginine into citrulline $(90,91)$. Recently, a function for arginase in the regulation of arginine availability for NO mediated smooth 
muscle relaxation required for erection has been reported (92). These results indicate that arginase II is involved in downregulation of NO production by reducing the availability of the substrate arginine.

On the other hand, high throughput NOS activity reduces arginase activity (93). In LPS-stimulated alveolar macrophages NO production was increased and arginase activity reduced (94). This observation may be related to accumulation of the intermediate or end products of the NOS pathway, $N^{\omega}$-hydroxyarginine (91) or nitrite (95) respectively, which are inhibitors of arginase. Studies by Buga et al. indicated that $\mathrm{N}^{\omega}$-hydroxyarginine accumulated to levels of 200-300 $\mu \mathrm{M}$, at least 2 orders of magnitude higher than its $\mathrm{K}_{\mathrm{i}}$ for arginase II (88). Administration of the arginase inhibitors nor- $\mathrm{N}^{\omega}$-hydroxyarginine and norvaline to LPS-stimulated macrophages increased nitrite and citrulline accumulation in the incubation media, indicating increased NO production $(96,97)$. Such regulatory mechanisms may be particularly important when the extracellular supply of arginine is limited, since the effects did not take place when extracellular arginine levels were high $(0.5 \mathrm{mM})(96)$.

In an experimental wound model in rats, temporal expression of different pathways of arginine metabolism was observed (98). Two distinct periods of reduced arginine concentration in wound fluids were observed. Initially, the concentrations of citrulline and nitrite were increased, indicating a period of increased iNOS activity. In this period, NO production is increased and exerts its bacterial killing effects. During the later phase of wound healing, ornithine concentration and arginase activity were increased. This reduced availability of arginine for iNOS, and enabled tissue growth. A similar mechanism was observed in nephritic glomeruli (99). In this respect, Munder et al. showed that T-cell phenotype (Th1 versus Th2) is important for the induction of iNOS or arginase. Th2 cells induced the production of arginase in cocultured macrophages, while Th1 cells induced iNOS (100). In agreement with these results, anti-inflammatory cytokines like IL-4 and IL-13 upregulated arginase I thereby depleting arginine availability for NOS $(101,102)$. 


\section{Models to measure NO production in vivo}

Constitutive NOS-mediated NO production may be studied under basal conditions. To study iNOS-mediated NO production it is necessary to induce iNOS. This protein is induced by injection with bacterial endotoxin. Endotoxins are lipopolysaccharides (LPS), present in the cell-wall of all gram-negative bacteria. In the experiments described in this thesis, mice were treated with a single injection of LPS to induce iNOS. In contrast to the iNOS inducing effect of a single dose of endotoxin, repeated doses of endotoxin cause a state of endotoxin tolerance and an inhibition of NOS gene expression $(103,104)$. In response to a single dose treatment, increased iNOS mRNA levels and enzymatic activity are induced in different organs of LPSchallenged rodents (105-111). The iNOS-inducing effect of LPS is largely mediated by pro-inflammatory cytokines like TNF- $\alpha$ and IL-1 $(112,113)$. The mechanism by which cytokines induce iNOS involves NF-KB.

Several methods have been used to measure increased NO production. Initial studies on nitric oxide, often using in vitro or ex-vivo systems or models of experimental endotoxemia used increased plasma nitrite and nitrate $(108,110,114$, $115)$, or urinary nitrate excretion (116) as indicators of NO production. As early as 1985, Stuehr and Marletta showed a sixfold increase in plasma nitrite/nitrate levels 6h after LPS injection (114). Similar results were obtained by Szabo (108) and Schultz (115). Stable isotope experiments have indeed indicated that administration of the stable isotope $\left[{ }^{15} \mathrm{~N}_{2}\right]$ arginine yields $\left[{ }^{15} \mathrm{~N}\right]$ nitrite and $\left[{ }^{15} \mathrm{~N}\right]$ nitrate $(3,117)$, indicating that nitrite and nitrate are metabolites of arginine. In addition, the only source of nitrite is NO (3), whereas nitrate may also be obtained from other sources. Besides the stable end-products of NO production, also changes in the stable intermediate compound of NO production, $N^{\omega}$-hydroxyarginine (1), have been used to detect changes in NO production (118-120). Other methods to detect NO include NO spin traps $(6,121)$ and miniature electrodes. A few years ago Castillo et al. measured the in vivo NO production rate in healthy men using an elegant stable isotope technique (17). A similar, although less direct, technique for the quantification of NO production using stable isotope technology involved the infusion of $\mathrm{Na}^{15} \mathrm{NO}_{3}$ (122). The stable isotope technique first described by Castillo et $\mathrm{al}$ is based on the fact that NOS produces citrulline and NO in stoichiometric amounts, with each containing a nitrogen atom derived from the guanidino moiety of arginine. By infusing a $\left[{ }^{15} \mathrm{~N}_{2}\right.$. 
guanidino]arginine stable isotope, it is thus possible to measure the actual NO production rate by conversion of $\left[{ }^{15} \mathrm{~N}_{2}\right]$ arginine to $\left[{ }^{15} \mathrm{~N}\right]$ citrulline. It was also shown that the NO production rate measured using this technique correlated very well to urinary nitrate excretion in healthy adults (17). Since then, this method has been used to measure the NO production rate in a variety of diseased subjects $(29,123$, 124).

\section{Measurement of metabolic fluxes using stable isotopes}

In the studies described in the present thesis, stable isotopes were used to quantify metabolic pathways related to arginine and nitric oxide metabolism. Whole body amino acid turnover is assessed in a one compartment model. The model evaluates the exchange of amino acid from and into the extracellular free amino acid pool. It is assumed that the infusion of a labeled amino acid and the rate of appearance of the same (unlabeled) amino acid occur in this single pool. Thus, a primed, continuous infusion of a labeled amino acid is given and at steady state conditions samples are drawn from the plasma pool. At steady state the amount of tracer amino acid lost will be equal to the tracer amino acid infused and the plasma Ra can be calculated as follows:

Tracer in $=$ Tracer out

$\mathrm{Ra}=\mathrm{Rd}$

$I=R a * T T R$

$\mathrm{Ra}=1 / \mathrm{TTR}$

where $\mathrm{Ra}$ is the rate of appearance in $\mathrm{nmol} / \mathrm{min}, \mathrm{Rd}$ is the rate of disappearance $(\mathrm{nmol} / \mathrm{min}), l$ is the infusion rate of the labeled amino acid ( $\mathrm{nmol} / \mathrm{min}$ ) and TTR is the tracer/tracee ratio of the infused amino acid measured in plasma at steady state. The transport rate across membranes is different for each amino acid. Therefore a difference may occur when calculations are made using the TTR of an amino acid in whole blood or in plasma. Arginine tracers show a different TTR in whole blood and plasma, because arginine exchange across the erythrocyte membrane is slow. The Ra obtained when measuring in plasma is should therefore not be termed whole body Ra. In the present thesis, Ra was therefore termed plasma flux, or plasma turnover. 
It is also possible to measure metabolism of amino acids across organs using stable isotopes. The measurements are in fact an $A-V$ dilution technique. The amino acid tracer is again given as a primed continuous infusion. When steady state has been obtained, plasma flow across an organ is measured and samples are drawn from the vessels supplying and draining an organ. Calculations in such a twocompartment model enable the simultaneous measurement of intra-organ amino acid production and disposal. When intra-organ production exceeds intra-organ disposal the organ is a net producer of the amino acid. Conversely, when intra-organ disposal exceeds intra-organ production the organ is a net consumer of the amino acid. Net production or consumption of amino acid is calculated as the AV difference of amino acid concentration multiplied by organ plasma flow. Net consumption or production rates are also called net flux.

\section{Outline of the thesis}

The aim of research reported in this thesis was to evaluate whether decreased circulating arginine causes a reduction of cNOS and iNOS-mediated NO production. The second aim was to study adaptations in arginine metabolism in response to reduced circulating arginine. The experiments were performed in mice because several transgenic and knockout mice with derangements in arginine / NO metabolism are available.

The thesis consists of three distinct sections. The first section deals with methodology on metabolic studies in mice on the use of stable isotopes and blood sampling. In the second section of the thesis the LPS model is characterized. Studies were performed on a whole body level and across intestine, liver and kidney. In addition, studies were performed in NOS knockout mice. The third section of the thesis deals with the effect of arginine availability on CNOS and iNOS-mediated NO production. Circulating arginine was reduced by three distinct mechanisms and the effect on NO production was evaluated. Circulating arginine was reduced in an acute fashion by intravenous administration of arginase. The effects of chronic reduction of circulating arginine were studied in ornithine transcarbamylase-deficient mice and in transgenic mice with over-expression of arginase. 


\section{References}

1. Stuehr DJ, Kwon NS, Nathan CF, Griffith OW, Feldman PL, Wiseman J. Nw-hydroxy-Larginine is an intermediate in the biosynthesis of nitric oxide from arginine. $J$ Biol Chem 1991;266:6259-6263.

2. Leone AM, Palmer RM, Knowles RG, Francis PL, Ashton DS, Moncada S. Constitutive and inducible nitric oxide synthases incorporate molecular oxygen into both nitric oxide and citrulline. J Biol Chem 1991;266:23790-23795.

3. Rhodes PM, Leone AM, Francis PL, Struthers AD, Moncada S. The L-arginine:nitric oxide pathway is the major source of plasma nitrite in fasted humans. Biochem.Biophys. Res.Comm. 1995;209(2):590-596.

4. Hrabàk A, Bajor T, Temesi A. Comparison of substrate and inhibitor specificity of arginase and nitric oxide (NO) synthase for arginine analogues and related compounds in murine and rat macrophages. Biochem.Biophys.Res.Comm. 1994;198(1):206-212.

5. Kwon NS, Nathan CF, Stuehr DJ. Reduced biopterin as a cofactor in the generation of nitrogen oxides by murine macrophages. J Biol Chem 1989;264:20496-20501.

6. Bune AJ, Shergill JK, Cammack R, Cook HT. L-Arginine depletion by arginase reduces nitric oxide production in endotoxic shock: an electron paramagnetic resonance study. FEBS Lett. 1995;366:127-130.

7. Griffith OW, Park KH, Aisaka K, Levi R, Gross SS. The role of plasma arginine in nitric oxide synthesis: studies with arginase-treated guinea pigs and rats. In: Moncada S. Marletta MA, Hibbs JBj, Higgs EA, editors. The biology of nitric oxide. 1. Physiological and clinical aspects. London: Portland Press; 1992. p. 6-10.

8. McCormick CC, Li WP, Calero M. Oxygen tension limits nitric oxide synthesis by activated macrophages. Biochem J 2000;350:709-716.

9. Toporsian M, Govindaraju K, Nagi M, Eidelman D, Thibault G, Ward ME. Downregulation of endothelial nitric oxide synthase in rat aorta after prolonged hypoxia in vivo. Circ Res 2000;86:671-675.

10. Bune AJ, Brand MP, Heales SJR, Shergill JK, Cammack R, Cook HT. Inhibition of tetrahydrobiopterin synthesis reduced in vivo nitric oxide production in experimental endotoxic shock. Biochem.Biophys.Res.Commun. 1996;220:13-19.

11. Heitzer T, Krohn K, Alberts S, Meinertz T. Tetrahydrobiopterin improves endotheliumdependent vasodilation by increasing nitric oxide activity in patients with type II diabetes mellitus. Diabetologica 2000;43:1435-1438.

12. Pastor $\mathrm{CM}$, Williams D, Yoneyama $\mathrm{T}$, Hatakeyama $\mathrm{K}$, Singleton $\mathrm{S}$, Naylor $\mathrm{E}$, et al. Competition for tetrahydrobiopterin between phenylalanine hydroxylase and nitric oxide synthase in rat liver. J Biol Chem 1996;271(40):24534-8.

13. Meininger CJ, Marinos RS, Hatakeyama K, Martinez-Zaguilan R, Rojas JD, Kelly KA, et al. Impaired nitric oxide production in coronary endothelial cells of spontaneously diabetic $B B$ rat is due to tetrahydrobiopterin deficiency. Biochem J 2000;349:353-356. 
14. Wever RMF, van Dam T, van Rijn HJ, de Groot F, Rabelink TJ. Tetrahydrobiopterin regulates superoxide and nitric oxide generation by recombinant endothelial nitric oxide synthase. Biochem Biophys Res Commun 1997;237:340-4.

15. Mayer B, Schmidt K, Humbert $P$, Bohme E. Biosynthesis of endothelium-derived relaxing factor: a cytosolic enzyme in porcine aortic endothelial cells Ca2+-dependently converts Larginine into an activator of soluble guanylyl cyclase. Biochem Biophys Res Commun 1989; 164:678-685.

16. Busse R, Mulsch A. Calcium-dependent nitric oxide synthesis in endothelial cytosol is mediated by calmodulin. FEBS Let 1990;265:133-136.

17. Castillo L, Beaumier L, Ajami AM, Young VR. Whole body nitric oxide synthesis in healthy men determined from [15N]-arginine-to-[15N]citrulline labeling. Proc.Natl.Acad.Sci.USA 1996;93:11460-11465

18. Knowles RG, Moncada S. Nitric oxide synthases in mammals. Biochem J 1994;298:249-258.

19. Forstermann U, Closs EI, Pollock JS, Nakane M, Schwartz P, Gath I, et al. Nitric oxide synthase isozymes. Characterization, purification, molecular cloning, and functions. Hypertension 1994:23:1121-1131.

20. Morris SMj, Billiar TR. New insights into the regulation of inducible nitric oxide synthesis. Am.J.Physiol. 1994;266:E829-E839.

21. Griffith OW, Stuehr DJ. Nitric oxide synthases: properties and catalytic mechanisms. Annu Rev Physiol 1995;57:707-736.

22. Castillo L, Chapman TE, Sanchez M, Yu YM, Burke JF, Ajami AM, et al. Plasma arginine and citrulline kinetics in adults given adequate and arginine-free diets. Proc.Natl.Acad.Sci.USA 1993;90:7749-7753.

23. Castillo L, Ajami A, Branch S, Chapman TE, Yu YM, Burke JF, et al. Plasma arginine kinetics in adult man: response to an arginine-free diet. Metabolism 1994;43(1):114-122.

24. Castillo L, Sanchez M, Chapman TE, Ajami A, Burke JF, Young VR. The plasma flux and oxidation rate of ornithine adaptively decline with restricted arginine intake.

Proc.Natl.Acad.Sci.USA 1994;91:6393-6397.

25. Tangphao O, Chalon S, Coulston AM, Moreno HJ, Chan JR, Cooke JP, et al. L-arginine and nitric oxide related compounds in plasma: comparison of normal and arginine-free diets in a 24-h crossover study. Vasc Med 1999;4:27-32.

26. Castillo L, Sanchez M, Vogt J, Chapman TE, DeRojas-Walker TC, Tannenbaum SR, et al. Plasma arginine, citrulline, and ornithine kinetics in adults, with observations on nitric oxide synthesis. Am.J.Physiol. 1995;268:E360-E367.

27. Wu G, Flynn NE, Flynn SP, Jolly CA, Davis PK. Dietary protein or arginine deficiency impairs constitutive and inducible nitric oxide synthesis by young rats. J Nutr 1999;129(7):1347-54.

28. Ratnakumari L, Qureshi IA, Butterworth RF, Marescau B, De Deyn PP. Arginine-related guanidino compounds and nitric oxide synthase in the brain of ornithine transcarbamylase deficient spf mutant mouse: the effect of metabolic arginine deficiency. Neurosci.Lett. 1996;215:153-156. 
29. Castilo L, deRojas TC, Sanchez M, Chapman TE, Shannon D, Tannenbaum S, et al. Whole body arginine metabolism and nitric oxide synthesis in newborns with persistent pulmonary hypertension. Pediatr.Res. 1995;38(1):17-25.

30. Escobales N, Rivera-Correa M, Altieri PI, Rodriguez JF. Relationship between NO synthesis, arginine transport, and intracellular arginine levels in vascular smooth muscle cells. Amino Acids 2000;19:451-468.

31. Cynober $L$, Le Boucher $J$, Vasson MP. Arginine metabolism in mammals. J.Nutr.Biochem. 1995;6:402-412.

32. Windmueller HG. Spaeth AE. Uptake and metabolism of plasma glutamine by the small intestine. J Biol Chem 1974;249.

33. Wu G. Synthesis of citrulline and arginine from proline in enterocytes of postnatal pigs. Am J Physiol 1997;272:G1382-G1390.

34. Windmueller HG, Spaeth AE. Source and fate of circulating citrulline. Am.J.Physiol. 1981;241:E473-E480.

35. Tizianello A, De Ferrari G, Garibotto G, Gurreri G, Robaudo C. Renal metabolism of amino acids and ammonia in subjects with normal renal function and in patients with chronic renal insufficiency. J.Clin.Invest. 1980;65:1162-1173.

36. Levillain O, Hus-Citharel A, Morel F, Bankir L. Localisation of arginine synthesis along rat nephron. Am.J.Physiol. 1990;259:F916-F923.

37. Dejong CHC, Welters CFM, Deutz NEP, Heineman E, Soeters PB. Renal arginine metabolism in fasted rats with subacute short bowel syndrome. Clin Sci 1998;95:409-418.

38. Rabier D, Narcy C, Bardet J, Parvy P, Saudubray JM, Kamoun P. Arginine remains an essential amino acid after liver transplantation in urea cycle enzyme deficiencies. $J$ Inherit Metab Dis 1991;14:277-283.

39. Nussler AK, Billiar TR, Liu ZZ, Morris SMj. Coinduction of nitric oxide synthase and argininosuccinate synthetase in a murine macrophage cell line. Implications for regulation of nitric oxide production. J.Biol.Chem. 1994;269:1257-1261.

40. Hattori $Y$, Campbell EB, Gross SS. Argininosuccinate synthetase mRNA and activity are induced by immunostimulants in vascular smooth muscle. Role in the regeneration of arginine for nitric oxide synthesis. J.Biol.Chem. 1994;269:9405-9408.

41. Hecker M, Sessa WC, Harris HJ, Anggard EE, Vane JR. The metabolism of L-arginine and its significance for the biosynthesis of endothelium-derived relaxing factor: cultured endothelial cells recycle L-citrulline to L-arginine. Proc Natl Acad Sci USA 1990;87:8612-8616.

42. Wu G, Brosnan J. Macrophages can convert citrulline into arginine. Biochem J 1992;281:4548.

43. Rattan S, Chakder S. L-Citrulline recycling in opposum internal anal sphincter relaxation by nonadrenergic noncholnergic, noncholinergic nerve stimulation. Gastroenterology 1997;112:1250-1259.

44. Mori M, Gotoh T, Nagasaki A, Takiguchi M, Sonoki T. Regulation of the urea cycle enzyme genes in nitric oxide synthesis. J Inherit Metab Dis 1998;21(Suppl 1):59-71. 
45. Nagasaki A, Gotoh T, Takeya M, Yu Y, Takiguchi M, Matsuzaki $H$, et al. Coinduction of nitric oxide synthase, argininosuccinate synthetase, and arginiosuccinate lyase in lipopolysaccharide-treated rats. J.Biol.Chem. 1996;271:2658-2662.

46. Zhang WY, Takiguchi M, Koshiyama Y, Gotoh T, Nagasaki A, Iwase K, et al. Expression of citrulline-nitric oxide cycle in lipopolysaccharide and cytokine-stimulated rat astroglioma C6 cells. Brain Res 1999;849:79-84.

47. Baydoun AR, Bogle RG, Pearson JD, Mann GE. Discrimination between citrulline and arginine transport in activated murine macrophages: inefficient synthesis of NO from recycling of citrulline to arginine. Br J Pharmacol 1994;112:487-492.

48. Dhanakoti SN, Brosnan JT, Brosnan ME, Herzberg GR. Net renal flux in rats is not affected by dietary arginine or dietary protein intake. J Nutr 1992;122:1127-1134.

49. Prins HA, Houdijk AP, Wiezer MJ, Teerlink T, van Lambalgen AA, Thijs LG, et al. Reduced arginine plasma levels are the drive for arginine production by the kidney in the rat. Shock 1999;11(3):199-204.

50. Bouby N, Coutaud C, Bankir L. Arginine synthesis by the proximal convoluted tubule in rats with chronic renal failure. Miner Electrolyte Metab 1992;18:101-103.

51. Bouby N, Hassler C, Parvy P, Bankir L. Renal synthesis of arginine in chronic renal failure: in vivo and in vitro studies in rats with 5/6 nephrectomy. Kidney Int 1993;44:676-683.

52. Devés R, Boyd CAR. Transporters for cationic amino acids in animal cells: discovery, structure and function. Physiol Rev 1998;78:487-545.

53. White MF, Christensen HN. Cationic amino acid transport into cultured animal cells. J Biol Chem 1982;257:4450-4457.

54. Van Winkle LJ, Campione AL, Gorman JL. Nat-independent of basic and zwitterionic amino acids in mouse blastocysts by a shared system and by processes which distinguish these substrates. J Biol Chem 1988;263:3150-3063.

55. Van Winkle LJ, Christensen HN, Campione AL. Na+-dependent transport of basic, zwitterionic, and bicyclic amino acids by a broad-scope system in mouse blastocysts. J Biol Chem 1985;260:12118-12123.

56. Deves $R$, Chavez $P$, Boyd CAR. Identification of a new transport system $(y+L)$ in human erythrocytes that recognizes lysine and leucine with high affinity. J Physiol (Lond) 1992;468:753-766.

57. Chillaron J. Obligatory amino acid exchange via systems b0, like and $y+l$ like. A tertiary active transport mechanism for renal reabsorption of cystine and dibasic amino acids. $J$ Biol Chem 1996;271:17761-17770.

58. Pfeiffer R, Rossier G, Spindler B, Meier C, Kuehn L, Verrey F. Amino acid transport of $y+L-$ type by heterodimers of $4 \mathrm{~F} 2 \mathrm{hc} / \mathrm{CD} 98$ and members of the glycoprotein-associated amino acid transporter family. EMBO J 1999;18:49-57.

59. Broer A, Wagner CA, Lang F, Broer $\mathrm{S}$. The heterodimeric amino acid transporter 4F2hc/y+LAT2 mediates arginine efflux in exchange with glutamine. Biochem J 2000;349:787795. 
60. White MF. The transport of cationic amino acids across the plasma membrane of mammalian cells. Biochim Biophys Acta 1985;822(3-4):355-74.

61. Closs EI. CATs, a family of three distinct mammalian cationic amino acid transporters. Amino Acids 1996;11:193-208.

62. Kavanaugh MP, Wang $H$, Zhang $Z$, Zhang W, Wu YN, Dechant $E$, et al. Control of cationic amino acid transport and retroviral receptor functions in a membrane protein family. J Biol Chem 1994;269:15445-15450.

63. Closs EI, Graf P, Habermeier A, Cunningham JM, Forstermann U. Human cationic amino acid transporters hCAT-1, hCAT-2A, and hCAT-2B: three related carriers with distinct transport properties. Biochemistry 1997;36:6462-6468.

64. Arnal JF, Munzel T, Venema RC, James NL, Bai CL, Mitch WE, et al. Interactions between Larginine and L-glutamine change endothelial NO production. An effect independent of NO synthase substrate availability. J Clin Invest 1995;95:2565-2572.

65. Norris KA, Schrimpf JE, Flynn JL, Morris SM. Enhancement of macrophage microbicidal activity: supplemental arginine and citrulline augment nitric oxide production in murine peritoneal macrophages and promote intracellular killing of Trypanosoma cruzi. Infect Immun 1995:63:2793-2796.

66. Pacitti AJ, Copeland EM, Souba WW. Stimulation of hepatocyte system y+-mediated Larginine transport by an inflammatory agent. Surgery 1992;112:403-411.

67. Simmons WW, Closs El, Cunningham JM, Smith TW, Kelly RA. Cytokines and insulin induce cationic amino acid transporter (CAT) expression in cardiac myocytes. $J$ Biol Chem 1996;271:11694-11702.

68. Sato H, Fujiwara M, Bannai S. Effect of lipopolysaccharide on transport and metabolism of arginine in mouse peritoneal macrophages. J.Leukoc.Biol. 1992;52:161-164.

69. Bogle RG, Baydoun AR, Pearson JD, Moncada S, Mann GE. L-Arginine transport is increased in macrophage generating nitric oxide. Biochem.J. 1992;284:15-18.

70. Hattori $Y$, Kasai K, Gross SS. Cationic amino acid transporter gene expression in cultured vascular smooth muscle cells and in rats. Am J Physiol 1999;276:H2020-8.

71. Hammermann R, Hirschmann J, Hey C, Moessner J, Folkerts G, Nijkamp FP, et al. Cationic proteins inhibit $L$-arginine uptake in rat alveolar macrophages and tracheal epithelial cells. Implications for nitric oxide synthesis. Am J Respir Cell Mol Biol 1999;21:155-162.

72. Hammermann R, Donata M, Dreissig M, Moessner J, Fuhrmann M, Berrino L, et al. Nuclear factor-kB mediates simultaneous induction of inducible nitric-oxide synthase and up-regulation of the cationic amino acid transporter CAT-2B in rat alveolar macrophages. Mol Pharmacol 2000;58:1294-1302.

73. Kakuda DK, Sweet MJ, Mac Leod CL, Hume DA, Markovich D. CAT2-mediated L-arginine transport and nitric oxide production in activated macrophages. Biochem J 1999;340:549-53.

74. Dreissig MDM, Hammermann R, Moessner J, Goethert M, Racke K. In rat alveolar macrophages lipopolysaccharides exert divergent effects on the transport of the cationic 
amino acids L-arginine and L-ornithine. Naunyn-Schmiedeberg's Arch Pharmacol 2000;361:621-628.

75. Closs EI, Scheld J-S, Sharafi M, Forstermann U. Substrate supply for nitric oxide synthase in macrophages and endothelial cells: role of cationic amino acid transporters. Mol Pharmacol 2000;57:68-74.

76. Liaudet L, Gnaegi A, Rosselet A, Markert M, Boulat O, Perret C, et al. Effect of L-Jysine on nitric oxide overproduction in endotoxic shock. Br J Pharmacol 1997;122:742-748.

77. Baydoun AR, Mann GE. Selective targetting of nitric oxide synthase inhibitors to system $y+$ in activated macrophages. Biochem.Biophys.Res.Comm. 1994;200(2):726-731.

78. Inoue Y, Bode BP, Beck DJ, Li AP, Bland KI, Souba WW. Arginine transport in human liver. Characterization and effects of nitric oxide synthase inhibitors. Ann.Surg. 1993;218(3):350363.

79. McDonald KK, Rouhani R, Handlogten ME, Block ER, Griffith OW, Allison RD, et al. Inhibition of endothelial cell amino acid transport system $y+$ by arginine analogs that inhibit nitric oxide synthase. Biochim Biophys Acta 1997:1324:133-141.

80. Bogle RG, McAllister RJ, Whitley GSJ, Vallance P. Induction of $\mathrm{Ng}$-monomethyl-L-arginine uptake: a mechanism for differential inhibition of NO synthases? Am.J.Physiol. 1995;269:C750-C756.

81. McDonaid KK, Zharikov S, Block ER, Kilberg MS. A caveolar complex between the cationic amino acid transporter 1 and endothelial nitric-oxide synthase may explain the "arginine paradox". J Biol Chem 1997;272:31213-31216.

82. Wu G, Morris SM, Jr. Arginine metabolism: nitric oxide and beyond. Biochem.J. 1998;336(Pt 1):1-17.

83. Morris SM, Jr., Kepka-Lenhart D, Chen LC. Differential regulation of arginases and inducible nitric oxide synthase in murine macrophage cells. Am J Physiol 1998;275(5 Pt 1):E740-7.

84. Gotoh T, Sonoki T, Nagasaki A, Terada K, Takiguchi M, Mori M. Molecular cloning of cDNA for nonhepatic mitochondrial arginase (arginase II) and comparison of its induction with nitric oxide synthase in a murine macrophage-like cell line. FEBS Lett 1996;395:119-122.

85. Jyer R, Jenkinson CP, Vockley JG, Kern RM, Grody WW, Cederbaum S. The human arginases and arginase deficiency. J Inher Metab Dis 1998;21:86-100.

86. Shi O, Morris SMj, Zoghbi H, Porter CW, O'Brien WE. Generation of a mouse model for arginase II deficiency by targeted disruption of the arginase II gene. Mol Cell Biol 2001;21:811. 813.

87. Levillain O, Hus-Citharel A, Morel F. Urea production by kidney collecting ducts in vitro: effect of amino acid addition. Pflugers Arch 1994:426:481-490.

88. Buga GM, Singh R, Pervin S, Rogers NE, Schmitz DA, Jenkinson CP, et al. Arginase activity in endothelial cells: inhibition by Ng-hydroxy-L-arginine during high-output NO production. Am.J.Physiol. 1996;271:H1988-H1998. 

nitric-oxide synthase and arginase $I$ in cultured rat peritoneal macrophages and rat tissues in vivo by lipopolysaccharide. J Biol Chem 1997;272(6):3689-93.

90. Hey C, Boucher JL, Vadon-Le Goff S, Ketterer G, Wessler I, Racké K. Inhibition of arginase in rat and rabbit alveolar macrophages by Nw-hydroxy-D,L-indospicine, effects on L-arginine utilization by nitric oxide synthase. Br J Pharmacol 1997;121:395-400.

91. Hecker $M$, Nematollahi $H$, Hey $C$, Busse R, Rackè K. Inhibition of arginase by NG-hydroxy-Larginine in alveolar macrophages: implications for the utilization of $L$-arginine for nitric oxide synthesis. FEBS Lett. 1995;359:251-254.

92. Cox JD, Kim NN, Traish AM, Christianson DW. Arginase-boronic acid complex highlights a physiological role in erectile function. Nat Struct Biol 1999;6:1043-1047.

93. Fligger J, Blum J, Jungi TW. Induction of intracellular arginase activity does not deminish the capacity of macrophages to produce nitric oxide in vitro. Immunobiology 1999;200:169-186.

94. Hey C, Wessler I, Racke K. Nitric oxide synthase activity is inducible in rat, but not rabbit alveolar macrophages, with a concomitant reduction in arginase activity. Naunyn Schmiedeberg's Arch Pharmacol 1995;351:651-659.

95. Hrabàk A, Bajor T, Temesi A, Mészáros $G$. The inhibitory effect of nitrite, a stable product of nitric oxide (NO) formation, on arginase. FEBS Lett. 1996;390:203-206.

96. Chang C-I, Liao JC, Kuo L. Arginase modulates nitric oxide production in activated macrophages. Am J Physiol 1998;274:H342-H348.

97. Tenu JP, Lepoivre M, Moali C, Brollo M, Mansuy D, Boucher JL. Effects of the new arginase inhibitor N(omega)-hydroxy-nor-L-arginine on NO synthase activity in murine macrophages. Nitric Oxide 1999;3:427-438.

98. Albina JE, Mills CD, Henry WLj, Caldwell MD. Temporal expression of different pathways of Larginine metabolism in healing wounds. J Immunol 1990;144:3877-3880.

99. Waddington SN, Tam FW, Cook HT, Cattell V. Arginase activity is modulated by IL-4 and HOArg in nephritic glomeruli and mesangial cells. Am J Physiol 1998;274(3 Pt 2):F473-80.

100. Munder M, Eichmann K, Moran JM, Centeno F, Soler G, Modolell M. Th1/Th2-regulated expression of arginase isoforms in murine macrophages and dendritic cells. $\mathrm{J}$ Immunol 1999;163:3771-7.

101. Rutschman R, Lang R, Hesse M, Inle JN, Wynn TA, Murray PJ. Cutting edge: Stat6dependent substrate depletion regulates nitric oxide production. J Immunol 2001;166:21732177.

102. Chang $\mathrm{Cl}$, Zoghi B, Liao JC, Kuo L. The involvement of tyrosine kinases, cyclic AMP/protein kinase $A$, and $p 38$ mitogen-activated protein kinase in IL-13-mediated arginase I induction in macrophages: its implications in IL-13 inhibited nitric oxide production. $\mathrm{J}$ Immunol 2000;165:2134-2141.

103. Chang CC, McCormick CC, Lin AW, Dietert RR, Sung Y-J. Inhibition of nitric oxide synthase gene expression in vivo and in vitro by repeated doses of endotoxin. Am.J.Physiol. 1996;271:G539-G548. 
104. Szabo C, Thiemermann C, Wu CC, Perretti M, Vane JR. Attenuation of the induction of nitric oxide synthase by endogenous glucocorticoids accounts for endotoxin tolerance in vivo. Proc.Natl.Acad.Sci.USA 1994;91:271-275.

105. Cook HT, Bune AJ, Jansen AS, Taylor GM, Loi RK, Cattell V. Cellular localisation of inducible nitric oxide synthase in experimental endotoxic shock in the rat. Clin.Sci. 1994;87:179-186.

106. Boughton-Smith NK, Evans SM, Laszlo F, Whittle BJR, Moncada S. The induction of nitric oxide synthase and intestinal vascular permeability by endotoxin in the rat. Br.J.Pharmacol. 1993;110:1189-1195.

107. Thiemermann C, Wu CC, Szabo C, Perretti M, Vane JR. Role of tumour necrosis factor in the induction of nitric oxide synthase in a rat model of endotoxin shock. Br.J.Pharmacol. 1993:110:177-182.

108. Szabo C, Salzman AL, Ischiropoulos $H$. Endotoxin triggers the expression of an inducible isoform of nitric oxide synthase and the formation of peroxynitrite in the rat aorta in vivo. FEBS Lett. 1995;363:235-238.

109. Salter M, Knowles RG, Moncada S. Widespread tissue distribution, species distribution and changes in activity of $\mathrm{Ca} 2+$-dependent and $\mathrm{Ca} 2+-$ independent nitric oxide synthases. FEBS Lett. 1991;291:145-149.

110. Ter Steege JCA, Van de Ven WCM, Forget PP, Brouckaert P, Buurman WA. The role of endogenous IFN-gamma, TNF-alpha and IL-10 in LPS-induced nitric oxide release in a mouse model. Cytokine 1998;10:115-123.

111. Ter Steege JCA, Van de Ven WCM, Forget PP. Buurman WA. Regulation of LPS-induced iNOS expression in the major organs in a mouse model. Eur Cytokine Netw 2000;11:39-46.

112. Balligand JL, Ungureanu-Longrois D, Simmons WW, Kobzik L, Lowenstein CJ, Lamas S, et al. Induction of NO synthase in rat cardiac microvascular endothelial cells by IL-1b and IFNgamma. Am.J.Physiol. 1995;268:H1293-H1303.

113. Cunha FQ, Assreuy J, Moss DW, Rees D, Leal LM, Moncada S, et al. Differential induction of nitric oxide synthase in various organs of the mouse during endotoxaemia: role of TNF-alpha and IL-1beta. Immunobiology 1994;81:211-215.

114. Stuehr DJ, Marletta MA. Mammalian nitrate biosynthesis: mouse macrophages produce nitrite and nitrate in response to Escherichia coli lipopolysaccharide. Proc NtI Acad Sci USA 1985;82:7738-7742.

115. Schulz R, Nava E, Moncada S. Induction and potential biological relevance of a Ca2tindependent nitric oxide synthase in the myocardium. Br J Pharmacol 1992;105:575-580.

116. Castillo L, deRojas TC, Chapman TE, Vogt J, Burke JF, Tannenbaum SR, et al. Splanchnic metabolism of dietary arginine in relation to nitric oxide synthesis in normal adult man. Proc.Natl.Acad.Sci.USA 1993;90:193-197.

117. Becker WK, Shippee RL, McManus AT, Mason AD, Pruitt BA. Kinetics of nitrogen oxide production following experimental thermal injury in rats. J Trauma 1993;34:855-862. 
118. Garlichs CD, Beyer J, Zhang H, Schmeisser A, Ploetze K, Muegge A, et al. Decreased plasma concentrations of L-hydroxyarginine as a marker of reduced NO formation in patients with combined cardiovascular risk. J Lab Clin Med 2000;135:419-425.

119. Hecker M, Schott C, Bucher B, Busse R, Stoclet JC. Increase in serum Ng-hydroxy-L-arginine in rats treated with bacterial lipopolysaccharide. Eur.J.Pharmacol. 1995;275:R1-R3.

120. Wigand R, Meyer J, Busse R, Hecker M. Increased serum NG-hydroxy-L-arginine in patients with rheumatoid arthritis and systemic lupus erythematosus as an index of increased nitric oxide synthase activity. Ann Rheum Dis 1997;56:330-332.

121. Battista S, Bar F, Mengozzi G, Zanon E, Grosso M, Molino G. Hyperdynamic circulation in patients with cirrhosis: direct measurement of nitric oxide levels in hepatic and portal veins. $J$ Hepatol 1997;26(1):75-80.

122. Santak $B$, Radermacher $P$, lber $T$, Adier $J$, Wachter $U$, Vassilev $D$, et al. In vivo quantification of endotoxin-induced nitric oxide production in pigs from Na15NO3-infusion. Br.J.Pharmacol. 1997:122:1605-1610.

123. Lau T, Owen W, Yu YM, Noviski N, Lyons J, Zurakowski D, et al. Arginine, citrulline, and nitric oxide metabolism in end-stage renal disease patients. J Clin Invest 2000;105:1217-1225.

124. Wever R, Boer $P$, Hijmering $M$, Stroes $E$, Verhaar $M$, Kastelein J, et al. Nitric oxide production is reduced in patients with chronic renal failure. Arterioscler Thromb Vasc Biol 1999;19(5):1168-72. 
Chapter 1 


\section{Chapter 2}

Methodological studies 
Chapter 2 


\section{1}

Metabolic flux measurements across portal drained viscera, liver, kidney and hindquarter in mice

Marcella M. Hallemeesch, Gabrie A.M. ten Have, Nicolaas E.P. Deutz

Dept. of Surgery, Maastricht University, Maastricht, The Netherlands 


\section{Summary}

A method was developed to measure metabolic fluxes across portally-drained viscera (PDV), liver, kidney and hindquarter (HQ) in anesthetized mice. The method includes a primed-constant infusion of ketamine-medetomidine anesthesia to stabilize the mice for the surgical procedures. For measurement of metabolic fluxes across PDV and liver, blood sampling catheters were inserted in the carotid artery, portal vein and hepatic vein and infusion catheters in the jugular vein and mesenteric vein. For measurement of metabolic flux across kidney and $\mathrm{HQ}$, blood sampling catheters were inserted in the carotid artery, renal vein and caval vein and infusion catheters the jugular vein and abdominal aorta. ${ }^{14} \mathrm{C}-\mathrm{PAH}$ was infused to enable plasma flow measurement in an indicator dilution method. In addition, we developed a blood sampling procedure without waste of blood.

We measured plasma flow and metabolic fluxes across PDV, liver, kidney and $H Q$. Mean plasma flow in post-absorptive mice was: PDV: $0.9 \pm 0.2$, liver: $1.2 \pm 0.3$, kidney: $1.0 \pm 0.1, H Q: 1.1 \pm 0.3 \mathrm{ml} / 10 \mathrm{~g}$ body weight (b.w.)/min. Significant glutamine release by the HQ and uptake of glutamine by the kidney and PDV was observed. In PDV, citrulline is produced from glutamine and is in turn used by the kidney for the production of arginine. In conclusion, the described model enables measurement of metabolic fluxes across PDV, liver, kidney and $\mathrm{HQ}$ in mice. The availability of such a small animal model allows the potential to measure metabolic parameters in transgenic and knockout mice, and therefore may implicate an important refinement of metabolic research.

\section{Introduction}

In the last decade, advances in recombinant DNA technology have permitted the development of mice that specifically lack the capacity to express a wide variety of genes, or alternatively, mice that specifically gained the capacity to express genes (1). The availability of mice that lack or gained certain enzymes in metabolic pathways provides an attractive new tool in metabolic research. The increasing availability of these mice increases the need for an experimental mouse model suitable for metabolic research. Up to now, only few metabolic studies have been 
performed in mice, which is probably related to technical problems due to the small body size of mice.

In mice, anesthesia is usually performed using ether or barbiturates. The use of ether is stressful (2), and has recently been forbidden in our institute. All barbiturate drugs cause cardio-respiratory depression (3). In large amounts these drugs cause liver damage and in small amounts these drugs cause a persistent fall in plasma potassium concentration (3). Anesthesia with a mixture of ketamine and medetomidine has been performed in several animals (4-6), and was shown a safe method (6). Therefore, our current regimen for anesthesia is a mixture of ketamine and medetomidine.

Measurement of arterial-venous differences is only possible when catheters are present in blood vessels supplying and draining an organ. To calculate the production or consumption across an organ, it is necessary to measure the plasma flow (7). An indicator-dilution technique, with para-aminohippuric acid (PAH) may be used, which is well known in animal research $(8-10)$. However, because of the small size of mice, only small blood samples can be taken, which leads to loss of accuracy. Therefore, we adapted the para-aminohippuric acid indicator-dilution technique of plasma flow measurements by using ${ }^{14} \mathrm{C}$-labeled $\mathrm{PAH}$. In our model, we used these techniques for plasma flow measurements across the splanchnic area, portal drained viscera (PDV), hindquarter (HQ), and kidney.

Using this design, it was possible, for the first time to our knowledge, to measure amino acid fluxes across portal drained viscera, liver, $\mathrm{HQ}$ and kidney in mice. Our model therefore establishes an experimental basis for the design of flux measurements in mice with altered genetic information that will give exciting new information on metabolic pathways under various patho-physiological states.

\section{Materials and Methods}

\section{Animals}

SPF Swiss mice (25-30 g) were obtained from IFFA Credo Broekman (Someren, The Netherlands). The mice were housed in standard housing (8-10 mice per cage, type 3 Eurostandard, Techniplast, Vianen, The Netherlands) with standard bedding material (autoclaved, BMI, Helmond, The Netherlands). Lab chow (2131 SMRA, 
Hope Farms, Woerden, The Netherlands) and water $(\mathrm{pH} 2.5)$ were changed weekly. The mice were subject to standard 12-hour light-dark cycle periods (7:30 A.M. to 7:30 P.M.) and $50 \pm 5 \%$ humidity. Room temperature was maintained at $20^{\circ} \mathrm{C}$.

Experiments were performed in accordance with the recommendations of the Guide for the Care and Use of Laboratory animals (11), and approved by the Ethical Committee of Animal Research of the Maastricht University.

\section{Standard procedures}

All mice were fasted for 5 hours before the start of the surgical procedures. Food was withheld in the morning (between 8 and $12 \mathrm{am}$ ). The surgical procedures started in the afternoon (between 1 and $4 \mathrm{pm}$ ). Immediately before the surgical procedures were started, the mice were given $1.5 \mathrm{ml}$ normal saline $(0.15 \mathrm{mM} \mathrm{NaCl})$ subcutaneously (s.c.). They were kept at $37^{\circ} \mathrm{C}$ using a rectal temperature controller (Technical Service, Maastricht University) and heat pads.

\section{Anesthesia}

Anesthesia was induced by an intraperitoneal injection of a mixture of ketamine (1.25 mg/ $10 \mathrm{~g}$ b.w., Nimatek, AUV, Cuyk, The Netherlands) and medetomidine (2 $\mu \mathrm{g} / 10 \mathrm{~g}$ b.w., Domitor, Farmos, Espoo, Finland). This caused a loss of withdrawal reflex in 5 minutes. For longer duration of anesthesia, anesthesia was maintained with a continuous s.c. infusion of a mixture of ketamine $(0.35 \mathrm{mg} / 10 \mathrm{~g} \mathrm{b.w./h})$ and medetomidine $(0.35 \mu \mathrm{g} / 10 \mathrm{~g}$ b.w./h) .

\section{Catheterization of blood vessels}

In principle, blood vessels were catheterized using a 30-gauge needle fixed in a silastic tube (Silastic Medical Grade tubing $0.012 \mathrm{~cm} \mathrm{ID,} 0.025 \mathrm{~cm}$ OD, Dow Corning Corporation, Medical Products, Midland, MO, USA) using an operation microscope at magnification 3.5 (Nikon, Japan). All catheter tips were bowed $90^{\circ}$. The opening of the needle tip was positioned exterior of the bow. After insertion, catheters were fixed on two places with cyano-acrylate (Cyanolit 201, Het Rubberhuis, Maastricht, The Netherlands). First the catheter was fixed peripherally on the animal and then at the insertion spot on the vessel. An exception is the hepatic vein catheter, which was not bowed and not fixed with cyano-acrylate, but remained in place by itself. 
For catheterization of the right carotid artery and the jugular vein, a ventral incision was made in the neck and the left and right salivary glands were moved to the left and right side respectively. Then the carotid artery was dissected free and the salivary glands were put back in position. Two catheters were inserted in the right jugular vein $\left(V_{\text {inf }}\right)$ against the direction of blood flow and fixed. Then a $1 \mathrm{ml} / 10 \mathrm{~g}$ b.w./h normal saline infusion was started in the first jugular vein catheter as a continuous fluid support to counteract the loss of body fluids by evaporation during the surgical procedures. Before catheterization of the carotid artery $(A)$, the right salivary gland was again moved to the right. The rostral side of the vessel was ligatured with Perma-hand seide ${ }^{\circledR}$ (0.7 metric, 6-0, Ethicon, Norderstedt, Germany), and the caudal side of the vessel was temporarily closed with a catgut ligature (2 metric, 4-0, Ethicon). The catheter tip was positioned in the artery against the direction of blood flow. After catheterization and fixation, the catgut ligature was released. For catheterization of the abdominal vessels a ventral abdominal incision was made from caudal to rostral at the level of the xyphoid processus. The skin was fixated to both sides.

In male animals, the portal drained viscera (PDV) catheters were placed as indicated in Figure 1. For catheterization of the portal vein $(P)$ the middle and left liver lobe and duodenum were gently put outside the abdomen on the left side of the animal and fixated temporarily with a saline-wet gauze. The catheter was inserted in the vessel and the tip was positioned in the direction of blood flow. After catheterization and fixation, the liver lobe and the duodenum were put back in normal position. For catheterization of the mesenteric vein $\left(M_{\text {inf }}\right)$, the intestines were gently moved outside the abdomen on a saline wet gauze. The intestine was positioned to reveal the colic vein. The catheter tip was pricked in the vein as distanced as possible from the portal vein, against the direction of blood flow. After the catheterization and fixation the intestines were covered with a saline-wet gauze. The last catheter was the hepatic vein catheter $(\mathrm{H})$. The right liver lobe was carefully moved right outside the abdomen and temporarily fixed with a cotton bud. The left liver lobe was gently pulled to the caudal side to reveal the hepatic vein in the hilus. The cathetertip was pricked peripherally in the lobe and pushed through the liver tissue until it was seen in the hepatic vein. Then the right liver lobe was released to normal position. 


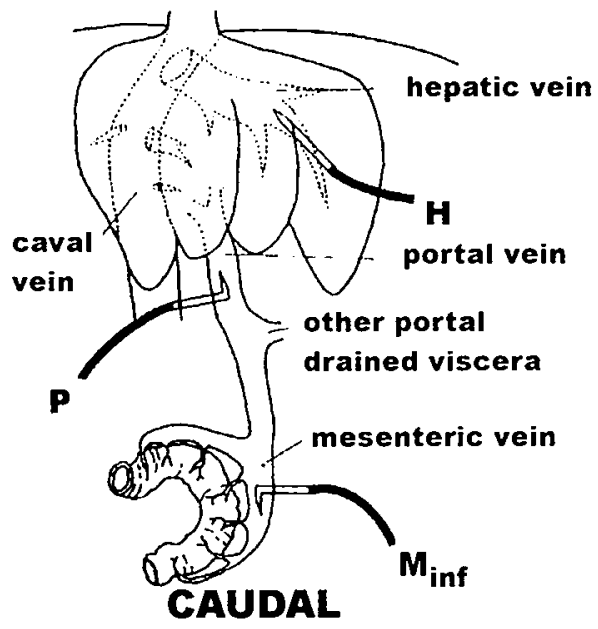

Figure 1. Positioning of the catheters in the PDV - liver area. For measurement across PDV and liver, catheters were inserted in the carotid artery ( $A$, not shown), portal vein $(P)$ and hepatic vein $(H)$. Blood was sampled from the $A, P$ and $H$ catheters. Infusion of ${ }^{14} \mathrm{C}$-PAH was into the mesenteric vein $\left(M_{\text {inf }}\right)$.

In female animals catheters were inserted in the hindquarter ( $H Q$ ) and kidney area as depicted in Figure 2. To create working-space, the intestines were moved outside the abdomen on the left side of the animal and covered with a saline-wet gauze. In addition, the uterus was pulled caudally out of the abdominal cavity. The uterus and intestines were kept wet throughout the procedures. First the abdominal aorta $\left(A_{\text {inf }}\right)$ and the inferior caval vein $(V)$ were dissected free. The aorta catheter was inserted with the tip directed against blood flow and the caval vein catheter was inserted in the direction of blood flow. The renal vein catheter $(R)$ was pricked in the right renal vein with its tip against blood flow.

All catheters were filled with heparinized saline solution $(20 \mathrm{U} / \mathrm{ml}$ Heparin Leo® Pharmaceutical Products BV, Weesp, The Netherlands) until blood sampling. 


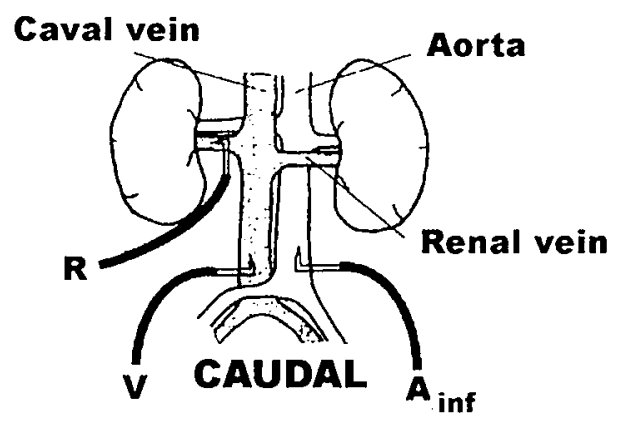

Figure 2. Positioning of catheters in the kidney - hindquarter area. For measurement across kidney and hindquarter, catheters were inserted in the carotid artery ( $A$, not shown), caval vein $(V)$ and renal vein $(R)$. Blood was sampled from the $A, R$ and $V$ catheters. Infusion of ${ }^{14} \mathrm{C}$-PAH was into the abdominal aorta $\left(A_{\text {inf }}\right)$.

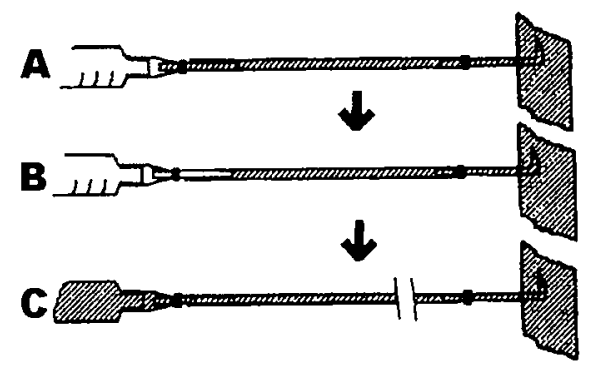

Figure 3. Blood sampling method with reduced dead-volume sampling. Panel A. Blood was pulled until the catheter was filled. Panel $B$. A clean needle and syringe was inserted in the catheter and blood was sampled. Panel C. After blood collection the catheter was cut off just after the $30 \mathrm{G}$ needle, so that the blood in the catheter was also used.

\section{Blood sampling}

The limited size of mice reduces the amount of blood that can be sampled from each animal. To avoid further reductions in the amount of blood that could be obtained from each mouse without influencing metabolism, we developed a method to reduce 
the dead-volume that usually has to be overcome during blood sampling. This method implied that blood was pulled until the catheter was filled and all heparinized saline disappeared from the catheter (Figure $3 A$ ), then a clean needle and syringe was inserted in the catheter (Figure 3B), and blood was sampled. After blood collection the catheter was cut off just after the $30 \mathrm{G}$ needle (Figure $3 \mathrm{C}$ ). Blood was collected in small heparinized cups (Microvette ${ }^{\circledR}$, CD $300 \mathrm{LH}$, Sarstedt, Nümbrecht, Germany) on ice.

Experiment 1. Determination of ${ }^{14} \mathrm{C}-\mathrm{PAH}$ steady state in arterial blood.

Long term anesthesia was performed as described above in 6 male Swiss mice. We intended to use the non-toxic indicator [glycyl-1- $\left.{ }^{14} \mathrm{C}\right]$-p-aminohippuric acid $\left({ }^{14} \mathrm{C}-\mathrm{PAH}\right.$, NEN Life Science Products, Boston, MA, USA) for blood flow measurements. To first measure whole blood steady state of ${ }^{14} \mathrm{C}-\mathrm{PAH}$, a primed continuous infusion of ${ }^{14} \mathrm{C}$ $\mathrm{PAH}$ in normal saline was given in the mesenteric vein $\left(\mathrm{M}_{\text {inf }}\right)$ using a low flow syringe pump (model 11, Harvard Apparatus Inc., Holliston, MA, USA). The bolus of ${ }^{14} \mathrm{C}-\mathrm{PAH}$ was $20 \mu \mathrm{l} / 10 \mathrm{~g}$ body weight of $3 \mu \mathrm{Ci} / \mathrm{ml}{ }^{14} \mathrm{C}-\mathrm{PAH}$. The infusion rate was $1 \mathrm{ml} / 10 \mathrm{~g}$ body weight/h of $0.6 \mu \mathrm{Ci} / \mathrm{ml}{ }^{14} \mathrm{C}-\mathrm{PAH}$. Directly before the start of the primed continuous infusion of ${ }^{14} \mathrm{C}-\mathrm{PAH}$, the standard normal saline infusion was ended. Arterial blood was obtained from the carotid artery 10 and 20 minutes after start of the ${ }^{14} \mathrm{C}$-PAH infusion.

For ${ }^{14} \mathrm{C}$-PAH determinations, $20 \mu \mathrm{L}$ whole blood was added to $280 \mu \mathrm{L} 8.6 \%$ Trichloroacetic acid, thoroughly mixed for deproteinization and centrifuged (4 min, $4^{\circ} \mathrm{C}, 8500 \mathrm{~g}$, Eppendorf 5413 centrifuge). $250 \mu$ supernatant was mixed with $6 \mathrm{ml}$ scintillation fluid (Ultima Gold, Packard, Groningen, The Netherlands) and radioactivity was counted on a Winspectral 1414 counter (Wallac, EG\&G, Breda, The Netherlands).

For hematocrit determinations, a micro-hematocrit tube (Vitrex, Herlev, Denmark) was filled with blood and centrifuged for 3 minutes at $6.8 \mathrm{~g}$ at room temperature in an EBA 12 centrifuge (Hettich, Dépex, De Bilt, Netherlands). Hematocrit was determined by dividing the length $(\mathrm{mm})$ of the red blood cells section by the total filled length of the tube. 
Experiment 2. Metabolic flux measurements across PDV, liver, hindquarter and kidney

Metabolic flux measurements were performed in 2 sets of animals. Measurement of metabolic flux across PDV and liver was performed in one set of animals, and involved the catheterization of the carotid artery, mesenteric vein, jugular vein, portal vein and hepatic vein. Measurement across hindquarter and kidney was performed in a second set of animals and involved the catheterization of the carotid artery, jugular vein, abdominal aorta, renal vein and caval vein. Because males were usually larger than females and because males had less fat than females, it was easier to catheterize the mesenteric vein in males than females. Therefore, flux measurements across PDV and liver were performed in males $(n=18)$, and measurements across hindquarter and kidney were performed in females $(n=10)$.

Long term anesthesia and ${ }^{14} \mathrm{C}$-PAH administration was performed as described above. In the PDV/Liver study, the infusion of ${ }^{14} \mathrm{C}$-PAH was in the mesenteric vein $\left(M_{\text {inf }}\right)$ catheter. In the Kidney/HQ study infusion of ${ }^{14} \mathrm{C}-\mathrm{PAH}$ was in the abdominal aorta $\left(A_{\text {inf }}\right)$. Because ${ }^{14} \mathrm{C}$-PAH was in steady state (Figure 2), blood $(0.2 \mathrm{ml}$ per catheter) was sampled after 15 minutes as described above. In small animals as mice blood sampling could influence the blood flow measurements. Despite excessive fluid resuscitation, blood sampling could diminish circulating volume and thus renal function, thereby decreasing renal ${ }^{14} \mathrm{C}$-PAH excretion and increasing the renal venous and arterial ${ }^{14} \mathrm{C}-\mathrm{PAH}$ concentration. To minimize these effects in the PDV/Liver studies blood was sampled from the aorta, hepatic vein and portal vein in this order. In the Kidney/Hindquarter studies blood was taken from renal vein first, followed by sampling from the carotid artery and caval vein.

Hematocrit and ${ }^{14} \mathrm{C}$-PAH measurements were performed as described above. Blood was centrifuged to obtain plasma. For determination of amino acid concentrations $100 \mu \mathrm{l}$ plasma was added to $8 \mathrm{mg}$ dry sulfosalicylic acid, vortexed, frozen in liquid nitrogen and stored at $-80^{\circ} \mathrm{C}$. Plasma and amino acid concentrations were measured using a fully automated HPLC system (12).

\section{Calculation of plasma flows}

All calculations were performed using plasma flows and plasma concentrations. The concentration of ${ }^{14} \mathrm{C}-\mathrm{PAH}$ in plasma was calculated from the ${ }^{14} \mathrm{C}-\mathrm{PAH}$ concentration in whole blood using the hematocrit value as follows: 
${ }^{14} \mathrm{C}-\mathrm{PAH}_{\text {(plasma) }}={ }^{14} \mathrm{C}-\mathrm{PAH}_{\text {(whole blood) }} /(1-(\mathrm{H} \mathrm{t} / 100))$.

Similar to the use of non-radioactive $\mathrm{PAH}$ in rats and pigs $(8,10,13-16),{ }^{14} \mathrm{C}-\mathrm{PAH}$ was used in two ways to measure organ plasma flow. First, by calculating the dilution of $\mathrm{PAH}$, plasma flow was measured. In this situation, the amount of ${ }^{14} \mathrm{C}-\mathrm{PAH}$ entering the vessel by infusion and by blood equals the amount leaving the vessel:

IN = OUT

IN $=\left(\right.$ Infusion rate $\left.\times\left[{ }^{14} \mathrm{C}-\mathrm{PAH}\right]_{\mathrm{infused}}\right)+\left(\right.$ Flow $\left.\times\left[{ }^{14} \mathrm{C}-\mathrm{PAH}\right]_{\mathrm{pre}}\right)$

OUT = Flow $\times\left[{ }^{14} \mathrm{C}-\mathrm{PAH}\right]_{\text {post }}$

In these formulae $\left[{ }^{14} \mathrm{C}-\mathrm{PAH}\right]$ infused is the concentration of ${ }^{14} \mathrm{C}-\mathrm{PAH}(\mathrm{dpm} / \mathrm{ml})$ in the infused solution, $\left[{ }^{14} \mathrm{C}-\mathrm{PAH}\right]_{\text {pre }}$ is the plasma concentration of ${ }^{14} \mathrm{C}-\mathrm{PAH}$ in the vessel entering the organ and $\left[{ }^{14} \mathrm{C}-\mathrm{PAH}\right]_{\text {post }}$ is the plasma concentration of ${ }^{14} \mathrm{C}-\mathrm{PAH}$ in the vessel leaving the organ. Using these formulae, calculation of plasma flow is easily made.

Flow $=\left(\right.$ Infusion rate $\left.x\left[{ }^{14} \mathrm{C}-\mathrm{PAH}\right]_{\text {infused }}\right) /\left(\left[{ }^{14} \mathrm{C}-\mathrm{PAH}\right]_{\text {post }}-\left[{ }^{14} \mathrm{C}-\mathrm{PAH}\right]_{\text {pre }}\right)$ This model is used in the measurement of PDV, liver and HQ plasma flow.

By measuring the extraction of ${ }^{14} \mathrm{C}-\mathrm{PAH}$ by the kidney, renal flow can be calculated. The amount extracted equals the amount infused when the system is in steady state:

$\mathrm{PAH}$ extracted $=$ Infusion rate $\times\left[{ }^{14} \mathrm{C}-\mathrm{PAH}\right]_{\text {infused }}$

Further, the sum of the amount extracted and the amount leaving the kidney by the renal vein equals the amount entering the kidney:

IN = OUT

IN $=\left(\right.$ Flow $\times\left[{ }^{14} \mathrm{C}-\mathrm{PAH}\right]$ pre $)$

OUT $={ }^{14} \mathrm{C}-\mathrm{PAH}$ extracted $+\left(\right.$ Flow $\left.\times\left[{ }^{14} \mathrm{C}-\mathrm{PAH}\right]_{\text {post }}\right)$

Flow $=\left(\right.$ Infusion rate $\left.x\left[{ }^{14} \mathrm{C}-\mathrm{PAH}\right]_{\text {infused }}\right) /\left(\left[{ }^{14} \mathrm{C}-\mathrm{PAH}\right]_{\text {arterial }}-\left[{ }^{14} \mathrm{C}-\mathrm{PAH}\right]_{\text {renal }}\right)$.

Plasma flows are expressed as $\mathrm{ml} / 10 \mathrm{~g} \mathrm{b.w./min.}$

\section{Calculation of metabolic fluxes}

PDV flux was calculated by multiplication of the portal-arterial difference with the portal plasma flow $(8,9)$. Similarly, HQ flux was calculated by multiplication of the central venous-arterial difference with $\mathrm{HQ}$ plasma flow $(15,17)$, and renal flux was calculated by multiplication of the renal venous-arterial difference with renal plasma flow $(13,14)$ and represents flux of both kidneys. The calculation of liver flux was 
more complex because of the portal and arterial routes of blood delivery. Liver flux was calculated by subtracting PDV flux from splanchnic flux $(8,10)$.

Statistical analysis

Significance from zero was tested using the Wilcoxon test $(P<0.01)$.

\section{Results}

Experiment 1. Determination of ${ }^{14} \mathrm{C}-\mathrm{PAH}$ steady state in arterial blood.

Arterial ${ }^{14} \mathrm{C}$-PAH steady state was reached within 10 minutes after start of the primed continuous infusion (Figure 4). In the flow experiments, blood was sampled 15 minutes after start of the primed continuous infusion.

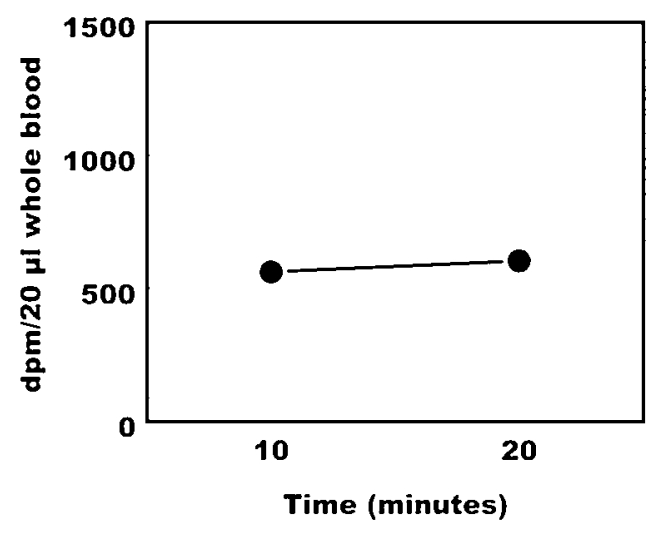

Figure 4. Primed continuous infusion of ${ }^{14} \mathrm{C}$-para-aminohippuric acid in arterial blood. ${ }^{14} \mathrm{C}-\mathrm{PAH}$ was infused in the mesenteric vein. Steady state was reached within 15 minutes. In further experiments blood was sampled 15 minutes after start of the primed continuous infusion of ${ }^{14} \mathrm{C}-\mathrm{PAH}$. Values are in $\mathrm{dpm} / 20 \mu \mathrm{L}$ whole blood. SEM is within the symbols. 
Chapter 2

Table 1. Plasma flows. Values are mean \pm SEM and are expressed in $\mathrm{ml} / 10 \mathrm{~g} \mathrm{b.w} / \mathrm{min}$.

\begin{tabular}{lcccc}
\hline & \multicolumn{3}{c}{ Plasma flow } & N \\
\hline PDV & 0.94 & \pm & 0.16 & 12 \\
Liver & 1.19 & \pm & 0.31 & 14 \\
Hindquarter & 1.12 & \pm & 0.27 & 9 \\
Kidney & 1.04 & \pm & 0.09 & 9 \\
\hline
\end{tabular}

Table 2. Arterial amino acid concentrations in male and female mice. Values are mean \pm SEM and are expressed in $\mu \mathrm{M}$.

\begin{tabular}{lrrlrlll}
\hline & \multicolumn{3}{c}{ Male } & \multicolumn{5}{l}{ Female } \\
\hline GLN & 336 & \pm & 26 & 482 & \pm & 30 \\
THR & 102 & \pm & 6 & 127 & \pm & 7 \\
HIS & 68 & \pm & 5 & 118 & \pm & 6 \\
CIT & 60 & \pm & 6 & 86 & \pm & 6 \\
ALA & 306 & \pm & 34 & 378 & \pm & 54 \\
TAU & 139 & \pm & 13 & 169 & \pm & 30 \\
ARG & 105 & \pm & 7 & 150 & \pm & 8 \\
TYR & 81 & \pm & 8 & 135 & \pm & 10 \\
VAL & 145 & \pm & 14 & 256 & \pm & 11 \\
MET & 34 & \pm & 2 & 28 & \pm & 4 \\
ILE & 61 & \pm & 7 & 101 & \pm & 6 \\
PHE & 77 & \pm & 7 & 133 & \pm & 7 \\
TRP & 38 & \pm & 3 & 74 & \pm & 5 \\
LEU & 114 & \pm & 14 & 187 & \pm & 8 \\
ORN & 90 & \pm & 11 & 134 & \pm & 10 \\
LYS & 355 & \pm & 41 & 458 & \pm & 34 \\
BCAA & 320 & \pm & 35 & 545 & \pm & 24 \\
SUMAA & 2811 & \pm & 189 & 3636 & \pm & 209 \\
\hline
\end{tabular}

Experiment 2. Metabolic flux measurements across PDV, liver, hindquarter and kidney

Post-absorptive plasma flows are plotted in Table 1. Arterial amino acid concentrations are given in Table 2. In general, the amino acid concentrations were higher in female than in male mice. Some characteristic fluxes across the PDV, liver, hindquarter and kidney are given in Figure 5. Glutamine (Figure 5) is a non-essential 
amino acid produced by the $H Q$, and taken up by the intestine and kidney. The amount of glutamine produced by the HQ was completely taken up by the PDV and kidney. In the PDV, glutamine was taken up from the circulation and used for the production of citrulline (Figure 5). Approximately $20 \%$ of the glutamine that was taken up by the PDV was used for the production of citrulline. Citrulline produced by the PDV, entered the circulation and was used by the kidney for the production of arginine (Figure 5). Hepatic arginine uptake and muscle arginine production did not reach significance from zero (Liver: $p=0.057, H Q: p=0.062$ ), indicating that the liver did not significantly consume arginine and muscle did not significantly release arginine.

\section{Discussion}

To be able to make use of transgenic and knockout mice in metabolic research, it is of importance to have a method in which mice are in a stable condition and which permits blood sampling from several blood vessels. We developed such a model by adapting ketamine-medetomidine anesthesia, which is a reliable anesthetic in other animals (4-6), to mice. Furthermore, we created techniques to reduce the amount of blood needed for the measurements of blood flow and plasma amino acids.

Measurements were performed under ketamine-medetomidine anesthesia. This anesthesia allowed abdominal surgery, while animals did not need mechanical ventilation. Thus, this method of anesthesia yielded a stable condition. The second improvement of the present method that added stability was the standard infusion of normal saline. During the surgical procedures the mice rapidly lost body fluids, due to evaporation, especially when the abdomen was opened. Therefore, a standard normal saline infusion was given s.c. immediately after anesthesia and continued i.v. before opening the abdomen. Moreover, during the surgical procedures, the mice were kept on $37^{\circ} \mathrm{C}$ using heat pads and a rectal temperature controller. Anesthetized mice rapidly lost body heat due to the lack of physical activity. The automatic control of body temperature also added stability during the surgical procedures. Stability of 

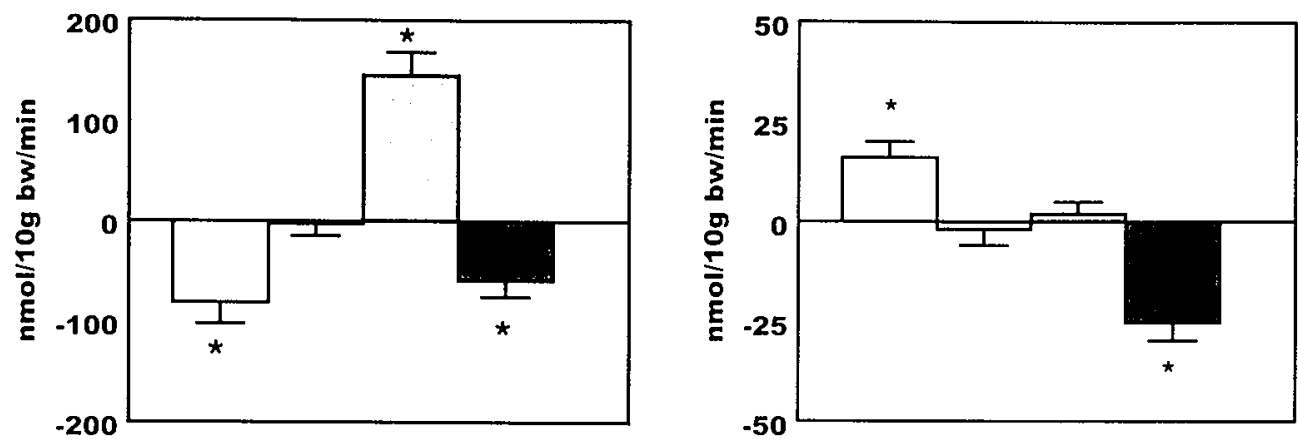

Figure 5. Amino acid fluxes across portal drained viscera, liver, hindquarter and liver. Fluxes calculated as the product of plasma flow and the arterio-venous concentration difference and expressed in nmol/10g bw/min. * significantly different from $0(p<0.01)$. Upper left panel: Glutamine; Upper right panel: Citrulline; Lower right panel: Arginine.

$\begin{array}{ll}\square \text { PDV } & \square \text { Liver } \\ \text { Kidney }\end{array}$

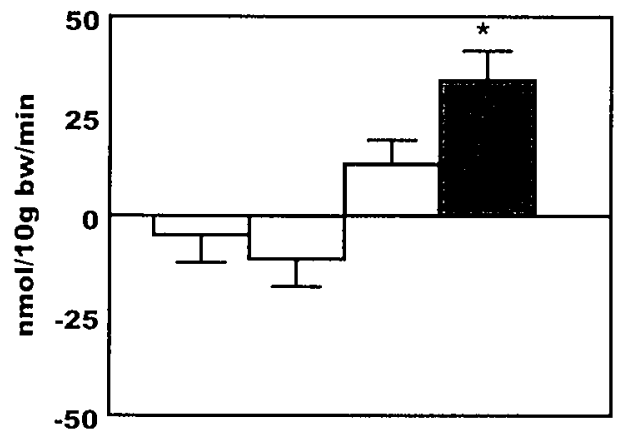

the mouse during the surgical procedures and blood sampling was crucial for the measurement of metabolic parameters.

Another important aspect of the present model was the reduction of deadvolume during blood sampling. The amount of blood that can be sampled from a mouse is small due to the small size of the mouse. To be able to perform several measurements in one mouse the dead-volume during sampling was reduced. Another adaptation that had to be made was the reduction of blood or plasma necessary to perform measurements. We made these adaptations by measuring blood flow using radio-labeled PAH, the measurement of which could be performed accurately using a small amount of blood. Furthermore, we previously described methods to measure plasma amino acids in $10 \mu \mathrm{L}$ plasma (12) and amino acid enrichments in $2 \mu \mathrm{L}$ plasma (18). 
Plasma flow measurement was needed for the determination of flux of substances across an organ or body region. The indicator-dilution technique using para-amino hippuric acid is a widely used method to measure plasma flow across organs. In mice, we used ${ }^{14} \mathrm{C}$-labeled $\mathrm{PAH}$, because in our hands the intra-sample variance in non-labeled arterial PAH concentrations in these small animals was too high (10-40\%, not shown). The probable cause for this high variance was the dilution necessary to obtain enough volume to measure unlabeled PAH by an enzymatic method on a Cobas Mira machine, as operated in our laboratory. When radio-labeled $\mathrm{PAH}$ was used, dilution of the sample was avoided, resulting in a much lower intrasample variance ( $5 \%$, not shown). When measuring blood flow using an indicatordilution technique, it is important that the indicator reaches steady state. In our primed-continuous infusion model, ${ }^{14} \mathrm{C}-\mathrm{PAH}$ was in steady state within 15 minutes. Therefore, in further experiments, blood was taken 15 minutes after start of the primed continuous infusion of ${ }^{14} \mathrm{C}-\mathrm{PAH}$. The variance in PDV and liver and hindquarter organ flows obtained using ${ }^{14} \mathrm{C}$-labeled $\mathrm{PAH}$ was approximately $15-25 \%$, which is comparable to values obtained with unlabeled $\mathrm{PAH}$ in rats $(9,10)$. The variance in renal flow was much lower, approximately $10 \%$.

In this study, fluxes across PDV and liver were performed in male mice, and fluxes across kidney and HQ were performed in female mice. In metabolic research most often only male rodents are used, because of the absence of oestrous cycle. From the amino acid concentrations it was obvious that the variance was similar for measurements in male and female mice. In our opinion, it is therefore not necessary to use male mice only in general metabolic research. In the future, this model may be used for metabolic measurements in transgenic and knockout mice. These mice often are more difficult to breed than most laboratory mice, and it may therefore be valuable to use both female and male mice. Because differences exist in plasma amino acid concentrations in male and female mice, it is best to use male and female mice in separate experiments.

In this study, muscle released a significant amount of glutamine. In the postabsorptive condition, glutamine was the predominant amino acid released by muscle. Glutamine production by muscle was balanced by glutamine uptake by the kidney and the PDV. In the kidney, glutamine was the main substrate for renal ammoniagenesis (19). In the PDV, approximately $17 \%$ of glutamine that was taken up from the circulation, was converted to citrulline. This value was consistent with 
values in pigs $(22 \%)(20)$ and rats $(16 \%)(21)$. Virtually all citrulline released from the PDV was taken up by the kidney. The kidney contains the enzymes argininosuccinate synthase and argininosuccinate lyase, which convert citrulline to arginine (22). The kidney is believed to be the main endogenous source of arginine (23). The amino acid fluxes are examples of measurement of metabolic substances in our mouse model. They illustrate a few of the many possibilities of this model.

We conclude that this model enables measurement of metabolic fluxes across PDV, liver, kidney and $H Q$ in mice. The availability of such a small animal model allows the measurement of metabolic parameters in transgenic and knockout mice, and therefore may implicate an important refinement of metabolic research.

\section{Acknowledgments}

The authors wish to thank JLJM Scheyen and HMH van Eijk for excellent amino acid analysis. We also wish to thank $A E$ van den Bogaard and the employees of the Centralized Animal Facilities of Maastricht University.

\section{References}

1. Picciotto MR, Wickman K. Using knockout and transgenic mice to study neurophysiology and behavior. Physiol Rev 1998;78(4):1131-63.

2. Sutanto $W$, de Kloet ER. The use of various animal models in the study of stress and stressrelated phenomena. Lab Animals 1994;28:293-306.

3. Hall LW, Clarke KW. Veterinary anaesthesia. London: Baillière Tindall; 1991.

4. Vainio OM, Bloor BC, Kim C. Cardiovascular effects of a ketamine-medetomidine combination that produces deep sedation in yukatan mini swine. Lab Anim Sci 1992;42:582-588.

5. Verstegen J, Fargetton X, Ectors F. Medetomidine/ketamine anaesthesia in cats. Acta Vet Scand 1989;85:117-123.

6. Nevalainen $T$, Pyhälä L, Voipio HM, Virtanen R. Evaluation of anaesthetic potency of medetomidine-ketamine combination in rats, guinea-pigs and rabbits. Acta Vet Scand 1989;85:139-143.

7. Zierler KL. Theory of the use of arteriovenous concentration differences for measuring metabolism in steady and non-steady states. J Clin Invest 1961;40:2111-2125.

8. Ten Have GAM, Bost MCF, Suyk-Wierts JCAW, van den Bogaart AEJM, Deutz NEP. Simultaneous measurement of metabolic flux in portally-drained viscera, liver, spleen, kidney and hindquarter in the conscious pig. Lab.Anim. 1996;30:347-358. 
9. Dejong $\mathrm{CHC}$, Deutz NEP, Soeters PB. Intestinal glutamine and ammonia metabolism during chronic hyperammonaemia induced by liver insufficiency. Gut 1993;34:1112-1119.

10. De Blaauw 1, Deutz NEP, Boers W, Von Meyenfeldt MF. Hepatic amino acid and protein metabolism in non-anorectic, moderately cachectic tumor-bearing rats. J.Hepatol. 1997;26:396-408.

11. Waldegrave W, Chairman Council of the European Community. Guide for the care and use of laboratory animals. Brussels, Belgium: European Community; 1986. Report No.: Publication 86/609.

12. Van Eijk HMH, Rooyakkers DR, Deutz NEP. Rapid routine determination of amino acids in plasma by high-performance liquid chromatography with a 2-3 $\mu \mathrm{M}$ Spherisorb ODS $\|$ column. J.Chromatogr. 1993;620:143-148.

13. Dejong CHC, Welters CFM, Deutz NEP, Heineman E, Soeters PB. Renal arginine metabolism in fasted rats with subacute short bowel syndrome. Clin Sci 1998;95:409-418.

14. Dejong CHC, Deutz NEP, Soeters PB. Renal ammonia and glutamine metabolism during liver insufficiency-induced hyperammonemia in the rat. J.Clin.Invest. 1993;92:2834-2840.

15. Dejong CHC, Kampman MT, Deutz NEP, Soeters PB. Altered glutamine metabolism in rat portal drained viscera and hindquarter during hyperammonemia. Gastroenterology 1992;102:936-948.

16. De Blaauw I, Deutz NEP, Von Meyenfeldt MF. In vivo amino acid metabolism of gut and liver during short and prolonged starvation. Am.J.Physiol. 1996;270:G298-G306.

17. De Blaauw I, Deutz NEP, Von Meyenfeldt MF. Muscle protein and amino acid turnover in rats in vivo: effects of short-term and prolonged starvation. Clin.Sci. 1996;90:457-466.

18. Van Eijk HMH, Rooyakkers DR, Deutz NEP. Determination of amino acid isotope enrichment using liquid chromatography-mass spectrometry. Anal.Biochem. 1999;271:8-17.

19. Pitts RF, DeHaas J, Klein J. Relation of renal amino and amide nitrogen extraction to ammonia production. Am J Physiol 1963;204:187-191.

20. Deutz NEP, Reijven PLM, Athanasas G, Soeters PB. Post-operative changes in hepatic, intestinal, splenic and muscle fluxes of amino acids and ammonia in pigs. Clin.Sci. 1992;83:607-614.

21. Deutz NEP, Dejong CHC, Athanasas G, Soeters PB. Partial enterectomy in the rat does not diminish muscle glutamine production. Metabolism 1992;41:1343-1350.

22. Levillain $O$, Hus-Citharel A, Morel F, Bankir L. Localisation of arginine synthesis along rat nephron. Am.J.Physiol. 1990;259:F916-F923.

23. Windmueller HG, Spaeth AE. Source and fate of circulating citrulline. Am.J.Physiol. 1981;241:E473-E480. 
Chapter 2 


\section{2}

Tracer methodology in whole body and organ balance metabolic studies: plasma sampling is required

A study in post-absorptive rats using isotopically labeled arginine, phenylalanine, valine and leucine

Marcella M. Hallemeesch, Peter B. Soeters, Nicolaas E.P. Deutz.

Dept. of Surgery, Maastricht University, Maastricht, The Netherlands 


\section{Abstract}

Background \& Aims -Radioactive and stable amino acid isotopes are frequently used in metabolic research. Blood cells contain amino acid transporters, which may influence tracer distribution in blood. The aim of this study was to determine whether plasma or whole blood specific activity or enrichment of amino acid tracers should be used in the calculation of whole body and organ production rates.

Methods -Seven male Wistar rats were infused with $\mathrm{L}-\left[2,3-{ }^{3} \mathrm{H}\right]$-Arginine, $\mathrm{L}-\left[2,6-{ }^{3} \mathrm{H}\right]-$ Phenylalanine, $L-\left[3,4-{ }^{3} H\right]-V a l i n e$, and $\left[L-\left[4,5-{ }^{3} H\right]-L e u c i n e\right.$. Whole body and portal drained visceral, hepatic and renal production rates of arginine, phenylalanine, valine and leucine were determined in plasma and in whole blood.

Results - Amino acid tracers that equilibrate well between plasma and blood cells (for instance phenylalanine, valine and leucine) yield similar whole body production rates when whole blood or plasma is sampled. Also, organ production rates measured using these amino acid tracers are consistent. However, a discrepancy exists between the whole body production rate and the sum of PDV, hepatic and renal production rates. When tracers are used that do not equilibrate well between plasma and blood cells (for instance arginine) the use of whole blood specific activity in the calculations yield overestimations of whole body and organ production rates. Conclusions -From our data we recommend plasma sampling and strongly advise against whole blood sampling in metabolic organ balance studies in which amino acid tracers are used.

\section{Introduction}

Radioactive and stable tracers are widely used in biomedicine to quantify metabolic routes in vivo, because they are functionally identical to the compound of interest (tracee), but distinct in some physical characteristics that enable their precise detection (1). Calculation of substrate kinetics traditionally measures the rate of appearance ( $\mathrm{Ra}$ ) which in steady state conditions equals the rate of disappearance of the substrate (1). In the single pool model it is assumed that the Ra of substrate and the infusion of tracer occur into, and sampling is from a single, homogenous, instantly mixing pool (1). 
In metabolic studies, the blood compartment is usually viewed as a single pool, which implicates that whole blood sampling is allowed for the calculation of whole body rate of appearance. However, erythrocytes, like all metabolic active cells, contain amino acid transporters (2-4), dividing whole blood into two pools, the plasma pool and the blood cell pool. If in tracer studies the specific activity or enrichment of the tracer is equal in plasma and blood cells, these two pools can again be viewed as a single pool. However, if equilibrium is not reached, plasma and blood cells should possibly be viewed as two separate pools. The fact that some amino acids are more concentrated in plasma or in blood cells suggests that variability exists in the activity of amino acid transporters. It may therefore be that in tracer studies some tracers reach equilibrium in specific activity or enrichment between plasma and blood cells, whereas other amino acid tracers do not. The presence of equilibrium of the tracer should determine if whole blood or plasma should be used for the determination of specific activity (SA) or enrichment (E).

More recently, investigators have combined tracer dilution and organ balance techniques to obtain tissue or organ specific metabolic information. These types of studies also require tracer steady state conditions and therefore in these studies it is also important to know the exchange of tracer across blood cell membranes. In addition, it has been suggested, that blood cells have a role in inter-organ transport (5-8). This view further complicates the use of tracers in the quantification of organ or tissue based metabolism. At present, most groups use plasma amino acid SA or $E$ $(9-14)$ in the subsequent calculations of whole body or organ production rates. Only a few groups use whole blood amino acid SA or E (15-17).

The goal of this study was to clarify in a rat model whether whole blood or plasma amino acid SA or E should be used in metabolic studies. We measured whole body appearance rates and organ production and disposal rates of arginine, phenylalanine, valine and leucine because these amino acids are commonly used.

\section{Materials and Methods}

\section{Animals}

Male SPF Wistar rats (280-380 g, n=7), obtained from IFFA Credo Broekman (Someren, The Netherlands) were used in this study. Rats were fed standard lab 
chow, water intake was ad libitum. Rats were subject to standard 12-hour light-dark cycle periods (7:30 A.M. to 7:30 P.M.). Room temperature was maintained at $25^{\circ} \mathrm{C}$. Experiments were performed in accordance with the recommendations of the Guide for the Care and Use of Laboratory animals (18), and approved by the Ethical Committee of Animal Research of the Maastricht University.

\section{Study and sampling procedures}

After an overnight fast, anesthesia was performed in the rats by an intraperitoneal injection of ketamine (25 mg/ $100 \mathrm{~g}$, Nimatek, AUV, Cuyk, The Netherlands) and medetomidine $(12.6 \mu \mathrm{g} / 100 \mathrm{~g}$, Domitor, Farmos, Espoo, Finland). This caused a loss of withdrawal reflex in 5 minutes. Anesthesia was maintained with a continuous s.c. infusion of ketamine $(5.7 \mathrm{mg} / 100 \mathrm{~g}$, Nimatek, AUV, Cuyk, The Netherlands) and medetomidine $(9.45 \mu \mathrm{g} / 100 \mathrm{~g}$, Domitor, Farmos, Espoo, Finland) at a rate of 1.13 $\mathrm{ml} / 100 \mathrm{~g} /$ hour. Rats were resuscitated s.c. with saline $(4 \mathrm{ml} / 100 \mathrm{~g})$ at the start of the surgical procedures $(19,20)$. The right jugular vein was catheterized (Intramedic Polyethylene Tubing PE 50, $0.051 \mathrm{~cm} \mathrm{ID,} 0.094 \mathrm{~cm}$ OD, Clay Adams, Parsipany, NY, USA). Then the portal vein, the hepatic vein, the renal vein, and the aorta were catheterized using a 25 gauge needle fixed in a silastic tube (Silastic Medical Grade tubing $0.051 \mathrm{~cm} I D, 0.094 \mathrm{~cm}$ OD, Dow Corning Corporation, Medical Products, Midland, MO, USA), and fixed with cyano-acrylate (Cyanolit 201, Het Rubberhuis, Maastricht, The Netherlands) $(9,21)$. The complete procedure took approximately 30 minutes.

To study amino acid kinetics $\mathrm{L}-\left[2,3-{ }^{3} \mathrm{H}\right]-$ Arginine $\left({ }^{3} \mathrm{H}-\mathrm{Arg}\right.$, NEN Life Science Products, USA), L-[2,6- $\left.{ }^{3} \mathrm{H}\right]-$ Phenylalanine $\left({ }^{3} \mathrm{H}\right.$-Phe, Amersham International plc, Buckinghamshire, UK), L-[3,4- $\left.{ }^{3} \mathrm{H}\right]$-Valine $\left({ }^{3} \mathrm{H}\right.$-Val, NEN Life Science Products, USA), and $\left[\mathrm{L}-\left[4,5-{ }^{3} \mathrm{H}\right]\right.$-Leucine $\left({ }^{3} \mathrm{H}\right.$-Leu, Amersham $)$ were used as tracers. A primed $(20 \mu \mathrm{Ci}$ ${ }^{3} \mathrm{H}$-Arg, $10 \mu \mathrm{Ci}{ }^{3} \mathrm{H}$-Phe, ${ }^{3} \mathrm{H}$-Val, ${ }^{3} \mathrm{H}$-Leu) constant infusion $\left(20 \mu \mathrm{Ci}{ }^{3} \mathrm{H}\right.$-Arg, $10 \mu \mathrm{Ci}{ }^{3} \mathrm{H}$ Phe, ${ }^{3} \mathrm{H}$-Val, ${ }^{3} \mathrm{H}$-Leu $/ \mathrm{h}$ ) was given in the right jugular vein.

At 30 ', blood ( $0.4 \mathrm{ml}$ per catheter) was sampled from the aorta, portal vein, hepatic vein and renal vein. At 15' and 45' blood was sampled from the aorta only. Blood was collected in heparinized cups (Sarstedt, Nümbrecht, Germany) on ice. Rats were euthanized by diaphragm rupture.

For hematocrit determinations, a micro-hematocrit tube was filled with heparinized blood and centrifuged at $10000 \mathrm{~g}$ at room temperature (Micro Hematocrit 
Centrifuge Centrifuge, Hawskley Ltd, UK). Hematocrit was read with a Micro Hematocrit Reader (Hawksley, Ltd, UK). For whole blood amino acid determinations, $100 \mu \mathrm{l}$ blood was deproteinized by adding it to $200 \mu 20 \%$ (w/v) 5 -sulfosalicylic acid (SSA, Brunschwig, Amsterdam, The Netherlands) solution, vortexed, and centrifuged. The supernatant was frozen in liquid nitrogen and stored at $-80^{\circ} \mathrm{C}$. Plasma was obtained by whole blood centrifugation at $8900 \mathrm{~g}$ at $4^{\circ} \mathrm{C}$ for 5 minutes. For determination of amino acids, $250 \mu \mathrm{L}$ plasma was deproteinized by adding it to $15 \mathrm{mg}$ dry SSA, vortexed, frozen in liquid nitrogen and stored at $-80^{\circ} \mathrm{C}$. Thus, the time period from blood sampling to deproteinization was approximately 15 minutes longer for plasma than for whole blood. Specific activities of arginine, citrulline, ornithine, phenylalanine, tyrosine, valine and leucine were determined as described recently (22).

Whole blood, plasma, and erythrocyte flow

Whole blood and plasma flow measurements were not performed in this experiment, because the amount of blood obtained necessary for the amino acid concentration and specific activity measurements reached $2.4 \mathrm{ml}$, which is approximately $11 \%$ of circulating volume in rats (23). This is the maximal amount of blood that can be taken from a living organism without disturbing amino acid metabolism. It was therefore not possible to measure blood flow using the indicator-dilution technique as performed routinely in our laboratory. The plasma flows that we used were obtained in postabsorptive Lewis $(19,24,25)$ and Wistar $(21,26)$ rats that weighed 200-225 (25), 225-250 (19), 200-300 (24) or 250-350 (21, 26) g. In previous experiments in our laboratory rats were studied under ether anesthesia. Maastricht University has recently prohibited the use of ether as an anesthetic. We therefore used a primed constant infusion of ketamine-medetomidine in this experiment. Plasma flows obtained in our laboratory using ketamine-medetomidine are similar to results obtained previously using ether, but have not been published yet.

PDV plasma flow was estimated to be $1.9 \mathrm{ml} / 100 \mathrm{~g} / \mathrm{min}(19,21,24)$, liver plasma flow $2.5 \mathrm{ml} / 100 \mathrm{~g} / \mathrm{min}(19,24,25)$, and renal plasma flow $2.4 \mathrm{ml} / 100 \mathrm{~g} / \mathrm{min}$ (26). Whole blood organ flows were calculated as the plasma flow corrected for hematocrit. Erythrocyte flow was calculated by subtracting plasma flow from whole blood flow. 


\section{Calculations}

The levels of AA in blood cells were calculated by the following formula:

$[A A]_{B C}=\left([A A]_{W B}-\left[(1-H t){ }^{\star}[A A]_{P L}\right]\right) / H t(27)$,

where $[A A]_{B C}=$ level of $A A$ in blood cells $(\mu M) ;[A A]_{W B}=$ level of $A A$ in whole blood $(\mu M)$ and $[A A]_{P L}=$ level of $A A$ in plasma $(\mu M)$.

Organ amino acid fluxes were calculated by multiplying the venous-arterial concentration differences with the flow, and are expressed in nmol/100 g/min. A positive flux indicates net release and a negative flux reflects net uptake.

In calculations using tracer data it is of importance that tracer steady state is obtained. It is however not necessary to obtain tracee steady state. Because the specific activities of arginine, phenylalanine, valine and leucine obtained in arterial plasma and whole blood did not change in time, only results of the 30' sampling are shown. Whole body Ra was calculated as the tracer infusion divided by the calculated central venous SA (1). Intra-organ disposal (D) of arginine, phenylalanine, valine and leucine were calculated by dividing organ tracer net balance across the PDV by the venous specific activity (SA) (28). Intra-organ production (P) was calculated by subtracting PDV tracee net balance from intra-organ disposal.

\section{Statistical analysis}

Results are presented as means \pm SEM. Significance was tested using the MannWhitney test (29). Whole blood and erythrocyte results were tested against plasma results. Significance was considered present at $p<0.05$.

\section{Results}

The concentrations of glutamate, asparagine, glycine, citrulline, arginine, taurine and lysine were higher in blood cells than in plasma, whereas the concentrations of tryptophane and the branched chain amino acids valine, leucine and isoleucine were higher in plasma than in blood cells (Table 1).

For most amino acids, the net fluxes across the PDV were similar when measured in plasma and blood cells (Table 2A). However, serine and glutamine are 
Table 1. Amino acid concentrations in whole blood, plasma, and blood celis. Values are mean \pm SEM in $\mu M$. * $p<0.05, f p<0.01$ vs. plasma, ND = not detectable.

\begin{tabular}{|c|c|c|c|c|c|c|c|c|c|}
\hline \multirow[b]{2}{*}{ GLU } & \multicolumn{3}{|c|}{ Plasma } & \multicolumn{3}{|c|}{ Whole blood } & \multicolumn{3}{|c|}{ Blood cells } \\
\hline & 58 & \pm & 4 & 199 & \pm & $5 \dagger$ & 333 & \pm & $8 t$ \\
\hline ASN & 50 & \pm & 2 & 55 & \pm & 2 & 59 & \pm & 2 \\
\hline SER & 261 & \pm & 6 & 254 & \pm & 6 & 247 & \pm & 8 \\
\hline GLN & 519 & \pm & 14 & 510 & \pm & 12 & 500 & \pm & 14 \\
\hline HIS & 71 & \pm & 1 & 66 & \pm & 2 & 62 & \pm & $4^{*}$ \\
\hline GLY & 240 & \pm & 12 & 306 & \pm & $10^{*}$ & 366 & \pm & 16 \\
\hline THR & 220 & \pm & 7 & 227 & \pm & 7 & 235 & \pm & 10 \\
\hline $\mathrm{CIT}$ & 59 & \pm & 2 & 83 & \pm & $3 \dagger$ & 107 & \pm & $4 t$ \\
\hline ARG & 129 & \pm & 4 & 215 & \pm & $6 \dagger$ & 295 & \pm & 12 \\
\hline ALA & 330 & \pm & 15 & 325 & \pm & 15 & 321 & \pm & 16 \\
\hline TAU & 103 & \pm & 4 & 389 & \pm & $7 \dagger$ & 662 & \pm & $12 \dagger$ \\
\hline TYR & 103 & \pm & 5 & 107 & \pm & 5 & 111 & \pm & 5 \\
\hline AAB & 14 & \pm & 1 & 11 & \pm & 1 & 10 & \pm & 2 \\
\hline VAL & 350 & \pm & 11 & 309 & \pm & $11^{*}$ & 270 & \pm & $11 \dagger$ \\
\hline MET & 50 & \pm & 2 & & ND & & & & \\
\hline ILE & 180 & \pm & 5 & 154 & \pm & $5^{\star}$ & 130 & \pm & $5 \dagger$ \\
\hline TRP & 95 & \pm & 2 & 45 & \pm & $2 \dagger$ & -2 & \pm & $2 t$ \\
\hline PHE & 68 & \pm & 3 & 62 & \pm & 3 & 56 & \pm & 3 \\
\hline ORN & 50 & \pm & 4 & 55 & \pm & 4 & 59 & \pm & 5 \\
\hline LEU & 291 & \pm & 10 & 234 & \pm & $8^{*}$ & 181 & \pm & $8 \dagger$ \\
\hline LYS & 345 & \pm & 15 & 383 & \pm & $11^{*}$ & 419 & \pm & $17 \dagger$ \\
\hline BCAA & 821 & \pm & 26 & 698 & \pm & 23 & 580 & \pm & 23 \\
\hline SUMAA & 3586 & \pm & 105 & 3994 & \pm & 95 & 4420 & \pm & 109 \\
\hline
\end{tabular}

mainly taken up from plasma, and glycine and alanine are mainly produced into plasma. In contrast, lysine is mainly taken up from blood cells. The fluxes of taurine and tryptophan are of equal magnitude, but in opposite direction in blood cells and plasma, yielding a whole blood flux near zero. The hepatic fluxes of citrulline, phenylalanine, tyrosine and valine were similar when measured in blood cells and plasma (Table 2B). The uptake of asparagine, serine, glutamine, glycine, alanine, taurine and arginine by the liver came solely from the plasma compartment. Ornithine was released into the plasma compartment. Leucine production by the liver occurred preferentially into the plasma compartment. Across the kidney, equal amounts of phenylalanine, tyrosine and leucine were taken up from blood cells and plasma 
Chapter 2

(Table $2 \mathrm{C}$ ). Valine and alanine were preferentially taken up from the blood cells.

Citrulline, serine, glutamine, and glycine were mainly taken up from the plasma.

Interestingly, arginine was taken up from blood cells, and released into the plasma.

Table 2. Net amino acid fluxes across PDV, liver and kidney. Values are mean \pm SEM in $\mathrm{nmol} / 100 \mathrm{~g}$ bw/min. ${ }^{*} \mathrm{p}<0.05, \dagger p<0.01$ vs. plasma.

A. PDV fluxes

\begin{tabular}{|c|c|c|c|c|c|c|c|c|c|}
\hline \multirow[b]{2}{*}{ GLU } & \multicolumn{3}{|c|}{ Plasma } & \multicolumn{3}{|c|}{ Whole blood } & \multicolumn{3}{|c|}{ Blood cells } \\
\hline & -10 & \pm & 18 & 0 & \pm & 20 & 10 & \pm & 15 \\
\hline ASN & 14 & \pm & 6 & 22 & \pm & 9 & 8 & \pm & 6 \\
\hline SER & -67 & \pm & 14 & -82 & \pm & 18 & -17 & \pm & $14^{*}$ \\
\hline GLN & -264 & \pm & 103 & -310 & \pm & 134 & -47 & \pm & 48 \\
\hline HIS & 2 & \pm & 3 & -5 & \pm & 7 & -5 & \pm & 5 \\
\hline GLY & 84 & \pm & 46 & 63 & \pm & 25 & 0 & \pm & 50 \\
\hline THR & -5 & \pm & 27 & -34 & \pm & 19 & -39 & \pm & 38 \\
\hline $\mathrm{CIT}$ & 60 & \pm & 17 & 110 & \pm & 37 & 49 & \pm & 30 \\
\hline ARG & -23 & \pm & 5 & -34 & \pm & 11 & -11 & \pm & 9 \\
\hline ALA & 183 & \pm & 66 & 159 & \pm & 62 & -16 & \pm & $20^{*}$ \\
\hline TAU & 102 & \pm & 31 & 35 & \pm & 37 & -61 & \pm & $29 \dagger$ \\
\hline TYR & -12 & \pm & 2 & -18 & \pm & 15 & -6 & \pm & 13 \\
\hline VAL & -48 & \pm & 16 & -88 & \pm & 22 & -39 & \pm & 17 \\
\hline ILE & -30 & \pm & 9 & -52 & \pm & 13 & -22 & \pm & 8 \\
\hline TRP & -8 & \pm & 3 & 5 & \pm & $4^{*}$ & 13 & \pm & $4 \dagger$ \\
\hline PHE & -5 & \pm & 3 & -12 & \pm & 5 & -7 & \pm & 4 \\
\hline ORN & -10 & \pm & 4 & -28 & \pm & 16 & -16 & \pm & 14 \\
\hline LEU & -50 & \pm & 11 & -87 & \pm & 17 & -37 & \pm & 15 \\
\hline LYS & 47 & \pm & 22 & -109 & \pm & 71 & -150 & \pm & $66^{*}$ \\
\hline$B C A A$ & -129 & \pm & 36 & -228 & \pm & 52 & -98 & \pm & 40 \\
\hline SUMAA & -40 & \pm & 126 & -475 & \pm & 258 & -397 & \pm & 258 \\
\hline
\end{tabular}




\begin{tabular}{|c|c|c|c|c|c|c|c|c|c|}
\hline \multirow[b]{2}{*}{$\overline{\text { GLU }}$} & \multicolumn{3}{|c|}{ Plasma } & \multicolumn{3}{|c|}{ Whole blood } & \multicolumn{3}{|c|}{ Blood cells } \\
\hline & 149 & \pm & 36 & 282 & \pm & 86 & 152 & \pm & 112 \\
\hline ASN & -82 & \pm & 11 & -92 & \pm & 12 & -12 & \pm & $8+$ \\
\hline SER & -275 & \pm & 17 & -279 & \pm & 23 & -9 & \pm & $11 \dagger$ \\
\hline GLN & -52 & \pm & 103 & 3 & \pm & 139 & 40 & \pm & 48 \\
\hline HIS & -29 & \pm & 6 & 11 & \pm & 24 & 40 & \pm & $27 \dagger$ \\
\hline GLY & -270 & \pm & 57 & -164 & \pm & 39 & 109 & \pm & $61 t$ \\
\hline THR & -49 & \pm & 19 & -115 & \pm & $21^{*}$ & -67 & \pm & 17 \\
\hline $\mathrm{CIT}$ & 12 & \pm & 19 & -12 & \pm & 36 & 17 & \pm & 44 \\
\hline ARG & -139 & \pm & 13 & -133 & \pm & 12 & 4 & \pm & $11 \dagger$ \\
\hline ALA & -648 & \pm & 96 & -691 & \pm & 108 & -52 & \pm & $20 \dagger$ \\
\hline TAU & -115 & \pm & 35 & -125 & \pm & 42 & -13 & \pm & $23^{*}$ \\
\hline TYR & 26 & \pm & 19 & 58 & \pm & 44 & 32 & \pm & 27 \\
\hline VAL & 257 & \pm & 31 & 483 & \pm & $60 \dagger$ & 229 & \pm & 38 \\
\hline ILE & 193 & \pm & 18 & 351 & \pm & $39 \dagger$ & 161 & \pm & 29 \\
\hline TRP & 38 & \pm & 7 & 56 & \pm & 7 & 20 & \pm & 10 \\
\hline PHE & 11 & \pm & 9 & 28 & \pm & 22 & 18 & \pm & 14 \\
\hline ORN & 42 & \pm & 13 & 14 & \pm & 46 & -22 & \pm & $34^{*}$ \\
\hline LEU & 316 & \pm & 28 & 521 & \pm & $63^{*}$ & 209 & \pm & $39^{\star}$ \\
\hline LYS & -81 & \pm & 43 & -49 & \pm & 112 & 23 & \pm & 82 \\
\hline$B C A A$ & 767 & \pm & 77 & 1356 & \pm & 161 & 600 & \pm & 105 \\
\hline SUMAA & -713 & \pm & 312 & 159 & \pm & 405 & 857 & \pm & 377 \\
\hline
\end{tabular}

The arterial specific activity of arginine was much lower in whole blood than in plasma (Table 3), indicating a large unlabeled pool in whole blood. The specific activities of the products of arginine metabolism, ornithine and citrulline also have a similar distribution in the whole blood compartments. No differences in the arterial specific activities of phenylalanine, valine and leucine between whole blood and plasma were observed. The breakdown product of phenylalanine, tyrosine, however, has a higher specific activity in plasma than in whole blood or blood cells. 
Chapter 2

\section{Renal fluxes}

\begin{tabular}{|c|c|c|c|c|c|c|c|c|c|}
\hline \multirow[b]{2}{*}{$\overline{G L U}$} & \multicolumn{3}{|c|}{ Plasma } & \multicolumn{3}{|c|}{ Whole blood } & \multicolumn{3}{|c|}{ Blood cells } \\
\hline & -35 & \pm & 11 & -12 & \pm & 34 & 19 & \pm & $25^{\star}$ \\
\hline ASN & 1 & \pm & 3 & -11 & \pm & 10 & -11 & \pm & 10 \\
\hline SER & 194 & \pm & 31 & 123 & \pm & 38 & -55 & \pm & $55 \dagger$ \\
\hline GLN & -416 & \pm & 58 & -480 & \pm & 81 & -75 & \pm & $31 t$ \\
\hline HIS & 1 & \pm & 4 & -17 & \pm & 14 & -15 & \pm & 17 \\
\hline GLY & -115 & \pm & 51 & -168 & \pm & 85 & -32 & \pm & 111 \\
\hline THR & 27 & \pm & 30 & -66 & \pm & 61 & -101 & \pm & 74 \\
\hline $\mathrm{CIT}$ & -54 & \pm & 4 & -43 & \pm & 17 & 8 & \pm & $14 \dagger$ \\
\hline ARG & 48 & \pm & 8 & 6 & \pm & $21^{*}$ & -36 & \pm & $22 \dagger$ \\
\hline ALA & -18 & \pm & 23 & -134 & \pm & 57 & -105 & \pm & 51 \\
\hline TAU & 7 & \pm & 12 & -33 & \pm & 40 & -36 & \pm & 45 \\
\hline TYR & -1 & \pm & 5 & -4 & \pm & 9 & -3 & \pm & 6 \\
\hline VAL & -35 & \pm & 16 & -135 & \pm & $47^{\star}$ & -95 & \pm & 53 \\
\hline ILE & -24 & \pm & 11 & -70 & \pm & $18^{\star}$ & -43 & \pm & 21 \\
\hline TRP & -3 & \pm & 3 & -1 & \pm & 4 & 3 & \pm & 4 \\
\hline PHE & -19 & \pm & 4 & -47 & \pm & $12^{*}$ & -27 & \pm & 11 \\
\hline ORN & -11 & \pm & 6 & -41 & \pm & 17 & -30 & \pm & 15 \\
\hline LEU & -42 & \pm & 18 & -108 & \pm & $26^{\star}$ & -61 & \pm & 29 \\
\hline LYS & 18 & \pm & 21 & -67 & \pm & 65 & .79 & \pm & 71 \\
\hline BCAA & -703 & \pm & 80 & -1400 & \pm & 244 & -696 & \pm & 173 \\
\hline SUMAA & 351 & \pm & 322 & -987 & \pm & 694 & -1261 & \pm & 547 \\
\hline
\end{tabular}

Table 3. Arterial specific activities. Values are mean \pm SEM and are expressed in $\mathrm{dpm} / \mathrm{nmol}$. $\dagger p<0.01$ vs. plasma.

\begin{tabular}{lrrlrllllll}
\hline & \multicolumn{3}{c}{ Plasma } & \multicolumn{3}{c}{ Whole blood } & \multicolumn{3}{c}{ Blood cells } \\
\hline ARG & 651 & \pm & 29 & 240 & \pm & $13 \dagger$ & 70 & \pm & $5 \dagger$ \\
CIT & 90 & \pm & 4 & 42 & \pm & 2 & 18 & \pm & 1 \\
ORN & 197 & \pm & 9 & 96 & \pm & 8 & 16 & \pm & 7 \\
PHE & 434 & \pm & 24 & 403 & \pm & 15 & 363 & \pm & 34 \\
TYR & 152 & \pm & 8 & 113 & \pm & 4 & 79 & \pm & 5 \\
VAL & 163 & \pm & 8 & 164 & \pm & 6 & 164 & \pm & 10 \\
LEU & 82 & \pm & 3 & 74 & \pm & 3 & 60 & \pm & 6 \\
\hline
\end{tabular}

The whole body appearance of arginine was much higher when calculated using whole blood data compared to plasma data (Table 4A). At the organ level 
higher arginine production and disposal values are obtained when whole blood is sampled than when plasma is used. In whole blood, the sum of PDV, liver and kidney arginine production $(833 \mathrm{nmol} / 100 \mathrm{~g} \mathrm{bw} / \mathrm{min})$ exceeds the whole body arginine rate of appearance. In contrast, when plasma data are used, the sum of PDV, liver and kidney arginine production is $211 \mathrm{nmol} / 100 \mathrm{~g} \mathrm{bw} / \mathrm{min}$, which is approximately $83 \%$ of whole body arginine appearance.

The whole body appearances of phenylalanine, valine and leucine were not different in whole blood and plasma (Table 4B-D). However, comparable to the data obtained for arginine, the sum of PDV, liver and kidney phenylalanine and valine production measured in whole blood exceeds the whole body appearance of phenylalanine and valine. In contrast, in plasma the sum of PDV, liver and kidney phenylalanine and valine appearance are 68 and $74 \%$ of their whole body appearances, respectively. Both in whole blood and plasma, the sum of PDV, liver and kidney leucine appearance is approximately $70 \%$ of whole body leucine appearance.

\section{Discussion}

The participation of red blood cells in the transport of amino acids has long been a controversial subject. In the present study we observed a role for red blood cells in interorgan transport. However, the extent of this participation depends on the amino acid and the organ. In organ based metabolic studies using isotopically labeled amino acids, the present data suggest that plasma sampling should be recommended when equilibrium is not reached between the plasma and the blood cells. When the tracer is equally distributed between plasma and blood cells, whole blood can be sampled as a surrogate for plasma.

The results concerning the unlabeled tracee amino acids indicate that the amino acids that are carried by the $\mathrm{y}^{+}$carrier, arginine, ornithine, and lysine were concentrated in blood cells compared to plasma (2). Also the concentrations of glycine, which is mainly transported by the Gly carrier (2), and glutamate, which is 
Table 4. Tracer data. Values are mean \pm SEM in nmol $/ 100 \mathrm{~g} b w / m i n . ~ \dagger p<0.01$ vs, plasma.

A. Arginine tracer data

\begin{tabular}{llrllllll}
\hline & & \multicolumn{3}{c}{ Plasma } & \multicolumn{3}{c}{ Whole blood } \\
\hline Whole Body & Ra & 254 & \pm & 10 & & 669 & \pm & $27 \dagger$ \\
PDV & Disposal & 103 & \pm & 12 & & 286 & \pm & $57 \dagger$ \\
PDV & Production & 81 & \pm & 13 & & 252 & \pm & $56 \dagger$ \\
Liver & Disposal & 156 & \pm & 13 & & 549 & \pm & $105 \dagger$ \\
Liver & Production & 18 & \pm & 2 & & 417 & \pm & $103 \dagger$ \\
Kidney & Disposal & 64 & \pm & 17 & & 158 & \pm & $65 \dagger$ \\
Kidney & Production & 112 & \pm & 17 & & 164 & \pm & 52 \\
\hline
\end{tabular}

B. Phenylalanine tracer data

\begin{tabular}{llrlllllll}
\hline & & \multicolumn{3}{c}{ Plasma } & \multicolumn{3}{c}{ Whole blood } \\
\hline Whole Body & Ra & 260 & \pm & 11 & & 240 & \pm & 6 \\
PDV & Disposal & 46 & \pm & 9 & & 82 & \pm & $13^{*}$ \\
PDV & Production & 41 & \pm & 9 & & 71 & \pm & 12 \\
Liver & Disposal & 109 & \pm & 8 & 216 & \pm & $15 \dagger$ \\
Liver & Production & 120 & \pm & 7 & 244 & \pm & $29 \dagger$ \\
Kidney & Disposal & 36 & \pm & 7 & 71 & \pm & $15^{*}$ \\
Kidney & Production & 17 & \pm & 6 & & 24 & \pm & 18 \\
\hline
\end{tabular}

locally produced from glutamine, are higher in blood cells than in plasma. The function of these high concentrations is probably linked to the production of glutathione in blood cells. Lastly, the taurine concentration was high in blood cells, which may be related to an osmolyte function of taurine. Rat blood cells do not contain tryptophan, although the tryptophan transporter, system $T$, has been described in blood cells (2).

Between 15' and 45' after start of the primed continuous infusion of labeled amino acids, in general hematocrit values slightly decreased $(4 \%)$ and plasma and whole blood amino acid concentrations slightly increased $(20 \%)$. The increase in concentrations of phenylalanine, valine and leucine was similar in plasma and whole blood. However, the increase in arginine concentration was less in whole blood than in plasma. The difference in time effect on whole blood and plasma amino acid concentrations of arginine, and phenylalanine, valine and leucine are consistent with 


\begin{tabular}{llrllllll}
\hline & & \multicolumn{3}{c}{ Plasma } & \multicolumn{3}{c}{ Whole blood } \\
\hline Whole Body & Ra & 515 & \pm & 42 & & 464 & \pm & 13 \\
PDV & Disposal & 137 & \pm & 17 & 213 & \pm & 27 \\
PDV & Production & 89 & \pm & 23 & 125 & \pm & 33 \\
Liver & Disposal & -10 & \pm & 18 & -50 & \pm & 25 \\
Liver & Production & 247 & \pm & 17 & 432 & \pm & $41 \dagger$ \\
Kidney & Disposal & 81 & \pm & 20 & 145 & \pm & 37 \\
Kidney & Production & 46 & \pm & 7 & 11 & \pm & 64 \\
\hline
\end{tabular}

D. Leucine tracer data

\begin{tabular}{llrllllll}
\hline & & \multicolumn{3}{c}{ Plasma } & \multicolumn{3}{c}{ Whole blood } \\
\hline Whole Body & Ra & 596 & \pm & 23 & & 632 & \pm & 25 \\
PDV & Disposal & 262 & \pm & 27 & & 153 & \pm & $37^{*}$ \\
PDV & Production & 211 & \pm & 23 & 65 & \pm & $38^{*}$ \\
Liver & Disposal & -142 & \pm & 27 & -102 & \pm & 46 \\
Liver & Production & 175 & \pm & 14 & 420 & \pm & $37 \dagger$ \\
Kidney & Disposal & 73 & \pm & 33 & 37 & \pm & 38 \\
Kidney & Production & 31 & \pm & 19 & -70 & \pm & 42 \\
\hline
\end{tabular}

the specific activity data (see below). In general, the amino acid concentrations were not completely in steady state. This may be the effect of blood sampling.

In this study measurable unlabeled tracee arterio-venous amino acid concentration differences were observed in the red blood cell-fraction of blood. Moreover, these arterio-venous amino acid concentration differences were often of a similar magnitude as the arterio-venous concentration differences measured in plasma. Therefore, we, and others $(5,6,30,31)$, conclude that blood cells participate to a certain extent in the transport of amino acids to and from organs and in their metabolism in organs. However, the extent to which blood cells participate in this transport differs for each amino acid and for each organ, and is influenced by starvation (7) and probably other (patho)physiologic conditions. Besides a role in inter-organ amino acid transport, blood cells participate in glutathione biosynthesis (32). Therefore, the erythrocyte is not an inert cell, but could influence tracer and tracee-based metabolic measurements. 
The results obtained with the tracer amino acids suggest that two distinct groups of tracers exist. First, tracers that are well exchanged between plasma and blood cells, and that therefore reach a similar SA in blood cells and plasma within a short period. Secondly, tracers exist that are not exchanged between plasma and blood cells, and therefore show a higher SA in plasma than in blood cells.

In this study, the first group of amino acid tracers was represented by phenylalanine, valine, and leucine. These amino acids are all transported by system $\mathrm{L}$, which has a very high uptake in blood cells in vitro (33). Indeed, in our study the specific activities of these amino acids were similar in whole blood, blood cells and plasma. In studies involving human subjects, however, the enrichments were lower in whole blood compared to plasma (34), which can be explained by the fact that human erythrocytes have a lower system $L$ activity than rat erythrocytes (35). The similar specific activities in whole blood, blood cells and plasma of phenylalanine, valine and leucine are also in agreement with the observation that changes in plasma concentration of these amino acids lead to changes in their erythrocyte concentration (36). As a result, the whole body rates of appearance of these amino acids were similar when measured in whole blood and plasma. Thus, when the systemic appearances of phenylalanine, valine or leucine are measured in rat studies, one can choose to sample either whole blood or plasma. However, the low system $L$ activity in human erythrocytes may lead to a situation of low SA in blood cells compared to plasma, which will be discussed below.

Radioactive and stable isotopes are also used for the measurement of disposal and production of amino acids in individual organs. Using whole blood the production rate is always higher than when plasma is used. The difference is approximately 2 fold and is mainly explained by the influence of blood flow. In rats, hematocrit is approximately $50 \%$ and therefore whole blood flow is approximately 2 fold higher than plasma flow. For tracers that readily exchange between plasma and blood cells, sampling may occur in whole blood or plasma. If plasma is used, a blood flow correction factor may be used to estimate whole body rate of appearance from plasma rate of appearance.

The organs measured in this study, PDV, liver and kidney are metabolically the most active organs. Therefore, the sum of the amino acids produced in PDV, liver and kidney should nearly equal the whole body appearance or plasma flux of that amino acid. It should be noted that organ blood flow was assessed based on blood 
flows measured previously in our laboratory. If the assessed blood flows are not correct, the true sum of amino acid production rates may be slightly different. However, this will affect both plasma and whole blood calculations. A discrepancy between whole blood and plasma (see below) cannot be explained by errors in the assessment of blood flow.

Although no difference in whole body phenylalanine and valine appearance was obtained between whole blood and plasma, differences between the organ productions of these amino acids were present between whole blood and plasma measurements. For phenylalanine and valine, like for arginine, the sum of PDV, liver and kidney production exceeds their whole body appearances $(141 \%$ and $122 \%$ respectively). These overestimations cannot be explained by the precursor pool, because all calculations were made using the venous specific activity. Similar results were obtained when the arterial precursor pool was used for the calculation of whole body and organ appearances. The reason for this discrepancy was not understood.

Using plasma data, the sum of the PDV, liver and kidney production rates almost equal plasma rate of appearance. For instance, using plasma data, PDV, liver and kidney together contribute $68 \%$ to whole body phenylalanine appearance, which is in the same range as was reported for healthy pigs (37). The remaining $32 \%$ are most probably accounted for by muscle (37). Calculated using plasma data, PDV, liver and kidney contribute $74 \%$ to whole body valine appearance, and $69 \%$ to whole body leucine appearance. For leucine, a negative production rate was observed in the kidney when measured in whole blood. This effect was not understood, but may be related to differences in the degradation rate of leucine to $\mathrm{KIC}$, which was not measured in this study.

Arginine belonged to the second group of amino acid tracers. The arterial specific activity of arginine was much lower in blood cells than in plasma, which is in accordance with the fact that the arginine carrier, system $\mathrm{y}^{+}$, is relatively scarce in erythrocytes compared to system $L$ (38). A similar result has also been published for glycine (39), mainly transported by system Gly (40). Therefore, in the case or arginine, and probably glycine, the blood pool must be considered as two separate pools, the plasma pool and the blood cell pool. In this case, whole blood cannot be used in the calculations. The arterial plasma specific activity or enrichment can be used for the calculation of plasma flux. The term whole body rate of appearance should not be used. Moreover, because during disease membrane transport of 
several amino acids changes, the equilibration in the blood compartments of tracers of these amino acids may change during disease.

Usually, not only arginine appearance, but also the flux through routes of arginine catabolism like arginase-based arginine breakdown to ornithine and nitric oxide synthase mediated arginine breakdown to citrulline are calculated (41). Because ornithine and citrulline tracers also mainly equilibrate in the plasma pool, the whole body fluxes of arginine to ornithine and the flux of arginine to citrulline should also be calculated using plasma data.

When a second-group tracer as arginine is used in organ balance studies, like with the first group amino acid tracers, the whole blood organ production rate exceed the plasma organ production rates. The primary reason now is not the difference in flow, but the erroneous precursor. Organ production rates are calculated as the tracer net balance divided by the venous specific activity. In this case, whole blood tracer net balance equals plasma tracer net balance because blood cells do not contain arginine tracer. As a result, the venous whole blood SA is not the correct precursor pool and yields an overestimation of organ production rates. Thus, when tracers are used that do not equilibrate with blood cells, plasma sampling is necessary both for the calculation of plasma flux and organ production rates. Using plasma-data, the sum of the production of arginine in PDV, liver and kidney calculated using plasma data is $83 \%$ of whole body arginine production measured in plasma. The kidney contributes the largest amount of arginine production, confirming earlier observations that the kidney is the main endogenous producer of arginine (42). PDV contributes $32 \%$ of whole body arginine production. This confirms observations in surgical patients (43).

Lastly, we would like to comment that, although not a primary goal of this study, plasma sampling in our hands, gives more accurate results than whole blood sampling.

In conclusion, when quantifying metabolic pathways in organs using tracerbased methods, one should know if the tracer of interest equilibrates in blood cells. If the tracer does not equilibrate in blood cells, plasma sampling should be performed. If the tracer equilibrates in blood cells, one can choose to use either whole blood or plasma data in whole body calculations. However, if organ balance studies are done 
plasma sampling should be performed. An additional advantage of plasma sampling is the better accuracy.

\section{Acknowledgements}

The authors wish to thank Mr. H. M. H. van Eijk, BSc, PhD for expert HPLC measurements. This study was supported by a grant from the Dutch Association for Scientific Research (NWO-902-23-098).

\section{References}

1. Wolfe RR. Radioactive and stable isotope tracers in biomedicine. Principles and practice of kinetic analysis. New York: Wiley-Liss; 1992.

2. Souba WW, Pacitti AJ. How amino acids get into cells: mechanisms, models, menus and mediators. JPEN 1992;16:569-578.

3. Devés R, Boyd CAR. Transporters for cationic amino acids in animal cells: discovery, structure and function. Physiol Rev 1998;78:487-545.

4. Tunnicliff G. Amino acid transport by human erythrocyte membranes. Comp Biochem Physiol 1994;108A:471-478.

5. Elwyn DH, Launder WJ, Parikh HC, Wise EM. Roles of plasma and erythrocytes in interorgan transport of amino acids in dogs. Am J Physiol 1972;222:1333-1342.

6. Christensen HN. Interorgan amino acid nutrition. Physiol Rev 1982;62:1193-1228.

7. Picó C, Lladó I, Pons A, Palou A. Blood cell to plasma gradients of amino acids in arterial and venous blood in fed and fasted rats. Comp Biochem Physiol 1994;107A:589-595.

8. Divino Filho JC, Bárány $P$, Stehle $P$, Fürst $P$, Bergström J. Free amino acid levels simultaneously measured in plasma, muscle, and erythrocytes of uraemic patients. Nephrol Dial Transplant 1997;12:2339-2348.

9. De Blaauw 1, Deutz NEP, Van der Huist RRWW, Von Meyenfeldt MF. Glutamine depletion and increased gut permeability in non-anorectic, non-weight losing tumor bearing rats. Gastroenterology 1997;112(1):118-126.

10. Castillo L, Chapman TE, Sanchez M, YU YM, Burke JF, Ajami AM, et al. Plasma arginine and citrulline kinetics in adults given adequate and arginine-free diets. Proc.Natl.Acad.Sci.USA 1993;90:7749-7753.

11. Chien PFW, Smith K, Watt PW, Scrimgeour CM, Taylor DJ, Rennie MJ. Protein turnover in the human fetus studied at term using stable isotope tracer amino acids. Am.J.Physiol. 1993;265:E31-E35. 
12. Matthews DE, Marano MA, Campbell RG. Splanchnic bed utilization of leucine and phenylalanine in humans. Am.J.Physiol. 1993;264:E109-E118.

13. Hoerr RA, Matthews DE, Bier DM, Young VR. Leucine kinetics from [2H3]- and [13C] leucine infused simultaneously by gut and vein. Am.J.Physiol. 1991;260:E111-R117.

14. Patterson BW, Carraro F, Klein S, Wolfe RR. Quantification of incorporation of [15N]ammonia into plasma amino acids and urea. Am.J.Physiol. 1995;269:E508-E515.

15. Biolo G, Fleming RYD, Maggi S, Wolfe RR. Transmembrane transport and intracellular kinetics of amino acids in human skeletal muscle. Am.J.Physiol. 1995;268:E75-E84.

16. Tessari P, Zanetti M, Barazzoni R, Vettore M, Michielan F. Mechanism of postprandial protein accretion in humam skeletal muscle. Insight from leucine and phenylalanine forearm kinetics. J.Clin.Invest. 1996;98:1361-1372.

17. Tessari P, Garibotto G, Inchiostro S, Robaudo C, Saffioti S, Vettore M, et al. Kidney, splanchnic, and leg protein turnover in humans. J.Clin.Invest 1996;98.

18. Waldegrave W, Chairman Council of the European Community. Guide for the care and use of laboratory animals. Brussels, Belgium: European Community; 1986. Report No.: Publication $86 / 609$.

19. Heeneman S, Deutz NEP. Effects of decreased glutamine supply on gut and liver metabolism in vivo in rats. Clin.Sci. 1993;85:437-444.

20. Rafferty JF, Noguchi $Y$, Fischer JE, Hasselgren PO. Sepsis in rats stimulates cellular proliferation in the mucosa of the small intestine. Gastroenterology 1994;107:121-127.

21. Dejong CHC, Kampman MT, Deutz NEP, Soeters PB. Altered glutamine metabolism in rat portal drained viscera and hindquarter during hyperammonemia. Gastroenterology 1992;102:936-948.

22. Van Eijk HMH, Rooyakkers DR, Wagenmakers AJM, Soeters PB, Deutz NEP. Isolation and quantification of isotopically labeled amino acids from biological samples. J.Chromatography $B$ 1997;691:287-296.

23. Waynforth HB, Flecknell PA. Experimental and surgical technique in the rat. 2nd ed. London: Academic Press Limited; 1992.

24. De Blaauw I, Deutz NEP, Von Meyenfeldt MF. In vivo amino acid metabolism of gut and liver during short and prolonged starvation. Am.J.Physiol. 1996;270:G298-G306.

25. De Blaauw I, Deutz NEP, Boers W, Von Meyenfeldt MF. Hepatic amino acid and protein metabolism in non-anorectic, moderately cachectic tumor-bearing rats. J.Hepatol. 1997;26:396-408.

26. Dejong $\mathrm{CHC}$, Deutz NEP, Soeters PB. Metabolic adaptation of the kidney to hyperammonemia during chronic liver insufficiency in the rat. Hepatology 1993;18:890-902.

27. Tizianello A, De Ferrari G, Garibotto G, Gurreri G, Robaudo C. Renal metabolism of amino acids and ammonia in subjects with normal renal function and in patients with chronic renal insufficiency. J.Clin.Invest. 1980;65:1162-1173.

28. Katz J. On the determination of turnover in vivo with tracers. Am.J.Physiol. 1992;263:E417E424. 
29. Norusis MJ, Ed. SPSS/PC+ V5.0 BASE MANUAL for the IBM PC/XT/AT and PS/2. SPSS Inc, 1989; Chicago, USA.

30. Heitmann RN, Bergman EN. Transport of amino acids in whole blood and plasma of sheep. Am J Physiol 1980;239:E242-E247.

31. Lobley GE, Connell A, Revell DK, Bequette BJ, Brown DS, Calder AG. Splanchnic bed transfer of amino acids in sheep blood and plasma, as monitored though use of a multiple $U$ 13C-labelied amino acid mixture. Br J Nutr 1996;75:217-235.

32. ảkeson J, Björkman S, Messeter K, Rosén I. Helfer M. Cerebral pharmacokinetics of anaesthetic and subanaesthetic doses of ketamine in the normoventilated pig. Acta Anaesthesiol Scand 1993;37:211-218.

33. Pico C, Serra F, Pons A, Palou A. Erytrocyte uptake kinetics and cell to plasma gradients of leucine and phenylalanine in fed and fated rats. Arch Int Physiol Biochim Biophys 1993;101:161-165.

34. Barrett EJ, Revkin JH, Young LH, Zaret BL, Jacob R, Gelfand RA. An isotopic method for measurement of muscle protein synthesis and degradation in vivo. Biochem J 1987;245:223228.

35. Yao SYM, George R, Young JD. Reconstitution studies of amino acid transport system $L$ in rat erythrocytes. Biochem J 1993;292:655-660.

36. Schaefer A, Piquard F, Haberey $P$. The effects of changes in plasma amino acid concentrations on erythrocyte amino acid content. Clin Biochem 1990;23:237-240.

37. Deutz NEP, Wagenmakers AJM, Soeters PB. Discrepancy between muscle and whole body protein turnover. Curr.Op.Clin.Nutr.Metab.Care 1999;2:29-32.

38. Tse C-M, Fincham DA, Ellory JC, Young JD. Use of membrane vesicles to estimate the numbers of system $y+$ and system $L$ amino acid transporters in human erythrocytes. Biochem J 1991;277:565-568.

39. Jahoor F, Wykes LJ, Reeds PJ, Henry JF, Del Rosario MP, Frazer ME. Protein-deficient pigs cannot maintain reduced glutathione homeostasis when subjected to the stress of inflammation. J Nutr 1995;125:1462-1472.

40. Ellory JC, Jones SEM, Young JD. Glycine transport in human erythrocytes. J Physiol 1981;320:403-422.

41. Beaumier L, Castillo L, Yu YM, Ajami AM, Young VR. Arginine: new and exciting developments for an "old" amino acid. Biomed.Environmental.Sci. 1996;9:296-315.

42. Dejong $\mathrm{CHC}$, Welters CFM, Deutz NEP, Heineman E, Soeters PB. Renal arginine metabolism in fasted rats with subacute short bowel syndrome. Clin Sci 1998;95:409-418.

43. Van der Hulst RRWJ, Von Meyenfeldt MF, Deutz NEP, Soeters PB. Glutamine extraction by the gut is reduced in patients with depleted gastrointestinal cancer. Ann Surg 1997;225:112121. 
Chapter 2 


\section{Chapter 3}

Arginine and NO metabolism during endotoxemia 
Chapter 3 
3.1

In vivo rate of NO synthesis is increased during mouse endotoxemia

Marcella M. Hallemeesch ${ }^{1}$, Wouter H. Lamers ${ }^{2}$, Alfred J. Meijer ${ }^{3}$, Peter B. Soeters ${ }^{1}$ and Nicolaas E.P. Deutz ${ }^{1}$

${ }^{1}$ Dept. of Surgery, Maastricht University, Maastricht, and ${ }^{2}$ Dept. of Anatomy and Embryology, and ${ }^{3}$ Dept. of Biochemistry, Academic Medical Center, University of Amsterdam, The Netherlands. 


\section{Abstract}

Background Nitric oxide (NO) is produced from arginine. It is possible to measure in vivo NO production using the stable isotope conversion $\left[{ }^{15} \mathrm{~N}_{2}\right]$ arginine to $\left[{ }^{15} \mathrm{~N}\right]$ citrulline. This method has not been used to measure increased NO production during sepsis or inflammation. We aimed to quantify NO production using stable isotopes in a mouse model of sepsis, where iNOS-mediated NO production is increased. The rate of de novo arginine synthesis was quantified because arginine may become limiting for NO production under these conditions.

Materials and Methods Male Swiss mice were treated with bacterial endotoxin (LPS, $10 \mathrm{mg} / \mathrm{kg}$ ), or $0.9 \% \mathrm{NaCl}$. After $5 \mathrm{~h}$ the mice were anesthetized. The right jugular vein and carotid artery were catheterized. A primed continuous infusion of $\left[{ }^{15} \mathrm{~N}_{2}\right]$ arginine and $\left[{ }^{13} \mathrm{C}^{2} \mathrm{H}_{2}\right]$ citrulline was given in the jugular vein. During steady state, blood was drawn from the carotid artery. The rate of NO synthesis was calculated from $\left[{ }^{15} \mathrm{~N}_{2}\right]$ arginine to $\left[{ }^{15} \mathrm{~N}\right]$ citrulline conversion. The rate of de novo arginine production was calculated from $\left[{ }^{13} \mathrm{C}^{2} \mathrm{H}_{2}\right]$ citrulline to $\left[{ }^{13} \mathrm{C}^{2} \mathrm{H}_{2}\right]$ arginine.

Results In response to LPS treatment, the rate of NO production was doubled, and similar to the rise in plasma nitrite and the rise in de novo arginine production. Conclusions It is possible to measure the increase in LPS-mediated NO production using stable isotopes. Increased NO production may be monitored using plasma nitrite. The endogenous synthesis of arginine is increased during endotoxemia, and may serve to sustain NO production.

\section{Introduction}

In the past two decades nitric oxide (NO) was discovered to be an important messenger both in physiological and patho-physiological conditions. It was also shown that arginine is the precursor for NO production. Endogenous production of arginine occurs mainly in the kidney from citrulline that in turn is formed in the small intestine. Besides NO, arginine is a precursor for the synthesis of proteins and creatine, and is involved in the detoxification of ammonia. In conditions of increased demand for arginine, the endogenous synthesis of arginine may become insufficient. 
Under baseline conditions, constitutively expressed isoforms of NO synthase produce low levels of NO. In contrast during infection, lipopolysaccharide leads to the induction of an inducible isoform of NOS in a variety of tissues, including macrophages, vascular smooth muscle and endothelial cells, and massive NO production. In the last decade many studies have been undertaken that aimed at increasing or decreasing NO production, either by supplementation of arginine or NO donors (1-3) or by the administration of NOS inhibitors or arginase. At present, NO production is usually measured by means of the sum of plasma nitrate $\left(\mathrm{NO}_{3}{ }^{-}\right)$and nitrite $\left(\mathrm{NO}_{2}{ }^{-}\right)$levels $(4,5)$, with elevated levels of $\mathrm{NO}_{2}{ }^{-}+\mathrm{NO}_{3}{ }^{-}$indicating increased whole body NO production $(4,6,7)$. However, these amounts of nitrite and nitrate in plasma are inversely correlated to renal function (8). In the diseased state, renal function is often compromised and it may therefore be favorable to measure other indices of NO production.

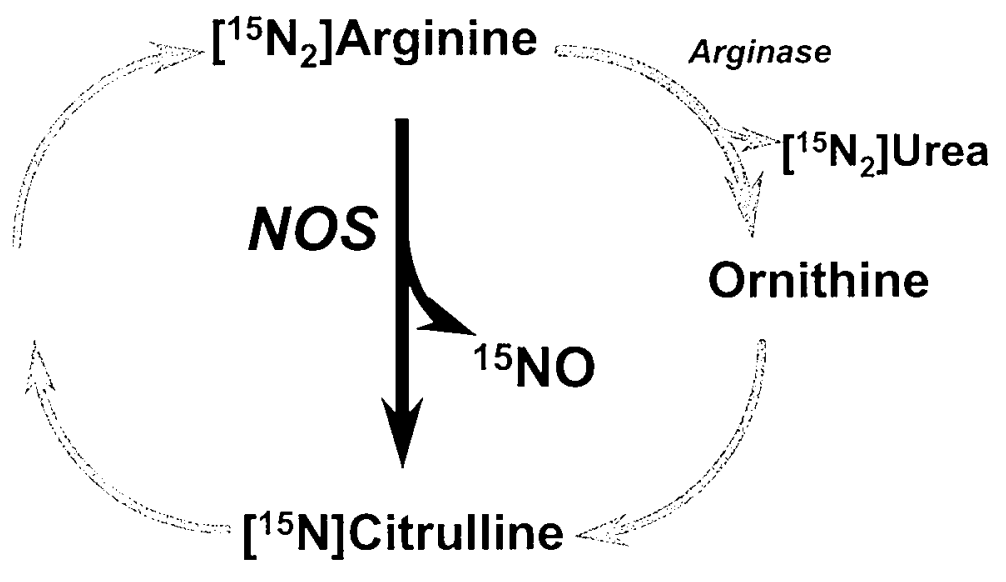

Figure 1. Principle of tracer-based measurement of NO production. The [guanidino- ${ }^{15} \mathrm{~N}_{2}$ ] arginine tracer is used by NOS for the production of [ureido- ${ }^{15} \mathrm{~N}$ ]citrulline and ${ }^{15} \mathrm{NO}$. Because [ureido${ }^{15} \mathrm{~N}$ ]citrulline and ${ }^{15} \mathrm{NO}$ are synthesized in an equimolar fashion, the production rate of [ureido${ }^{15} \mathrm{~N}$ ]citrulline is a measure of NO production rate.

Using stable isotopes, the rate of NO production can be measured by the conversion of L-[guanidino- ${ }^{15} \mathrm{~N}_{2}$ ]arginine to $\mathrm{L}$-[ureido- ${ }^{15} \mathrm{~N}$ ]citrulline (9). This technique 
is based on the fact that NOS produces citrulline and NO in stoichiometric amounts, with each containing a nitrogen atom derived from the guanidino moiety of arginine (Figure 1). It has been applied in healthy and diseased subjects (9-11). However, the rate of NO production has not been measured in (models of) sepsis or inflammation, conditions in which iNOS-mediated $\mathrm{NO}$ production and plasma $\mathrm{NO}_{2}{ }^{-}$and $\mathrm{NO}_{3}{ }^{-}$are increased. Therefore, we measured the rate of NO production by means of the stable isotope technique, and the end-products of NO metabolism, plasma nitrite and nitrate, in a mouse model of endotoxemia.

\section{Materials and Methods}

\section{Animals}

Male Swiss mice (25-35 g) were obtained from IFFA Credo Broekman (Someren, The Netherlands). The mice were fed standard lab chow and were subject to standard 12 hour light-dark cycle periods (7:30 A.M. to 7:30 P.M.). Room temperature was maintained at $25^{\circ} \mathrm{C}$. Experiments were performed in accordance with the recommendations of the Guide for the Care and Use of Laboratory animals (12), and approved by the Ethical Committee of Animal Research of the Maastricht University.

\section{Experimental protocol}

LPS ( $E$ coli O55:B5, Sigma, St. Louis, MO, $250 \mu \mathrm{g}$ in $0.5 \mathrm{ml}$ saline) was given by i.p. injection to mice $(n=15)(13)$. Control animals $(n=17)$ received a corresponding volume of saline. After injection with LPS or endotoxin, the mice were transferred to a clean cage and no food was given. Drinking water was provided.

Five hours after LPS treatment, ketamine-medetomidine anesthesia was induced and maintained in the mice as described before (14). During the surgical procedures, the mice were kept at $37^{\circ} \mathrm{C}$ using a temperature controller (Technical Service, Maastricht University) and heat pads. The jugular vein and carotid artery were catheterized as described previously (14). A primed-constant infusion of L[guanidino- ${ }^{15} \mathrm{~N}_{2}$ ] arginine, $\mathrm{L}-\left[\right.$ ureido- ${ }^{13} \mathrm{C} ;{ }^{2} \mathrm{H}_{2}$ ]citrulline and $\mathrm{L}-\left[\right.$ ring $-{ }^{2} \mathrm{H}_{5}$ ]phenylalanine (Mass Trace, Woburn, MA) was given in the jugular vein (per mouse: prime $\left[{ }^{15} \mathrm{~N}_{2}\right]$ arginine: $850 \mathrm{nmol},\left[{ }^{13} \mathrm{C}_{-}{ }^{2} \mathrm{H}_{2}\right]$ citrulline: $215 \mathrm{nmol},{ }^{2} \mathrm{H}_{5}$-phenylalanine: $340 \mathrm{nmol}$, 
infusion $\left[{ }^{15} \mathrm{~N}_{2}\right]$ arginine: $1700 \mathrm{nmol} / \mathrm{hr},\left[{ }^{13} \mathrm{C}-{ }^{2} \mathrm{H}_{2}\right]$ citrulline: $430 \mathrm{nmol} / \mathrm{hr},{ }^{2} \mathrm{H}_{5}$ phenylalanine: $680 \mathrm{nmol} / \mathrm{hr}$ ). In a pilot experiment, the time to reach tracer steady state in mice was determined. In this pilot experiment blood was sampled 10, 20, 30 and 45 minutes after the start of the primed continuous infusion of stable isotopes. The time to reach steady state was 20-30 minutes (Figure 2). In the experiment we therefore sampled blood from the carotid artery 30 minutes after start of the primed continuous infusion of stable isotopes.

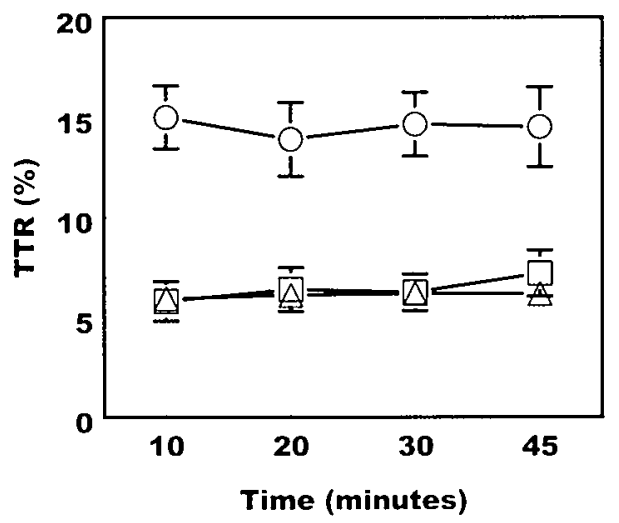

Figure 2. Pilot experiment to determine the time to reach steady state. Plasma TTRs of the tracers $\left[{ }^{15} \mathrm{~N}_{2}\right]$ arginine and $\left[{ }^{13} \mathrm{C}^{2} \mathrm{H}_{2}\right]$ citrulline, the metabolites $\left[{ }^{15} \mathrm{~N}\right]$ citrulline and $\left[{ }^{13} \mathrm{C}^{2} \mathrm{H}_{2}\right]$ arginine during a 45 -minute primed continuous infusion in mice. Infusion of stable isotopes was started at $t=0$. Blood was sampled at 10,20,30 and 45 minutes. Symbols: $\circ$ Arginine $M+2, \square$ Citrulline $M+3, \Delta$ Phenylalanine $M+5$. Mean \pm SEM in \%.

Blood was collected in heparinized cups (Sarstedt, Nümbrecht, Germany) on ice, and centrifuged $\left(4 \mathrm{~min}, 4^{\circ} \mathrm{C}, 8500 \mathrm{~g}\right)$ to obtain plasma. For determination of amino acid concentrations and tracer-tracee ratios (TTR), $100 \mu \mathrm{l}$ plasma was added to $8 \mathrm{mg}$ dry sulfosalicylic acid, vortexed, frozen in liquid nitrogen and stored at $-80^{\circ} \mathrm{C}$. Plasma amino acid concentrations and TTRs were measured by LC-MS system, as described before (15). For plasma $\mathrm{NO}_{2}{ }^{-}$and $\mathrm{NO}_{3}{ }^{-}$determinations, $50 \mu \mathrm{l}$ plasma was deproteinized by adding it to $100 \mu \mathrm{l}$ acetonitrile (Biosolve LTD, Valkenswaard, The Netherlands). Nitrite and nitrate were separated on an IC-PackHR column 
(75mm*4.6mm, Waters, Etten-Leur Netherlands). The column effluent was monitored at $205 \mathrm{~nm}$ using a UV-975 detector (Jasco, B\&L-systems, Wassenaar, The Netherlands). Anions were isocratically eluted from the column within 20 minutes using a $6 \mathrm{mM}$ sodium chloride solution containing $1 \mathrm{mM}$ potassium dihydrogenphosphate $(\mathrm{pH}=6)$.

\section{Calculations}

TTR (tracer-tracee ratio) is an equivalent of specific activity (16). Therefore, formulae were derived from metabolic studies using radioactive tracers. Correction for the contribution of lower isotopomers was performed as described by Wolfe (16). Plasma arginine, citrulline and phenylalanine fluxes were calculated from the arterial isotope TTR values of respectively $\mathrm{L}-\left[\right.$ guanidino- ${ }^{15} \mathrm{~N}_{2}$ ]arginine, $\mathrm{L}-\left[\right.$ ureido- $\left.{ }^{13} \mathrm{C} ;{ }^{2} \mathrm{H}_{2}\right]$ citrulline and $\mathrm{L}-\left[\right.$ ring $\left.-{ }^{2} \mathrm{H}_{5}\right]$-phenylalanine, using steady state isotope dilution equation: $Q=\operatorname{I} / T T R(16)$, where TTR is the tracer tracee ratio, and I is the rate of infusion of the tracer.

Calculation of the plasma arginine to citrulline flux (NO production rate, Figure 1) was made essentially as described by Castillo et al. (9):

$\mathrm{Q}_{\mathrm{Arg}_{\rightarrow} \mathrm{Cit}}=\mathrm{Q}_{\mathrm{Cit}} \times \mathrm{TTR}_{\mathrm{Cit}(\mathrm{M}+1)} / \mathrm{TTR}_{\mathrm{Arg}(\mathrm{M}+2)}$ where $Q_{\text {Cit }}$ is the plasma citrulline flux ( $\mathrm{nmol} / 10 \mathrm{~g} / \mathrm{min}$ ), estimated from the primed constant infusions of the $L-\left[\right.$ ureido- $\left.{ }^{13} \mathrm{C}_{i}{ }^{2} \mathrm{H}_{2}\right]$ citrulline tracer and TTR $\mathrm{Cit}_{\text {and }}$ TTR $\mathrm{R}_{\mathrm{Arg}}$ are the respective TTRs of [ureido- ${ }^{15} \mathrm{~N}$ ]citrulline and [guanidino- ${ }^{15} \mathrm{~N}_{2}$ ] larginine. $\mathrm{M}$ indicates the molecular mass of the unlabeled compound.

Calculation of the plasma citrulline to arginine flux (de novo arginine production rate) was made in a similar fashion:

$Q_{\mathrm{Cit}_{\rightarrow} \mathrm{Arg}}=\mathrm{Q}_{\mathrm{Arg}} \times \mathrm{TTR}_{\mathrm{Arg}(\mathrm{M}+3)} / \mathrm{TTR}_{\mathrm{Cit}(\mathrm{M}+3)}$

where $Q_{A r g}$ is the plasma arginine flux (nmol $/ 10 \mathrm{~g} / \mathrm{min}$ ), estimated from the primed constant infusions of the $L$-[guanidino- ${ }^{15} \mathrm{~N}_{2}$ ]arginine tracer and TTR $R_{\text {Arg }}$ and TTR $R_{\text {Cit }}$ are the respective TTRs of $\mathrm{L}$-[guanidino- ${ }^{13} \mathrm{C} ;{ }^{2} \mathrm{H}_{2}$ ]arginine and $\mathrm{L}$-[ureido- ${ }^{13} \mathrm{C} ;{ }^{2} \mathrm{H}_{2}$ ]citrulline.

\section{Statistical analysis}

Results are presented as means \pm SEM. Significance was tested using the MannWhitney test, and was considered present at $p<0.05$. 


\section{Results}

Endotoxemic mice showed signs of illness including lethargy, piloerection, and exudate around the eyes at the end of the experimental period. There was no mortality among saline or endotoxin injected mice.

Table 1. Arterial substrate concentrations. Values in $\mu \mathrm{M} .{ }^{*}=p<0.01$ vs. Control.

\begin{tabular}{lrrlrrrr}
\hline & \multicolumn{3}{c}{ Control } & \multicolumn{3}{c}{ LPS } \\
\hline $\mathrm{NO}_{2}{ }^{*}$ & 2.7 & \pm & 0.6 & 4.7 & \pm & $0.8^{*}$ \\
$\mathrm{NO}_{3}$ & 26 & \pm & 3 & 151 & \pm & $20^{*}$ \\
$\mathrm{GLN}$ & 336 & \pm & 26 & 439 & \pm & $27^{*}$ \\
$\mathrm{ARG}$ & 105 & \pm & 7 & 134 & \pm & $6^{*}$ \\
$\mathrm{CIT}$ & 60 & \pm & 6 & 79 & \pm & 7 \\
$\mathrm{ORN}$ & 90 & \pm & 11 & 120 & \pm & $9^{*}$ \\
$\mathrm{PHE}$ & 77 & \pm & 7 & 114 & \pm & $8^{*}$ \\
\hline
\end{tabular}

Plasma $\mathrm{NO}_{2}{ }^{-}$and $\mathrm{NO}_{3}{ }^{-}$were increased in the LPS-treated animals (Table 1), which is generally considered to indicate increased NO production. Moreover, the arterial concentrations of glutamine, arginine, ornithine, and phenylalanine increased 1.3 fold in LPS-treated mice (Table 1).

Plasma phenylalanine flux, an indicator of protein turnover, was not significantly increased after endotoxin treatment (Table 2). The plasma arginine flux was higher than plasma citrulline flux, and similar to plasma phenylalanine flux, indicating that plasma arginine flux is mainly determined by protein turnover. These plasma fluxes were not changed by LPS treatment. LPS treatment did however increase the rate of plasma NO production (Table 3). In fact, the rate of NO production increased from $7 \%$ to $14 \%$ of plasma arginine flux. To determine if an increased rate of NO production is matched by an increase in endogenous production of its precursor arginine, $\left[{ }^{13} \mathrm{C}^{2} \mathrm{H}_{2}\right]$ citrulline to $\left[{ }^{13} \mathrm{C}^{2} \mathrm{H}_{2}\right]$ arginine labeling was determined. As shown in Table 3, the rate of de novo arginine production from citrulline was indeed increased after endotoxin challenge in mice. Similar to NO production, de novo arginine production increased from $9 \%$ to $13 \%$ of plasma arginine flux after endotoxin challenge in mice. 
Table 2. Plasma fluxes of arginine, citrulline and phenylalanine. Values in $\mathrm{nmol} / 10 \mathrm{~g}$ bw/min.

\begin{tabular}{lcc}
\hline & Control & LPS \\
\hline ARG & $58 \pm 5$ & $69 \pm 6$ \\
CIT & $23 \pm 3$ & $29 \pm 4$ \\
PHE & $60 \pm 3$ & $66 \pm 5$ \\
\hline
\end{tabular}

Table 3. NO production and de novo arginine production. Values in $\mathrm{nmol} / 10 \mathrm{~g}$ bw/min. * $=p<0.05$ vs. Control.

\begin{tabular}{lll}
\hline & Control & LPS \\
\hline NO & $3.5 \pm 1.1$ & $8.2 \pm 1.7^{\star}$ \\
de novo ARG & $5.4 \pm 0.7$ & $8.9 \pm 1.4^{\star}$ \\
\hline
\end{tabular}

\section{Discussion}

In the present experiments we have shown that the rate of NO synthesis from arginine is increased during endotoxemia in mice. The endogenous synthesis of arginine is also increased and may serve to sustain systemic NO production. Our data also indicate that measurement of plasma nitrate gives an estimate of increased NO production during endotoxemia, but is not a quantitative parameter. In the present experiment the rate of nitric oxide production was measured in a mouse model of endotoxemia, which mimics the septic condition (17). Arginine turnover was $58 \mathrm{nmol} / 10 \mathrm{~g} \mathrm{bw} / \mathrm{min}$ in mice under baseline conditions, and was higher than figures reported for dogs and healthy human subjects (dogs: $39 \mathrm{nmol} / 10 \mathrm{~g} \mathrm{bw} / \mathrm{min}(18)$, human: $12 \mathrm{nmol} / 10 \mathrm{~g} \mathrm{bw} / \mathrm{min}(9))$. In control and endotoxin-treated mice the plasma arginine flux was very close to the plasma phenylalanine flux, suggesting that arginine flux is mainly determined by protein turnover (assuming equal incorporation of arginine and phenylalanine into protein).

Despite the fact that plasma arginine and citrulline fluxes were not significantly changed by LPS treatment, the NO production rate, measured from $\left[{ }^{15} \mathrm{~N}_{2}\right]$ arginine to

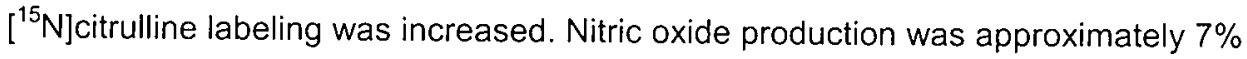
of plasma arginine flux in the control mice and was higher than the value obtained in healthy human subjects (1.4\%) (9). This NO production is most probably related to constitutive NOS, present in endothelium and brain $(19,20)$. During LPS treatment NO production increased to $14 \%$ of plasma arginine flux, and indicates high-output NO generation by iNOS, which is induced in a variety of tissues by LPS (21).

Plasma nitrite and nitrate are frequently measured as a surrogate for the NO production rate. Plasma nitrite and nitrate are influenced by dietary intake, 
endogenous production, and clearance. The mice were studied in the post-absorptive condition, so that dietary intake is not different between the groups. In response to LPS treatment, plasma $\mathrm{NO}_{2}{ }^{-}+\mathrm{NO}_{3}{ }^{-}\left(\mathrm{NO}_{\mathrm{x}}\right)$ increased 5 -fold, in agreement with results by Ter Steege et al (13). The increase in $\mathrm{NO}_{\mathrm{x}}$ was mainly caused by the increase in plasma nitrate. The increase in plasma nitrite was approximately 2 -fold and quantitatively comparable to the increase in the NO production rate. The most important route of $\mathrm{NO}_{3}{ }^{-}$, but not $\mathrm{NO}_{2}{ }^{-}$disposal is urinary excretion $(4,22)$, which, under baseline conditions, is linearly related to its plasma concentration (23), and highly correlated to NO production (9). Under pathological conditions, plasma $\mathrm{NO}_{\mathrm{x}}$ is strongly correlated to plasma creatinine, indicating that plasma nitrate is inversely correlated to renal function (8). Thus, despite the low plasma half-life of $\mathrm{NO}_{3}{ }^{-}$in mice $(1.5 \mathrm{hrs})(24)$, its plasma value may increase more than the actual increase in NO production during endotoxemia. It is, however, clear that although plasma nitrate does not give quantitative information on the NO production rate, increased plasma nitrate is certainly correlated to increased NO production during endotoxemia. Urinary nitrate excretion may give a better indication of NO production.

De novo arginine production, determined from $\left[{ }^{13} \mathrm{C}^{2} \mathrm{H}_{2}\right]$ citrulline to ${ }^{13} \mathrm{C}^{2} \mathrm{H}_{2}$ larginine labeling, was approximately $9 \%$ of arginine flux in control animals. This value is consistent with earlier reports suggesting that renal arginine production, the main endogenous source of arginine production, is approximately $10 \%$ of plasma arginine flux (25). It is also consistent with the value obtained with tracer technology in human subjects (15\%) (9). In response to endotoxemia, de novo arginine production increased to $13 \%$ of plasma arginine flux, which was too small to make a large contribution to plasma arginine flux. This small increase in systemic arginine flux was accompanied by a $30 \%$ increase in circulating arginine. Interestingly, the increase in de novo arginine production was quantitatively comparable to the increase in NO production, and we therefore hypothesize that during endotoxemia in mice, de novo arginine production is increased to ensure the continuation of NO production. Such a mechanism is in agreement with the observations that LPS treatment causes a co-induction of iNOS and argininosuccinate synthetase in vitro (26) and in vivo (27). In addition, it has been suggested that the source of arginine for inducible NOS-mediated NO production is mainly extracellular $(28,29)$.

We have measured an increase in the in vivo NO production rate in response to endotoxemia in mice. This method, although invasive, has also been applied in a 
variety of conditions in humans, but not in sepsis. We have shown that the method enables measuring increased NO production during mouse sepsis. This now offers the exciting opportunity to assess the effects of medical strategies that aim at changing nitric oxide production. Moreover, the possibility to use this technique in mice enables the assessment of the importance of individual pathways related to arginine - NO metabolism in transgenic and knockout mice.

The present study shows that the rate of NO synthesis from arginine is increased during endotoxemia in mice. In addition, the endogenous synthesis of arginine is increased which may serve to sustain systemic NO production. Measurement of plasma nitrate only gives a qualitative estimate of increased NO production during endotoxemia. Plasma nitrite may be a quantitative indicator of the rate of NO production.

\section{Acknowledgments}

The authors wish to thank Hans van Eijk, Ph.D. and Jean Scheyen, B.Sc. for expert LC-MS measurements. This study was supported by grants 902-23-098 and 902-23239 from the Dutch Association for Scientific Research (NWO).

\section{References}

1. Cui $X L$, Iwasa $M$, Iwasa $Y$, Ohmori $Y$, Yamamoto $A$, Maeda $H$, et al. Effects of dietary arginine supplementation on protein turnover and tissue protein synthesis in scald-burn rats. Nutrition 1999;15(7-8):563-9.

2. Peck MD, Babcock GF, Alexander JW, Billiar T, Ochoa J. High doses of dietary arginine during repletion impair weight gain and increase infectious mortality in protein-malnourished mice. Br.J.Nutr. 1995;74:787-795.

3. Pastor CM, Losser M-R, Payen D. Nitric oxide donor prevents hepatic and systemic perfusion decrease induced by endotoxin in anesthetized rabbits. Hepatology 1995;22(5):1547-1553.

4. Grisham MB, Johnson GG, Lancaster JR. Quantitation of nitrate and nitrite in extracellular fluids. Meth Enzymol 1996;268:237-246.

5. Yoon Y, Song J, Hong SH, Kim JQ. Plasma nitric oxide concentrations and nitric oxide synthase gene polymorphisms in coronary heart disease. Clin Chem 2000;46:1626-1630. 
6. Suzuki H, Ikenaga H, Hishikawa K, Nakaki T, Kato R, Saruta T. Increases in NO2-/NO3excretion in the urine as an indicator of the release of endothelium-derived relaxing factor during elevation of blood pressure. Clin Sci (Colch) 1992;82(6):631-4.

7. Moncada S, Palmer RMJ, Higgs EA. Nitric oxide: physiology, pathophysiology and pharmacology. Pharmacol Rev 1991:13:109-142.

8. Mackenzie IM, Ekangaki A, Young JD, Garrard CS. Effect of renal function on serum nitrogen oxide concentrations. Clin Chem 1996;42(3):440-4.

9. Castillo L, Beaumier L, Ajami AM, Young VR. Whole body nitric oxide synthesis in healthy men determined from [15N]-arginine-to-[15N]citrulline labeling. Proc.Natl.Acad.Sci.USA 1996;93:11460-11465.

10. Wever R, Boer P, Hijmering M, Stroes E, Verhaar M, Kastelein J, et al. Nitric oxide production is reduced in patients with chronic renal failure. Arterioscler Thromb Vasc Biol 1999;19(5):1168-72.

11. Lau T, Owen W, Yu YM, Noviski N, Lyons J, Zurakowski D, et al. Arginine, citrulline, and nitric oxide metabolism in end-stage renal disease patients. J Clin Invest 2000:105:1217-1225.

12. Waldegrave W, Chairman Council of the European Community. Guide for the care and use of laboratory animals. Brussels, Belgium: European Community; 1986. Report No.: Publication $86 / 609$.

13. Ter Steege JCA, Van de Ven WCM, Forget PP, Brouckaert P, Buurman WA. The role of endogenous IFN-gamma, TNF-alpha and IL-10 in LPS-induced nitric oxide release in a mouse model. Cytokine 1998:10:115-123.

14. Hallemeesch MM, Ten Have GAM, Deutz NEP. Measurement of metabolic fluxes across PDV, liver, kidney and hindquarter in mice. Lab Anim 2001;35:101-110.

15. Van Eijk HMH, Rooyakkers DR, Deutz NEP. Determination of amino acid isotope enrichment using liquid chromatography-mass spectrometry. Anal.Biochem. 1999;271:8-17.

16. Wolfe RR. Radioactive and stable isotope tracers in biomedicine. Principles and practice of kinetic analysis. New York: Wiley-Liss; 1992.

17. Fink MP, Heard SO. Laboratory models of sepsis and septic shock. J.Surg.Res. 1990;49:186196.

18. Yu YM, Burke JF, Tompkins RG, Martin R, Young VR. Quantitative effects of interorgan relationships among arginine and citrulline metabolism. Am.J.Physiol. 1996;271:E1098-E1109.

19. Palmer R, Ashton D, Moncada S. Vascular endothelial cells syntesize nitric oxide from Larginine. Nature 1988;333:664-666.

20. Knowles RG, Palacios M, Palmer RMJ, Moncada S. Kinetic characteristics of nitric oxide synthase from rat brain. Biochem.J. 1990;269:207-210.

21. Salter $M$, Knowles RG, Moncada $S$. Widespread tissue distribution, species distribution and changes in activity of $\mathrm{Ca} 2+-$ dependent and $\mathrm{Ca} 2+-$ independent nitric oxide synthases. FEBS Lett. 1991;291:145-149. 
22. Castillo L, deRojas TC, Chapman TE, Vogt J, Burke JF, Tannenbaum SR, et al. Splanchnic metabolism of dietary arginine in relation to nitric oxide synthesis in normal adult man. Proc.Natl.Acad.Sci.USA 1993;90:193-197.

23. Godfrey M, Majid DSA. Renal handling of circulating nitrates in anesthetized dogs. Am J Physiol 1998;275(1 Pt 2):F68-73.

24. Veszelovszky E, Holford NHG, Thomsen LL. Knowles RG, Baguley BC. Plasma nitrate clearance in mice: modelling of the systemic production of nitrate following the induction of nitric oxide synthesis. CancerChemother.Pharmacol. 1995;36:155-159.

25. Dejong CHC, Welters CFM, Deutz NEP, Heineman E, Soeters PB. Renal arginine metabolism in fasted rats with subacute short bowel syndrome. Clin Sci 1998;95:409-418.

26. Nussier AK, Billiar TR, Liu ZZ, Morris SMj. Coinduction of nitric oxide synthase and argininosuccinate synthetase in a murine macrophage cell line. Implications for regulation of nitric oxide production. J.Biol.Chem. 1994;269:1257-1261.

27. Nagasaki A, Gotoh T, Takeya M, Yu Y, Takiguchi M, Matsuzaki H, et al. Coinduction of nitric oxide synthase, argininosuccinate synthetase, and arginiosuccinate lyase in lipopolysaccharide-treated rats. J.Biol.Chem. 1996;271:2658-2662.

28. Bune A.J, Shergill JK, Cammack R, Cook HT. L-Arginine depletion by arginase reduces nitric oxide production in endotoxic shock: an electron paramagnetic resonance study. FEBS Lett. 1995;366:127-130.

29. Hrabàk A, Idei M, Temesi A. Arginine supply for nitric oxide synthase and arginase is mainly exogenous in elicited murine and rat macrophages. Life Sciences 1994;55:797-805. 


\section{2}

Endotoxemia differentially affects arginine and protein metabolism in intestine and liver of mice

Marcella M. Hallemeesch, Wouter H. Lamers, Peter B. Soeters, Nicolaas E.P. Deutz

Dept. of Surgery, Maastricht University, Maastricht and Dept. of Anatomy and Embryology, University of Amsterdam, Amsterdam, The Netherlands 


\section{Abstract}

Background In intestine and liver, the amino acid arginine is a precursor for the production of nitric oxide (NO) and polyamines, and is involved in protein turnover. In the liver, arginine also has a role in the urea cycle. In conditions like endotoxemia, NO production is increased and may influence arginine metabolism.

Objective We therefore measured the influence of experimental endotoxemia on arginine metabolism in intestine and liver of mice. Because arginine flux is largely dependent on protein flux, we also measured protein metabolism in intestine and liver of these mice.

Design Mice were treated with LPS (10 mg/kg i.p.) or saline. At $t=5 \mathrm{~h}$, arginine and protein metabolism of intestine and liver was studied under anesthesia using the stable isotopes $\mathrm{L}-\left[{ }^{15} \mathrm{~N}_{2}\right.$-guanidino]arginine and $\mathrm{L}-\left[{ }^{2} \mathrm{H}_{5}\right.$-ring $]$ phenylalanine Results In endotoxin-treated mice, increased systemic NO production was confirmed by $L-\left[{ }^{15} \mathrm{~N}_{2}\right]$ arginine to $\mathrm{L}-\left[{ }^{15} \mathrm{~N}\right]$ citrulline labeling. This result was confirmed by an increase in plasma $\mathrm{NO}_{2}{ }^{-}$and $\mathrm{NO}_{3}^{-}$, the end-products of $\mathrm{NO}$ production. Intestinal protein synthesis was increased, whereas intestinal arginine disposal was decreased. Simultaneously, intestinal ornithine uptake and putrescine concentration in jejunum and ileum were increased. In contrast, hepatic protein synthesis was unchanged, whereas arginine disposal was increased. In addition, hepatic ornithine concentration and production and hepatic putrescine content were increased. Conclusions In a condition of increased systemic NO production, intestinal arginine disposal directed to protein synthesis is increased, whereas arginine disposal towards other compounds including ornithine is decreased. In the liver, arginine disposal directed towards protein synthesis is decreased, whereas arginine disposal and ornithine production are increased.

\section{Introduction}

The amino acid arginine is the precursor of a number of important bioactive compounds affecting a broad range of physiological and pathophysiological functions. Of these, nitric oxide (NO) production by NO synthase (NOS) has recently received much attention. Arginine is also converted to ornithine, the precursor to 
polyamines, by arginase, and by arginine decarboxylase to agmatine. Besides the production of these compounds, arginine is also incorporated into, and released from proteins.

In disease states like sepsis or endotoxemia, arginine metabolism is likely to be affected. First, bacterial products such as lipopolysaccharide (LPS) trigger the expression of inducible NOS, causing massive NO production. In addition, protein turnover may be affected in states of disease. Arginine turnover in plasma is largely determined by whole body protein turnover, as assessed using stable isotopes (1). Because arginine has a role in a number of metabolic pathways, it seems likely that feedback mechanisms for these pathways interact. For instance, it was shown that polyamines inhibit NO production (2), and agmatine inhibits both NO and polyamine production $(3,4)$.

The flux of arginine through protein turnover is large compared to arginine flux through synthesis of products like nitric oxide and agmatine. The question arises whether protein turnover, which is altered in states of disease, may supply arginine for other metabolic pathways. In addition, arginine metabolism varies between organs. In the present experiments, we measured arginine and protein metabolism in intestine and liver of mice, under baseline conditions and during endotoxemia, a condition of increased iNOS-mediated NO production.

\section{Methods}

\section{Animals}

Male Swiss mice (25-35 g) were obtained from Charles River Breeding Laboratories (Heidelberg, FRG). The mice were fed standard lab chow and were subject to standard 12 hour light-dark cycle periods (7:30 A.M. to 7:30 P.M.). Room temperature was maintained at $25^{\circ} \mathrm{C}$. Experiments were performed in accordance with the recommendations of the Guide for the Care and Use of Laboratory Animals (5), and approved by the Ethical Committee of Animal Research of the Maastricht University. 


\section{Experimental protocol}

LPS (E coli O55:B5, Sigma, St. Louis, MO, $250 \mu \mathrm{g}$ in $0.5 \mathrm{ml}$ saline) was administered by intraperitoneal injection to mice $(n=15)(6)$. Control animals $(n=17)$ received a similar volume of saline. Drinking water was provided but food was withheld after the injection of endotoxin or saline to avoid influences of differences of food intake.

Five hours after LPS treatment, anesthesia was induced in the mice by an intraperitoneal injection followed by a subcutaneous infusion of ketamine and medetomidine (7). Catheterization of the mesenteric vein, portal vein, hepatic vein, jugular vein and carotid artery was performed as described recently (7). During the surgical procedures the mice were kept at $37^{\circ} \mathrm{C}$ using a temperature controller (Technical Service, Maastricht University) and heat pads (7).

A primed-constant infusion of L-[guanidino- ${ }^{15} \mathrm{~N}_{2}$ ] arginine, L-[ureido- ${ }^{13} \mathrm{C}$ ${ }^{2} \mathrm{H}_{2}$ ]citrulline, $\mathrm{L}$-[ring- ${ }^{2} \mathrm{H}_{5}$ ]phenylalanine and $\mathrm{L}$-[ring- ${ }^{2} \mathrm{H}_{2}$ ]tyrosine (Mass Trace, Woburn, MA) was given in the jugular vein (per mouse: prime $\left[{ }^{15} \mathrm{~N}_{2}\right]$ arginine: 850 nmol, $\left[{ }^{13} \mathrm{C}^{2} \mathrm{H}_{2}\right]$ citrulline: $215 \mathrm{nmol},\left[{ }^{2} \mathrm{H}_{5}\right]$ phenylalanine: $340 \mathrm{nmol},\left[{ }^{2} \mathrm{H}_{2}\right]$ tyrosine: 215 nmol, infusion $\left[{ }^{15} \mathrm{~N}_{2}\right]$ arginine: $1700 \mathrm{nmol} / \mathrm{hr},\left[{ }^{13} \mathrm{C}_{-}^{2} \mathrm{H}_{2}\right]$ citrulline: $430 \mathrm{nmol} / \mathrm{hr}$, $\left.{ }^{2} \mathrm{H}_{5}\right]$ phenylalanine: $680 \mathrm{nmol} / \mathrm{hr},\left[{ }^{2} \mathrm{H}_{2}\right]$ tyrosine $430 \mathrm{nmol} / \mathrm{hr}$ ). In a pilot study it was shown that these infusion rates yielded measurable tracer-tracee ratios and that steady state of tracers and metabolites was reached within 20 minutes (Figure 1).

For flow measurements, the indicator dilution method with [glycyl-1 $-{ }^{14} \mathrm{C}$ ]-paminohippuric acid $\left({ }^{14} \mathrm{C}\right.$-PAH, NEN Life Science Products, Boston, MA) was used. Briefly, a primed $\left(20 \mu \mathrm{l} / 10 \mathrm{~g}\right.$ bw of $3 \mu \mathrm{Ci} / \mathrm{ml}^{14} \mathrm{C}-\mathrm{PAH}$ in $0.9 \% \mathrm{NaCl}$ ) continuous ( $1 \mathrm{ml} /$ $10 \mathrm{~g} \mathrm{bw} / \mathrm{h} 3 \mu \mathrm{Ci} / \mathrm{ml}{ }^{14} \mathrm{C}$-PAH in $0.9 \% \mathrm{NaCl}$ ) infusion was given in the mesenteric vein. After 30 minutes, blood ( $0.2 \mathrm{ml}$ per catheter) was sampled from the hepatic vein, portal vein and carotid artery in this order, and collected in heparinized cups (Sarstedt, Nümbrecht, Germany) on ice. The amount of blood taken from the animals was $600 \mu \mathrm{L}$. This equals approximately $25 \%$ of circulating volume in mice, assuming $8 \%$ of a $25 \mathrm{~g}$ mouse is blood. The mice were not given replacement blood. There was no difference in hematocrit between the groups. Hematocrit was $37.5,35.8$ and 34.5 in blood from the hepatic vein, portal vein and carotid artery respectively. The decrease in hematocrit between the first and last blood sample was approximately $8 \%$. 
A

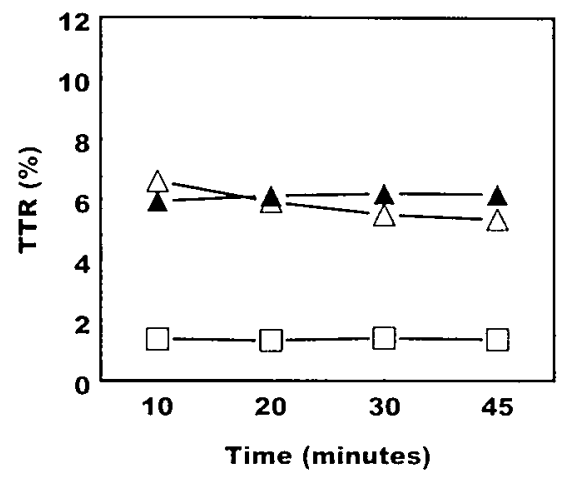

B

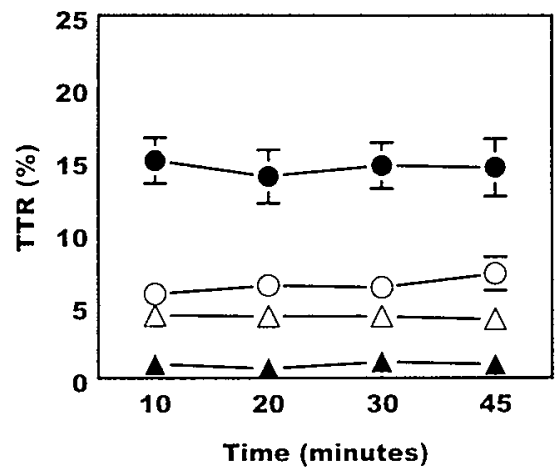

Figure 1. Pilot experiment to determine the time to reach steady state. A primed continuous infusion of stable isotopes was started at $t=0$ and blood was sampled at 10, 20,30 and 45 minutes. A: Plasma TTRs of $\Delta\left[{ }^{2} \mathrm{H}_{5}\right.$ ?phenylalanine, $\Delta\left[{ }^{2} \mathrm{H}_{2}\right]$ tyrosine, and $0\left[{ }^{2} \mathrm{H}_{4}\right]$ tyrosine during a 45-minute primed continuous infusion of $\left[{ }^{2} \mathrm{H}_{5}\right]$ phenylalanine and $\left[{ }^{2} \mathrm{H}_{2}\right]$ tyrosine in mice. B: Plasma TTRs of $\bullet$

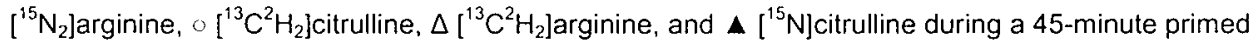
continuous infusion of $\left[{ }^{15} \mathrm{~N}_{2}\right]$ arginine and $\left[{ }^{13} \mathrm{C}^{2} \mathrm{H}_{2}\right]$ citrulline in mice. Mean $\pm \mathrm{SEM}$ in $\%$.

Jejunum, ileum and liver pieces were directly freeze-clamped, frozen in liquid nitrogen and stored at $-80^{\circ} \mathrm{C}$. Whole thickness sections of intestinal tissue were taken. The animals were post-absorptive, and luminal food content was minimal. The order in which the tissues were taken was: 1. jejunum, 2. ileum, 3. liver. The time from tissue sampling until freeze-clamping was a few seconds. For deproteinization the tissue was taken out of the $-80^{\circ} \mathrm{C}$ freezer and immediately put in liquid nitrogen. The tissue was pulverized using a pestle and mortar precooled with liquid nitrogen. The tissue was further homogenized and deproteinized in a Mini-Beadbeater (Biospec Products, Bartlesville, USA). Approximately $100 \mathrm{mg}$ pulverized frozen tissue was added to $400 \mu$ sulfosalicylic acid (SSA) 5\%, with $300 \mathrm{mg}$ glass beads (diameter $1 \mathrm{~mm}$, Biospec Products) and beaten for 30 seconds. The homogenate was centrifuged at $4^{\circ} \mathrm{C}$ at $1,100 \mathrm{~g}$ and the supernatant frozen in liquid nitrogen and stored at $-80^{\circ} \mathrm{C}$ until determination of amino acids and polyamines (8). 
Hematocrit and ${ }^{14} \mathrm{C}-\mathrm{PAH}$ were determined in whole blood as described (7). Blood was centrifuged to obtain plasma, because we have recently shown that plasma sampling is required in organ balance metabolic studies using amino acid tracers that do not equilibrate well with blood cell cytoplasm (9). For determination of amino acid concentrations and enrichments $80 \mu \mathrm{l}$ plasma was added to $7 \mathrm{mg}$ dry SSA, mixed, frozen in liquid nitrogen and stored at $-80^{\circ} \mathrm{C}$. Plasma and tissue amino acid concentrations and enrichments were measured using a fully automated LC-MS system, using pre-column derivatization with OPA (10). Tissue polyamines (putrescine (PUT), spermine (SPM) and spermidine (SPD)) were determined as described before (11). In a subset of animals (5 Control, 5 LPS), $20 \mu$ l plasma was added to $80 \mu \mathrm{l} 1 \%$ trichloroacetic acid for determination of plasma urea and ammonia. Plasma urea and ammonia were determined using commercially available kits on a Cobas Mira S (Roche Diagnostica, Hoffman La Roche, Basel, Switzerland), as described previously (12). For measurement of plasma nitrite and nitrate, $50 \mu \mathrm{l}$ plasma was added to $100 \mu$ lacetonitrile (Biosolve LTD, Valkenswaard, The Netherlands). Plasma nitrite and nitrate were analyzed on an isocratic HPLC system (eluens: $6 \mathrm{mM}$ sodium chloride, $1 \mathrm{mM}$ potassium dihydrogenphosphate, $\mathrm{pH}=6$ ).

\section{Calculations}

The rate of $\mathrm{NO}$ production was measured using $\left[{ }^{15} \mathrm{~N}_{2}\right]$ arginine to $\left[{ }^{15} \mathrm{~N}\right]$ citrulline conversion. This method has been described by a number of groups before (13-15), and is based on the fact that $\left[{ }^{15} \mathrm{~N}\right]$ citrulline can only be produced from $\left[{ }^{15} \mathrm{~N}_{2}\right]$ arginine by nitric oxide synthase. Calculation of the rate of NO production was made as described by Castillo et al. (13):

$\mathrm{Q}_{\mathrm{Arg}_{\rightarrow} \mathrm{Cit}}=\mathrm{Q}_{\mathrm{Cit}} \times \mathrm{TTR}_{\mathrm{Ci}(\mathrm{M}+1)} / \mathrm{TTR}_{\mathrm{Arg}(M+2)}$. where $Q_{C i t}$ is the plasma citrulline flux ( $\mathrm{nmol} / 10 \mathrm{~g} / \mathrm{min}$ ), estimated from the primed constant infusions of the $\mathrm{L}-\left[\right.$ ureido- ${ }^{13} \mathrm{C} ;{ }^{2} \mathrm{H}_{2}$ ]citrulline tracer and TTR $\mathrm{Cit}$ and TTR $\mathrm{Arg}$ are the respective TTRs of [ureido- ${ }^{15} \mathrm{~N}$ ]citrulline and [ guanidino- ${ }^{15} \mathrm{~N}_{2}$ ] arginine. $\mathrm{M}$ indicates the molecular mass of the unlabeled compound.

Calculation of the plasma citrulline to arginine flux (de novo arginine production rate) was made in a similar fashion:

$\mathrm{Q}_{\mathrm{Cit}_{\rightarrow} \text { Arg }}=\mathrm{Q}_{\text {Arg }} \times \mathrm{TTR}_{\mathrm{Arg}(M+3)} / \mathrm{TTR}_{\mathrm{Cit}(M+3)}$. 
where $Q_{A r g}$ is the plasma arginine flux ( $\mathrm{nmol} / 10 \mathrm{~g} / \mathrm{min}$ ), estimated from the primed constant infusions of the $\mathrm{L}$-[guanidino- ${ }^{15} \mathrm{~N}_{2}$ ] arginine tracer and TTR $\mathrm{Arg}_{\mathrm{Ag}}$ and TTR $\mathrm{Cit}$ are the respective TTRs of $\mathrm{L}$-[guanidino- ${ }^{13} \mathrm{C} ;{ }^{2} \mathrm{H}_{2}$ ] arginine and $\mathrm{L}$-[ureido- ${ }^{13} \mathrm{C} ;{ }^{2} \mathrm{H}_{2}$ ]citrulline.

Calculation of the plasma phenylalanine to tyrosine flux (phenylalanine hydroxylation) was made as follows:

$Q_{\text {Phe }_{\rightarrow} \text { Tyr }}=Q_{T y r} \times T_{T R} R_{\text {Tyr }(M+4)} / \operatorname{TTR}_{\text {Phe }(M+5)}(16)$, where $Q_{T y r}$ is the plasma tyrosine flux ( $\left.\mathrm{nmol} / 10 \mathrm{~g} / \mathrm{min}\right)$, estimated from the primed constant infusions of the $\left[{ }^{2} \mathrm{H}_{2}\right]$ tyrosine tracer and TTR $\mathrm{Try}_{\mathrm{T}(\mathrm{M}+4)}$ and TTR $\mathrm{TPhe}_{\mathrm{M}+5)}$ are the respective arterial TTRs of $\left[{ }^{2} \mathrm{H}_{4}\right]$ tyrosine and $\left[{ }^{2} \mathrm{H}_{5}\right]$ phenylalanine.

\section{Plasma flow, substrate fluxes and intracellular concentrations}

Plasma flow across the PDV and liver was calculated using the indicator dilution technique with ${ }^{14} \mathrm{C}$-labeled $\mathrm{PAH}$ as described recently (7). PDV amino acid fluxes were calculated by multiplying the portal venous-arterial concentration differences with the mean PDV plasma flow, and are expressed in nmol/10g body weight per minute. Splanchnic organ flux was calculated by multiplying the hepatic plasma flow with hepatic vein-arterial concentration differences. Liver flux was calculated by subtracting portal drained visceral flux from the splanchnic flux as described previously $(7,12,17)$. A positive flux indicates net release and a negative flux reflects net uptake. BCAA indicates the sum of the Branched Chain Amino Acids valine, leucine and isoleucine. SUMAA indicates the SUM of the Amino Acids glutamine, glycine, threonine, histidine, citrulline, alanine, taurine, arginine, tyrosine, valine, methionine, isoleucine, phenylalanine, tryptophane, leucine, ornithine and lysine. The portal drained viscera will be referred to as intestine under "Results" and "Discussion".

\section{Protein turnover}

The rates of phenylalanine disposal and production in the splanchnic region were evaluated using, in principle, the models described previously for quantifying leucine metabolism in the splanchnic region (18). Net balance of respectively phenylalanine and $\left[{ }^{2} \mathrm{H}_{5}\right]$ phenylalanine across PDV is equal to:

$$
\mathrm{NB}=\mathrm{PF}_{\mathrm{POV}} \times\left([\mathrm{PHE}]_{\mathrm{A}}-[\mathrm{PHE}]_{\mathrm{P}}\right)
$$

and

$\left.\left.n b=P F_{P D V} \times\left\{\left(T T R_{A}\right\} \times[P H E]_{A}\right)-\left(T T R_{P}\right\} \times[P H E]_{P}\right)\right\}$ 
where PFPOV is PDV plasma flow, and $[\mathrm{PHE}]_{A}$ and $[\mathrm{PHE}]_{P}$ are the arterial and portal plasma concentrations of phenylalanine, and $T T R_{A}$ and $T T R_{P}$ are the tracer-tracee $(\mathrm{M}$ vs. $\mathrm{M}+5$ ) ratios of phenylalanine in arterial and portal plasma respectively.

The NB of phenylalanine equals the difference between disposal and production of phenylalanine, and therefore the following formulae are derived:

$D=n b / T T R_{p}$

$P=D-N B$,

where $D$ is the intra-organ disposal of phenylalanine and $P$ is the intra-organ production of phenylalanine.

Calculation of intestinal hydroxylation of phenylalanine to tyrosine (Phe $\rightarrow$ Tyr) was estimated from the appearance of $M+4$ labeled tyrosine in the portal vein by the following equation, which has in principle already been used to calculate splanchnic leucine to KIC deamination (18):

$P h e \rightarrow \operatorname{Tyr}_{(\mathrm{PDV})}=$

$\mathrm{PF}_{\mathrm{POV}} \times[\mathrm{A}]_{\text {Phe }} \times\left\{\left([\mathrm{PV}]_{\mathrm{Tyr}} \times \operatorname{TTR}_{\mathrm{PTyr}(\mathrm{M}+4)}-[\mathrm{A}]_{\mathrm{Tyr}} \times \operatorname{TTR}_{\mathrm{ATyr}(\mathrm{M}+4)}\right) /[\mathrm{A}]_{\text {Phe }} \times \operatorname{TTR}_{\mathrm{APhe}(\mathrm{M}+5)\}}\right.$, where $P F_{P D V}$ is PDV plasma flow, and $[\mathrm{PV}]$ and $[\mathrm{A}]$ are the portal and arterial plasma concentrations of substrates, and TTR $R_{A}$ and TTR are the tracer-tracee ratios of substrate in arterial and portal venous plasma respectively. In this formula, the arterial $\mathrm{TTR}_{\mathrm{Tyr}(\mathrm{M}+4)}$ was corrected for the fractional extraction of tyrosine in the intestine. Fractional extraction of tyrosine in intestine and liver was calculated using $\left[{ }^{2} \mathrm{H}_{2}\right]$ tyrosine. The splanchnic Phe $\rightarrow$ Tyr was calculated similarly. In the above formula PDV plasma flow was substituted by splanchnic plasma flow and [PV] $]_{\text {Tr }}$ and $T_{T R}$ Pyr $(M+4)$ were substituted by the hepatic venous tyrosine concentration and $M+4$ tyrosine TTR, respectively.

Splanchnic phenylalanine NB and nb were calculated as described above using the phenylalanine concentration and TTR in the hepatic vein. Hepatic phenylalanine NB and $\mathrm{nb}$ were calculated by subtracting intestinal phenylalanine NB and $\mathrm{nb}$ from splanchnic NB and $\mathrm{nb}$. Similarly, hepatic $\mathrm{Phe} \rightarrow$ Tyr was calculated by subtracting intestinal $P h e \rightarrow$ Tyr from splanchnic Phe $\rightarrow$ Tyr.

\section{Arginine metabolism}

Arginine turnover across PDV and liver was calculated as above, using the $\left[{ }^{15} \mathrm{~N}_{2}\right]$ arginine tracer. The rates of conversion of $\left[{ }^{15} \mathrm{~N}_{2}\right]$ arginine to $\left[{ }^{15} \mathrm{~N}\right]$ citrulline (NO production), and of $\left[{ }^{13} \mathrm{C}^{2} \mathrm{H}_{2}\right]$ citrulline to $\left[{ }^{13} \mathrm{C}^{2} \mathrm{H}_{2}\right]$ arginine (de novo arginine production) 
in PDV and liver were calculated in an essentially similar manner as the conversion of Phe to Tyr. In the calculation of NO production in intestine and liver, the arterial TTR of $\left[{ }^{15} \mathrm{~N}\right]$ citrulline was corrected for the fractional extraction of citrulline in intestine and liver respectively. The fractional extraction of citrulline in intestine and liver was calculated using $\left[{ }^{13} \mathrm{C}^{2} \mathrm{H}_{2}\right]$ citrulline. In the calculation of de novo arginine production in intestine and liver, the arterial TTR of $\left[{ }^{13} \mathrm{C}^{2} \mathrm{H}_{2}\right.$ ]arginine was corrected for the fractional extraction of arginine in intestine and liver respectively. The fractional extraction of arginine in intestine and liver was calculated using $\left[{ }^{15} \mathrm{~N}_{2}\right]$ arginine.

\section{Statistical analysis}

Results are presented as means \pm SEM. Significance (LPS versus Control) was tested using the Mann Whitney $U$ test. Net amino acid production or consumption rates across intestine and liver are usually small. Therefore, net amino production or consumption rates were tested against zero, i.e. no net consumption or production using the Wilcoxon test. Significance was considered present at $p<0.05$.

\section{Results}

Systemic

All mice survived the 6-hour period after treatment with LPS or saline. In response to challenge with bacterial endotoxin, the arterial concentrations of glutamine, citrulline, arginine and phenylalanine were increased (Table 1). Increased systemic NO production in LPS-challenged mice was confirmed by increased concentration of the end-products $\mathrm{NO}_{2}{ }^{-}$and $\mathrm{NO}_{3}{ }^{-}$(Table 1 ), and by an increased systemic rate of $\mathrm{NO}$ production, as detected by $\left[{ }^{15} \mathrm{~N}_{2}\right]$ arginine to $\left[{ }^{15} \mathrm{~N}\right]$ citrulline labeling (Control: $3.5 \pm 1.1$ nmol/10g BW per minute; LPS: $8.2 \pm 1.7 \mathrm{nmol} / 10 \mathrm{~g}$ BW per minute, $p<0.05$ ).

\section{Intestine}

Arginine metabolism in the intestine was assessed by measurement of the concentration of amino acids in jejunum and ileum, and by measurement of the net balance of amino acids across the intestine. In response to endotoxin challenge, the concentrations of glutamine and the polyamine putrescine were increased in the jejunum (Table 2). The concentrations of arginine, ornithine and citrulline, however, 
Table 1. Arterial substrate concentrations. Values are mean $\pm S E M$ in $\mu M$, urea in $m M .{ }^{8} p<0.05$, "p<0.01 vs. Control.

\begin{tabular}{lrrlrlll}
\hline & \multicolumn{3}{c}{ Control } & \multicolumn{3}{c}{ LPS } \\
\hline $\mathrm{NO}_{2}^{-}$ & 2.7 & \pm & 0.6 & 4.7 & \pm & $0.8^{8}$ \\
$\mathrm{NO}_{3}^{-}$ & 26 & \pm & 3 & 151 & \pm & $20^{\#}$ \\
Urea & 6.0 & \pm & 0.3 & 9.0 & \pm & $0.9^{\prime \prime}$ \\
Ammonia & 214 & \pm & 29 & 280 & \pm & $23^{\#}$ \\
GLN & 336 & \pm & 26 & 439 & \pm & $27^{\#}$ \\
GLY & 282 & \pm & 27 & 255 & \pm & 24 \\
HIS & 68 & \pm & 5 & 113 & \pm & $6^{\#}$ \\
CIT & 60 & \pm & 6 & 79 & \pm & $7^{8}$ \\
ALA & 306 & \pm & 34 & 361 & \pm & 41 \\
ARG & 105 & \pm & 7 & 134 & \pm & $6^{\#}$ \\
TYR & 81 & \pm & 8 & 104 & \pm & 10 \\
PHE & 77 & \pm & 7 & 114 & \pm & $8^{\#}$ \\
ORN & 90 & \pm & 11 & 120 & \pm & 9 \\
LYS & 355 & \pm & 41 & 424 & \pm & 34 \\
BCAA & 320 & \pm & 35 & 352 & \pm & 25 \\
SUMAA & 2399 & \pm & 182 & 2814 & \pm & 177 \\
\hline
\end{tabular}

were not changed. In tissue of the ileum of LPS-treated mice, the concentrations of many amino acids, including glutamine, arginine and citrulline, and the polyamine putrescine were increased (Table 2). In addition, the concentration of BCAAs was increased in the ileum. In general, endotoxin treatment had a large impact on net intestinal amino acid metabolism (Table 3). Endotoxin challenge caused a switch from net production of amino acids to net consumption of amino acids, suggesting increased protein synthesis. Net arginine flux was not changed in response to endotoxin treatment, but endotoxin challenge resulted in a switch from ornithine consumption to ornithine production in the intestine. Intestinal citrulline production was reduced in LPS-treated animals. 
Table 2. Amino acid concentrations in jejunum and ileum. Values are mean $\pm S E M$ in $\mu \mathrm{mol} / \mathrm{kg}$ wet weight. ${ }^{\&} p<0.05$, "p<0.01 vs. Control. PUT = putrescine, $S P M=$ spermine, $S P D=$ spermidine.

\begin{tabular}{|c|c|c|c|c|c|c|c|c|c|c|c|c|}
\hline \multirow[b]{3}{*}{ GLN } & \multicolumn{6}{|c|}{ Jejunum } & \multicolumn{6}{|c|}{ Ileum } \\
\hline & \multicolumn{3}{|c|}{ Control } & \multicolumn{3}{|c|}{ LPS } & \multicolumn{3}{|c|}{ Control } & \multicolumn{3}{|c|}{ LPS } \\
\hline & 211 & \pm & 17 & 370 & \pm & $29^{H}$ & 343 & \pm & 46 & 492 & \pm & $30^{8}$ \\
\hline $\mathrm{CIT}$ & 113 & \pm & 7 & 158 & \pm & 9 & 123 & \pm & 13 & 186 & \pm & $12^{\&}$ \\
\hline ALA & 1107 & \pm & 90 & 1193 & \pm & 80 & 1073 & \pm & 80 & 1429 & \pm & $81^{\#}$ \\
\hline ARG & 110 & \pm & 16 & 113 & \pm & 9 & 95 & \pm & 15 & 124 & \pm & 10 \\
\hline TYR & 106 & \pm & 9 & 112 & \pm & 8 & 115 & \pm & 16 & 145 & \pm & 18 \\
\hline PHE & 99 & \pm & 8 & 117 & \pm & 7 & 91 & \pm & 7 & 125 & \pm & $9^{\#}$ \\
\hline ORN & 48 & \pm & 6 & 47 & \pm & 4 & 65 & \pm & 12 & 57 & \pm & 7 \\
\hline $\mathrm{BCAA}$ & 390 & \pm & 34 & 326 & \pm & 18 & 356 & \pm & 39 & 373 & \pm & 29 \\
\hline SUMAA & 21019 & \pm & 808 & 22057 & \pm & 599 & 21795 & \pm & 1529 & 22499 & \pm & 1172 \\
\hline PUT & 165 & \pm & 14 & 406 & \pm & $56^{\#}$ & 178 & \pm & 13 & 407 & \pm & $51^{\#}$ \\
\hline SPM & 564 & \pm & 44 & 543 & \pm & 79 & 634 & \pm & 37 & 693 & \pm & 39 \\
\hline SPD & 1427 & \pm & 80 & 1364 & \pm & 98 & 1555 & \pm & 110 & 1695 & \pm & 115 \\
\hline
\end{tabular}

Table 3. Net intestinal fluxes. Values are mean \pm SEM in $\mathrm{nmol} / 10 \mathrm{~g}$ body weight per minute. Plasma flow in $\mathrm{ml} / 10 \mathrm{~g}$ body weight per minute. ${ }^{8} p<0.05$ vs. Control, ${ }^{*} p<0.05$ vs. 0 .

\begin{tabular}{lrrlrll}
\hline & \multicolumn{3}{c}{ Control } & \multicolumn{3}{c}{ LPS } \\
\hline Plasma flow & 0.8 & \pm & 0.2 & 0.6 & \pm & 0.1 \\
GLN & -79 & \pm & $14^{\star}$ & -104 & \pm & $12^{\star}$ \\
CIT & 13 & \pm & $5^{\star}$ & 5 & \pm & $3^{\star}$ \\
ALA & 124 & \pm & $30^{\star}$ & 45 & \pm & $15^{8}$ \\
ARG & -7 & \pm & 5 & -8 & \pm & $2^{\star}$ \\
TYR & 5 & \pm & 7 & -5 & \pm & 6 \\
PHE & 1 & \pm & 3 & -6 & \pm & $3^{\star}$ \\
ORN & 15 & \pm & 10 & -11 & \pm & $3^{8 *}$ \\
BCAA & 13 & \pm & 9 & -20 & \pm & $9^{8 *}$ \\
SUMAA & 177 & \pm & 92 & -122 & \pm & $73^{8}$ \\
\hline
\end{tabular}



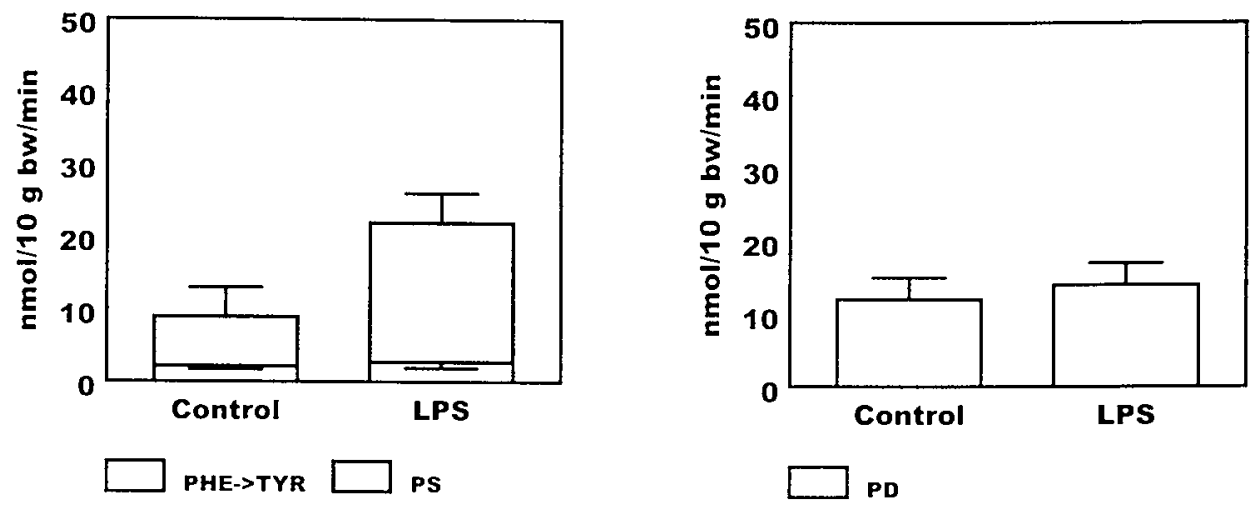

Figure 2. Intestinal protein synthesis and degradation in control and endotoxin treated mice measured using $\left[{ }^{2} \mathrm{H}_{5}\right]$ phenylalanine. Left panel: intestinal phenylalanine disposal. Total phenylalanine disposal is divided in phenylalanine hydroxylation to tyrosine (Phe $\rightarrow$ Tyr) and true protein synthesis (PS). Right panel: intestinal phenylalanine production. Because phenylalanine is not obtained from other sources than protein, phenylalanine production is a direct indicator of protein degradation $(P D)$.
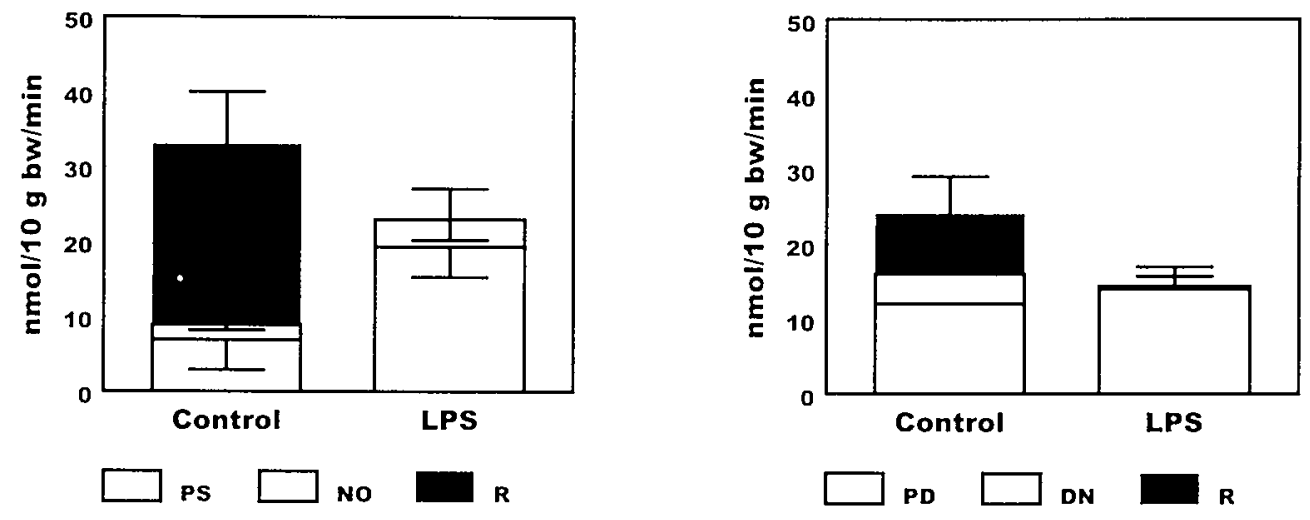

Figure 3. Intestinal arginine metabolism in control and endotoxin-treated mice measured using $\left[{ }^{15} \mathrm{~N}_{2}\right.$ ]arginine. Left panel: intestinal arginine disposal. Arginine disposal is divided in arginine disposal aimed at protein synthesis (PS), NO production and remaining (R) pathways of arginine disposal, including arginase. Right panel: Total arginine production is divided in arginine production obtained from protein degradation (PD), de novo arginine production (de novo), and remaining sources of arginine production. 
Stable isotope measurements across the intestine were performed to compare arginine metabolism to protein metabolism. Intestinal protein synthesis and breakdown rates were measured using $\left[{ }^{2} \mathrm{H}_{5}\right]$ phenylalanine. In agreement with the increased consumption of amino acids by the intestine, intra-intestinal phenylalanine disposal was increased (Figure 2). Phenylalanine may be hydroxylated to tyrosine (Phe $\rightarrow$ Tyr), or may be used for protein synthesis (PS). Phe $\rightarrow$ Tyr contributed only marginally to phenylalanine disposal, and was not increased by endotoxin treatment. These results indicate that the increase in phenylalanine disposal reflects increased protein synthesis. Intra-intestinal protein degradation was not changed (Figure 2). As a result, net protein synthesis is increased in the intestine in response to endotoxemia.

Although protein synthesis was increased, intestinal arginine disposal, measured using $\left[{ }^{15} \mathrm{~N}_{2}\right]$ arginine, was reduced in endotoxin-treated mice (Figure 3 ). In this figure, the contribution of arginine disposal to protein synthesis and NO production to intra-intestinal arginine disposal is depicted. Equal incorporation of phenylalanine and arginine into protein was assumed. Intestinal NO production, measured as $\left[{ }^{15} \mathrm{~N}_{2}\right]$ arginine to $\left[{ }^{15} \mathrm{~N}\right]$ citrulline labeling, was $2 \%$ of arginine disposal under baseline conditions. After LPS treatment intestinal NO production was $10 \%$ of arginine disposal, but the difference was not statistically significant. Because intestinal protein synthesis was increased and NO production was very limited, the decrease in arginine disposal indicates a large decrease in arginine disposal towards other arginine-derived compounds, including ornithine. Indeed, in response to LPS treatment, the intestine consumed ornithine.

Total arginine production was reduced in the intestine after endotoxin challenge (Figure 3). Since protein breakdown was not reduced, this decrease in arginine production must arise from other sources than protein breakdown. The intestinal conversion of $\left[{ }^{13} \mathrm{C}^{2} \mathrm{H}_{2}\right]$ citrulline to $\left[{ }^{13} \mathrm{C}^{2} \mathrm{H}_{2}\right]$ arginine was significantly decreased, indicating decreased de novo arginine production in the intestine of endotoxemic mice.

\section{Liver}

Hepatic arginine and citrulline concentrations were not changed by LPS treatment (Table 4). In contrast, the concentrations of glutamine, ornithine, and the polyamine putrescine were increased. Total amino acid content in the liver was increased. The 
net hepatic amino acid fluxes were not changed, with the exception of ornithine, which was produced in the livers of LPS-treated mice, but not in control mice (Table 5).

Table 4. Amino acid concentrations in liver.

Values are mean \pm SEM in $\mu \mathrm{mol} / \mathrm{kg}$ wet weight. ${ }^{\&} p<0.05, " p<0.01$ vs. Control.

\begin{tabular}{lrlrl}
\hline & \multicolumn{2}{c}{ Control } & \multicolumn{2}{c}{ LPS } \\
\hline GLN & 1180 & \pm 72 & 1394 & \pm 130 \\
CIT & 78 & \pm 28 & 55 & \pm 6 \\
ALA & 2432 & \pm 431 & 3924 & $\pm 629^{8}$ \\
ARG & 59 & \pm 12 & 57 & \pm 8 \\
TYR & 134 & \pm 15 & 126 & \pm 12 \\
PHE & 105 & \pm 10 & 114 & \pm 5 \\
ORN & 555 & \pm 85 & 812 & $\pm 69^{8}$ \\
BCAA & 623 & \pm 76 & 611 & \pm 44 \\
SUMAA & 17604 & \pm 1759 & 24381 & $\pm 1208^{\#}$ \\
PUT & 10 & \pm 1 & $33 \pm 6^{\#}$ \\
SPM & 967 & \pm 62 & 867 & \pm 81 \\
SPD & 1365 & \pm 180 & $1473 \pm 159$ \\
\hline
\end{tabular}

Table 5. Net liver fluxes. Values are mean \pm SEM in nmol/10g body weight per minute. Plasma flow in $\mathrm{ml} / 10 \mathrm{~g}$ body weight per minute. ${ }^{*} p<0.05$ vs. 0 .

\begin{tabular}{|c|c|c|c|c|c|c|}
\hline & \multicolumn{3}{|c|}{ Control } & \multicolumn{3}{|c|}{ LPS } \\
\hline Flow & 1.2 & \pm & 0.3 & 1.1 & \pm & 0.2 \\
\hline GLN & -17 & \pm & $9^{*}$ & -35 & \pm & $18^{*}$ \\
\hline $\mathrm{CIT}$ & 1 & \pm & 5 & -4 & \pm & 3 \\
\hline ALA & -100 & \pm & $48^{*}$ & -138 & \pm & $19^{*}$ \\
\hline ARG & -11 & \pm & 9 & -34 & \pm & $8^{*}$ \\
\hline TYR & -5 & \pm & 7 & -10 & \pm & 7 \\
\hline PHE & -1 & \pm & 6 & -9 & \pm & 3 \\
\hline ORN & 1 & \pm & 6 & 16 & \pm & $8^{\star}$ \\
\hline BCAA & 35 & \pm & 22 & 3 & \pm & 16 \\
\hline SUMAA & -173 & \pm & 148 & -329 & \pm & $97^{*}$ \\
\hline
\end{tabular}

Hepatic protein synthesis and hepatic protein degradation were not significantly changed in response to early endotoxemia (Figure 4). Although hepatic protein synthesis was not changed, arginine disposal was increased in the liver (Figure 5). The increase in hepatic arginine disposal is therefore directed towards compounds other than protein, including arginase. An increase in arginase activity is in agreement with the increase in hepatic ornithine production and hepatic ornithine content. 

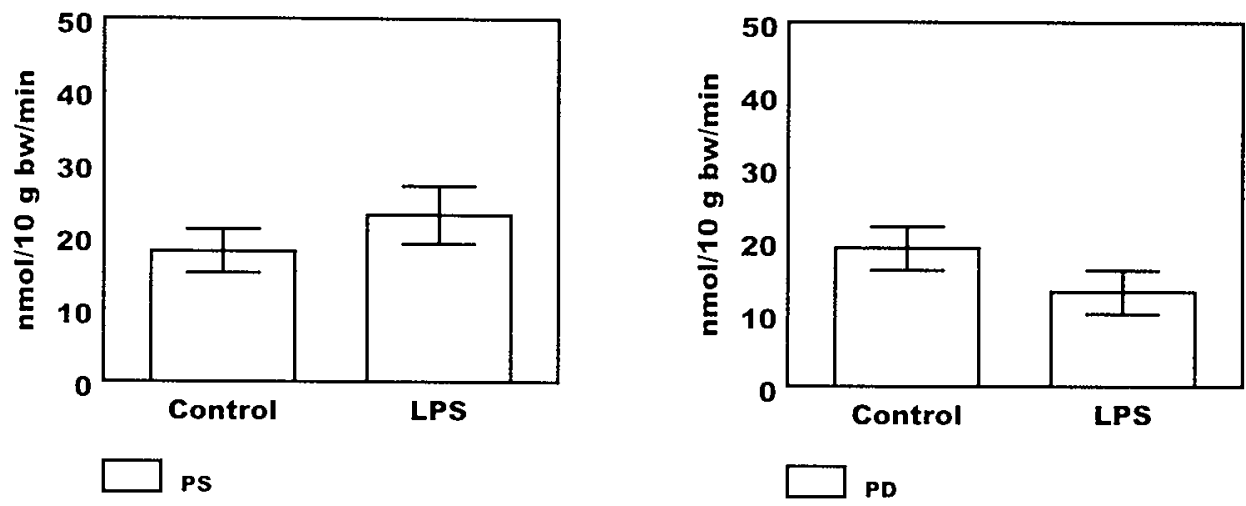

Figure 4. Hepatic protein synthesis and degradation in control and endotoxin-treated mice measured using $\left[{ }^{2} \mathrm{H}_{5}\right]$ phenylalanine. Left panel: hepatic phenylalanine disposal. Total phenylalanine disposal is divided in phenylalanine hydroxylation to tyrosine (Phe $\rightarrow$ Tyr) and true protein synthesis (PS). Right panel: hepatic phenylalanine production. Because phenylalanine is not obtained from other sources than protein, phenylalanine production is a direct indicator of protein degradation (PD).
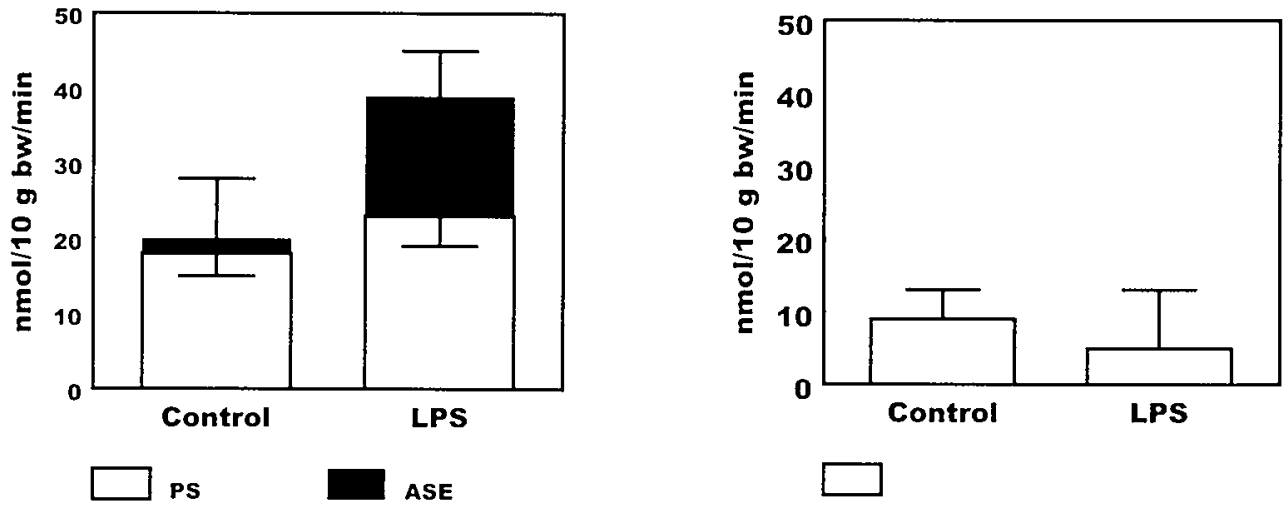

Figure 5. Hepatic arginine metabolism in control and endotoxin-treated mice measured using $\left[{ }^{15} \mathrm{~N}_{2}\right.$ ] arginine. Left panel: hepatic arginine disposal. Arginine disposal is divided in arginine disposal aimed at protein synthesis (PS), NO production and remaining (R) pathways of arginine disposal, including arginase. Right panel: Total arginine production is divided in arginine production obtained from protein degradation $(\mathrm{PD})$, de novo arginine production (de novo), and remaining sources of arginine production. 


\section{Discussion}

In the present study we measured arginine and protein metabolism in the intestine and liver during short-term endotoxemia in mice. The main results of the study are that the intestinal response to LPS treatment was an increase in protein synthesis and a decrease in arginase-mediated arginine disposal. The production of polyamines was maintained through increased intestinal uptake of ornithine. In contrast, liver arginase-mediated arginine disposal was increased and resulted in an increase in hepatic putrescine.

In the present experiment, endotoxemia was used as a model of the septic condition (19). In agreement with results in endotoxemic mice (20) and septic rats (21), protein synthesis was increased in the intestine of endotoxin-treated mice. However, net protein synthesis is determined by protein synthesis and protein breakdown, and the latter has not been studied before in LPS-treated mice. A transorgan tracer balance method is the only available method to simultaneously measure protein synthesis and protein breakdown in vivo (22). Using this approach, we now show that protein breakdown was not changed after endotoxin challenge, and thus net protein synthesis is increased in the intestine after endotoxin injection in mice. Four hours after an i.v. bolus of LPS in humans, an increase in spanchnic protein synthesis was observed (18). In these volunteers it was not possible to establish whether the increase in splanchnic protein synthesis occurred in the intestine or the liver (18). From the present data it is clear that the increase in splanchnic protein synthesis is mainly caused by increased intestinal protein synthesis. Renal protein metabolism is also increased in response to endotoxin treatment (15). It thus seems that, with respect to protein turnover, intestine and kidney respond similarly to endotoxemia. Although the mechanism underlying the increase in intestinal protein synthesis cannot be established from the present data, the modulating factors may be cytokines like IL-6 (23). It is known that systemic IL-6 concentrations and intestinal IL-6 production are increased in models of endotoxemia $(6,24)$.

Although intestinal protein synthesis was increased in response to challenge with bacterial endotoxin, intestinal arginine disposal was decreased. These results suggest that the flux through arginine directed to other pathways than protein 
synthesis were dramatically decreased in the intestine of LPS-treated mice. Compounds which production was decreased in intestinal tissue may include ornithine, and agmatine. Evidence for a decrease in intestinal arginase activity was obtained from the change from ornithine production to ornithine uptake in response to treatment with LPS. Despite the decrease in intestinal arginine disposal, the concentration of putrescine was increased in jejunum and ileum, in agreement with results by Noguchi et al (25). Putrescine is produced from ornithine by ornithine decarboxylase. Therefore, these data indicate that ornithine is actively taken up from the circulation to sustain intestinal putrescine production, when intestinal arginine disposal is reduced. The sustained production of putrescine may be important for the maintenance of intestinal integrity. In addition, putrescine is a source of energy in the intestine (26).

From the changes in amino acid concentrations, it seems that the changes in intestinal arginine metabolism predominantly take place in the ileum, not the jejunum. The concentrations of arginine and citrulline were increased in the ileum, which is in agreement with the histochemical observation that especially the ileum has capacity for NO generation (27). In contrast, the conversion of $\left[{ }^{15} \mathrm{~N}_{2}\right]$ arginine to $\left[{ }^{15} \mathrm{~N}\right]$ citrulline across the intestine was not increased by LPS treatment. The reason for this apparent discrepancy may be that the method does not discriminate between NO production by constitutive NOS or inducible NOS. In addition, the method does not discriminate between cell types.

The response of the liver with respect to arginine metabolism after endotoxin challenge is very different. Five hours after injection with bacterial LPS, protein turnover was not changed. Possibly, the time of measurement, 5 hours after LPS challenge, is too early to observe changes in hepatic protein turnover. Despite unchanged protein synthesis, hepatic arginine disposal was significantly increased. Thus in the liver, arginine flux directed to compounds other than protein was increased. These results suggest that the hepatic activities of NOS, arginine decarboxylase (ADC) and arginase are increased by LPS treatment. Indeed, increased iNOS and ADC mRNA levels were detected in hepatic tissue after endotoxin challenge (28-30).

In the present experiment, hepatic arginine disposal and hepatic ornithine production were increased in LPS-treated mice. It may be argued that the liver has 
no net ornithine production from arginine. The increase in arginine disposal may indicate increased urea cycle activity (via arginase l), without the net production of ornithine. This would imply glutamate abundance causing ornithine aminotransferase to produce ornithine. Alternatively, arginase II, which is available in the liver (31), rather than arginase I may be involved in the increase in hepatic arginine disposal in LPS-treated animals. Arginase II activity may be independent from hepatic urea cycle activity, as has been discussed before $(32,33)$.

It is well known that, under baseline conditions, the rate of urea production is 5-7 times higher than the plasma arginine flux (1). The increase of the plasma urea concentration is also in line with this. These data indicate that labeled arginine does not exchange well with the urea cycle pool in the liver, which is in agreement with the channeling of urea cycle intermediates in the liver (34). It has been suggested that about $5 \%$ of the plasma arginine flux represent arginine that is formed in the urea cycle in the liver (1).

Increased hepatic endogenous ornithine production may favor the production of polyamines. Indeed, hepatic ornithine decarboxylase was increased in response to treatment with bacterial endotoxin (30), and so was hepatic putrescine in our study and in a study by others (35).

In conclusion, endotoxemia differentially affects arginine and protein metabolism in intestine and liver of mice. The intestinal response to LPS treatment is an increase in protein synthesis and a decrease in arginase-mediated arginine disposal. Despite the decrease in intestinal arginine disposal, the concentration of the polyamine putrescine was increased. The data suggest that the production of putrescine was maintained by an increase in intestinal ornithine uptake. In contrast, hepatic protein metabolism was not significantly changed, and arginase-mediated arginine disposal was increased in the liver. Increased endogenous ornithine production facilitated the increase in hepatic putrescine.

\section{Acknowledgments}

The authors wish to thank Mr. JLJM Scheyen, BSc and Mr. HMH van Eijk, Ph.D. for excellent LC-MS measurements, and Mrs. GAM ten Have, BSc for help with the animal experiments. 


\section{References}

1. Beaumier L, Castillo L, Yu YM, Ajami AM, Young VR. Arginine: new and exciting developments for an "old" amino acid. Biomed.Environmental.Sci. 1996;9:296-315.

2. Szabo C, Southan GJ, Wood E, Thiemermann C, Vane JR. Inhibition by spermine of the induction of nitric oxide synthase in $\mathbf{J 7 7 4 . 2}$ macrophages: requirement of a serum factor. $\mathrm{Br} J$ Pharmacol 1994;112:355-356.

3. Satriano J, Matsufuji S, Murakami Y, Lortie MJ, Schwartz D, Kelly CJ, et al. Agmatine suppresses proliferation by frameshift induction of antizyme and attenuation of cellular polyamine levels. J Biol Chem 1998;273:15313-15316.

4. Schwartz D, Peterson OW, Mendonca M, Satriano J, Lortie M, Blantz RC. Agmatine affects glomerular filtration via a nitric oxide synthase-dependent mechanism. Am J Physiol: Renal Physiol 1997;272:F597-F601.

5. Waldegrave W, Chairman Council of the European Community. Guide for the care and use of laboratory animals. Brussels, Belgium: European Community; 1986. Report No.: Publication $86 / 609$.

6. Ter Steege JCA, Van de Ven WCM, Forget PP, Brouckaert P, Buurman WA. The role of endogenous IFN-gamma, TNF-alpha and IL-10 in LPS-induced nitric oxide release in a mouse model. Cytokine 1998;10:115-123.

7. Hallemeesch MM, Ten Have GAM, Deutz NEP. Measurement of metabolic fluxes across PDV, liver, kidney and hindquarter in mice. Lab Anim 2001;35:101-110.

8. De Blaauw I, Deutz NEP, Van der Hulst RRWW, Von Meyenfeldt MF. Glutamine depletion and increased gut permeability in non-anorectic, non-weight losing tumor bearing rats. Gastroenterology 1997;112(1):118-126.

9. Hallemeesch MM, Soeters PB, Deutz NEP. Tracer methodology in whole body and organ balance metabolic studies: plasma sampling is required. Clin Nutr 2000;19:157-163.

10. Van Eijk HMH, Rooyakkers DR, Deutz NEP. Determination of amino acid isotope enrichment using liquid chromatography-mass spectrometry. Anal.Biochem. 1999;271:8-17.

11. Van Eijk HMH, Rooyakkers DR, Deutz NEP. Automated determination of polyamines by highperformance liquid chromatography with simple sample preparation. J.Chromatogr. 1996;730:115-120.

12. Dejong $\mathrm{CHC}$, Deutz NEP, Soeters PB. Renal ammonia and glutamine metabolism during liver insufficiency-induced hyperammonemia in the rat. J.Clin.Invest. 1993:92:2834-2840.

13. Castillo L, Beaumier L, Ajami AM, Young VR. Whole body nitric oxide synthesis in healthy men determined from [15N]-arginine-to-[15N]citrulline labeling. Proc.Natl.Acad Sci.USA 1996;93:11460-11465.

14. Lagerwerf FM, Wever RM, van Rijn HJ, Versiuis C, Heerma W, Haverkamp J, et al. Assessment of nitric oxide production by measurement of [15N]citrulline enrichment in human plasma using high-performance liquid chromatography- mass spectrometry. Anal Biochem 1998:257(1):45-52. 
15. Hallemeesch MM, Soeters PB, Deutz NEP. Renal arginine and protein synthesis are increased during early endotoxemia in mice. Am J Physiol: Renal Physiol 2001;August 21, 10.1152/ajprenal.0039.2001 (In Press).

16. Moldawer LL, Kawamura I, Bistrian BR, Blackburn GL. The contribution of phenylalanine to tyrosine metabolism in vivo. Studies in the post-absorptive and phenylalanine-loaded rat. Biochem J 1983;210:811-7.

17. Dejong CHC, Kampman MT, Deutz NEP, Soeters PB. Altered glutamine metabolism in rat portal drained viscera and hindquarter during hyperammonemia. Gastroenterology 1992; 102:936-948.

18. Fong Y, Matthews DE, He W, Marano MA, Moldawer LL, Lowry SF. Whole body and splanchnic leucine, phenylalanine, and glucose kinetics during endotoxemia in humans. Am J Physiol 1994;266:R419-25.

19. Fink MP, Heard SO. Laboratory models of sepsis and septic shock. J.Surg.Res. 1990;49:186196.

20. Higashiguchi $T$, Noguchi $Y, O^{\prime} B$ rien W, Wagner $K$, Fischer JE, Hasselgren PO. Effect of sepsis on mucosal protein synthesis in different parts of the gastrointestinal tract in rats. Clin.Sci. 1994;87:207-211.

21. Breuille D, Arnal M, Rambourdin F, Bayle G, Levieux D, Obled C. Sustained modifications of protein metabolism in various tissues in a rat model of long-lasting sepsis. Clin Sci (Colch) 1998;94(4):413-23.

22. Reeds PJ, Davis TA. Of flux and flooding: the advantages and problems of different isotopic methods for quantifying protein turnover in vivo: I. Methods based on the dilution of a tracer. Curr Opin Clin Nutr Metab Care 1999;2(1):23-8.

23. Wang $Q$, Fischer JE, Hasselgren PO. Treatment of endotoxemic mice with anti-interleukin-6 antibody paradoxically increases interleukin-6 levels and stimulates mucosal protein synthesis. Arch.Surg. 1997;132:82-88.

24. Wang Q, Wang JJ, Boyce S, Fischer JE, Hasselgren PO. Endotoxemia and IL-1 beta stimulate mucosal IL-6 production in different parts of the gastrointestinal tract. J Surg Res 1998;76(1):27-31.

25. Noguchi Y, Meyer T, Tiao G, Fischer JE, Hasselgren PO. Sepsis increases putrescine concentration and protein synthesis in mucosa of small intestine in rats. Shock 1996;5(5):333340.

26. Bardocz S, Grant G, Brown DS, Pusztai A. Putrescine as a source of instant energy in the small intestine of the rat. Gut 1998;42:24-28.

27. Nichols $K$, Staines $W$, Krantis A. Nitric oxide synthase distribution in the rat intestine: a histochemical analysis. Gastroenterology 1993;105(6):1651-61.

28. Geller DA, Nussler AK, Di Silvo M, Lowenstein CJ, Shapiro RA, Wang SC, et al. Cytokines, endotoxin, and glucocorticoids regulate the expression of inducible nitric oxide synthase in hepatocytes. Proc. Nati.Acad.Sci.USA 1993;90:522-526. 
29. Laskin DL, Rodriguez Del Valle M, Heck DE, Hwang S-H, Ohnishi ST, Durham SK, et al. Hepatic nitric oxide production following acute endotoxaemia in rats is mediated by increased inducible nitric oxide gene expression. Hepatology 1995;22:223-234.

30. Lortie MJ, Ishizuka S, Schwartz D, Blantz RC. Bioactive products of arginine in sepsis: tissue and plasma composition after LPS and iNOS blockade. Am J Physiol 2000;278:C1191-C1199.

31. Gotoh T, Araki M, Mori M. Chromosomal localisation of the human arginase II gene and tissue distribution of its mRNA. Biochem Biophys Res Commun 1997;233:487-491.

32. O'Sullivan D, Brosnan JT, Brosnan ME. Catabolism of arginine and ornithine in the perfused rat liver: effect of dietary protein and of glucagon. Am J Physiol 2000;278:E516-E521.

33. O'Sullivan D, Brosnan JT, Brosnan ME. Hepatic zonation of the catabolism of arginine and orinthine in the perfused rat liver. Biochem J 1998;330:627-632.

34. Cheung C-W, Cohen NS, Raijman L. Channeling of urea cycle intermediates in situ in permeabilized hepatocytes. J Biol Chem 1989;264:4038-4044.

35. Tiao G, Noguchi Y, Lieberman MA, Fischer JE, Hasselgren PO. Sepsis stimulates polyamine biosynthesis in the liver and increases tissue levels of ornithine decarboxylase mRNA. Shock $1995 ; 4(6): 403-10$. 
Chapter 3 
3.3

Renal arginine and protein synthesis are increased during early endotoxemia in mice.

Marcella M. Hallemeesch, Peter B. Soeters, Nicolaas E.P. Deutz

Dept of Surgery, Maastricht University, Maastricht, The Netherlands 


\section{Abstract}

The kidney has an important function in arginine metabolism, because the kidney is the main endogenous source for de novo arginine production from circulating citrulline. In conditions as sepsis, NO production is increased, and is dependent on extracellular arginine availability. To elucidate the adaptive role of renal de novo arginine synthesis in a condition of increased NO production, we studied renal arginine metabolism in a mouse model of endotoxemia. Because arginine flux is largely dependent on protein flux, we also measured protein metabolism in these mice. Female mice were injected i.p. with LPS, control mice received $0.9 \% \mathrm{NaCl}$. Six hours later, renal blood flow was measured using para-aminohippuric acid. Arginine and protein metabolism were studied using organ balance stable isotope techniques. Systemic NO production was increased in the endotoxin-treated mice. In addition, renal protein synthesis and de novo arginine production from citrulline were increased. However, no effect was observed on renal nitric oxide production. In conclusion, increased renal de novo arginine production may serve to sustain systemic NO production. For the first time to our knowledge, it was shown that renal protein synthesis is enhanced in the early response to endotoxemia.

\section{Introduction}

The amino acid arginine has an important role in cellular regeneration, immune function, and protein breakdown and synthesis $(1,2)$. Arginine also is the precursor of urea, agmatine and nitric oxide. In the past years many studies have been undertaken that aimed at increasing or decreasing NO production, either by supplementation of arginine or NO donors (3-5), or by the administration of nitric oxide synthase (NOS) inhibitors or arginase (6-8). In general, the effects of these treatments were conflicting and confusing. More detailed information on local arginine metabolism and NO production may be helpful to understand the effects of arginine supplementation or NOS inhibition.

The kidney has an important function in arginine metabolism, because the kidney is the main endogenous source for de novo arginine production (9). Arginine production involves collaboration between the gut and the kidney. Citrulline is 
produced from glutamine and arginine in the gut, and released into the circulation. The liver does not consume citrulline, which leaves it available for the kidney. In the kidney citrulline is used for the production of arginine, which is in turn released into the circulation (9). The importance of this pathway is illustrated by the fact that arginine becomes an essential amino acid when intestinal citrulline synthesis is inhibited (10).

During sepsis and experimental endotoxemia, the expression of inducible nitric oxide synthase (iNOS) is increased in a variety of organs and cells (11). iNOS is dependent on the extracellular supply of arginine $(12,13)$, and reduced arginine availability may impair systemic nitric oxide production $(8,12)$. During conditions of increased arginine utilisation the kidney may increase endogenous arginine production to serve systemic nitric oxide production, however it is well known that less than $5 \%$ of arginine disposal is used for NO production.

To unravel the renal metabolic response during enhanced systemic NO production, we measured renal arginine turnover in a mouse model of endotoxemia, which mimics the septic condition (14). We chose experimental endotoxemia as a model to study renal arginine metabolism because increases in plasma nitrite and plasma nitrate data suggest that systemic nitric oxide production is increased in this condition (15). We also measured renal protein turnover, because arginine turnover is mainly dependent on protein turnover (16). Finally, we measured renal de novo arginine production, and related this to arginine and protein turnover.

\section{Methods}

\section{Animals}

Female Swiss mice (22-26 g) were obtained from IFFA Credo Broekman (Someren, The Netherlands). The mice were fed standard lab chow and were subject to standard 12 hour light-dark cycle periods (7:30 A.M. to 7:30 P.M.). Room temperature was maintained at $25^{\circ} \mathrm{C}$. Experiments were performed in accordance with the recommendations of the Guide for the Care and Use of Laboratory Animals (17), and approved by the Ethical Committee of Animal Research of Maastricht University. 


\section{Experimental protocol}

LPS (E coli O55:B5, Sigma, St. Louis, MO, $10 \mathrm{mg} / \mathrm{kg}$ body wt.) was given by i.p. injection to mice $(n=10)(15)$. Control animals $(n=10)$ received a corresponding volume of $150 \mathrm{mM} \mathrm{NaCl}$ (saline). Drinking water was provided but food was withheld after the injection of endotoxin or saline to avoid influences of differences of food intake.

Five hours after LPS treatment, anesthesia was induced in the mice by an intraperitoneal injection followed by a subcutaneous infusion of ketamine and medetomidine (18). Mice were sufficiently anesthetized to start surgical procedures after 10 minutes. Catheterization of the jugular vein, abdominal aorta, carotid artery, renal vein, caval vein was performed as described recently, and took approximately 20 minutes (18). During the surgical procedures the mice were kept at $37^{\circ} \mathrm{C}$ using a temperature controller (Technical Service, Maastricht University) and heat pads (18). A primed-constant infusion of $\mathrm{L}$-[guanidino- ${ }^{15} \mathrm{~N}_{2}$ ] arginine, L-[ureido- ${ }^{13} \mathrm{C}-{ }^{2} \mathrm{H}_{2}$ ]citrulline, $L$-[ring- ${ }^{2} \mathrm{H}_{5}$ ]phenylalanine, and $L$-[ring- ${ }^{2} \mathrm{H}_{2}$ ]tyrosine (Mass Trace, Woburn, MA) was given in the jugular vein (per mouse: prime $\left[{ }^{15} \mathrm{~N}_{2}\right]$ arginine: $850 \mathrm{nmol},\left[{ }^{13} \mathrm{C}\right.$ ${ }^{2} \mathrm{H}_{2}$ ]citrulline: $215 \mathrm{nmol},{ }^{2} \mathrm{H}_{5}$-phenylalanine: $340 \mathrm{nmol},{ }^{2} \mathrm{H}_{2}$-tyrosine: $215 \mathrm{nmol}$, infusion $\left[{ }^{15} \mathrm{~N}_{2}\right]$ arginine: $1700 \mathrm{nmol} / \mathrm{hr},\left[{ }^{13} \mathrm{C}^{2} \mathrm{H}_{2}\right]$ citrulline: $430 \mathrm{nmol} / \mathrm{hr}$, $\left[{ }^{2} \mathrm{H}_{5}\right]$ phenylalanine: $680 \mathrm{nmol} / \mathrm{hr},\left[{ }^{2} \mathrm{H}_{2}\right]$ tyrosine $430 \mathrm{nmol} / \mathrm{hr}$ ). Steady state of tracers and metabolites was reached within 20 minutes (not shown).

For flow measurements, the indicator dilution method with [glycyl- $\left.1-{ }^{14} \mathrm{C}\right]-\mathrm{p}-$ aminohippuric acid $\left({ }^{14} \mathrm{C}-\mathrm{PAH}, \mathrm{NEN}\right.$ Life Science Products, Boston, MA) was used. Briefly, a primed $\left(20 \mu \mathrm{l} / 10 \mathrm{~g}\right.$ body wt of $\left.3 \mu \mathrm{Ci} / \mathrm{ml}{ }^{14} \mathrm{C}-\mathrm{PAH}\right)$ continuous $(1 \mathrm{ml} / 10 \mathrm{~g}$ bw/h $3 \mu \mathrm{Ci} / \mathrm{ml}{ }^{14} \mathrm{C}$-PAH) infusion was given in the abdominal aorta. When steady state had been reached, blood $(0.2 \mathrm{ml}$ per catheter) was sampled from the carotid artery and the renal vein, and collected in heparinized cups (Sarstedt, Nümbrecht, Germany) on ice. Blood collection was 6 h after LPS treatment. The right kidney was freeze-clamped in liquid nitrogen and stored at $-80^{\circ} \mathrm{C}$. In the present model, renal metabolism and hindquarter metabolism are measured in one animal (18). Data on hindquarter metabolism will be reported elsewhere.

In whole blood, hematocrit and ${ }^{14} \mathrm{C}-\mathrm{PAH}$ were determined as described (18). Blood was centrifuged to obtain plasma, because we have shown recently that plasma sampling is required in organ balance metabolic studies using amino acid tracers that do not equilibrate well in blood cells (19). For determination of amino acid 
concentrations and TTRs $80 \mu \mathrm{l}$ plasma was added to $7 \mathrm{mg}$ dry sulfosalicylic acid, vortexed, frozen in liquid nitrogen and stored at $-80^{\circ} \mathrm{C}$. For determination of plasma urea and ammonia concentrations, $20 \mu$ plasma was added to $80 \mu \mathrm{l} 1 \%$ trichloroacetic acid. Plasma urea and ammonia were determined on a Cobas Mira S (Roche Diagnostica, Hoffman La Roche, Basel, Switzerland) by standard enzymatic methods, using commercially available kits as described previously (20). For determination of tissue amino acid concentrations, tissue was homogenized and deproteinized as described before (21). Approximately $80 \mathrm{mg}$ tissue was added to $400 \mu \mathrm{l} \mathrm{SSA} \mathrm{5 \% ,} \mathrm{with} 300 \mathrm{mg}$ glass beads and beaten for 30 seconds (21). Plasma and tissue amino acid concentrations and enrichments were measured using a fully automated LC-MS system, using pre-column derivatization with OPA (22). Plasma $\mathrm{NO}_{2}{ }^{-}$and $\mathrm{NO}_{3}{ }^{-}$were measured in deproteinized plasma $(40 \mu$ l plasma $+80 \mu \mathrm{l}$ acetonitrile (Biosolve LTD, Valkenswaard, The Netherlands) on an isocratic HPLC system (eluens: $6 \mathrm{mM}$ sodium chloride, $1 \mathrm{mM}$ potassium dihydrogenphosphate, $\mathrm{pH}=6)$.

For western-blot determination of iNOS protein in renal tissue, approximately $100 \mathrm{mg}$ tissue was homogenized in homogenization buffer $(1 / 10 \mathrm{w} / \mathrm{v}, 20 \mathrm{mM}$ TRIS$\mathrm{HCl}, 1 \mathrm{mM}$ EDTA, $0.25 \mathrm{M}$ sucrose, $\mathrm{pH} 7.4$, supplemented with protease inhibitor cocktail (Complete $^{\text {TM }}$ Mini EDTA-free, Boehringer Mannheim GmbH, Germany)). Five $\mu \mathrm{g}$ of protein (Bio-rad protein assay, Bio-rad Laboratories $\mathrm{GmbH}$, Munich, Germany) was separated on 5-to-15\% pseudogradient SDS polyacrylamide gels and blotted onto polyvinylidene difluoride membranes (Millipore Coorporation, Bedford, MA). Mouse macrophage lysate (Transduction Laboratories, Lexington, $\mathrm{KY}$ ) was used as positive control. Membranes were blocked in 5\% non-fat milk in PBS and subsequently incubated with primary antibody (anti-iNOS antibody, 1:10000, Transduction Laboratories). Goat anti-mouse IgG conjugated to HRPO (1:2000) was used as secondary antibody.

\section{Calculations}

\section{Whole body arginine and protein metabolism}

Plasma arginine, citrulline, phenylalanine and tyrosine fluxes were calculated from the arterial isotope enrichment values of respectively $L-\left[{ }^{15} N_{2}\right]$ arginine, $L-\left[{ }^{13} C\right.$; ${ }^{2} \mathrm{H}_{2}$ ]citrulline, ${ }^{2} \mathrm{H}_{5}$-phenylalanine and ${ }^{2} \mathrm{H}_{2}$-tyrosine, using steady state isotope dilution equation: 
$Q=I / T T R(23)$,

where TTR is the tracer-tracee ratio, and $\mathrm{l}$ is the rate of infusion of the tracer.

The rate of NO production was measured using $\left[{ }^{15} \mathrm{~N}_{2}\right]$ arginine to $\left[{ }^{15} \mathrm{~N}\right]$ citrulline conversion. This method has been described by a number of groups before $(24,25)$, and is based on the fact that $\left[{ }^{15} \mathrm{~N}\right]$ citrulline can only be produced from $\left[{ }^{15} \mathrm{~N}_{2}\right]$ arginine by nitric oxide synthase. Calculation of the plasma arginine to citrulline flux (NO production) was made essentially according to the tracer model of Castillo et al. (24): $Q_{\mathrm{Arg}_{\rightarrow} \mathrm{Cit}}=Q_{\mathrm{Cit}} \times \operatorname{TTR}_{\mathrm{Cit}(\mathrm{M}+1)} / \operatorname{TTR}_{\mathrm{Arg}(\mathrm{M}+2) \text {. }}$ where $Q_{C i t}$ is the plasma citrulline flux (nmol/10 $\mathrm{g} / \mathrm{min}$ ), estimated from the primed constant infusions of the $L-\left[{ }^{13} \mathrm{C} ; \mathrm{H}_{2}\right]$ citrulline tracer and $T T R_{\mathrm{Cit}}$ and $T T R_{\mathrm{Arg}}$ are the respective TTRs of $\left[{ }^{15} \mathrm{~N}\right]$ citrulline and $\left[{ }^{15} \mathrm{~N}_{2}\right]$ arginine. Using this method we recently identified the NOS isoform involved in NO production under baseline and endotoxemic conditions in mice by applying it to $\mathrm{eNOS}^{-1 /}$ and $\mathrm{iNOS}^{-1 .}$ mice (26).

Calculation of the plasma citrulline to arginine flux (de novo arginine production) was made in a similar fashion (27):

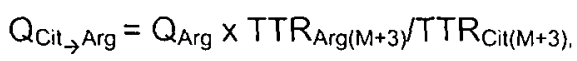
where $Q_{A r g}$ is the plasma arginine flux ( $\mathrm{nmol} / 10 \mathrm{~g} / \mathrm{min}$ ), estimated from the primed constant infusions of the L- $\left[{ }^{15} \mathrm{~N}_{2}\right]$ arginine tracer and TTR Arg and TTR $\mathrm{Cit}$ are the respective TTRs of $L-\left[{ }^{13} \mathrm{C} ;{ }^{2} \mathrm{H}_{2}\right]$ arginine and $L-\left[{ }^{13} \mathrm{C} ;{ }^{2} \mathrm{H}_{2}\right]$ citrulline.

Calculation of the plasma phenylalanine to tyrosine flux (phenylalanine hydroxylation) was made as described (28):

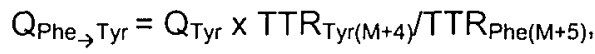
where $Q_{\text {Tyr }}$ is the plasma tyrosine flux (nmol/10 $\mathrm{g} / \mathrm{min}$ ), estimated from the primed constant infusions of the $\left[{ }^{2} \mathrm{H}_{2}\right]$ tyrosine tracer and TTR $\operatorname{Try}_{\mathrm{T}(\mathrm{M}+4)}$ and TTR $\mathrm{The}_{\mathrm{M}+5)}$ are the respective arterial TTRs of $\left[{ }^{2} \mathrm{H}_{4}\right]$ tyrosine and $\left[{ }^{2} \mathrm{H}_{5}\right]$ phenylalanine.

\section{Renal plasma flow and net substrate fluxes}

The calculation of plasma flow across the kidney has been described recently (18).

Organ substrate fluxes are calculated by multiplying the renal venous-arterial concentration difference with the mean plasma flow and are expressed in nmol/10 $\mathrm{g}$ body wt per minute. A positive flux indicates net release and a negative flux reflects net uptake. 


\section{Organ balance tracer methodology}

The amino acid stable isotope tracers are used to obtain additional information regarding the net fluxes. Using these tracers organ disposal and production rates can be calculated. However, the mathematical formulae that are used to calculate disposal and production rates can only be applied if a few criteria are met. The most important criterium is that sampling should occur from a pool in which the tracer mixes freely (23). We have recently shown that arginine tracers do not mix with blood cell cytoplasm, and that erroneous results are obtained when organ disposal and production rates are calculated using whole blood in this condition (19). Although it is known that red blood cells do play a role in renal metabolism $(19,29)$, the use of stable isotopes requires plasma sampling (19).

\section{Renal protein metabolism}

The phenylalanine tracer was used to measure whole body (see above) and renal protein turnover. Previously, we have shown that phenylalanine, valine and leucine yield similar results with regard to renal protein synthesis as percentage of whole body protein synthesis (19). If phenylalanine and tyrosine tracers are used to estimate protein synthesis and breakdown additional information is received on renal phenylalanine to tyrosine hydroxylation, an important aspect of renal metabolism (30).

The rates of phenylalanine and tyrosine metabolism in the kidney were evaluated using, in principle, the models described previously for quantifying leucine metabolism in the splanchnic region (31). Calculation of renal hydroxylation of phenylalanine to form tyrosine (Phe $\rightarrow$ Tyr) can be estimated from the venous appearance of $\mathrm{M}+4$ labeled tyrosine by the following equation, which has in principle already been used to calculate splanchnic leucine to KIC deamination (31):

Phe $\rightarrow$ Tyr $=$

$P F \times[A]_{\text {Phe }} \times\left\{\left([V]_{T y r} \times \operatorname{TTR}_{V T y r(M+4)}-[A]_{T y r} \times \operatorname{TTR}_{\text {ATyr }(M+4)}\right) /[A]_{\text {Phe }} \times T T R_{A P h e(M+5)}\right\}$, where $P F$ is renal plasma flow, and $[\mathrm{V}]$ and $[\mathrm{A}]$ are the venous and arterial plasma concentrations of substrates, and TTR $\mathrm{R}_{\mathrm{A}}$ and TTR $\mathrm{T}$ are the plasma tracer-tracee ratios. 


\section{Renal arginine metabolism}

Renal arginine turnover was calculated in principle as described in detail by Yu et al. (32), with the adaptation that renal $\left[{ }^{15} \mathrm{~N}_{2}\right]$ arginine tracer net balance, was corrected for $\left[{ }^{2} \mathrm{H}_{2}\right]$ arginine production in the kidney. The rationale for this correction is that the $\left[{ }^{13} \mathrm{C}^{2} \mathrm{H}_{2}\right]$ citrulline tracer leads to the formation of $\left[{ }^{13} \mathrm{C}^{2} \mathrm{H}_{2}\right]$ arginine (see below). $\left[{ }^{13} \mathrm{C}^{2} \mathrm{H}_{2}\right]$ arginine in turn may be catabolized by arginase leading to $\left[{ }^{2} \mathrm{H}_{2}\right]$ ornithine, which will give rise to $\left[{ }^{2} \mathrm{H}_{2}\right]$ citrulline and $\left[{ }^{2} \mathrm{H}_{2}\right]$ arginine. Circulation of $\mathrm{M}+2$ tracers does not disturb the measurements, except in kidney where $\left[^{2} \mathrm{H}_{2}\right]$ citrulline is used for the production of $\left[{ }^{2} \mathrm{H}_{2}\right]$ arginine. Correction of $\left[{ }^{15} \mathrm{~N}_{2}\right]$ arginine tracer net balance for $\left[{ }^{2} \mathrm{H}_{2}\right]$ arginine production is performed in the following way:

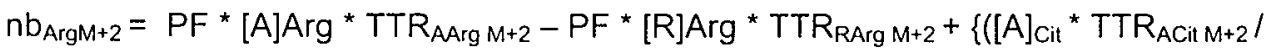
$\left.\left.[A]_{\text {Cit }}{ }^{*} \operatorname{TTR}_{\mathrm{ACit} \mathrm{M}+3}\right)^{*}[\mathrm{R}]_{\mathrm{Arg}}{ }^{*} \operatorname{TTR}_{\mathrm{RArg} \mathrm{M}+3}\right\}$

where $P F$ is renal plasma flow, and $[R]$ and $[A]$ are the venous and arterial plasma concentrations of substrates, and $\operatorname{TTR}_{\mathrm{A}}$ and $T T R_{\mathrm{V}}$ are the plasma tracer-tracee ratios. This correction is based on the assumption that the rate of $\left[{ }^{2} \mathrm{H}_{2}\right]$ citrulline to $\left[{ }^{2} \mathrm{H}_{2}\right]$ arginine labeling is equal to the rate of $\left[{ }^{13} \mathrm{C}^{2} \mathrm{H}_{2}\right]$ citrulline to $\left[{ }^{13} \mathrm{C}^{2} \mathrm{H}_{2}\right]$ arginine labeling.

Renal citrulline turnover was calculated using the $\left[{ }^{13} \mathrm{C}^{2} \mathrm{H}_{2}\right]$ citrulline tracer. The renal rate of conversion of $\left[{ }^{15} \mathrm{~N}_{2}\right]$ arginine to $\left[{ }^{15} \mathrm{~N}\right]$ citrulline was calculated essentially according to the tracer model of Fong et al, as described above (31). Calculation of renal de novo arginine synthesis was calculated from $\left[{ }^{13} \mathrm{C}^{2} \mathrm{H}_{2}\right]$ citrulline to $\left[{ }^{13} \mathrm{C}^{2} \mathrm{H}_{2}\right]$ arginine labeling as described in detail by $\mathrm{Yu}$ et al. (32).

\section{Statistical Analysis}

Results are presented as means \pm SEM. Significance between the groups was tested by the Mann Whitney $U$ test. Net substrate fluxes across the kidney were tested against zero using the Wilcoxon test, to test if a significant amount of substrate was produced or consumed by the kidney. Significance was considered present at $p<$ 0.05 . 


\section{Results}

The arterial concentrations of nitrate, urea, ammonia, and many amino acids, including glutamine, citrulline, ornithine, tyrosine and phenylalanine, were increased after LPS treatment (Table 1). The arterial concentration of arginine, however, was not changed in LPS-treated mice.

Table 1. Arterial substrate concentrations.

Values are mean \pm SEM in $\mu M$. * $p<0.05$, "p<0.01 vs. Control.

\begin{tabular}{lrrl}
\hline & \multicolumn{2}{c}{ Control } & \multicolumn{2}{c}{ LPS } \\
\hline $\mathrm{NO}_{3}{ }^{*}$ & $10 \pm 1$ & $63 \pm 5^{\#}$ \\
Urea & $6282 \pm 292$ & $9647 \pm 898^{*}$ \\
Ammonia & $131 \pm 25$ & $193 \pm 12^{\#}$ \\
GLN & $401 \pm 20$ & $482 \pm 30^{*}$ \\
GLY & $212 \pm 41$ & $160 \pm 34$ \\
THR & $129 \pm 7$ & $127 \pm 7$ \\
HIS & $73 \pm 4$ & $118 \pm 6^{*}$ \\
CIT & $68 \pm 4$ & $86 \pm 6^{*}$ \\
ALA & $324 \pm 61$ & $378 \pm 54$ \\
TAU & $111 \pm 10$ & $169 \pm 30$ \\
ARG & $138 \pm 10$ & $150 \pm 8$ \\
TYR & $90 \pm 7$ & $135 \pm 10^{*}$ \\
VAL & $238 \pm 9$ & $256 \pm 11$ \\
MET & $40 \pm 3$ & $28 \pm 4^{*}$ \\
ILE & $105 \pm 5$ & $101 \pm 6$ \\
PHE & $83 \pm 6$ & $133 \pm 7^{*}$ \\
TRP & $57 \pm 3$ & $74 \pm 5^{*}$ \\
LEU & $178 \pm 7$ & $187 \pm 8$ \\
ORN & $83 \pm 7$ & $134 \pm 10^{*}$ \\
LYS & $331 \pm 30$ & $458 \pm 34$ \\
BCAA & $521 \pm 21$ & $545 \pm 24$ \\
SUMAA & $3093 \pm 178$ & $3636 \pm 209^{*}$ \\
\hline & & \pm & \pm
\end{tabular}

Table 2. Whole body protein and arginine turnover. Values are mean \pm SEM. Values are plasma fluxes (nmol/10g body wt. per minute). ${ }^{*} p<0.05, " p<0.01$ vs. Control.

\begin{tabular}{lrrr}
\hline & \multicolumn{2}{c}{ Control } & \multicolumn{2}{c}{ LPS } \\
\hline PHE & $65 \pm 4$ & $76 \pm 4^{*}$ \\
TYR & $61 \pm 3$ & $69 \pm 3^{*}$ \\
PHE $\rightarrow$ TYR & $8.8 \pm 0.7$ & $13.5 \pm 0.8^{*}$ \\
ARG & $77 \pm 3$ & $80 \pm 2$ \\
CIT & $25 \pm 2$ & $27 \pm 3$ \\
ARG $\rightarrow$ CIT & $2.0 \pm 0.5$ & $4.9 \pm 0.6^{*}$ \\
CIT $\rightarrow$ ARG & $14 \pm 1$ & $12 \pm 1$ \\
\hline
\end{tabular}

Table 3. Renal amino acid concentrations.

Values are mean \pm SEM in $\mu \mathrm{mol} / \mathrm{kg}$ wet weight. " $p<0.05,{ }^{*} p<0.01$ vs. Control.

\begin{tabular}{lrlrl}
\hline & \multicolumn{2}{c}{ Control } & \multicolumn{2}{c}{ LPS } \\
\hline ARG & 147 & \pm 34 & 125 & \pm 35 \\
GLN & 924 & \pm 64 & $971 \pm 87$ \\
CIT & 97 & \pm 6 & $70 \pm 8^{*}$ \\
ORN & $208 \pm 46$ & $249 \pm 36$ \\
PHE & $169 \pm 15$ & $205 \pm 23$ \\
TYR & $212 \pm 18$ & $234 \pm 25$ \\
BCAA & $872 \pm 70$ & $870 \pm 113$ \\
SUMAA & $35428 \pm 4371$ & $26852 \pm 4437$ \\
\hline
\end{tabular}


$130 \mathrm{kDa}$

lane 1 lane 2 lane 3 lane 4 lane 5 lane 6

Figure 1. Western blot analysis of iNOS protein in mouse kidney. Lane 1: positive control; lanes 2,

3, 6: LPS-treated animals; lanes 4,5: Control animals.

LPS treatment resulted in an increase in whole body protein turnover, as shown by the increase in plasma phenylalanine and tyrosine flux (Table 2). Moreover, phenylalanine-to-tyrosine labeling, indicating net protein breakdown, was increased. Plasma arginine and citrulline flux were not significantly changed by LPS treatment. In addition, whole body de novo arginine synthesis (CIT $\rightarrow$ ARG) was not significantly changed. Whole body nitric oxide production ( $A R G \rightarrow C I T)$ was increased after endotoxin challenge.

Under baseline conditions, no iNOS protein could be detected in renal tissue. In addition, stimulation with LPS did not induce iNOS protein in the kidney (Figure 1). Most renal intracellular amino acid concentrations, including arginine, and ornithine, were not significantly changed by LPS treatment (Table 3 ). Renal citrulline was however increased in LPS-treated animals (Table 3). Renal plasma flow was not significantly increased after LPS-treatment (Table 4). Moreover, LPS treatment caused an increase in net renal citrulline uptake and an increase in net arginine release. Besides an increase in citrulline uptake also an increase in uptake of glutamine, phenylalanine and tyrosine was present in the kidney after LPS treatment.

\section{Renal protein metabolism}

In control mice renal phenylalanine disposal was $7 \mathrm{nmol} / 10 \mathrm{~g}$ body wt per minute (Figure 2). Phenylalanine disposal consists of protein synthesis and phenylalanine hydroxylation to tyrosine. In the control condition, phenylalanine hydroxylation to tyrosine, irreversible protein breakdown, contributes approximately $50 \%$ to phenylalanine disposal, i.e. net protein synthesis equals $7-3=4 \mathrm{nmol} / 10 \mathrm{~g}$ body wt per minute. Renal tyrosine disposal is a direct indicator of protein synthesis (Figure 3 ), and is similar to the protein synthesis part of phenylalanine disposal. 
Table 4. Renal fluxes. Values are mean \pm SEM in nmol/10 $\mathrm{g}$ body wt per minute, except plasma flow in $\mathrm{ml} / 10 \mathrm{~g}$ body weight per minute. A negative value indicates net uptake, and a positive value indicates net production. ${ }^{*} p<0.05$ vs. Control. " $p<0.05$ vs. 0 , i.e. no net uptake or production.

\begin{tabular}{|c|c|c|c|c|c|c|}
\hline & & C & & & L & \\
\hline Plasma flow & 0.72 & \pm & 0.04 & 0.94 & \pm & 0.12 \\
\hline Urea & -121 & \pm & 229 & -586 & \pm & $223^{\#}$ \\
\hline Ammonia & 76 & \pm & 38 & 9 & \pm & 26 \\
\hline GLN & -47 & \pm & $10^{\#}$ & -89 & \pm & $17^{\star \#}$ \\
\hline GLY & -16 & \pm & 12 & 14 & \pm & 13 \\
\hline THR & 4 & \pm & 3 & -4 & \pm & 6 \\
\hline HIS & 2 & \pm & 2 & -5 & \pm & 5 \\
\hline $\mathrm{CIT}$ & -16 & \pm & $3^{*}$ & -27 & \pm & $4^{* \#}$ \\
\hline$A L A$ & 15 & \pm & 8 & 6 & \pm & 15 \\
\hline TAU & 2 & \pm & 4 & -6 & \pm & 7 \\
\hline ARG & 19 & \pm & $3^{*}$ & 28 & \pm & $4^{* \#}$ \\
\hline TYR & 4 & \pm & 3 & -13 & \pm & $8^{*}$ \\
\hline VAL & 8 & \pm & 6 & -12 & \pm & 11 \\
\hline MET & 1 & \pm & 2 & -5 & \pm & 4 \\
\hline ILE & 5 & \pm & 3 & -7 & \pm & 7 \\
\hline PHE & -3 & \pm & 2 & -17 & \pm & $6^{* *}$ \\
\hline TRP & 4 & \pm & $2^{\#}$ & -4 & \pm & 6 \\
\hline LEU & 9 & \pm & 6 & -11 & \pm & 9 \\
\hline ORN & 0 & \pm & 4 & -10 & \pm & 8 \\
\hline LYS & 16 & \pm & 10 & -14 & \pm & 25 \\
\hline BCAA & 22 & \pm & 15 & -30 & \pm & 26 \\
\hline SUMAA & 40 & \pm & 63 & -158 & \pm & 107 \\
\hline
\end{tabular}

After LPS treatment, renal phenylalanine disposal is increased due to an increase in true protein synthesis and unchanged phenylalanine to tyrosine hydroxylation (17 - 4=13 nmol/10 g body wt per minute) (Figure 2). The increase in protein synthesis in endotoxin-treated mice was also detected when tyrosine tracer was used (Figure 3). A three to fourfold increase in protein synthesis was measured using the phenylalanine and tyrosine tracers respectively. These observations are in agreement with the increase in total amino acid uptake by the kidney. Because protein breakdown, measured as phenylalanine and tyrosine production, is not changed after endotoxin treatment (Figures 2 and 3 ), net protein synthesis is increased in mouse kidney after endotoxin challenge. 

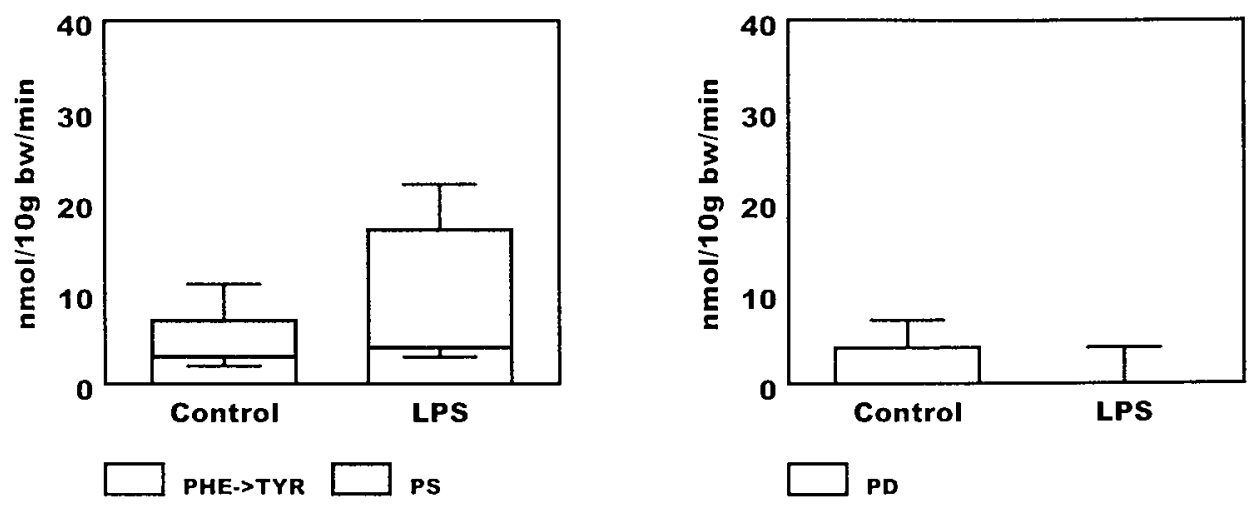

Figure 2. Renal protein synthesis and degradation in control and endotoxin-treated mice measured using $\left[{ }^{2} \mathrm{H}_{5}\right]$ phenylalanine. Left panel: renal phenylalanine disposal. Total phenylalanine disposal is divided in phenylalanine hydroxylation to tyrosine ( $P H E \rightarrow T Y R$ ) and true protein synthesis (PS). Right panel: renal phenylalanine production. Because phenylalanine is not obtained from other sources than protein, phenylalanine production is a direct indicator of protein degradation (PD).
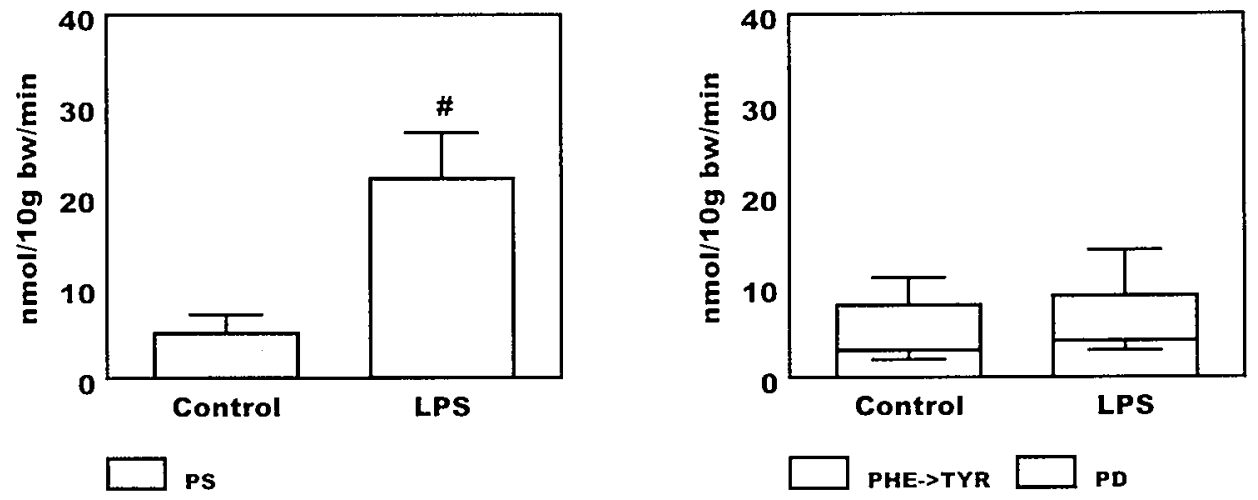

Figure 3. Renal protein synthesis and degradation in control and endotoxin-treated mice measured using $\left[{ }^{2} \mathrm{H}_{2}\right]$ tyrosine. Left panel: renal tyrosine disposal. Because tyrosine is only used in protein synthesis, tyrosine disposal is a direct indicator of protein synthesis (PS). Right panel: Total tyrosine production is divided in phenylalanine hydroxylation to tyrosine (PHE $\rightarrow$ TYR) and true protein breakdown (PD). 

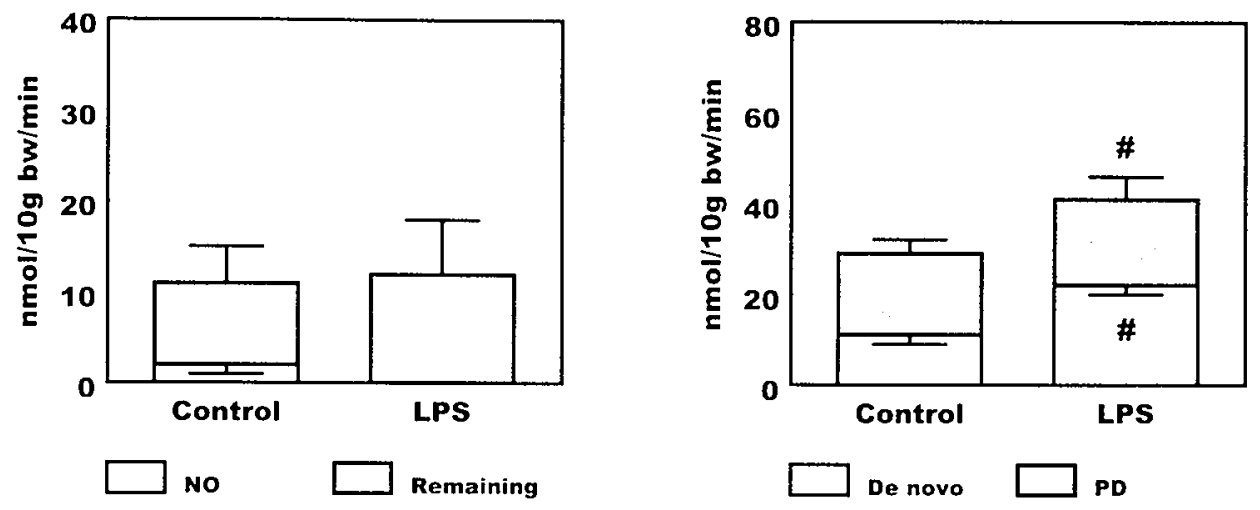

Figure 4. Renal arginine metabolism in control and endotoxin-treated mice measured using $\left[{ }^{15} \mathrm{~N}_{2}\right]$ arginine. Left panel: renal arginine disposal. Renal arginine disposal is divided in NO production and remaining pathways of arginine disposal. Remaining arginine disposal consists of protein synthesis, arginase activity, arginine decarboxylase activity, and possibly other pathways. Right panel: Total arginine production is divided in de novo arginine production and arginine production from other sources than de novo production.

\section{Renal arginine metabolism}

In control mice, renal arginine disposal was $11 \mathrm{nmol} / 10 \mathrm{~g}$ body wt per minute (Figure 4 ), and was comparable to renal phenylalanine disposal. Arginine disposal may consist of arginine incorporated in protein and arginine degradation by arginase and NOS. After LPS treatment, arginine disposal was not significantly changed. Arginineto-citrulline labeling (NO production) was detectable, but very small in the control condition. After LPS treatment, no increase in renal NO production could be detected. Theoretically, arginine production in the kidney can be obtained from protein breakdown, and de novo arginine production from citrulline. In control mice, de novo arginine production ( $11 \mathrm{nmol} / 10 \mathrm{~g}$ body wt per minute) contributes $38 \%$ to total arginine production ( $29 \mathrm{nmol} / 10 \mathrm{~g}$ body wt per minute) in the kidney (Figure 4 ). It is noteworthy that de novo arginine production is similar to citrulline disposal ( $16 \pm 3$ $\mathrm{nmol} / 10 \mathrm{~g}$ body wt per minute) in the kidney.

After endotoxin challenge, renal arginine production was increased. Also, de novo arginine production and citrulline disposal $(27 \pm 4 \mathrm{nmol} / 10 \mathrm{~g}$ body wt per 
minute) were increased in endotoxin-treated mice. Thus, the LPS-induced increase in net arginine release from the kidney results from an increase in de novo arginine production from citrulline, not from an increase in renal protein degradation.

\section{Discussion}

The results of the present study indicate that renal arginine and protein metabolism change in the early response to sepsis. For the first time, we report that endotoxin challenge induces a combined increase in renal protein synthesis and renal de novo arginine synthesis. The increases in renal protein synthesis and renal de novo arginine production were independent of renal NO production.

In the present experiment renal arginine metabolism was measured in a shortterm mouse model of endotoxemia. Although it is also interesting to obtain further information on LPS-induced changes in renal metabolism in time, in our opinion this should be performed in an animal model that allows repeated blood sampling (33). The mouse model is well established, because of its iNOS-induced increase in NO production (15), and because it mimics the septic condition (14). Usually increased NO production is assessed from changes in plasma nitrate or the sum of nitrite and nitrate. We indeed detected an increase in plasma nitrate. In addition, we measured an increase in systemic NO production using the stable isotope technique. The increase in plasma nitrate was six-fold, whereas the increase in stable isotope measured NO production was approximately two fold. Many studies have used urinary nitrate excretion as a parameter of systemic NO production. It has been shown that under baseline conditions, urinary nitrate excretion is linearly related to the nitrate plasma concentration (34), and that the urinary nitrate excretion rate is highly correlated to systemic NO production measured using stable isotopes (24). However, the discrepancy between the increase in plasma nitrate and systemic NO production indicates that this is probably not true in disease states like experimental endotoxemia. In our opinion in the diseased state, quantification of systemic NO production is only possible using stable isotope technology.

Septic patients are characterized by a catabolic state. In our endotoxemic mice net protein breakdown, measured as whole body PHE $\rightarrow$ TYR, was increased. In this model of endotoxemia, phenylalanine hydroxylation to tyrosine was increased 
in LPS-treated mice from $8.2 \mathrm{nmol} / 10 \mathrm{~g}$ body weight to $12.6 \mathrm{nmol} / 10 \mathrm{~g}$ body weight, indicating an increase in net protein breakdown in this condition.

Despite the increase in net whole body protein loss, renal protein synthesis was markedly increased after LPS-treatment. In a previous study in which renal amino acid metabolism was studied after $16 \mathrm{~h}$ in rats, renal uptake of total amino acids was decreased, which may indicate that renal protein synthesis is decreased at this time (35). It appears that the increase in renal protein synthesis is specific for the time-point studied. Which if any specific proteins are made at this time is unknown. The intestines also produce proteins in response to LPS injection (see review (36)). With respect to general protein metabolism it seems that kidney and intestine respond similarly to early endotoxemia. The differences between the present $6 \mathrm{~h}$ study and the previous $16 \mathrm{~h}$ study may well be caused by the difference in timing, and we therefore introduced the terms late endotoxemia for the previous study and early endotoxemia for the present study.

Although renal protein synthesis was increased by LPS treatment, renal arginine disposal was unchanged. This apparent discrepancy can be explained by the fact that arginine has several other metabolic fates besides protein synthesis. The kidney for instance also contains arginase $\|$ (37), arginine:glycine amidinotransferase (38), and arginine decarboxylase (39). It is possible that protein synthesis is increased and (some of) the other pathways of arginine disposal are reduced in response to endotoxin-treatment.

Previous studies have suggested that systemic NO production is dependent on extracellular arginine supply $(12,13)$, and that reduced arginine availability may impair systemic $\mathrm{NO}^{\circ}$ production $(8,12)$. It therefore appears important to regulate arginine availability. The adaptive role of the kidney in increasing de novo arginine production was questioned (27). However, in agreement with the LPS-induced increase in renal argininosuccinate lyase mRNA (40), renal citrulline uptake and arginine release were increased, and the stable isotope measurements confirmed that indeed de novo arginine production from citrulline was increased. Possibly, renal arginine production was up-regulated to sustain systemic NO production during endotoxemia. In the present study renal protein synthesis was increased, since phenylalanine disposal and the net uptake of total amino acids were increased. In a previous rat study where measurements were performed $16 \mathrm{~h}$ after the onset of endotoxemia, renal arginine release was increased, but renal citrulline uptake was 
not (35). These results indicate that the increase in arginine production by the kidney did not originate from citrulline. Possibly, in this study of late endotoxemia, the increase in arginine release was caused by an increase in renal protein breakdown, since the net uptake in total amino acids by the kidney was decreased in these animals (35). The fact that glutamine uptake was decreased in the rat study without any effect on ammonia, may also indicate that there was no need for glutamine uptake because glutamine was probably released from protein.

Although systemic NO production was increased during endotoxemia, we were not able to detect renal NO production in LPS-treated mice. In agreement with this result, we, and others (41), were unable to detect iNOS protein in kidney of endotoxin-treated mice. The amount of iNOS RNA and protein induced by activation is highly differential. The animal species and strain, the host organism of LPS, the serotype and dose of LPS, the lagtime after LPS administration, and the coadministration of pro-inflammatory cytokines all influence the expression level of iNOS. The results of the study may have been different had iNOS been induced. In control mice, renal phenylalanine production contributed $6 \%$ to the systemic phenylalanine flux, which is comparable to the value obtained in post-absorptive rats $(7 \%)(19)$. Renal tyrosine production and renal phenylalanine to tyrosine hydroxylation contributed $13 \%$ and $36 \%$ to the systemic tyrosine and PHE $\rightarrow$ TYR fluxes, indicating the importance of the mouse kidney in tyrosine metabolism. Similar results have recently been demonstrated in the human kidney (30). Endotoxin treatment did not change the contribution of the kidney to the plasma fluxes of phenylalanine, tyrosine and PHE $\rightarrow$ TYR. Under baseline conditions, the contribution of the kidney to plasma arginine flux was $38 \%$, again comparable to the value obtained in post-absorptive rats (44\%) (19). Renal citrulline disposal contributed $64 \%$ to the systemic flux of citrulline, and was comparable to renal de novo arginine production, indicating that whole body citrulline disposal is mainly determined by renal de novo arginine production. Renal de novo arginine production was similar to the plasma CIT $\rightarrow$ ARG flux, suggesting that de novo arginine production from citrulline mainly takes place in the kidney. After endotoxin challenge, the renal contribution to plasma arginine flux increased to $51 \%$, again indicating the importance of the kidney in arginine production during endotoxemia in mice.

In the present study, we measured systemic NO production and renal arginine and protein metabolism under baseline conditions and during endotoxemia in mice. 
These stable isotope measurements can now be used to obtain new information on the metabolic role of the kidney in a variety of circumstances by applying it to transgenic and knockout mice.

In conclusion, the kidney has an anabolic function in the early response to endotoxemia. In addition, renal de novo arginine synthesis from citrulline is increased. This increase in arginine production may serve to sustain systemic NO production.

\section{Acknowledgments}

The authors thank Jean Scheyen, B.Sc. and Hans van Eijk, Ph.D. for expert LC-MS measurements. The assistance of Gabrie Ten Have, B.Sc. with the animal experiments is gratefully acknowledged. This study was supported by grants 902-23098 and 902-23-239 from the Dutch Association for Scientific Research (NWO).

\section{References}

1. Cynober L, Le Boucher J, Vasson MP. Arginine metabolism in mammals. J.Nutr.Biochem. 1995;6:402-412.

2. Wu G, Morris SM, Jr. Arginine metabolism: nitric oxide and beyond. Biochem.J. 1998;336(Pt 1):1-17.

3. Cui $X L$, Iwasa M, Iwasa $Y$, Ohmori $Y$, Yamamoto A, Maeda $H$, et al. Effects of dietary arginine supplementation on protein turnover and tissue protein synthesis in scald-burn rats. Nutrition 1999;15(7-8):563-9.

4. Peck MD, Babcock GF, Alexander JW, Billiar T, Ochoa J. High doses of dietary arginine during repletion impair weight gain and increase infectious mortality in protein-malnourished mice. Br.J.Nutr. 1995;74:787-795.

5. Pastor CM, Losser M-R, Payen D. Nitric oxide donor prevents hepatic and systemic perfusion decrease induced by endotoxin in anesthetized rabbits. Hepatology 1995;22(5):1547-1553.

6. Cobb JP, Natanson C, Hoffman WD, Lodato RF, Banks S, Koev CA, et al. Nw-amino-Larginine, an inhibitor of nitric oxide synthase, raises vascular resistance but increases mortality rates in awake canines challenged with endotoxin. J.Exp.Med. 1992;176:1175-1182.

7. Grover R, Zaccardelli D, Colice G, Guntupalli K, Watson D, Vincent JL. An open-label dose escalation study of the nitric oxide synthase inhibitor, $\mathrm{Ng}$-methyl-L-arginine hydrochloride (546C88), in patients with septic shock. Crit Care Med 1999;27:913-922. 
8. Waddington S, Cook HT, Reaveley D, Jansen A, Cattell V. L-arginine depletion inhibits glomerular nitric oxide synthesis and exacerbates rat nephrotoxic nephritis. Kidney Int. 1996;49:1090-1096.

9. Windmueller HG, Spaeth AE. Source and fate of circulating citrulline. Am.J.Physiol. 1981;241:E473-E480.

10. Wakabayashi Y, Yamada E, Yoshida T, Takahashi H. Arginine becomes an essential amino acid after massive resection of rat small intestine. J.Biol.Chem. 1994;269:32667-32671.

11. Salter M, Knowles RG, Moncada S. Widespread tissue distribution, species distribution and changes in activity of $\mathrm{Ca} 2+-$ dependent and $\mathrm{Ca} 2+-$ independent nitric oxide synthases. FEBS Lett. 1991;291:145-149.

12. Bune AJ, Shergill JK, Cammack R, Cook HT. L-Arginine depletion by arginase reduces nitric oxide production in endotoxic shock: an electron paramagnetic resonance study. FEBS Lett. 1995:366:127-130.

13. Hrabàk $A$, Idei $M$, Temesi A. Arginine supply for nitric oxide synthase and arginase is mainly exogenous in elicited murine and rat macrophages. Life Sciences 1994;55:797-805.

14. Fink MP, Heard SO. Laboratory models of sepsis and septic shock. J.Surg.Res. 1990;49:186196.

15. Ter Steege JCA, Van de Ven WCM, Forget PP, Brouckaert P, Buurman WA. The role of endogenous IFN-gamma, TNF-alpha and IL-10 in LPS-induced nitric oxide release in a mouse model. Cytokine 1998;10:115-123.

16. Yu YM, Young VR, Castillo L, Chapman TE, Tompkins RG, Ryan CM, et al. Plasma arginine and leucine kinetics and urea production rates in burn patients. Metabolism 1995;44(5):659666.

17. Waldegrave W, Chairman Council of the European Community. Guide for the care and use of laboratory animals. Brussels, Belgium: European Community; 1986. Report No.: Publication $86 / 609$.

18. Hallemeesch MM, Ten Have GAM, Deutz NEP. Measurement of metabolic fluxes across PDV, liver, kidney and hindquarter in mice. Lab Anim 2001;35:101-110.

19. Hallemeesch MM, Soeters PB, Deutz NEP. Tracer methodology in whole body and organ balance metabolic studies: plasma sampling is required. Clin Nutr 2000;19:157-163.

20. Dejong CHC, Deutz NEP, Soeters PB. Renal ammonia and glutamine metabolism during liver insufficiency-induced hyperammonemia in the rat. J.Clin.Invest. 1993;92:2834-2840.

21. De Blaauw I, Deutz NEP, Van der Hulst RRWW, Von Meyenfeldt MF. Glutamine depletion and increased gut permeability in non-anorectic, non-weight losing tumor bearing rats. Gastroenterology 1997;112(1):118-126.

22. Van Eijk HMH, Rooyakkers DR, Deutz NEP. Determination of amino acid isotope enrichment using liquid chromatography-mass spectrometry. Anal.Biochem. 1999;271:8-17.

23. Wolfe RR. Radioactive and stable isotope tracers in biomedicine. Principles and practice of kinetic analysis. New York: Wiley-Liss; 1992. 
24. Castillo L, Beaumier L, Ajami AM, Young VR. Whole body nitric oxide synthesis in healthy men determined from [15N]-arginine-to-[15N]citrulline labeling. Proc.Natl.Acad.Sci.USA 1996;93:11460-11465.

25. Lagerwerf FM, Wever RM, van Rijn HJ, Versluis C. Heerma W, Haverkamp J, et al. Assessment of nitric oxide production by measurement of [15N]citrulline enrichment in human plasma using high-performance liquid chromatography- mass spectrometry. Anal Biochem 1998;257(1):45-52.

26. Hallemeesch MM, De Jonge WJ, Soeters PB, Lamers WH, Deutz NEP. Contribution of eNOS and iNOS to in vivo systemic nitric oxide production in endotoxin-treated mice. FASEB J 2001;15(5):A771 (abstract).

27. Castillo L, Chapman TE, Sanchez M, Yu YM, Burke JF, Ajami AM, et al. Plasma arginine and citrulline kinetics in adults given adequate and arginine-free diets. Proc.Natl.Acad.Sci.USA 1993;90:7749-7753.

28. Moldawer LL, Kawamura I, Bistrian BR, Blackburn GL. The contribution of phenylalanine to tyrosine metabolism in vivo. Studies in the post-absorptive and phenylalanine-loaded rat. Biochem J 1983;210:811-7.

29. Tizianello A, De Ferrari G, Garibotto G, Gurreri G, Robaudo C. Renal metabolism of amino acids and ammonia in subjects with normal renal function and in patients with chronic renal insufficiency. J.Clin.Invest. 1980;65:1162-1173.

30. Birdsey GM, Leiper JM, Vallance P. Intracellular localization of dimethylarginine dimethylaminohydrolase overexpressed in an endothelial cell line. Acta Physiol Scand 2000;168:73-79.

31. Fong Y, Matthews DE, He W, Marano MA, Moldawer LL, Lowry SF. Whole body and splanchnic leucine, phenylalanine, and glucose kinetics during endotoxemia in humans. Am J Physiol 1994;266:R419-25.

32. Yu YM, Burke JF, Tompkins RG, Martin R, Young VR. Quantitative effects of interorgan relationships among arginine and citrulline metabolism. Am.J.Physiol. 1996;271:E1098-E1109.

33. Ten Have GAM, Bost MCF, Suyk-Wierts JCAW, van den Bogaart AEJM, Deutz NEP. Simultaneous measurement of metabolic flux in portally-drained viscera, liver, spleen, kidney and hindquarter in the conscious pig. Lab.Anim. 1996;30:347-358.

34. Godfrey M, Majid DSA. Renal handling of circulating nitrates in anesthetized dogs. Am J Physiol 1998;275(1 Pt 2):F68-73.

35. Hallemeesch MM, Cobben DCP, Dejong CHC, Soeters PB, Deutz NEP. Renal amino acid metabolism during endotoxemia in the rat. J Surg Res 2000;92:193-200.

36. Fischer JE, Hasselgren PO. Cytokines and glucocorticoids in the regulation of the "hepatoskeletal muscle axis" in sepsis. Am J Surg 1991;161:266-71.

37. Ozaki M, Gotoh T, Nagasaki A, Miyanaka K, Takeya M, Fujiyama S, et al. Expression of arginase $\mathrm{II}$ and related enzymes in the rat small intestine and kidney. J Biochem $1999 ; 125: 586-593$. 
Chapter 3

38. Watanabe $Y$, Van Pilsum JF, Yokoi I, Mori A. Synthesis of neuroactive guanidino compounds by rat kidney L-arginine:glycine amidinotransferase. Life Sci 1994;55:351-358.

39. Feron $\mathrm{O}$. Endothelial nitric oxide synthase expression and its functionality. Curr Opin Clin Nutr Metab Care 1999:2:291-296.

40. Hattori $Y$, Shimoda S, Gross SS. Effect of lipopolysaccharide treatment in vivo on tissue expression of argininosuccinate synthetase and argininosuccinate lyase mRNAs: relationship to nitric oxide synthase. Biochem Biophys Res Commun 1995;215(1):148-53.

41. Ter Steege JCA, Van de Ven WCM, Forget PP, Buurman WA. Regulation of LPS-induced iNOS expression in the major organs in a mouse model. Eur Cytokine Netw 2000;11:39-46. 


\section{4}

Increased iNOS-mediated and decreased cNOS-mediated NO production rates reflect blood pressure changes in LPSchallenged mice

Marcella M. Hallemeesch ${ }^{1}$, Ben J.A. Janssen ${ }^{2}$, Wouter J. de Jonge ${ }^{3}$, Peter B. Soeters ${ }^{1}$, Wouter H. Lamers ${ }^{3}$, and Nicolaas E.P. Deutz ${ }^{1}$

Depts. of ${ }^{1}$ Surgery, and ${ }^{2}$ Pharmacology, Maastricht University, Maastricht, and ${ }^{3}$ Dept of Anatomy and Embryology, University of Amsterdam, Amsterdam, The Netherlands 


\section{Abstract}

Increased NO production is the cause of hypotension and shock during sepsis. In the present experiments we have measured the contribution of eNOS and iNOS to the systemic NO production rate in baseline conditions and during endotoxemia (LPS 10 $\mathrm{mg} / \mathrm{kg}$ i.p.) in mice. The systemic NO production rate was measured as the in vivo conversion of $\left[{ }^{15} \mathrm{~N}_{2}\right]$ arginine to $\left[{ }^{15} \mathrm{~N}\right.$ ]citrulline and the contribution of the specific NOS isoforms was evaluated by comparing $\mathrm{NO}$ production in $\mathrm{NOSS}^{-1-}$ and $\mathrm{NOS}^{-1-}$ to NO production in wildtype (WT) mice. Under baseline conditions, NO production was similar in WT and iNOS $^{-/-}$mice but lower in NNOS $^{-/-}$mice (WT: $1.2 \pm 0.2$; eNOS $^{-1-}: 0.6$ $\pm 0.3 ;$ iNOS $^{-1}: 1.2 \pm 0.2 \mathrm{nmol} / 10 \mathrm{~g}$ b.w. $/ \mathrm{min}$ ). In response to endotoxin challenge (5h), the systemic NO production rate increased in WT and eNOS ${ }^{-/-}$mice, but fell in iNOS ${ }^{-1-}$ mice (WT: $2.7 \pm 0.3$; eNOS $^{-\mu}: 2.2 \pm 0.6$; NOS $^{-/}: 0.7 \pm 0.1$ nmol $/ 10 \mathrm{~g}$ b.w./min). Heart rate and blood pressure was recorded in WT and iNOS ${ }^{-1-}$ mice after LPS treatment. After $5 \mathrm{~h}$, blood pressure had dropped $14 \mathrm{mmHg}$ in WT, but not iNOS ${ }^{-1-}$ mice. In conclusion, the present data provides firm evidence that (1) iNOS is not active in baseline, unstimulated conditions, (2) the increase of NO production in response to treatment with bacterial endotoxin is solely dependent upon iNOS, (3) cNOSmediated NO production is reduced in response to treatment with bacterial endotoxin, and (4) elimination of iNOS abrogates the LPS-induced blood pressure response.

\section{Introduction}

Nitric oxide (NO) is one of the major mediators involved in the cardiovascular collapse associated with septic shock. Under baseline conditions, constitutively expressed isoforms of NO synthase (NOS) produce low levels of NO, that participate in the regulation of vascular tone. In contrast, infection with lipopolysaccharide leads to the induction of an inducible isoform of NOS in many tissues, including macrophages, vascular smooth muscle and endothelial cells. iNOS is considered to be the high-capacity NO-producing enzyme that causes the fall in blood pressure in septic shock. However, direct measurements of iNOS-mediated NO production have not yet been performed. Many researchers have tried to establish a role for iNOS in the hemodynamic consequences of endotoxemia using NOS inhibitors $(1,2)$. In 
addition, a substantial amount of research is devoted to therapies aiming to decrease or increase NO production during disease, but it has not been possible to measure the effect of these therapies on NO production rate.

A few years ago, Castillo et al. measured the in vivo NO production rate in healthy men using an elegant stable isotope technique (3). This technique is based on the fact that NOS produces citrulline and NO in stoichiometric amounts, with each containing a nitrogen atom derived from the guanidino moiety of arginine. By infusing an $\left[{ }^{15} \mathrm{~N}_{2}\right.$-guanidino]arginine stable isotope, it is possible to measure the actual NO

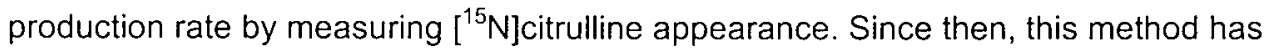
been used to measure the NO production rate in a variety of diseased subjects (4-6).

In the present experiments we aimed to measure the contribution of eNOS and iNOS to whole body NO production under baseline conditions and during endotoxemia induced by LPS. We therefore measured NO production rates using the stable isotope $\left[{ }^{15} \mathrm{~N}_{2}\right]$ arginine to $\left[{ }^{15} \mathrm{~N}\right]$ citrulline conversion method in mice engineered to specifically lack iNOS (7) or eNOS (8). In addition, we linked the NO production rates by the individual NOS isoforms to hemodynamic measurements.

\section{Experimental Procedures}

\section{Animals}

Male wildtype (C57BL6/J), eNOS ${ }^{-1-}$ and iNOS $^{-/-}$mice (22-26 g, 2-3 months old) were originally obtained from Jackson Laboratories, bred at the Department of Anatomy and Embryology (AMC, Amsterdam, The Netherlands), and transported to the Centralized Animal Facilities at Maastricht University. They adapted to the new environment for at least one week. The mice were subject to standard 12 hour lightdark cycle periods (7:30 A.M. to 7:30 P.M.). Room temperature was maintained at $25^{\circ} \mathrm{C}$. The mice were fed standard lab chow and had free access to water. During the experiments with endotoxin, food was withdrawn. Experiments were performed in accordance with the recommendations of the Guide for the Care and Use of Laboratory Animals (9), and approved by the Ethical Committee for Animal Research of Maastricht University. 
Experiment 1. NO production in response to LPS treatment in C57BL6/J, eNOS $\%$ and iNOS $^{*-}$ mice.

C57BL6/J, iNOS $^{-1-}$ and $\mathrm{eNOS}^{-1-}$ mice were randomly assigned to receive LPS ( $E$ coli $055: B 5,10 \mathrm{mg} / \mathrm{kg}$ ) or a corresponding volume of saline $(0.5 \mathrm{ml} / 25 \mathrm{~g} \mathrm{b.w}$.). Five hours after LPS treatment, mice were anesthetized using a mixture of ketamine and medetomidine, as described before (10). Catheterization of the jugular vein and carotid artery was performed as described recently (10). During the surgical procedures the mice were kept at $37^{\circ} \mathrm{C}$ using a temperature controller (Technical Service, Maastricht University) and heating pads.

A primed-constant infusion of L-[guanidino- $\left.{ }^{15} \mathrm{~N}_{2}\right]$ arginine and L-[ureido- ${ }^{13} \mathrm{C}-$ ${ }^{2} \mathrm{H}_{2}$ ]citrulline (Mass Trace, Woburn, MA) was given in the jugular vein (per mouse: a prime dose of $850 \mathrm{nmol}\left[{ }^{15} \mathrm{~N}_{2}\right]$ arginine and $215 \mathrm{nmol}\left[{ }^{13} \mathrm{C}_{-}{ }^{2} \mathrm{H}_{2}\right]$ citrulline, followed by an infusion rate of $1700 \mathrm{nmol} / \mathrm{hr}\left[{ }^{15} \mathrm{~N}_{2}\right]$ arginine and $430 \mathrm{nmol} / \mathrm{hr}\left[{ }^{13} \mathrm{C}-{ }^{2} \mathrm{H}_{2}\right]$ citrulline. Steady state of tracers and metabolites was reached within 20 minutes. Twenty minutes after the start of the surgical procedures, blood (200 $\mu \mathrm{l})$ was sampled from the carotid artery. Blood was centrifuged to obtain plasma, because we recently showed that plasma sampling is required in metabolic organ-balance studies with amino-acid tracers that do not equilibrate well in blood cells (11). For determination of amino-acid concentrations and tracer-tracee ratios (TTR), $80 \mu \mathrm{l}$ plasma was added to $7 \mathrm{mg}$ dry sulfosalicylic acid, vortexed, frozen in liquid nitrogen and stored at $-80^{\circ} \mathrm{C}$. Plasma amino-acid concentrations were determined as described before (12). Amino acid TTRs were measured using a fully automated liquid chromatography-mass spectrometry system (13), using pre-column derivatization with FMOC (14). For the measurement of plasma nitrate, $100 \mu \mathrm{l}$ acetonitrile was added to $50 \mu \mathrm{l}$ plasma, vortexed and centrifuged. Sixty $\mu$ l of the clear supernatant was added to $140 \mu \mathrm{l}$ Super-Q water. From the resulting solution $100 \mu \mathrm{l}$ was injected on an IC-PackHR $(75 \mathrm{~mm} * 4.6 \mathrm{~mm}$, Waters, Etten-Leur Netherlands). The column effluent was monitored at $205 \mathrm{~nm}$. Nitrate was isocratically eluted from the column within 20 minutes using a $6 \mathrm{mM}$ sodium chloride solution containing $1 \mathrm{mM}$ potassium dihydrogenphosphate $(\mathrm{pH}=6)$.

\section{Calculation of arginine and citrulline flux and NO production}

TTR is an equivalent of specific activity (15). Therefore, formulae were derived from metabolic studies using radioactive tracers. Correction for the contribution of lower 
isotopomers was performed as described by Wolfe (15). Plasma arginine and citrulline fluxes were calculated from the arterial isotope TTR values of respectively L[guanidino- ${ }^{15} \mathrm{~N}_{2}$ ] arginine and $\mathrm{L}-\left[\right.$ ureido- ${ }^{13} \mathrm{C} ;{ }^{2} \mathrm{H}_{2}$ ]citrulline, using the steady state isotope dilution equation:

$Q=I / T T R(15)$,

where TTR is the tracer-tracee ratio, and $\mathrm{I}$ is the rate of infusion of the tracer.

Calculation of the plasma arginine-to-citrulline flux (NO production) was made essentially as described by Castillo et al (3):

$\mathrm{Q}_{\mathrm{Arg}_{\rightarrow} \mathrm{Cit}}=\mathrm{Q}_{\mathrm{Cil}} \times \operatorname{TTR}_{\mathrm{Ci}(\mathrm{M}+1)} / \operatorname{TTR}_{\mathrm{Arg}(\mathrm{M}+2)}$.

where $Q_{C i t}$ is the plasma citrulline flux ( $\mathrm{nmol} / 10 \mathrm{~g} / \mathrm{min}$ ), estimated from the primed constant infusions of the $L-\left[\right.$ ureido $^{13}{ }^{3} \mathrm{C}_{\mathrm{H}_{2}}$ ]citrulline tracer and TTR $\mathrm{R}_{\mathrm{Cit}}$ and $T T R_{\mathrm{Arg}}$ are the respective TTRs of [ureido- ${ }^{15} \mathrm{~N}$ ]citrulline and [guanidino- ${ }^{15} \mathrm{~N}_{2}$ ]arginine.

Experiment 2. Heart rate and blood pressure in response to LPS treatment in C57BL6/J and iNOS ${ }^{-/}$mice.

A catheter was implanted in the femoral artery of $7 \mathrm{C} 57 \mathrm{BL} 6 / \mathrm{J}$ and $7 \mathrm{iNOS}^{-1-}$ mice using a technique described in detail before (16). Animals were allowed to recover from surgery for 2 days. On the third day after surgery data acquisition was started 1.5h before the administration of LPS ( $E$ coli O55:B5, Sigma, St Louis, MO, $10 \mathrm{mg} / \mathrm{kg}$ i.p.). Because LPS-challenged iNOS $^{-1}$ mice became hypothermic (17), mice were put under a heating lamp after LPS injection to maintain body temperature. Blood pressure and heart rate were recorded for $5 \mathrm{~h}$ after LPS injection. Detailed information on data acquisition was given before (16).

\section{Statistical analysis}

Comparisons were made between NOS knockout and WT mice under baseline conditions. In addition, the effect of LPS treatment was tested. The MannWhitney $U$ non-parametric test was used to test for differences. For the hemodynamic data an ANOVA with time as repeated factor and genotype as factor was performed. An interaction between time and genotype on mean arterial pressure was present. Therefore, the difference between the genotypes was determined for each time point using the Student's t-test. $P<0.05$ was considered significant. Data are presented as means \pm SEM. 


\section{Results}

\section{Contribution of eNOS and iNOS-mediated NO production}

Under basal conditions, NO production was $1.2 \pm 0.2 \mathrm{nmol} / 10 \mathrm{~g} \mathrm{bw} / \mathrm{min}$ in wildtype mice (Figure 1), which was $2.6 \%$ of arginine turnover (Table 1). In eNOS ${ }^{-/}$mice, the NO production rate was reduced by $50 \%$, but iNOS disruption did not change systemic NO production in the basal state (Figure 1).

Table 1. Plasma fluxes. Values are mean \pm SEM in $\mathrm{nmol} / 10 \mathrm{~g} \mathrm{bw/min.} \mathrm{Measurements} \mathrm{were} \mathrm{performed}$ at $t=5 \mathrm{~h} .{ }^{8} \mathrm{p}<0.05$ vs. iNOS ${ }^{/ 1}$ Control.

\begin{tabular}{|c|c|c|c|c|c|c|}
\hline & \multicolumn{3}{|c|}{ Control } & \multicolumn{3}{|c|}{ LPS } \\
\hline & C57BL6/J & eNOS $^{*}$ & $\mathrm{iNOS}^{-1 /}$ & C57BL6/J & $\mathrm{eNOS}^{-j-}$ & $\mathrm{iNOS}^{1 /}$ \\
\hline ARG & $46 \pm 2$ & $45 \pm 3$ & $50 \pm 4$ & $47 \pm 5$ & $49 \pm 5$ & $47 \pm 4$ \\
\hline $\mathrm{ClT}$ & $12 \pm 1$ & $10 \pm 1$ & $15 \pm 1$ & $14 \pm 1$ & $14 \pm 1$ & $10 \pm 1^{8}$ \\
\hline
\end{tabular}

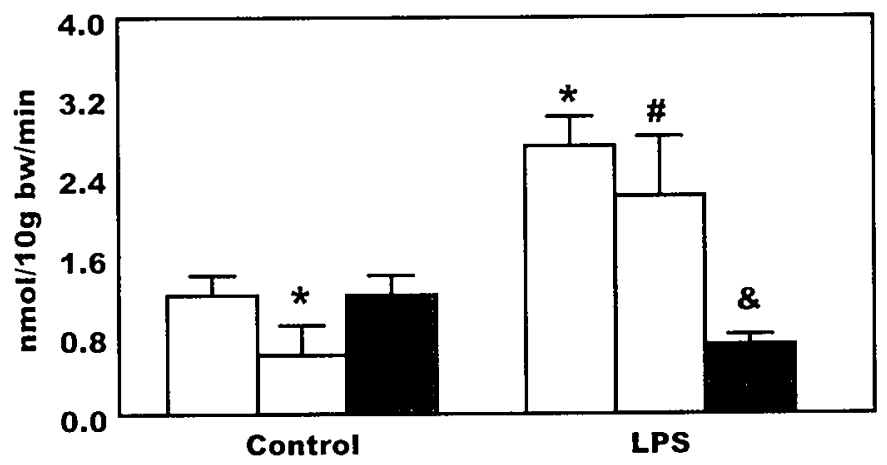

Figure 1. Contribution of eNOS and iNOS to systemic NO production rates under baseline conditions and during endotoxemia. Systemic NO production was measured as $\left[{ }^{15} \mathrm{~N}_{2}\right]$ arginine to

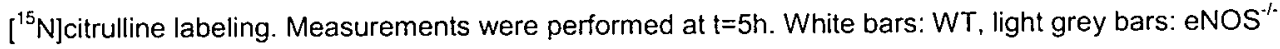
, dark grey bars: iNOS ${ }^{\%}$. ${ }^{*} p<0.05$ vs. WT Control, ${ }^{*} p<0.05$ vs. eNOS ${ }^{-1 .}$ Control, $^{8} p<0.05$ vs. iNOS ${ }^{*}$ Control.

In endotoxin-treated wildtype mice, the systemic NO production rate increased to 2.7 $\pm 0.3 \mathrm{nmol} / 10 \mathrm{~g} \mathrm{bw} / \mathrm{min}$ (Figure 1 ), which equaled $5.7 \%$ of arginine turnover (Table 1 ). A similar increase in $\mathrm{NO}$ production rate was observed in $\mathrm{eNOS}^{-1-}$ mice. 


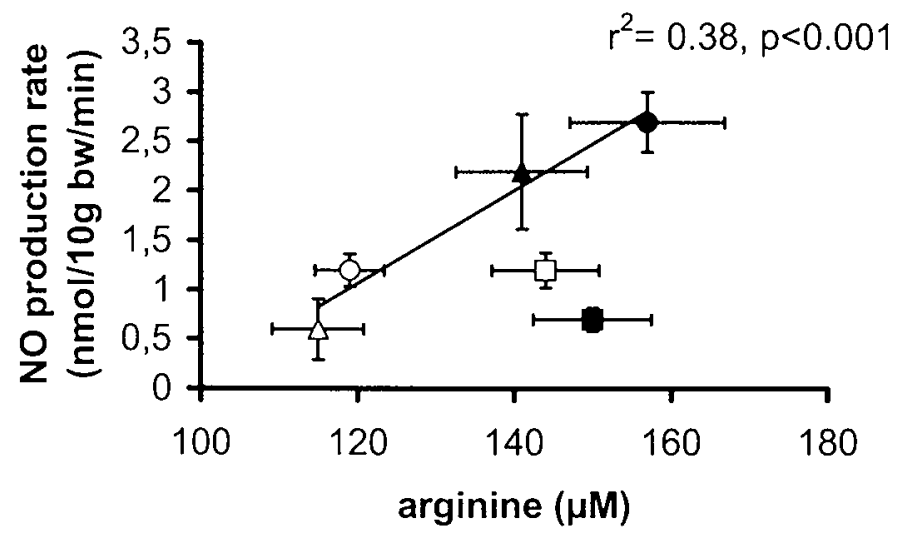

Figure 2. Correlation between circulating arginine and the NO production rate. LPS treatment caused an increase in circulating arginine. NO production correlated very well with circulating arginine in wildtype and eNOS ${ }^{-/}$mice $(p<0.001)$, but not in iNOS ${ }^{-t}$ mice. $\bullet W T ;-$ iNOS $^{-t} ; \Delta$ eNOS $^{t^{-}}$. Grey symbols: Control; black symbols: LPS.

Disruption of the iNOS gene prevented the increase in NO production in response to endotoxemia, indicating that the increase in NO production observed during experimental endotoxemia is solely dependent on iNOS. In addition, cNOSmediated NO production was down-regulated after stimulation with endotoxin.

\section{Correlation between NO production rates and circulating arginine}

In Figure 2 the correlation between circulating arginine and the rate of NO production is depicted. In wildtype and $\mathrm{eNOS}^{-1 /}$ mice, the rate of NO production was significantly correlated to circulating arginine levels ( $p<0.001$ ), and $38 \%$ of variance in the rate of NO production was explained by the level of circulating arginine. When iNOS $^{-1 /}$ mice were included in the regression analysis the correlation between circulating arginine and the rate of NO production was lost. These data strongly suggest that iNOS-mediated NO production is dependent on extracellular arginine (Figure 2). In iNOS $^{-1-}$ mice, basal NO production was similar to basal NO production in wildtype mice, but required a higher circulating arginine concentration (Figure 2). 


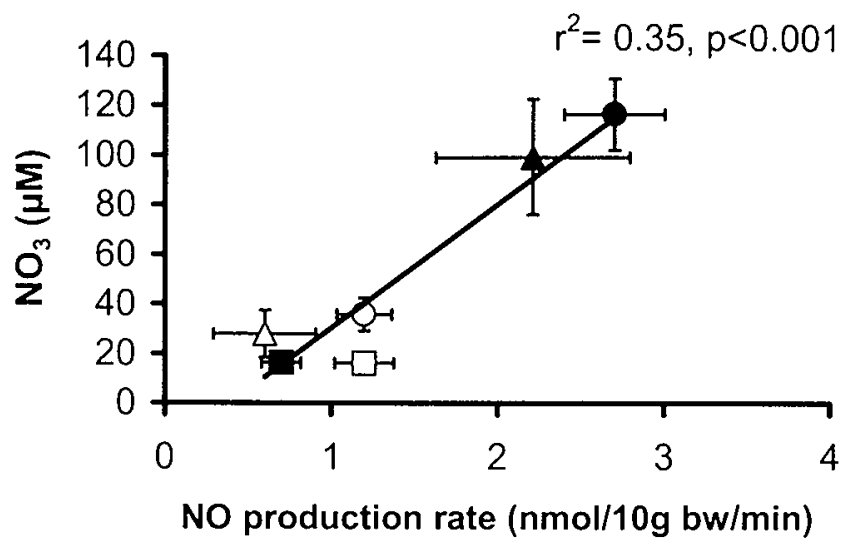

Figure 3. Correlation between the NO production rate and plasma nitrate. NO production correlated very well with plasma nitrate $(\mathrm{p}<0.001)$. - WT; $\boldsymbol{m} \mathrm{iNOS}^{*-*} ; \boldsymbol{\Delta}$ eNOS ${ }^{*}$. Grey symbols: Control, black symbols: LPS.

Correlation between NO production and plasma nitrate

Under baseline conditions, the plasma nitrate concentration was $36 \pm 6,28 \pm$ 9 , and $16 \pm 1 \mu \mathrm{M}$ in WT, eNOS ${ }^{-1 /}$ and NNOS $^{-1 /}$ mice respectively. In response to treatment with LPS, the plasma nitrate concentration increased 3.2-fold and 3.5-fold in wildtype and $\mathrm{eNOS}^{-1}$ mice respectively. In contrast, the rate of NO production increased 2.3-fold and 3.6-fold in wildtype and $\mathrm{eNOS}^{-1-}$ mice respectively. In $\mathrm{iNOS}^{-1-}$ mice, plasma nitrate was unchanged, whereas the rate of NO production was reduced by $50 \%$ in response to endotoxemia. In Figure 3 the correlation between the rate of NO production and plasma nitrate is depicted. When all groups were included in the regression analysis, plasma nitrate was significantly correlated to the rate of NO production ( $p<0.001$ ), and $35 \%$ of variance in plasma nitrate was explained by the rate of NO production. When all LPS-treated animals were excluded from the analysis, there was no significant correlation between the rate of NO production and the plasma nitrate value $(p=0.68)$. When analysis was performed on LPS-treated animals only, the correlation between the rate of NO production and plasma nitrate remained highly significant $\left(p<0.02, r^{2}=0.38\right)$. These data indicate that plasma nitrate is an indicator of iNOS-mediated NO production. Plasma nitrate is not indicative of cNOS-mediated NO production rate. 
NO production and circulatory parameters

We then performed mean arterial pressure and heart rate measurements in wildtype and NOS $^{-1-}$ mice to link NO production rates from the individual NOS isoforms to circulatory parameters. Because the effects of endotoxemia on NO production were similar between wildtype and $\mathrm{NNOS}^{-/ .}$mice, hemodynamic measurements were only performed in wildtype and $\mathrm{NOS}^{/-}$mice. Under basal conditions, blood pressure and heart rate were not different between C57BL6/J and iNOS $^{-1-}$ mice (Figure 4), which is in agreement with the fact that the NO production rates were also similar in wildtype and NOS $^{-1-}$ mice under baseline conditions. In response to treatment with bacterial endotoxin, blood pressure decreased slightly but significantly in C57BL6/J mice, but not in NOS $^{-1-}$ mice. At $5 \mathrm{~h}$ after endotoxin challenge, a $14 \mathrm{mmHg}$ difference $(p<0.05)$ between C57BL6/J and iNOS ${ }^{-1-}$ mice was recorded. These data are in agreement with the difference in iNOS related NO production between wildtype and NOS $^{-1-}$ mice after endotoxin treatment. In addition, no relation was observed between the reduced eNOS-mediated NO production and blood pressure. Heart rate was not significantly changed by iNOS gene disruption or LPS treatment (Figure 4B).

\section{Discussion}

The present study was undertaken to measure the contribution of iNOS and eNOS to systemic NO production under basal and LPS-stimulated conditions. The data presented, for the first time, offer direct support in the form of in vivo NO production rates for the well-established theory that iNOS is not active under baseline conditions. In addition, we have shown that the increase in NO production in response to treatment with bacterial endotoxin is exclusively dependent upon iNOS, not cNOS, and that the blood pressure response to LPS is absent in iNOS ${ }^{-1-}$ mice. Moreover, this is the first time that NO production rates reveal down-regulation of cNOS-mediated NO production in response to treatment with bacterial endotoxin. 

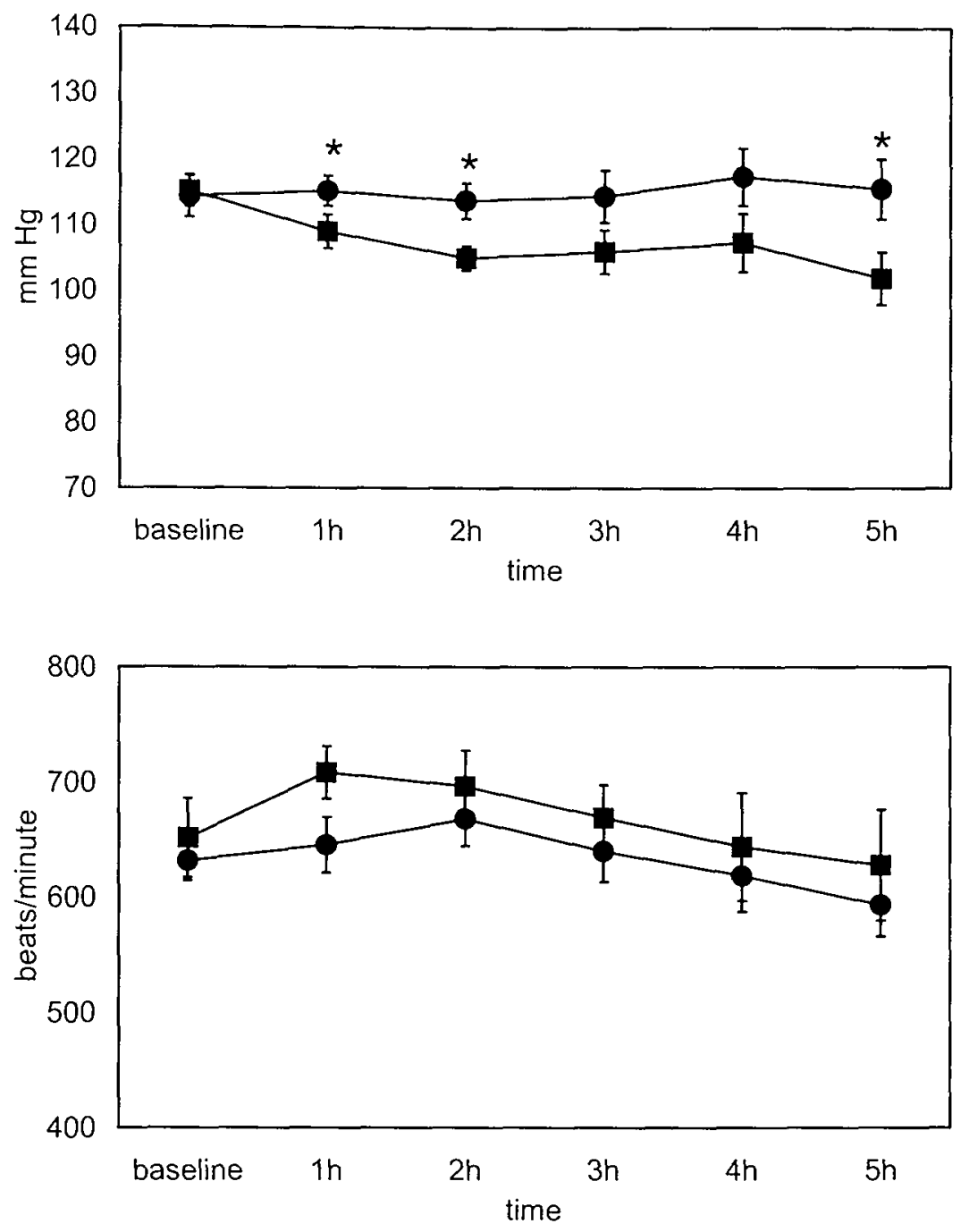

Figure 4. Blood pressure and heart rate in response to LPS treatment in C57BL6/J and iNOS ${ }^{-1}$ mice. Upper panel: blood pressure. Lower panel: heart rate. - C57BL6/J; • iNOS ${ }^{-1 /}$. "p<0.05 vs. WT.

Under baseline conditions, and in agreement with data from Shesely et al (18), blood pressure and heart rate were not different in iNOS ${ }^{-1}$ and C57BL6/J mice. In contrast, in eNOS ${ }^{-1-}$ mice blood pressure was increased with $15-20 \%(18,19)$, and heart rate is decreased with $6 \%$ under basal conditions (18). We have not measured blood pressure and heart rate in eNOS ${ }^{-1-}$ mice, because NO production increased to a 
similar extent as in the C57BL6/J control group, and therefore similar hemodynamic effects were expected.

Hypotension in septic shock appears to be mediated by production of NO. Indeed, in response to bacterial endotoxin, arterial blood pressure decreased in C57BL6/J mice, but not in iNOS ${ }^{-/-}$mice. Nava et al reported reversal of endotoxininduced hypotension in rats by treatment with an inhibitor of NO synthesis (20). A high dose of this inhibitor, accelerated and enhanced the fall in blood pressure, indicating that complete inhibition of NO synthesis is counterproductive (20). These results underline the importance of accurate measurement of NO production rates.

Using the $\left[{ }^{15} \mathrm{~N}_{2}\right]$ arginine to $\left[{ }^{15} \mathrm{~N}\right]$ citrulline conversion assay, we found that basal $\mathrm{NO}$ production was the same in $\mathrm{C} 57 \mathrm{BL} 6 / \mathrm{J}$ and $\mathrm{NOS}^{-1-}$ mice. These data indicate that iNOS does not contribute to systemic NO production in the basal, unstimulated, condition. A 50\% reduction under baseline NO production was measured in $\mathrm{eNOS}^{-1-}$ mice in comparison to C57BL6/J and NOS $^{-/-}$mice. Thus, under baseline conditions, eNOS and nNOS each contribute $50 \%$ to systemic NO production.

In response to LPS treatment, systemic NO production was increased. The present study firmly establishes that the increase in systemic NO production was solely caused by an increase in iNOS-mediated NO production, since NO production was not increased in iNOS $^{-/}$mice treated with bacterial endotoxin. In fact, systemic NO production was decreased in $\mathrm{iNOS}^{-/-}$mice in this condition, indicating that eNOS/nNOS mediated NO production was reduced in response to LPS treatment. This is the first time that NO production rates reveal down-regulation of cNOSmediated NO production. The present study therefore confirms earlier studies indicating a reduction of eNOS/nNOS expression both at the protein and MRNA level after treatment with LPS $(21,22)$. It is conceivable that the reduction of cNOSmediated NO production indicates a tendency towards increased blood pressure, which may have contributed to the limited decrease in blood pressure in $\mathrm{iNOS}^{-/-}$mice compared to wildtype mice.

We also showed that plasma nitrate correlated very well with the NO production rate in animals treated with bacterial endotoxin. These results indicate that the measurement of plasma nitrate is a qualitative alternative for measuring the NO production rate in conditions of inflammation. The obvious advantage of stable isotope measurement of NO production is that it is a direct quantitative measure of 
NO production. In contrast, under baseline conditions, plasma nitrate did not correlate with the NO production rate. The results suggest that it is not possible to measure reductions in the rate of NO production by means of plasma nitrate. Plasma nitrate increased in C57BL6/J and $\mathrm{NNOS}^{-/}$mice, and did not increase in iNOS ${ }^{-1-}$ mice. Thus, after LPS-challenge, plasma nitrate is an indicator of increased iNOS mediated NO production.

The study further indicates that the rate of iNOS-mediated NO production is linearly related to circulating arginine. Extrapolation of the correlation between circulating arginine and the rate of NO production suggests that iNOS-mediated NO production ceases when arginine levels drop below $100 \mu \mathrm{M}$. The study therefore supports the supplementation of arginine (up to $160 \mu \mathrm{M}$ ) in conditions of compromised iNOS-mediated NO production. In NOS $^{-1}$ mice, in which cNOSmediated NO production is not compromised, NO production was not related to circulating arginine.

In conclusion, the present data provides firm evidence that (1) iNOS is not active under baseline, unstimulated conditions, (2) the increased NO production in response to treatment with bacterial endotoxin is solely due to iNOS, (3) elimination of iNOS abrogates the LPS-induced blood pressure response, (4) cNOS-mediated NO production is reduced under endotoxemic conditions, and (5) the iNOSdependent NO production rate correlates very well with circulating arginine concentration.

\section{Acknowledgments}

The authors wish to thank Mr. JLJM Scheyen, BSc and Mr. HMH van Eijk, PhD for the LC-MS measurements. We also thank Mrs. GAM Ten Have, B.Sc. for assistance with the animal experiments. This study was supported by grants 902-23-098 and 902-23-239 from the Dutch Association for Scientific Research (NWO). 


\section{References}

1. Wright CE, Rees DD, Moncada S. Protective and pathological roles of nitric oxide in endotoxin shock. Cardiovasc. Res. 1992;26:48-57.

2. Kilbourn RG, Jubran A, Gross SS, Griffith OW, Levi R, Adams J, et al. Reversal of endotoxinmediated shock by $\mathrm{N}$-methyl-L-arginine, an inhibitor of nitric oxide synthesis. Biochem Biophys Res Commun 1990;172:1132-1138.

3. Castillo L, Beaumier L, Ajami AM, Young VR. Whole body nitric oxide synthesis in healthy men determined from [15N]-arginine-to-[15N]citrulline labeling. Proc.Natl.Acad.Sci.USA 1996;93:11460-11465.

4. Castillo L, deRojas TC, Sanchez M, Chapman TE, Shannon D, Tannenbaum S, et al. Whole body arginine metabolism and nitric oxide synthesis in newborns with persistent pulmonary hypertension. Pediatr.Res. 1995;38(1):17-25.

5. Lau T, Owen W, Yu YM, Noviski N, Lyons J, Zurakowski D, et al. Arginine, citrulline, and nitric oxide metabolism in end-stage renal disease patients. J Clin Invest 2000;105:1217-1225.

6. Wever R, Boer P, Hijmering M, Stroes E, Verhaar M, Kastelein J, et al. Nitric oxide production is reduced in patients with chronic renal failure. Arterioscler Thromb Vasc Biol 1999;19(5):1168-72.

7. Sewer MB, Barclay TB, Morgan ET. Down-regulation of cytochrome $\mathrm{p} 450 \mathrm{mRNAs}$ and proteins in mice lacking a functional NOS2 gene. Mol Pharmacol 1998:54:273-279.

8. Huang PL, Lo EH. Genetic analysis of NOS isoforms using nNOS and eNOS knockout animals. Prog Brain Res 1998;118:13-25.

9. Waidegrave W, Chairman Council of the European Community. Guide for the care and use of laboratory animals. Brussels, Belgium: European Community; 1986. Report No.: Publication $86 / 609$.

10. Hallemeesch MM, Ten Have GAM, Deutz NEP. Measurement of metabolic fluxes across PDV, liver, kidney and hindquarter in mice. Lab Anim 2001;35:101-110.

11. Hallemeesch MM, Soeters PB, Deutz NEP. Tracer methodology in whole body and organ balance metabolic studies: plasma sampling is required. Clin Nutr 2000;19:157-163.

12. Van Eijk HMH, Rooyakkers DR, Deutz NEP. Rapid routine determination of amino acids in plasma by high-performance liquid chromatography with a 2-3 $\mu \mathrm{M}$ Spherisorb ODS II column. J.Chromatogr. 1993;620:143-148.

13. Van Eijk HMH, Rooyakkers DR, Deutz NEP. Determination of amino acid isotope enrichment using liquid chromatography-mass spectrometry. Anal.Biochem. 1999;271:8-17.

14. Van Eijk HMH, Rooyakkers DR, Wagenmakers AJM, Soeters PB, Deutz NEP. Isolation and quantification of isotopically labeled amino acids from biological samples. J.Chromatography $B$ 1997;691:287-296.

15. Wolfe RR. Radioactive and stable isotope tracers in biomedicine. Principles and practice of kinetic analysis. New York: Wiley-Liss; 1992. 
16. Janssen BJA, Leenders PJA, Smits JFM. Short-term and long-term blood pressure and heart rate variability in the mouse. Am J Physiol Regulatory Integrative Comp Physiol 2000;278:R215-R225.

17. Gunnett CA, Chu Y, Heistad DD, Loihl A, Faraci FM. Vascular effects of LPS in mice deficient in expression of the gene for inducible nitric oxide synthase. Am J Physiol 1998;275(2 Pt 2):H416-21.

18. Shesely EG, Maeda N, Kim HS, Desai KM, Krege JH, Laubach VE, et al. Elevated blood pressures in mice lacking endothelial nitric oxide synthase. Proc Natl Acad Sci U S A 1996;93(23):13176-81.

19. Huang PL, Huang Z, Mashimo H, Bloch KD, Moskowitz MA, Bevan JA, et al. Hypertension in mice lacking the gene for endothelial nitric oxide synthase. Nature 1995;377:239-242.

20. Nava E, Palmer RMJ, Moncada S. Inhibition of nitric oxide synthesis in septic shock: how much is beneficial. The Lancet 1991;338:1555-1557.

21. Lu JL, Schmiege LMr, Kuo L, Liao JC. Downregulation of endothelial constitutive nitric oxide synthase expression by lipopolysaccharide. Biochim Biophys Res Commun 1996;225:1-5.

22. Liu SF, Adcock IM, Old RW, Barnes PJ, Evans TW. Differential regulation of the constitutive and inducible nitric oxide synthase mRNA by lipopolysaccharide treatment in vivo in the rat. Crit Care Med 1996:24:1219-1225. 


\section{Chapter 4}

Reduced arginine availability and nitric oxide production 
Chapter 4 
4.1

Acute reduction of circulating arginine in mice does not compromise cNOS or iNOS-mediated NO production.

Marcella M. Hallemeesch, Yvonne L.J. Vissers, Peter B. Soeters, Nicolaas E.P. Deutz

Dept. of Surgery, Maastricht University, Maastricht, The Netherlands 


\section{Abstract}

The amino acid arginine is the sole precursor for nitric oxide (NO) synthesis. We have now studied the role of reduced circulating arginine on CNOS and iNOSmediated NO production in mice. Measurements were performed in 4 groups of mice, treated with saline (SAL) or arginase (ASE), and SAL or bacterial endotoxin (LPS). A $57 \%$ reduction in circulating arginine was obtained by intravenous injections of arginase (SAL/SAL: $138 \pm 7$; ASE/SAL: $59 \pm 10 \mu \mathrm{M}$ ). Reduced circulating arginine caused a reduction in plasma arginine flux (SAL/SAL: $82 \pm 6$; ASE/SAL: $63 \pm 5$ $\mathrm{nmol} / 10 \mathrm{~g} \mathrm{bw} / \mathrm{min}$ ), independent of protein turnover. Under baseline conditions, the in vivo rate of $\mathrm{NO}$ production measured as $\left[{ }^{15} \mathrm{~N}_{2}\right]$ arginine-to- $\left[{ }^{15} \mathrm{~N}\right]$ citrulline labeling, was not reduced by the reduction in circulating arginine. In response to treatment with bacterial endotoxin, the rate of NO production was increased (SAL/SAL: $1.3 \pm 0.3$ SAL/LPS $2.3 \pm 0.4 \mathrm{nmol} / 10 \mathrm{~g} \mathrm{bw} / \mathrm{min}$ ), indicating increased iNOS-mediated NO production. Reduced circulating arginine did not compromise the increase in iNOSmediated NO production in response to LPS treatment. Renal de novo arginine production was not increased in LPS-challenged mice with reduced circulating arginine levels. The present study indicates that acute decrease in circulating arginine does not compromise cNOS or iNOS mediated NO production and provides evidence against a role for renal de novo arginine production to counteract a reduction of circulating arginine.

\section{Introduction}

The discovery of the production of the radical nitric oxide (NO) from the amino acid arginine in mammalian cells has triggered renewed interest in arginine metabolism. Besides NO, arginine serves multiple functions, including the production of protein, creatine and agmatine, and has a role in the urea cycle (1). NO plays crucial roles in cardiovascular, neuronal and immune systems.

$\mathrm{NO}$ is produced from arginine by nitric oxide synthase, of which three isoforms exist: endothelial NOS (eNOS), neuronal NOS (nNOS) and inducible NOS (iNOS) (2, 3). Of these, eNOS and nNOS are expressed constitutively and are therefore often termed cNOS. The third isoform is inducible by various microbes, microbial products 
(including lipopolysaccharide, (LPS)), and inflammatory cytokines, and is therefore named iNOS (4).

In physiological conditions, the concentration of arginine is approximately 100 $\mu \mathrm{M}$, and the tissue concentration is approximately $150 \mu \mathrm{M}$ in kidney (5) and $400 \mu \mathrm{M}$ in intestine (6). In healthy volunteers the rate of NO production is $0.96 \mu \mathrm{mol} / \mathrm{kg} / \mathrm{hr}$, and equals $1.2 \%$ of arginine turnover (7). Although the percentage of arginine turnover involved in NO production is low, the plasma arginine compartment serves as a significant precursor pool (54\%) for whole body NO formation (7). Thus, circulating arginine may regulate NO production. Several lines of evidence indicate that the endogenous production of NO by NOS is dependent on extracellular arginine and cellular arginine transport. In macrophages, induction of iNOS is accompanied by an upregulation of arginine transport $(8,9)$, and competitive inhibition of arginine transport reduces intracellular arginine and abolishes NOS activity (10). In addition, the $K_{m}$ of NO synthesis by endothelial cells is approximately 73-150 $\mu \mathrm{M}(1)$, which is in the range of normal physiological arginine concentration and the $K_{m}$ values of the $\mathrm{y}^{+}$-like arginine transporters CAT1 and CAT2B.

In the present experiment, we studied the response of systemic arginine deficiency on NO production both under baseline conditions and after treatment with bacterial endotoxin. Experimental short-term reduction of plasma arginine was accomplished by systemic injection of arginase (11-13). Endogenous adaptations to ensure nitric oxide production despite reduced arginine availability may include increased de novo arginine synthesis from citrulline in the kidney (13), although this has been under debate (14). We therefore also studied de novo production of arginine in these conditions.

\section{Materials and Methods}

\section{Animals}

Male Swiss mice (22-26 g, 2-3 months old) were obtained from IFFA Credo Broekman (Someren, The Netherlands). The mice were fed standard lab chow and were subject to standard 12-hour light-dark cycle periods (7:30 A.M. to 7:30 P.M.). Room temperature was maintained at $25^{\circ} \mathrm{C}$. Experiments were performed in accordance with the recommendations of the Guide for the Care and Use of 
Laboratory Animals (15), and approved by the Ethical Committee of Animal Research of Maastricht University.

\section{Experimental Procedures}

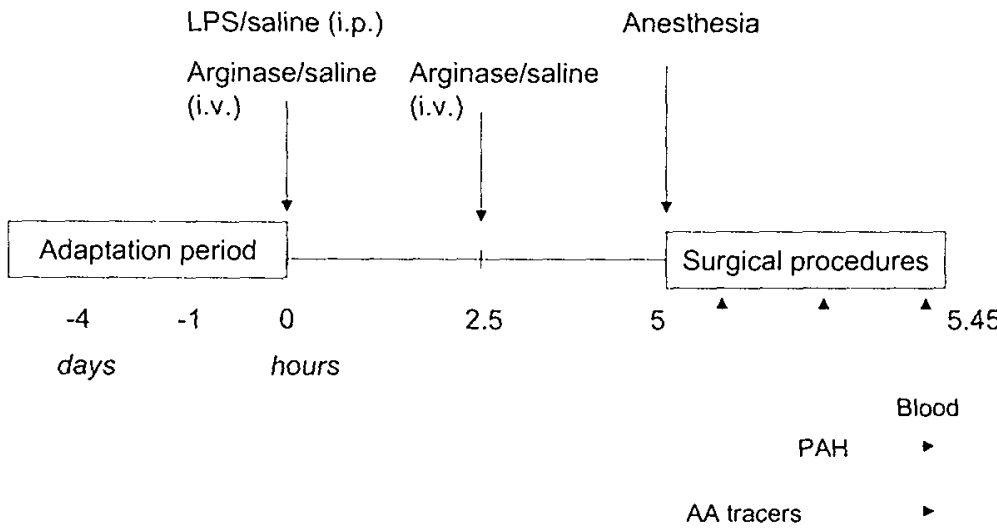

Figure 1. Experimental Procedures. Mice adapted to laboratory environment for 4 days. At 0 h, food was withheld and mice were injected i.p. with LPS $(10 \mathrm{mg} / \mathrm{kg})$ or saline. At 0 and $2.5 \mathrm{~h}$ mice were injected i.v. with arginase $(600 \mathrm{U} / 25 \mathrm{~g}$ body wt.) or saline. At $5 \mathrm{~h}$, the mice were anesthetized and the surgical procedures started. First the primed constant infusion of labeled amino acids (AA) was started in the jugular vein. Then catheters were inserted into the carotid artery, abdominal aorta, portal vein and renal vein. Next a primed constant infusion of ${ }^{14} \mathrm{C}-\mathrm{PAH}$ was started in the abdominal aorta. Fifteen minutes later, blood was sampled from the carotid artery, renal vein and portal vein. By that time, labeled AA and ${ }^{14} \mathrm{C}$-PAH had been infused for 30 and 15 minutes respectively, and had reached steady state.

\section{Experimental protocol}

The experimental setup is depicted in Figure 1. Mice were assigned to receive an intravenous injection of $0.9 \% \mathrm{NaCl}$ (saline, SAL) or arginase (ASE, Sigma, St. Louis, $\mathrm{MO}, 600 \mathrm{U} / 25 \mathrm{~g}$ at 0 and $2.5 \mathrm{~h}$ ). To obtain access to the tailvein without anesthesia, the mice were kept in an animal restrainer (Technical Service, Maastricht University) for 1-2 minutes. Also, at $0 \mathrm{~h}$, mice received an i.p. injection with lipopolysaccharide 
(LPS, E coli O55:B5, Sigma, St. Louis, MO, $10 \mathrm{mg} / \mathrm{kg}$ in $0.5 \mathrm{ml} / 25 \mathrm{~g} 0.9 \% \mathrm{NaCl}$ ) or a corresponding volume of $0.9 \% \mathrm{NaCl}(16)$. These procedures resulted in the formation of four experimental groups: 1. SAL/SAL $(n=6), 2$. SAL/LPS $(n=9), 3$. ASE/SAL $(n=8)$, 4. ASE/LPS $(n=10)$. Drinking water was provided during the experiment, but food was withheld after the injection of LPS or SAL to avoid influences of differences of food intake. iNOS knockout mice (17) and transgenic mice with low plasma arginine levels became hypothermic after LPS administration (Hallemeesch et al, unpublished observation). In our study, it was obvious that mice treated with LPS were less active. Therefore, in agreement with others (17), LPS-treated mice were put under a heating lamp to ensure maintenance of body temperature.

Five hours after LPS or SAL treatment, anesthesia was induced by an intraperitoneal injection of a mixture of ketamine $(1.25 \mathrm{mg} / 10 \mathrm{~g} \mathrm{b.w.,} \mathrm{Nimatek,} \mathrm{AUV,}$ Cuyk, The Netherlands) and medetomidine ( $2 \mu \mathrm{g} / 10 \mathrm{~g}$ b.w., Domitor, Farmos, Espoo, Finland). Anesthesia was maintained with a continuous s.c. infusion of a mixture of ketamine $(0.35 \mathrm{mg} / 10 \mathrm{~g} \mathrm{b.w./h})$ and medetomidine $(0.35 \mu \mathrm{g} / 10 \mathrm{~g} \mathrm{~b} . \mathrm{w} . / \mathrm{h})(18)$. This anesthesia allowed abdominal surgery, while animals did not need mechanical ventilation. During the surgical procedures the mice were kept at $37^{\circ} \mathrm{C}$ using a temperature controller (Technical Service, Maastricht University) and heat pads (18). A catheter was inserted in the jugular vein, as described recently (18).

A primed-constant infusion of $L-\left[\right.$ guanidino- ${ }^{15} \mathrm{~N}_{2-}{ }^{2} \mathrm{H}_{2}$ ]arginine, $L$-[ureido${ }^{13} \mathrm{C}$ ]citrulline, $\mathrm{L}-\left[\mathrm{ring}^{-}{ }^{2} \mathrm{H}_{5}\right.$ ]phenylalanine (Mass Trace, Woburn, MA) was given in the jugular vein (per mouse: prime $\left[{ }^{15} \mathrm{~N}_{2}{ }^{2} \mathrm{H}_{2}\right]$ arginine: $850 \mathrm{nmol},\left[{ }^{13} \mathrm{C}\right]$ citrulline: $215 \mathrm{nmol}$, $\left[{ }^{2} \mathrm{H}_{5}\right]$ phenylalanine: $340 \mathrm{nmol}$, infusion $\left[{ }^{15} \mathrm{~N}_{2}{ }^{2} \mathrm{H}_{2}\right]$ arginine: $1700 \mathrm{nmol} / \mathrm{hr},\left[{ }^{13} \mathrm{C}\right]$ citrulline: $430 \mathrm{nmol} / \mathrm{hr},\left[{ }^{2} \mathrm{H}_{5}\right]$ phenylalanine: $680 \mathrm{nmol} / \mathrm{hr}$ ). The solution was iso-osmolar, at room temperature and infused at a rate of $1 \mathrm{ml} / \mathrm{hr}$. This protocol yields isotopic steady state within 30 minutes (not shown). In the meanwhile the abdominal aorta, carotid artery, renal vein and portal vein were catheterized as described recently (18).

Plasma flow across intestine and kidney was measured using the indicator dilution method with [glycyl-1- ${ }^{14} \mathrm{C}$ ]-p-aminohippuric acid $\left({ }^{14} \mathrm{C}-\mathrm{PAH}, \mathrm{NEN}\right.$ Life Science Products, Boston, MA), as described in detail before (18). Briefly, a primed $(20 \mu / 10$ $\mathrm{g}$ body wt of $3 \mu \mathrm{Ci} / \mathrm{ml}{ }^{14} \mathrm{C}-\mathrm{PAH}$ ) continuous ( $1 \mathrm{ml} / 10 \mathrm{~g}$ bw/h $3 \mu \mathrm{Ci} / \mathrm{ml}{ }^{14} \mathrm{C}-\mathrm{PAH}$ ) infusion was given in the mesenteric vein. Fifteen minutes later, when ${ }^{14} \mathrm{C}-\mathrm{PAH}$ steady state was obtained (18), blood $(0.2 \mathrm{ml}$ per catheter) was sampled from the renal vein, carotid artery and portal vein, and collected in heparinized cups (Sarstedt, 
Nümbrecht, Germany) on ice. Then full-thickness pieces of jejunum, ileum and the right kidney were freeze-clamped in liquid nitrogen and stored at $-80^{\circ} \mathrm{C}$. For the determination of tissue arginine concentrations, frozen tissue was homogenized and deproteinized. Briefly, tissue was pulverized using a mortal and pestle precooled in liquid nitrogen. Homogenisation was performed using a Mini-Beadbeater (Biospec Products, Bartlesville, USA). Approximately $50 \mathrm{mg}$ of pulverized frozen tissue was added to $250 \mu \mathrm{SSA} 5 \%$ at $4^{\circ} \mathrm{C}$, with $100 \mathrm{mg}$ glass beads (diameter $1 \mathrm{~mm}$, Biospec Products) and beaten for 30 seconds (19). The homogenate was centrifuged at $4^{\circ} \mathrm{C}$ at $1,100 \mathrm{~g}$ and the supernatant frozen at $-80^{\circ} \mathrm{C}$ until determination of arginine concentration.

In whole blood, hematocrit and ${ }^{14} \mathrm{C}-\mathrm{PAH}$ were determined as described (18). The ${ }^{14} \mathrm{C}$-PAH intra-sample variance was approximately $5 \%$, and the variance of intestinal and renal blood flow was $15 \%$ and $10 \%$ (18). Blood was centrifuged to obtain plasma, because we have shown recently that plasma sampling is required in organ balance metabolic studies using amino acid tracers that do not equilibrate well in blood cells (20). For determination of plasma amino acid concentration and tracertracee ratio (TTR), $80 \mu$ plasma was added to $7 \mathrm{mg}$ dry sulfosalicylic acid, vortexed, frozen in liquid nitrogen and stored at $-80^{\circ} \mathrm{C}$. For determination of plasma urea concentrations, $20 \mu \mathrm{l}$ plasma was added to $80 \mu \mathrm{l} 1 \%$ trichloroacetic acid. Remaining plasma was frozen without further treatment. Plasma and tissue amino acid concentrations were measured as described before (21). Phenylalanine TTRs were measured as described in detail before (22). Arginine and citrulline TTRs were measured using the same methods (22), but as 9-fluorenylmethylchloroformate derivatives. For the measurement of plasma nitrite and nitrate, $100 \mu$ lacetonitrile was added to $50 \mu \mathrm{l}$ plasma, vortexed and centrifuged. Sixty $\mu$ l of the clear supernatant was added to $140 \mu \mathrm{I}$ Super-Q water, mixed and sealed with a Teflon ${ }^{R}$ seal. From the resulting solution $100 \mu \mathrm{l}$ was injected on an IC-PackHR column (Waters, Etten-Leur Netherlands). Anions $\left(\mathrm{NO}_{2}\right.$ and $\left.\mathrm{NO}_{3}\right)$ were isocratically eluted from the column using a $6 \mathrm{mM}$ sodium chloride solution containing $1 \mathrm{mM}$ potassium dihydrogenphosphate $(\mathrm{pH}=6)$, and detected at $205 \mathrm{~nm}$. Plasma urea was determined using commercially available kits on a Cobas Mira S (Roche Diagnostica, Hoffman La Roche, Basel, Switzerland), as described previously (23). 


\section{Calculations}

Whole body arginine and protein metabolism

Plasma arginine, citrulline and phenylalanine fluxes were calculated from the arterial isotope enrichment values of respectively $L-\left[{ }^{15} \mathrm{~N}_{2}-{ }^{2} \mathrm{H}_{2}\right]$ arginine, $L-\left[{ }^{13} \mathrm{C}\right]$ citrulline and $L$ $\left[{ }^{2} \mathrm{H}_{5}\right]$ phenylalanine, using steady state isotope dilution equation:

$\mathrm{Q}=\mathrm{I} / \mathrm{TTR}(24)$,

where TTR is the tracer-tracee ratio, and $\mathrm{l}$ is the rate of infusion of the tracer.

\section{Systemic NO production rate}

Calculation of the plasma arginine to citrulline flux (NO production) was made as described by Castillo et al (7):

$\mathrm{Q}_{\mathrm{Arg}_{\rightarrow} \mathrm{Cit}}=\mathrm{Q}_{\mathrm{Cit}} \times \mathrm{TTR}_{\mathrm{Cit}(\mathrm{M}+3)} / \mathrm{TTR}_{\mathrm{Arg}(\mathrm{M}+4) \text {. }}$

where $Q_{\text {Cit }}$ is the plasma citrulline flux ( $\mathrm{nmol} / 10 \mathrm{~g} / \mathrm{min}$ ), estimated from the primed constant infusions of the $\mathrm{L}-\left[\right.$ ureido- $\left.{ }^{13} \mathrm{C}\right]$ citrulline tracer and $T T R_{\mathrm{Cit}}$ and $T T R_{\mathrm{Arg}}$ are the respective TTRs of $L-\left[{ }^{15} \mathrm{~N}-{ }^{2} \mathrm{H}_{2}\right]$ citrulline and $L-\left[{ }^{15} \mathrm{~N}_{2^{-}}{ }^{2} \mathrm{H}_{2}\right]$ arginine.

\section{Plasma flow and net substrate fluxes}

Plasma flow across the small intestine and kidney was calculated using the indicator dilution technique with ${ }^{14} \mathrm{C}-\mathrm{PAH}$ as described recently (18). Organ substrate fluxes are calculated by multiplying the venous-arterial concentration difference with the mean plasma flow and are expressed in nmol/10 $\mathrm{g}$ body wt per minute. A positive flux indicates net release and a negative flux reflects net uptake. BCAA is the sum of the Branched Chain Amino Acids: valine, leucine and isoleucine. SUMAA is the SUM of the Amino Acids glutamate, asparagine, serine, glutamine, glycine, threonine, histidine, citrulline, alanine, taurine, arginine, tyrosine, valine, methionine, isoleucine, phenylalanine, tryptophan, leucine, ornithine and lysine.

\section{Statistics}

Comparisons were made between SAL/SAL and ASE/SAL to test the effect of arginase treatment. The SAL/SAL group was compared with the SAL/LPS group to test for the effect of LPS administration. Further the ASE/LPS group was compared with the ASE/SAL group to test the effect of LPS treatment during reduced arginine availability. The Mann-Whitney $U$ non-parametric test was used to test for 
differences, $P<0.05$ was considered significant. Data are presented as means \pm SEM.

\section{Results}

All animals survived the $5 \mathrm{~h}$ experimental period.

\section{Systemic parameters}

Injection of mice with arginase specifically reduced circulating arginine by $-60 \%$ at $\mathrm{t}=5 \mathrm{~h}$ (Figure 2). Arginase catalyses the production of ornithine and urea from arginine. In the arginase-treated mice plasma ornithine was indeed increased (Table 1), but urea was not.

Table 1. Arterial concentrations. Values are mean \pm SEM in $\mu M .{ }^{*} p<0.05$ vs. SAL/SAL, $" p<0.05$ vs. ASEISAL.

\begin{tabular}{lrlrlrl}
\hline & SAL & $/$ SAL & SAL $/$ LPS & ASE $/$ SAL & ASE $/$ LPS \\
\hline CIT & 77 & \pm 5 & 98 & \pm 8 & $75 \pm 7$ & $84 \pm 9$ \\
ORN & 75 & \pm 14 & $131 \pm 12^{*}$ & $109 \pm 8^{*}$ & $140 \pm 9^{*}$ \\
Urea & $4250 \pm 523$ & $6080 \pm 653^{*}$ & $3438 \pm 641$ & $6166 \pm 786^{*}$ \\
GLN & $445 \pm 32$ & $599 \pm 37^{*}$ & $488 \pm 24$ & $574 \pm 50$ \\
LYS & $386 \pm 26$ & $495 \pm 41^{*}$ & $395 \pm 33$ & $450 \pm 35$ \\
& & & & & & \\
PHE & 86 & \pm 8 & $136 \pm 12^{*}$ & $96 \pm 8$ & $136 \pm 14^{*}$ \\
BCAA & 437 & \pm 34 & $598 \pm 62^{*}$ & $388 \pm 35$ & $541 \pm 39^{*}$ \\
SUM & 3168 & \pm 207 & $3876 \pm 319$ & $2885 \pm 189$ & $3437 \pm 323$ \\
\hline
\end{tabular}

Table 2. Plasma fluxes of arginine, citrulline and phenylalanine. Values are mean \pm SEM in nmol/ $10 \mathrm{~g}$ body wt per minute. ${ }^{*} p<0.05 \mathrm{vs}$. SAL/SAL.

\begin{tabular}{lcccrrr}
\hline & SAL & / SAL & SAL $/$ LPS & ASE $/$ SAL & ASE / LPS \\
\hline ARG & $82 \pm 6$ & $83 \pm 6$ & $63 \pm 5^{*}$ & $61 \pm 3$ \\
CIT & $16 \pm 2$ & $17 \pm 2$ & $18 \pm 4$ & $17 \pm 2$ \\
PHE & $67 \pm 6$ & $75 \pm 5$ & $85 \pm 11$ & $79 \pm 5$ \\
\hline
\end{tabular}




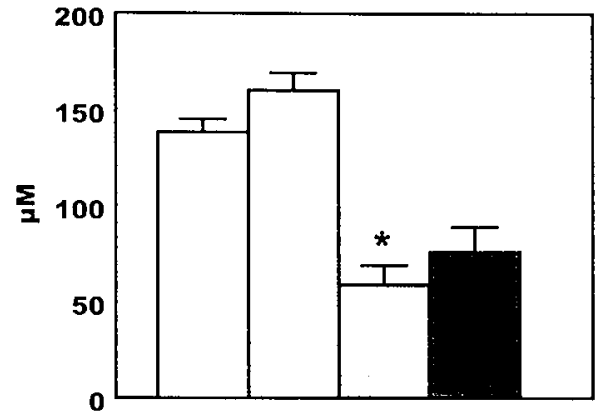

Figure 2. Effects of treatment with arginase and/or bacterial endotoxin on circulating arginine. Measurements performed at $t=5 \mathrm{~h}$. ${ }^{*} p<0.05$ vs. SAL/SAL.

$\square$ SALISAL
SAL/LPS ASE/SAL

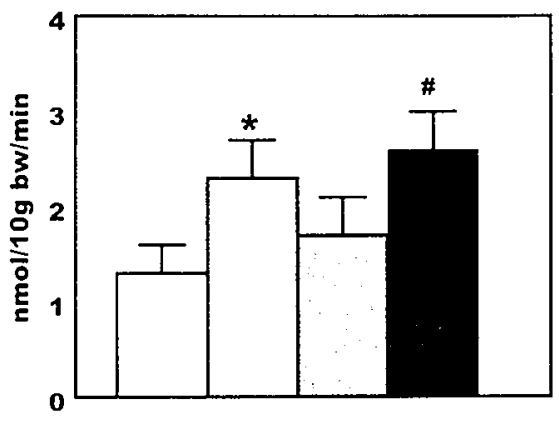

Figure 3. Effects of reduced circulating arginine and/or bacterial endotoxin on systemic NO production. NO production measured as the conversion of $\left[{ }^{15} \mathrm{~N}_{2}{ }^{2} \mathrm{H}_{2}\right.$ ] arginine to $\left[{ }^{15} \mathrm{~N}^{2} \mathrm{H}_{2}\right.$ ]citrulline. ${ }^{*} \mathrm{p}<0.05$ vs. SAL/SAL, " $p<0.05$ vs. ASE/SAL.

Stable isotope tracers were infused to quantify the plasma fluxes of arginine and citrulline and to quantify the rate of NO production. Administration of arginase reduced plasma arginine flux (Table 2). Plasma citrulline flux was not changed by arginase treatment. Also, the rate of conversion of $\left[{ }^{15} \mathrm{~N}_{2}\right]$ arginine to $\left[{ }^{15} \mathrm{~N}\right]$ citrulline, the rate of NO production, was not affected by the reduction of circulating arginine (Figure 3). In agreement with this result, the end-products of NO in blood, nitrite and nitrate, were not changed by arginase treatment (Figure 4). Together these results indicate that cNOS mediated NO production was not compromised by the reduction of arterial arginine.

To measure the relation between protein turnover and plasma arginine flux, we also measured the plasma flux of phenylalanine. The decrease in arginine flux observed in animals with reduced circulating arginine levels was not caused by a reduction of protein turnover, because the phenylalanine flux was not decreased by arginase treatment. Therefore, non-protein related arginine flux was decreased by treatment with arginase. 


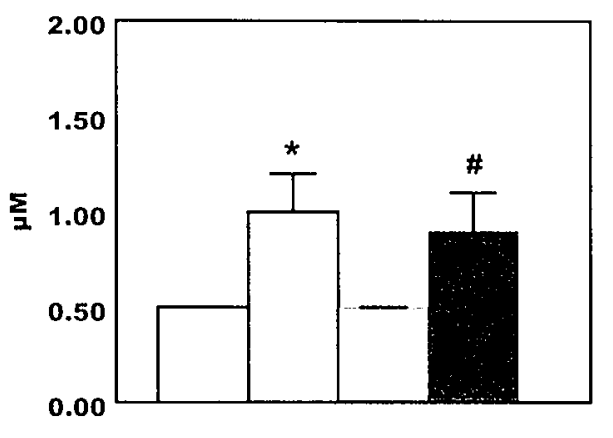

$\square$ SAL/SAL $\square$ ASE/SAL

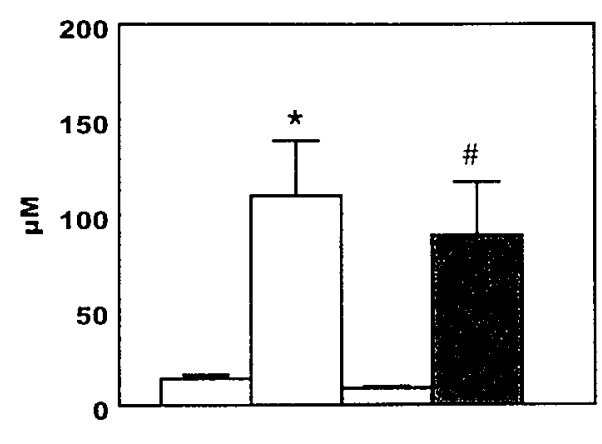

SAL/LPS $\square$ ASE/LPS

Figure 4. Effects of reduced circulating arginine and/or bacterial endotoxin on the arterial $\mathrm{NO}_{2}{ }^{\circ}$ and $\mathrm{NO}_{3}{ }^{-}$concentrations. Left panel: $\mathrm{NO}_{2}{ }^{-}$; right panel: $\mathrm{NO}_{3}{ }^{-}$. Measurements performed at $t=5 \mathrm{~h}$. ${ }^{*} p<0.05$ vs. SAL/SAL, " $p<0.05$ vs. ASE/SAL.

To investigate the effect of reduced circulating arginine on iNOS-mediated NO production, control and arginase treated mice were challenged with bacterial endotoxin. In response to this challenge, plasma arginine tended to increase $(p=0.07)$ (Figure 2). LPS treatment also increased arterial ornithine, urea, glutamine, phenylalanine and the branched-chain amino acids (Table 1).

The plasma fluxes of arginine and citrulline were unaffected (Table 2). As expected, the rate of NO synthesis was increased by LPS treatment (Figure 3), indicating increased iNOS-mediated NO production. The concentrations of nitrite and nitrate were also increased in response to LPS treatment (Figure 4).

Co-administration of arginase and LPS did not compromise the rate of NO production (Figure 3), indicating that arginine availability was sufficient to maintain iNOS-mediated NO production. This result was also reflected in the plasma nitrite and nitrate concentrations (Figure 4). Co-administration of arginase and LPS caused an increase in circulating ornithine, urea, phenylalanine and the branched chain amino acids, but not of glutamine (Table 1).

\section{Intestine}

Intestinal plasma flow was not changed by treatment with arginase and/or endotoxin. 
Decreased circulating arginine levels did not induce increased intestinal citrulline production from glutamine (Table 3). Arginine uptake by the intestine was, however, decreased by the reduction of circulating arginine. The decrease in arginine uptake by the intestine was reflected in a decrease in arginine concentration in the ileum (Table 5). In jejunum, arginine concentration was not changed by the reduction of circulating arginine. In response to endotoxin challenge, net citrulline production by the intestine was significantly increased (Table 3 ). The increased citrulline production caused by LPS was blunted by arginase treatment (Table 3). Intestinal ornithine metabolism was not changed by arginase or LPS treatment (Table 3).

Table 3. Net intestinal substrate fluxes. Values are mean \pm SEM in nmol/10 $\mathrm{g}$ body wt per minute. Flow in $\mathrm{ml} / 10 \mathrm{~g}$ body wt per minute. ${ }^{*} \mathrm{p}<0.05 \mathrm{vs}$. SAL/SAL, ${ }^{*} \mathrm{p}<0.05 \mathrm{vs}$. ASE/SAL.

\begin{tabular}{|c|c|c|c|c|c|c|c|c|c|c|c|c|}
\hline & SAL & 1 & SAL & SAL & 1 & LPS & ASE & 1 & SAL & ASE & 1 & LPS \\
\hline Flow & 0.61 & \pm & 0.11 & 0.63 & \pm & 0.23 & 0.60 & \pm & 0.31 & 0.59 & \pm & 0.28 \\
\hline GLN & -105 & \pm & 16 & -105 & \pm & 8 & -90 & \pm & 15 & -95 & \pm & 11 \\
\hline $\mathrm{CIT}$ & 8 & \pm & 2 & 13 & \pm & $2^{\star}$ & 9 & \pm & 2 & 11 & \pm & 2 \\
\hline ARG & -9 & \pm & 4 & -5 & \pm & 2 & 2 & \pm & $2^{*}$ & -2 & \pm & $1^{\# \prime}$ \\
\hline ORN & 0 & \pm & 3 & -3 & \pm & 1 & -6 & \pm & 8 & -2 & \pm & 7 \\
\hline Urea & -176 & \pm & 125 & -93 & \pm & 95 & -127 & \pm & 144 & 101 & \pm & 143 \\
\hline PHE & -4 & \pm & 2 & 0 & \pm & 1 & 2 & \pm & 3 & 2 & \pm & 2 \\
\hline BCAA & -18 & \pm & 11 & -18 & \pm & 7 & 6 & \pm & 7 & -11 & \pm & 7 \\
\hline SUM & -95 & \pm & 71 & -18 & \pm & 53 & 21 & \pm & 46 & 3 & \pm & 44 \\
\hline
\end{tabular}

Table 4. Tissue arginine concentrations. Values are mean \pm SEM in $\mu$ mol $/ \mathrm{kg}$ wet weight. ${ }^{*} p<0.05$ vs. SAL/SAL.

\begin{tabular}{|c|c|c|c|c|c|c|c|c|c|}
\hline & SAL & I SAL & SAL & 7 & LPS & ASE & I SAL & ASE & 1 LPS \\
\hline Jejunum & 73 & \pm 10 & 86 & $I$ & 11 & 66 & \pm 8 & 69 & \pm 5 \\
\hline Ileum & 109 & \pm 15 & 114 & \pm & 7 & 68 & $\pm 14^{*}$ & 99 & \pm 16 \\
\hline Kidney & 98 & \pm 11 & 125 & \pm & $9^{*}$ & 88 & \pm 9 & 86 & 5 \\
\hline
\end{tabular}


Table 5. Net renal substrate fluxes. Values are mean \pm SEM in nmol/10 g body wt per minute. Flow in $\mathrm{ml} / 10 \mathrm{~g}$ body wt per minute. ${ }^{*} \mathrm{p}<0.05 \mathrm{vs}$. ASE/SAL.

\begin{tabular}{|c|c|c|c|c|c|c|c|c|c|c|c|c|}
\hline & SAL & 1 & SAL & SAL & 1 & LPS & $\overline{A S E}$ & 1 & SAL & ASE & 7 & LPS \\
\hline Flow & 0.73 & \pm & 0.08 & 0.84 & \pm & 0.14 & 0.71 & \pm & 0.10 & 0.84 & \pm & 0.11 \\
\hline $\mathrm{CIT}$ & -15 & \pm & 3 & -20 & \pm & 2 & -15 & \pm & 2 & -18 & \pm & 1 \\
\hline ORN & -7 & \pm & 8 & -2 & \pm & 1 & 3 & \pm & 5 & 0 & \pm & 4 \\
\hline Urea & -308 & \pm & 65 & -83 & \pm & 159 & -72 & \pm & 237 & -544 & \pm & 252 \\
\hline GLN & -42 & \pm & 22 & -61 & \pm & 7 & -12 & \pm & 26 & -68 & \pm & $7^{\#}$ \\
\hline Amm & 55 & \pm & 67 & 12 & \pm & 13 & 41 & \pm & 13 & -2 & \pm & $12^{*}$ \\
\hline PHE & -3 & \pm & 2 & -6 & \pm & 2 & 6 & \pm & 4 & -2 & \pm & 2 \\
\hline BCAA & -4 & \pm & 10 & 6 & \pm & 3 & 18 & \pm & 9 & -3 & \pm & $7^{\#}$ \\
\hline SUM & -40 & \pm & 69 & 8 & \pm & 20 & 81 & \pm & 75 & -92 & \pm & 53 \\
\hline
\end{tabular}

\section{Kidney}

In the kidney, arginine is produced from circulating citrulline that originates from intestinal glutamine metabolism. In response to reduced circulating arginine, renal citrulline uptake (Table 5) and arginine production (Figure 5) were not changed. Thus, the intestinal-renal axis for the production of arginine was not activated in response to acute reduction of circulating arginine. Renal arginine concentration was not changed in arginase-treated animals (Table 4).

Net renal arginine production was increased in response to LPS treatment (Figure 5). In addition, the concentration of arginine in the kidney was increased by LPS administration (Table 4). LPS treatment did not increase renal arginine concentration and production in mice with reduced circulating arginine levels (Table 4, Figure 5).

\section{Discussion}

In the present study, the effects of reduced circulating arginine on cNOS and iNOSmediated NO production were investigated. Systemic injection of arginase was used to obtain a reduction of circulating arginine, as has been described before in guinea pigs (11) and rats $(11,13,25)$. Injected arginase may be cleared from the circulation 
by macrophages, since deletion of hepatic Kupffer cells caused an increase in circulating liver-derived arginase in a rat model of hepatic failure (26). To make sure that sufficient arginase is present in the circulation throughout the study, the intravenous injection with arginase was given twice.

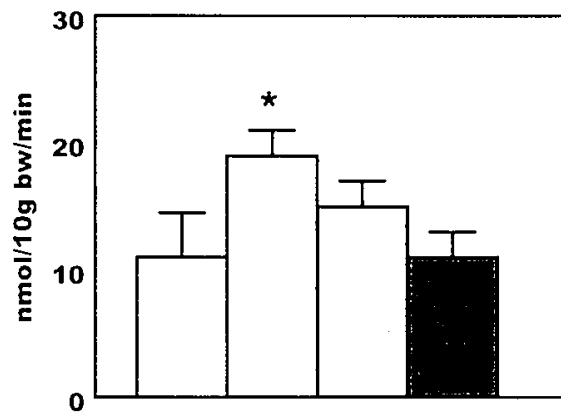

$\square$ SAL/SAL $\square$ ASE/SAL $\square$ SAL/LPS $\square$ ASE/LPS

Figure 5. Effects of reduced circulating arginine and/or bacterial endotoxin on net renal arginine production. $p<0.05 \mathrm{vs}$. SAL/SAL.

Several lines of evidence indicate that, although the $K_{m}$ of NOS for arginine is around $2-20 \mu \mathrm{M}(27)$, the production of $\mathrm{NO}$ is dependent on extracellular arginine and cellular arginine transport $(8-10,28)$. The CAT1 transporter, the main arginine transporter in intestine and kidney (29), has a $\mathrm{K}_{\mathrm{m}}$ of 100-150 $\mu \mathrm{M}(29)$. In the present study, plasma arginine was reduced from $138 \mu \mathrm{M}$ to $59 \mu \mathrm{M}$ by arginase treatment. Thus, if arginine transport from the circulation determines the rate of NO synthesis, we would likely detect it.

The $\sim 60 \%$ reduction of circulating arginine caused a $\sim 40 \%$ reduction of arginine concentration in the ileum, which was in agreement with the reduction of arginine uptake by the intestines in arginase treated animals. In contrast, the concentration of arginine in the jejunum was not compromised at all. These results indicate that the arginine concentration in the ileum is dependent on circulating arginine. The arginine concentration in the jejunum seems independent from circulating arginine. Intestinal absorption of amino acids mainly takes place in the 
jejunum, and it may thus be that arginine concentration in the jejunum is mainly determined by arginine intake.

Renal intracellular arginine was also unaffected by the decrease in circulating arginine. In contrast, in response to LPS administration the concentration of arginine was increased in the circulation and in renal tissue and coincided with increased de novo arginine production by the kidney. It thus seems that the arginine concentration in renal tissue is mainly determined by intrarenal arginine production.

Although a large reduction of circulating arginine was obtained by intravenous injection of arginase, in general the tissue data point to a limited reduction of tissue arginine levels. This may also explain why the inter-organ arginine synthetic pathway via glutamine and citrulline was not up-regulated by a reduction in circulating arginine. Our study does not support a previous study in which renal arginine synthesis was increased in response to reduced plasma arginine levels (13). In that study, tissue arginine levels were not reported, but possibly arginase administration causes a rapid decrease in tissue arginine levels in rats, but not in mice.

In the present experiments, cNOS-mediated NO production was studied in saline treated mice, and iNOS-mediated NO production was studied after LPS treatment. After entering the blood, $80-90 \%$ of the LPS is present in the plasma compartment, whereas only a minor part is cell associated (30). In a short-term study like ours, the main route of LPS clearance is uptake by phagocytic cells (31).

Therefore, out present data suggest that circulating arginine is not an important determinant for the rate of NO production, either by cNOS or iNOS, when tissue arginine levels are not reduced. It is possible that we would have obtained different results had tissue arginine levels been reduced. In endothelial cells a complex between the arginine transporter CAT1 and eNOS has been described (32). This complex is believed to provide a mechanism for the direct delivery of substrate arginine to eNOS. In the present study, a reduction of circulating arginine did not compromise cNOS mediated NO production, and it thus seems that eNOS also uses intracellular sources of arginine.

The apparent discrepancy between the 5-fold increase in plasma nitrate and the doubling of the NO production rate indicates that it is impossible to estimate the rate of NO production from a plasma concentration. Plasma nitrate is influenced by other processes besides nitric oxide production, including urinary excretion. In the basal condition, the rate of NO production correlates very well to the urinary nitrate 
excretion rate (7), which is linearly related to plasma nitrate (33). However, in the diseased state, like endotoxemia or sepsis, renal function may deteriorate, causing a rise in plasma nitrate that is more pronounced than the actual rate of NO production.

In response to endotoxin challenge both systemic NO production and de novo arginine synthesis in the kidney were increased, in agreement with previous results in our laboratory (34). These findings have led us to the conclusion that increased arginine production is necessary to maintain increased iNOS mediated NO production in response to endotoxemia (34). Increased NO production was sustained in the arginase-treated mice that suffered from reduced arginine levels and that did not show increased renal de novo arginine synthesis. Possibly, circulating arginine and arginine transport determine NO production only when they induce a drop in the tissue arginine level. We did not expect a reduction in the plasma arginine flux after treatment with arginase. This reduction in systemic arginine flux by arginase treatment was not caused by a reduction in whole body protein turnover or de novo arginine production. Therefore, our results most probably indicate that endogenous arginase activity was reduced in response to reduced circulating arginine. In this respect the present study confirms and expands data in human volunteers indicating that arginine homeostasis is maintained via regulation of arginine catabolism (35).

In conclusion, the present study indicates that an acute reduction of circulating arginine does not compromise cNOS or iNOS mediated NO production in mice. In addition, the present study provides evidence against a role for de novo arginine production from citrulline to counteract reduced systemic arginine availability.

\section{Acknowledgments}

We wish to thank Jean Scheyen and Hans van Eijk for the LC-MS measurements and Gabrie ten Have for help with the animal experiments. This study was supported by grants 902-23-098 and 902-23-239 from the Dutch Association for Scientific Research (NWO). 


\section{References}

1. Wu G, Morris SM, Jr. Arginine metabolism: nitric oxide and beyond. Biochem.J. 1998;336(Pt 1):1-17.

2. Knowles RG, Moncada S. Nitric oxide synthases in mammals. Biochem J 1994;298:249-258.

3. Forstermann U, Closs El, Pollock JS, Nakane M, Schwartz P, Gath I, et al. Nitric oxide synthase isozymes. Characterization, purification, molecular cloning, and functions. Hypertension 1994;23:1121-1131.

4. Morris SMj, Billiar TR. New insights into the regulation of inducible nitric oxide synthesis. Am.J.Physiol. 1994;266:E829-E839.

5. Hallemeesch MM, Cobben DCP, Dejong CHC, Soeters PB, Deutz NEP. Renal amino acid metabolism during endotoxemia in the rat. J Surg Res 2000;92:193-200.

6. De Jonge WJ, Hallemeesch MM, Kwikkers KL, Ruijter JM, De Gier-de Vries C, Van Roon MA, et al. Overexpression of arginase $I$ in enterocytes of transgenic mice elicits a selective arginine deficiency and affects skin, muscle and lymphoid development. Am J Clin Nutr 2001; accepted.

7. Castillo L, Beaumier L, Ajami AM, Young VR. Whole body nitric oxide synthesis in healthy men determined from [15N]-arginine-to-[15N]citrulline labeling. Proc.Natl.Acad.Sci.USA 1996;93:11460-11465.

8. Bogle RG, Baydoun AR, Pearson JD, Moncada S, Mann GE. L-Arginine transport is increased in macrophage generating nitric oxide. Biochem.J. 1992;284:15-18.

9. Hammermann R, Hirschmann J, Hey C, Moessner J, Folkerts G, Nijkamp FP, et al. Cationic proteins inhibit $L$-arginine uptake in rat alveolar macrophages and tracheal epithelial cells. Implications for nitric oxide synthesis. Am J Respir Cell Mol Biol 1999;21:155-162.

10. Closs EI, Scheld J-S, Sharafi M, Forstermann U. Substrate supply for nitric oxide synthase in macrophages and endothelial cells: role of cationic amino acid transporters. Mol Pharmacol 2000;57:68-74.

11. Griffith OW, Park KH, Aisaka K, Levi R, Gross SS. The role of plasma arginine in nitric oxide synthesis: studies with arginase-treated guinea pigs and rats. In: Moncada S, Marletta MA, Hibbs JBj, Higgs EA, editors. The biology of nitric oxide. 1. Physiological and clinical aspects. London: Portland Press; 1992. p. 6-10.

12. Längle $F$, Roth $E$, Steininger R, Winkler $S$, Mühlbacher $F$. Arginase release following liver reperfusion. Evidence of hemodynamic action of arginase infusion. Transplantation 1995;59:1542-1549.

13. Prins HA, Houdijk AP, Wiezer MJ, Teerlink T, van Lambalgen AA, Thijs LG, et al. Reduced arginine plasma levels are the drive for arginine production by the kidney in the rat. Shock 1999;11(3):199-204.

14. Castillo L, Chapman TE, Sanchez M, Yu YM, Burke JF, Ajami AM, et al. Plasma arginine and citrulline kinetics in adults given adequate and arginine-free diets. Proc.Natl.Acad.Sci.USA 1993;90:7749-7753. 
15. Waldegrave W. Chairman Council of the European Community. Guide for the care and use of laboratory animals. Brussels, 1986. Publication 86/609.

16. Ter Steege JCA, Van de Ven WCM, Forget PP, Brouckaert P, Buurman WA. The role of endogenous IFN-gamma. TNF-alpha and IL-10 in LPS-induced nitric oxide release in a mouse model. Cytokine 1998;10:115-123.

17. Gunnett CA, Chu Y, Heistad DD, Loihi A, Faraci FM. Vascular effects of LPS in mice deficient in expression of the gene for inducible nitric oxide synthase. Am J Physiol 1998;275(2 Pt 2): $H 416-21$

18. Hallemeesch MM, Ten Have GAM, Deutz NEP. Measurement of metabolic fluxes across PDV, liver, kidney and hindquarter in mice. Lab Anim 2001;35:101-110.

19. De Blaauw I, Deutz NEP, Van der Hulst RRWW, Von Meyenfeldt MF. Glutamine depletion and increased gut permeability in non-anorectic, non-weight losing tumor bearing rats. Gastroenterology 1997;112(1):118-126.

20. Hallemeesch MM, Soeters PB, Deutz NEP. Tracer methodology in whole body and organ balance metabolic studies: plasma sampling is required. Clin Nutr 2000;19:157-163.

21. Van Eijk HMH, Rooyakkers DR, Deutz NEP. Rapid routine determination of amino acids in plasma by high-performance liquid chromatography with a 2-3 $\mu \mathrm{M}$ Spherisorb ODS II column. J.Chromatogr. 1993;620:143-148.

22. Van Eijk HMH, Rooyakkers DR, Deutz NEP. Determination of amino acid isotope enrichment using liquid chromatography-mass spectrometry. Anal.Biochem. 1999;271:8-17.

23. Dejong $\mathrm{CHC}$, Deutz NEP, Soeters PB. Renal ammonia and glutamine metabolism during liver insufficiency-induced hyperammonemia in the rat. J.Clin.Invest. 1993;92:2834-2840.

24. Wolfe RR. Radioactive and stable isotope tracers in biomedicine. Principles and practice of kinetic analysis. New York: Wiley-Liss; 1992.

25. Bune AJ, Shergill JK, Cammack R, Cook HT. L-Arginine depletion by arginase reduces nitric oxide production in endotoxic shock: an electron paramagnetic resonance study. FEBS Lett. 1995;366:127-130.

26. Prins HA, Meijer C, Nijveldt RJ, Wiezer MJ, Van Leeuwen PAM. High piasma levels of arginine and liver arginase in Kupffer-cell-depleted rats after partial hepatectomy. J Hepatol 2000;32:399-405.

27. Griffith OW, Stuehr DJ. Nitric oxide synthases: properties and catalytic mechanisms. Annu Rev Physiol 1995;57:707-736.

28. Wu G, Flynn NE, Flynn SP, Jolly CA, Davis PK. Dietary protein or arginine deficiency impairs constitutive and inducible nitric oxide synthesis by young rats. J Nutr 1999:129(7):1347-54.

29. Devés $R$, Boyd CAR. Transporters for cationic amino acids in animal cells: discovery, structure and function. Physiol Rev 1998;78:487-545.

30. Roth RI, Levin FC, Levin J. Distribution of bacterial endotoxin in human and rabbit blood and effects of stroma-free hemoglobin. Infect Immun 1993;61:3209-3215.

31. Mathison JC, Ulevitch RJ. The clearance, tissue distribution, and cellular localization of intravenously injected lipopolysaccharide in rabbits. J Immunol 1979;123:2133-2143. 
Chapter 4

32. McDonald KK, Zharikov S, Block ER, Kilberg MS. A caveolar complex between the cationic amino acid transporter 1 and endothelial nitric-oxide synthase may explain the "arginine paradox". J Biol Chem 1997;272:31213-31216.

33. Godfrey M, Majid DSA. Renal handling of circulating nitrates in anesthetized dogs. Am J Physiol 1998:275(1 Pt 2):F68-73.

34. Hallemeesch MM, Soeters PB, Deutz NEP. Renal arginine and protein synthesis are increased during early endotoxemia in mice. Am J Physiol: Renal Physiol 2001; August 21 , 10.1152/ajprenal.0039.2001 (In Press).

35. Castillo L, Sanchez M, Chapman TE, Ajami A, Burke JF, Young VR. The plasma flux and oxidation rate of ornithine adaptively decline with restricted arginine intake.

Proc.Natl.Acad.Sci.USA 1994;91:6393-6397. 


\section{2}

Chronic reduction of circulating arginine by ornithine transcarbamylase-deficiency causes a reduction of cNOSmediated NO production.

Marcella M. Hallemeesch', Cornelis H.C. Dejong ${ }^{1}$, Wouter J. de Jonge ${ }^{2}$, Peter B. Soeters ${ }^{1}$, Wouter H. Lamers ${ }^{2}$, Nicolaas E.P. Deutz ${ }^{1}$

${ }^{1}$ Dept of Surgery, Maastricht University, Maastricht and ${ }^{2}$ Dept. of Anatomy and Embryology, University of Amsterdam, The Netherlands. 


\section{Abstract}

The amino acid arginine is the sole precursor for nitric oxide (NO) synthesis. We recently demonstrated that acute reduction of circulating arginine caused a reduction of phenylalanine hydroxylation, but did not compromise constitutive nitric oxide synthase (CNOS) or inducible NOS (iNOS)-mediated NO production. In the present experiment we studied the effect of a chronic reduction in arginine availability on cNOS and iNOS-mediated NO production and phenylalanine hydroxylation in ornithine transcarbamylase-deficient (OTCD) mice. cNOS-mediated NO production was measured under baseline conditions, and iNOS mediated NO production was measured after endotoxin treatment (LPS $10 \mathrm{mg} / \mathrm{kg}$ i.p.). Plasma amino acids and tracer-tracee ratios were measured by LC-MS. NO production was measured as the in vivo conversion of $L-\left[{ }^{15} \mathrm{~N}_{2}\right.$-guanidino $]$ arginine to $\mathrm{L}-\left[{ }^{15} \mathrm{~N}\right]$ citrulline, and phenylalanine hydroxylation as the in vivo conversion of $L-\left[r i n g-{ }^{2} \mathrm{H}_{5}\right]$ phenylalanine to $L-[$ ring${ }^{2} \mathrm{H}_{4}$ ]tyrosine. OTC deficiency caused a reduction of circulating arginine (28\% and $38 \%$ in male and female mice, respectively). Reduced plasma arginine caused a reduction of cNOS-mediated NO production and phenylalanine hydroxylation. In response to endotoxin treatment, circulating arginine increased and iNOS-mediated NO production was induced, regardless of phenotype. In conclusion, chronic arginine deficiency caused by OTC deficiency impairs cNOS but not iNOS-mediated NO production. Chronic arginine deficiency may therefore interfere with physiological functions related to cNOS. In addition, this study provides evidence for a relationship between arginine deficiency and phenylalanine hydroxylation.

\section{Introduction}

The amino acid arginine serves multiple functions including the production of nitric oxide (NO) (1). The production of arginine is characterized by the successive action of the small intestine and the kidney (the gut-kidney axis) (2). The small intestine produces citrulline from glutamine. Citrulline is released into the circulation and taken up by the kidney where it is converted to arginine. The importance of this route was recently illustrated in rats with short bowel syndrome in our lab (3). Reduction of citrulline production by the intestine caused a reduction of renal arginine production. 
It is conceivable that a reduction of circulating arginine might affect NO synthesis. In this respect, an interesting model of reduced arginine and citrulline levels is ornithine transcarbamylase (OTC) deficiency.

OTC deficiency is an $X$-linked disease (4), and the most common inborn error of the urea cycle (Figure 1), with a prevalence of about 1 in 40,000 births (5) and a high morbidity and mortality rate. The OTC enzyme normally is present in the periportal zone of the liver and in the intestinal mucosa (6). It involves diminished conversion of ornithine and carbamylphosphate to citrulline accompanied by elevated glutamine and reduced citrulline and arginine $(7,8)$. The reduction of circulating arginine may limit NO production.

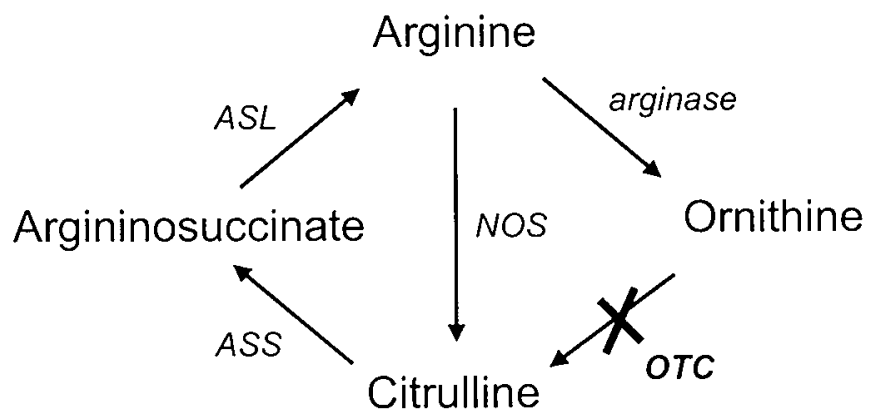

Figure 1. Location of the ornithine transcarbamylase gene defect in arginine metabolism. OTC $=$ ornithine transcarbamylase, NOS= nitric oxide synthase, ASS= argininosuccinate synthase, $A S L=$ argininosuccinate lyase .

NO has important cardiovascular, neuronal and immunological functions. NO is produced from arginine by nitric oxide synthase, of which three isoforms exist: endothelial NOS (eNOS), neuronal NOS (nNOS) and inducible NOS (iNOS) $(9,10)$. Of these, eNOS and nNOS are expressed constitutively and are therefore often collectively termed cNOS. The third isoform is inducible by various microbial products (including lipopolysaccharide, LPS) and inflammatory cytokines, and is therefore named iNOS (11). NOS and phenylalanine hydroxylase share the co-factor tetrahydrobiopterin. In mice challenged with an acute reduction of circulating arginine, we recently observed a tendency towards a reduction of phenylalanine 
hydroxylation. A relationship between circulating arginine and phenylalanine hydroxylation has, to the best of our knowledge, not yet been documented.

A reliable model for reduced circulating arginine by OTC deficiency is the sparse fur mouse (spf ${ }^{\text {ash }}$ ) (12). Up to now, this model was mainly used to explore the effects of gene therapy (8). We have developed methods to measure metabolic parameters in vivo in mice (13). In the present experiment, we sought to measure the effect of reduced arginine synthetic capacity caused by OTC deficiency on CNOS and iNOSmediated NO production and phenylalanine hydroxylation.

\section{Materials and Methods}

\section{Animals}

OTC deficient spf ${ }^{\text {ash }}$ and the parental background strain C57BL6/J (15-22 g, 2-3 months old) were bred at the Dept. of Anatomy and Embryology (AMC, Amsterdam, The Netherlands) and transported to the Centralized Animal Facilities of Maastricht University. They were allowed to adapt for at least one week to their new housing. The mice were fed standard lab chow and were subject to a standard 12 hour lightdark cycle (7:30 A.M. to 7:30 P.M.). Room temperature was maintained at $25^{\circ} \mathrm{C}$. Experiments were performed in accordance with the recommendations of the Guide for the Care and Use of Laboratory Animals (14), and approved by the Ethical Committee of Animal Research of Maastricht University.

\section{Experimental protocol}

In the present experiment both male and female mice were used. Genetically altered mice are often more difficult to breed than wild-type mice. Therefore, we decided to use both male and female mice. We did, however, use male and female mice in separate groups, as described before (13). C57BL6/J wild-type mice (WT) and OTCdeficient $\mathrm{spf}^{\text {ash }}$ mice (OTCD) were randomly assigned to receive LPS (E coli O55:B5, $250 \mu \mathrm{g}$ in $0.5 \mathrm{ml}$ saline, Sigma, St. Louis, MO) or a corresponding volume of saline (Figure 2). Drinking water was provided but food was withheld after the injection of endotoxin or saline to avoid influences of differences in food intake. After LPS injection, the OTC deficient mice were put under a heating lamp to ensure maintenance of body temperature. 


\section{Experimental set-up}

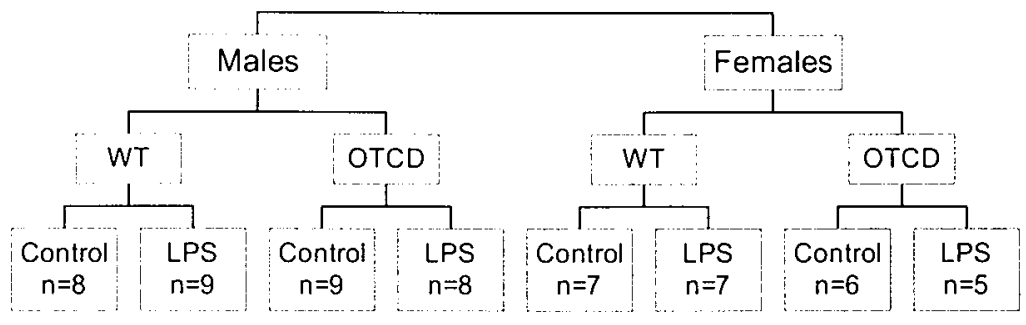

Figure 2. Experimental set-up. Male and female WT and OTCD mice were assigned to receive LPS or saline. The number of mice in each group is indicated.

Five hours after LPS treatment, anesthesia was induced in the mice by an intraperitoneal injection followed by a subcutaneous infusion of ketamine and medetomidine (13). Catheters were inserted into the jugular vein and the carotid artery. During the surgical procedures the mice were kept at $37^{\circ} \mathrm{C}$ using a temperature controller (Technical Service, Maastricht University) and heat pads (13). A primed-constant infusion of $\mathrm{L}$-[guanidino- ${ }^{15} \mathrm{~N}_{2}$ ] arginine, $\mathrm{L}$-[ureido- ${ }^{13} \mathrm{C}-{ }^{2} \mathrm{H}_{2}$ ]citrulline, L-[ring- ${ }^{2} \mathrm{H}_{5}$ ]phenylalanine and L-[ring- ${ }^{2} \mathrm{H}_{2}$ ]tyrosine (Mass Trace, Woburn, MA) was given in the jugular vein (per mouse: prime $\left[{ }^{15} \mathrm{~N}_{2}\right]$ arginine: $850 \mathrm{nmol},\left[{ }^{13} \mathrm{C}\right.$ -

${ }^{2} \mathrm{H}_{2}$ Jcitrulline: $215 \mathrm{nmol},{ }^{2} \mathrm{H}_{5}$-phenylalanine: $340 \mathrm{nmol},{ }^{2} \mathrm{H}_{2}$-tyrosine: $215 \mathrm{nmol}$, infusion $\left[{ }^{15} \mathrm{~N}_{2}\right]$ arginine: $1,700 \mathrm{nmol} / \mathrm{hr},\left[{ }^{13} \mathrm{C}_{-}{ }^{2} \mathrm{H}_{2}\right]$ citrulline: $430 \mathrm{nmol} / \mathrm{hr}$, $\left[{ }^{2} \mathrm{H}_{5}\right]$ phenylalanine: $680 \mathrm{nmol} / \mathrm{hr},\left[{ }^{2} \mathrm{H}_{2}\right]$ tyrosine $430 \mathrm{nmol} / \mathrm{hr}$ ). Steady state of tracers and metabolites was reached within 20 minutes (15). Blood was sampled from the carotid artery (13) and collected in heparinized cups (Sarstedt, Nümbrecht, Germany) on ice.

Blood was centrifuged to obtain plasma, because we have shown recently that plasma sampling is required in organ balance metabolic studies using amino acid tracers that do not equilibrate well with blood cell cytoplasm (16). For determination of amino acid concentrations and tracer to tracee ratios (TTRS) $80 \mu \mathrm{l}$ plasma was added to $7 \mathrm{mg}$ dry sulfosalicylic acid, vortexed, frozen in liquid nitrogen and stored at $-80^{\circ} \mathrm{C}$. Plasma amino acid concentrations were measured as described (17). Amino 
acid TTRs were measured using a fully automated liquid chromatography-mass spectrometry system (18), using FMOC as amino acid derivative. BCAA is the sum of the Branched Chain Amino Acids: valine, leucine and isoleucine. SUMAA is the SUM of the Amino Acids glutamate, asparagine, serine, glutamine, glycine, threonine, histidine, citrulline, alanine, taurine, arginine, tyrosine, valine, methionine, isoleucine, phenylalanine, tryptophan, leucine, ornithine and lysine. For determination of plasma urea and ammonia, $20 \mu \mathrm{l}$ plasma was added to $80 \mu \mathrm{l} 1 \%$ trichloroacetic acid. Plasma urea and ammonia were determined using commercially available kits on a Cobas Mira S (Roche Diagnostica, Hoffman La Roche, Basel, Switzerland), as described previously (19). For plasma nitrite and nitrate analysis, $50 \mu$ plasma was added to $100 \mu$ acetonitrile (Biosolve LTD, Valkenswaard, The Netherlands). Plasma nitrite and nitrate were analyzed on an isocratic HPLC system (eluens: $6 \mathrm{mM}$ sodium chloride, $1 \mathrm{mM}$ potassium dihydrogenphosphate, $\mathrm{pH}=6$ ).

\section{Calculations}

Whole body arginine and protein metabolism

Plasma arginine, citrulline, phenylalanine and tyrosine fluxes were calculated from the arterial isotopic enrichment values of respectively L-[guanidino $-{ }^{15} \mathrm{~N}_{2}$ ] $\operatorname{larginine,~} \mathrm{L}$ [ureido- ${ }^{13} \mathrm{C} ;{ }^{2} \mathrm{H}_{2}$ ]citrulline, L-[ring- ${ }^{2} \mathrm{H}_{5}$ ]phenylalanine and $\mathrm{L}$-[ring $-{ }^{2} \mathrm{H}_{2}$ ]tyrosine, using the standard steady state isotope dilution equation:

$Q=\mathrm{I} / \mathrm{TTR}(20)$,

where TTR is the tracer to tracee ratio, and I is the rate of infusion of the tracer.

Calculation of the plasma arginine to citrulline flux (NO production) was performed as follows:

$\mathrm{Q}_{\mathrm{Arg}_{\rightarrow} \mathrm{Cit}}=\mathrm{Q}_{\mathrm{Cit}} \times \operatorname{TTR}_{\mathrm{Cit}(\mathrm{M}+1)} / \operatorname{TTR}_{\mathrm{Arg}(\mathrm{M}+2)}(21)$, where $Q_{\text {Cit }}$ is the plasma citrulline flux (nmol/10 $\mathrm{g} / \mathrm{min}$ ), estimated from the primed constant infusions of $\mathrm{L}$-[ureido- ${ }^{13} \mathrm{C} ;{ }^{2} \mathrm{H}_{2}$ ]citrulline; TTR $\mathrm{Cit}$ and TTR $\mathrm{Arg}$ are the respective TTRs of [ureido- ${ }^{15} \mathrm{~N}$ ]citrulline and [guanidino $-{ }^{15} \mathrm{~N}_{2}$ ]arginine.

Calculation of the plasma citrulline to arginine flux (de novo arginine production) was performed as follows:

$\mathrm{Q}_{\mathrm{Cit} \rightarrow \text { Arg }}=\mathrm{Q}_{\mathrm{Arg}} \times \mathrm{TTR}_{\mathrm{Arg}(\mathrm{M}+3)} / \mathrm{TTR}_{\mathrm{Cit}(\mathrm{M}+3)}(22)$,

where $Q_{A r g}$ is the plasma arginine flux (nmol $/ 10 \mathrm{~g} / \mathrm{min}$ ), estimated from the primed constant infusions of $L$-[guanidino- ${ }^{15} \mathrm{~N}_{2}$ ] ]arginine; $T \mathrm{TR}_{\mathrm{Arg}}$ and $T T \mathrm{R}_{\mathrm{Cit}}$ are the respective TTRs of $\mathrm{L}$-[guanidino- ${ }^{13} \mathrm{C} ;{ }^{2} \mathrm{H}_{2}$ ]arginine and $\mathrm{L}$-[ureido- ${ }^{13} \mathrm{C} ;{ }^{2} \mathrm{H}_{2}$ ]citrulline. 
Calculation of the plasma phenylalanine to tyrosine flux (phenylalanine hydroxylation) was performed as follows:

$Q_{\text {Phe }_{\rightarrow} \text { Tyr }}=Q_{\text {Tyr }} \times \operatorname{TTR}_{\text {Tyr(M+4) }} / \operatorname{TTR}_{\text {Phe }_{(M+5)}}(23)$,

where $Q_{T y r}$ is the plasma tyrosine flux (nmol/10 $\mathrm{g} / \mathrm{min}$ ), estimated from the primed

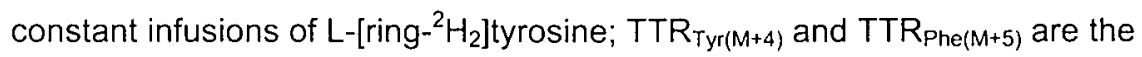
respective arterial enrichments of $L$-[ring- $\left.{ }^{2} \mathrm{H}_{4}\right]$ tyrosine and $L$-[ring- $\left.{ }^{2} \mathrm{H}_{5}\right]$ phenylalanine.

\section{Statistics}

ANOVA with compound as repeated measure, and genotype, sex and treatments factor showed significant compound-genotype and compound-sex interactions. Therefore an ANOVA per compound was carried out. This ANOVA (with significance level 0.002 to safeguard against accumulation of Type I errors; Bonferroni correction) showed no genotype, sex and treatment interaction, indicating that treatment and sex effects are independent of genotype.

\section{Results}

Effects of OTC deficiency on arginine - NO metabolism

OTCD causes the sparse-fur phenotype in male and homozygous female mice. Compared to the wild-type C57BL6/J mice, the fur of OTCD mice is brownish. In male and homozygous female OTCD mice, circulating citrulline was reduced $40-45 \%$ and arginine $30 \%$ (male) and $40 \%$ (female) (Table 1). In addition, OTC deficiency caused an increase in plasma ammonia (Table 1).

The reduction of circulating citrulline was accompanied by a reduction of systemic citrulline flux (Table 2). Circulating citrulline and citrulline turnover were higher in female animals than in male animals. In contrast, the reduction of circulating arginine was not accompanied by a reduction of systemic arginine turnover. Reduced arginine availability caused by OTC deficiency caused a significant reduction of the systemic NO production rate, measured as $\left[{ }^{15} \mathrm{~N}_{2}\right]$ arginine to $\left[{ }^{15} \mathrm{~N}\right] c$ citrulline labeling (Figure 3). These results indicate that chronic reduction of plasma arginine caused a reduction of cNOS-mediated NO production. The reduction of the NO production rate by the chronic reduction of circulating arginine in OTC deficient mice was not correlated by the plasma values of the end-products nitrite and nitrate (Table 1). 


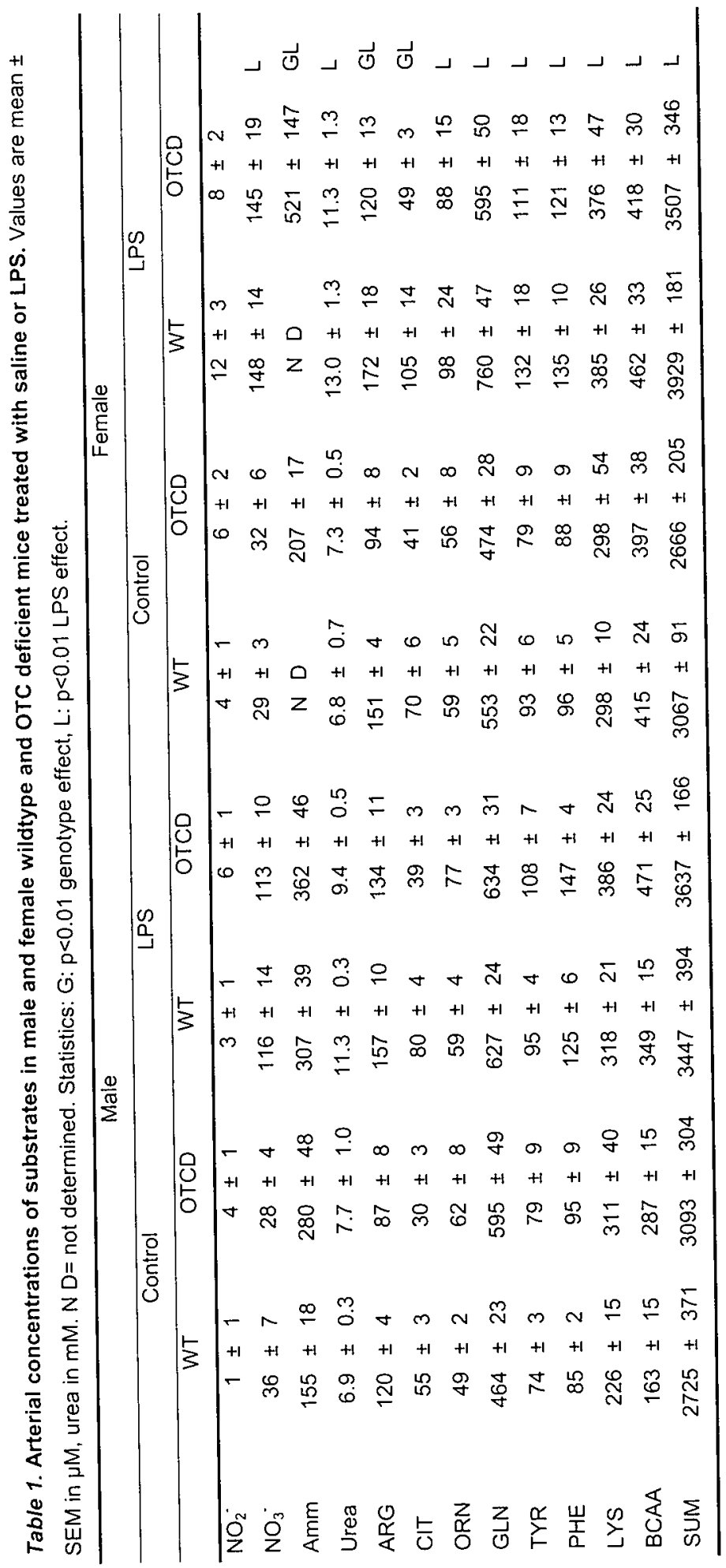




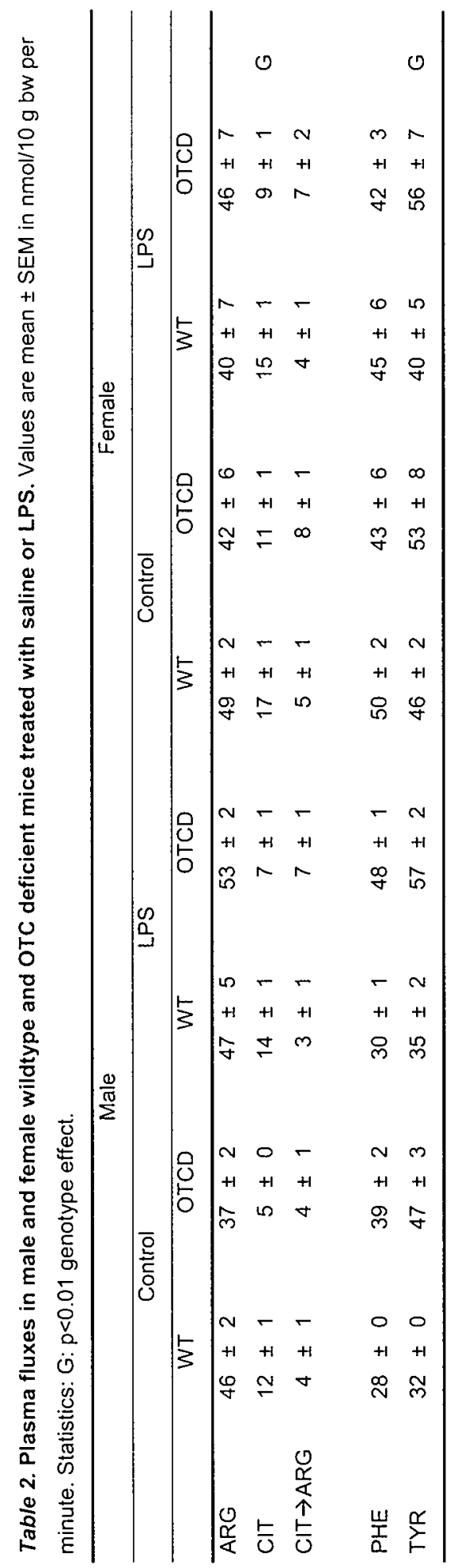



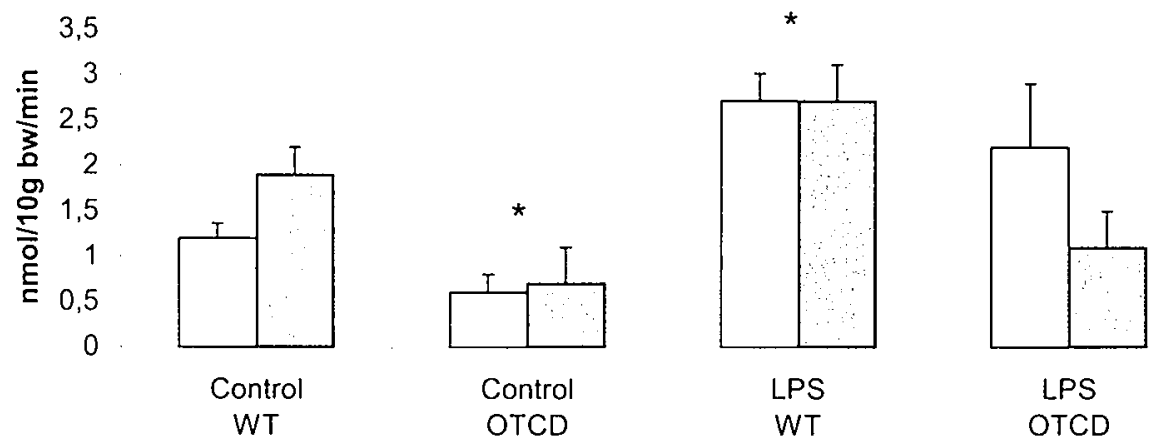

Figure 3. Nitric oxide production in WT and OTCD mice under baseline and LPS-treated conditions. Nitric oxide production was measured as the in vivo conversion of $L-\left[{ }^{15} N_{2}\right.$ guanidino]arginine to L- $\left[{ }^{15} \mathrm{~N}\right]$ citrulline.

Effects of LPS treatment on arginine metabolism in wildtype and OTC deficient mice In response to treatment with bacterial endotoxin, plasma nitrite $(p<0.05)$ and plasma nitrate were increased, regardless of genotype and sex. In response to treatment with bacterial endotoxin, the arterial concentration of ammonia, urea and amino acids increased (Table 1).

In response to endotoxin challenge the conversion of $\left[{ }^{15} \mathrm{~N}_{2}\right]$ arginine to $\left[{ }^{15} \mathrm{~N}\right]$ citrulline was increased (Figure 3 ). The increase was higher in males than in females (WT males: $+125 \%$ vs females: $+40 \%$ ). The increase in iNOS-mediated NO production appeared more pronounced during OTC deficiency (OTCD males: $+260 \%$ vs females: $+60 \%$ ).

NO production was significantly correlated to circulating arginine levels (Figure 4). This relationship was evident in male and female mice, but stronger in male $\left(p<0.001, r^{2}=0.44\right)$ than in female mice $\left(p=0.013, r^{2}=0.23\right)$. Thus, 23 to $44 \%$ of variance in the rate of NO production was explained by the level of circulating arginine.

\section{Effects of OTC-deficiency on phenylalanine metabolism}

With respect to phenylalanine and tyrosine metabolism, the general tendency was that plasma phenylalanine and tyrosine concentration increased in male OTCD mice, whereas these amino acids tended to decrease in female animals (Table 1). 

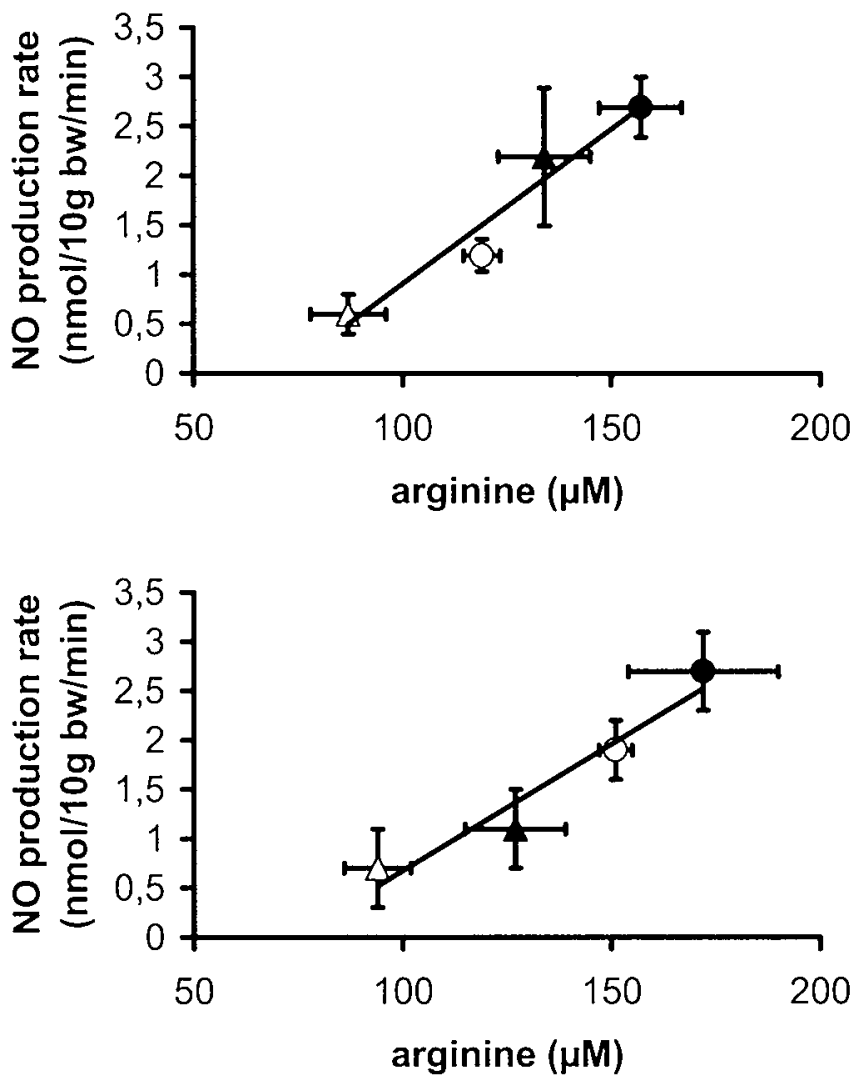

Figure 4. Correlation between circulating arginine and the rate of NO production in male and female mice. Upper panel: males, lower panel: females. Symbols: $O W T ; \triangle O T C D ;$ open symbols: Control; closed symbols: LPS.

Significance was however not reached. The systemic phenylalanine flux was not changed in OTC deficient mice. In contrast, the systemic tyrosine flux was significantly decreased by OTC deficiency. In agreement with the change in systemic tyrosine flux, the plasma phenylalanine to tyrosine concentration ratio was increased in OTC deficient mice (males: WT 1.15 vs. OTCD 1.20; females: WT 1.03 vs. OTCD 1.11), indicating a change in phenylalanine to tyrosine hydroxylation. These results were confirmed by direct measurement of phenylalanine to tyrosine hydroxylation by means of [ring- ${ }^{2} \mathrm{H}_{5}$ ]phenylalanine to [ring- ${ }^{2} \mathrm{H}_{4}$ ]tyrosine conversion (Figure 5). In 
addition, it was shown that in male mice, phenylalanine hydroxylation was decreased by $25 \%$, whereas phenylalanine hydroxylation was decreased by $50 \%$ in female mice. In male WT mice, approximately $10 \%$ of phenylalanine flux was directed towards hydroxylation. In male OTCD mice, only $5 \%$ of phenylalanine flux was directed towards hydroxylation. In female WT mice, a larger percentage $(19 \%)$ of phenylalanine flux consisted of hydroxylation. Also in female mice OTC deficiency caused a reduction of the percentage of phenylalanine flux towards hydroxylation $(11 \%)$.

No effect of LPS treatment on the turnover rates of phenylalanine and tyrosine were observed. In addition, phenylalanine to tyrosine hydroxylation was not changed by treatment with bacterial endotoxin (Figure 5).

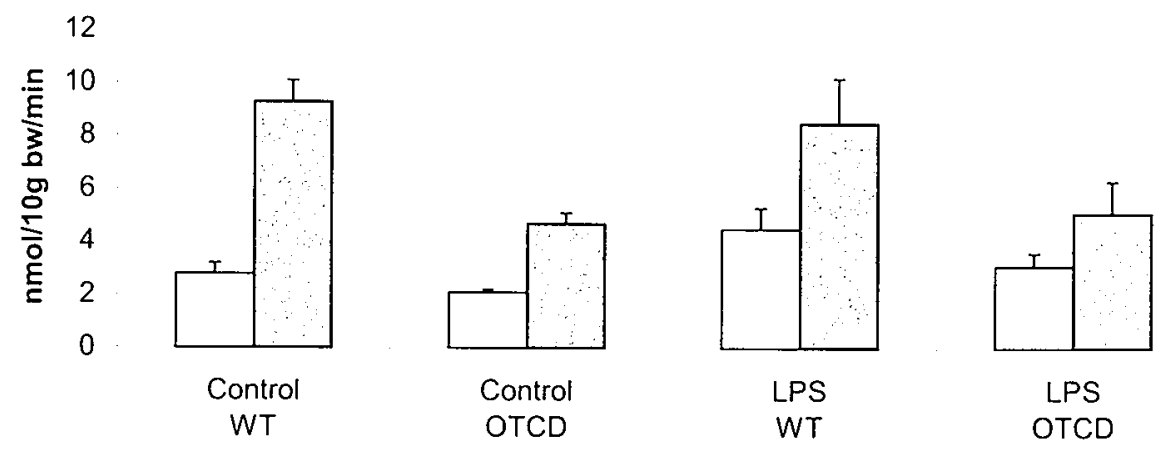

Figure 5. Phenylalanine hydroxylation in WT and OTCD mice under baseline and LPS-treated conditions. Phenylalanine hydroxylation was measured as the in vivo conversion of $\mathrm{L}$-[ring${ }^{2} \mathrm{H}_{5}$ ]phenylalanine to $\mathrm{L}-\left[\right.$ ring. $\left.{ }^{2} \mathrm{H}_{4}\right]$ tyrosine.

\section{Discussion}

In the present study, the effects of reduced circulating arginine on cNOS- and iNOSmediated NO production and phenylalanine hydroxylation were investigated. Sparse fur and abnormal skin and hair (Spf-ash) mutant mice were used as a model of arginine deficiency. These mice only have $5-10 \%$ of normal OTC activity (24), leading to a $40-45 \%$ decrease in circulating citrulline and a $30 \%$ (male) to $40 \%$ (female) decrease in circulating arginine levels. 


\section{OTCD, arginine and NO production}

In OTC deficiency the production of citrulline from ornithine is severely compromised. Indeed, in both male and female mice the concentration and systemic turnover of citrulline were significantly reduced in the present studies. In OTC-deficient mice the systemic citrulline flux nearly equals de novo arginine production, whereas in WT mice de novo arginine production is approximately $30 \%$ of citrulline turnover.

Several lines of evidence indicate that the endogenous production of NO by NOS is dependent on extracellular arginine and cellular arginine transport. Arginine transport is mediated by several transporters, and the kinetic constants $V_{\max }$ (maximal transport when excess substrate is available) and $K_{m}$ (substrate concentration at which transport rate is half-maximum) are different for these transporters. The $y^{+}$transporter (CAT2A) has a $K_{m}$ of $2-5 \mathrm{mM} \mathrm{(25),} \mathrm{which} \mathrm{is} \mathrm{above}$ the physiological arginine concentration. In contrast, the CAT1 and CAT2B transporters have a $K_{m}$ of $100-150 \mu \mathrm{M}(26)$. In the present study, plasma arginine was reduced from 120-150 $\mu \mathrm{M}$ to 87-94 $\mu \mathrm{M}$ by OTC deficiency. Thus, in the present study, plasma arginine was reduced well below the $K_{m}$ values of CAT1 and CAT2B. Although the $K_{m}$ of NOS for arginine is much lower, between $2-20 \mu \mathrm{M}$, the $K_{m}$ of NO synthesis by endothelial cells is approximately $73-150 \mu \mathrm{M}(1)$. Therefore, the $K_{m}$ of NO production by cells is in the range of normal physiological arginine concentration and mainly determined by arginine uptake.

Under baseline conditions, reduced circulating arginine by OTC deficiency compromised cNOS-mediated NO production leading to diminished NO production. OTC deficiency did not prevent an increase in circulating arginine in response to treatment with LPS. This increase in circulating arginine was not caused by an increase in de novo arginine production or increased protein breakdown, because arginine and protein turnover were not increased by LPS treatment. Possibly, the increase in circulating arginine was caused by redistribution of arginine.

In general, male and female mice responded similarly to decreased or increased arginine availability. However, under baseline conditions, NO productiuon was lower in male than in female mice. The iNOS-mediated increase in NO production in response to treatment with LPS was larger in male than in female mice. This may explain why the male gender predisposes to endotoxic shock (27). 


\section{Reduced phenylalanine hydroxylation}

The most striking phenotypic abnormality of the OTCD mice was their sparse fur phenotype, which has been described in detail before. It has been hypothesized that the sparse-fur phenotype is a direct consequence of the reduced availability of arginine, because trichohyalin, a major intermediate filament-associated protein in the inner rooth sheath and medulla of hair follicles, is very rich in arginine $(21.5 \%$ arginine). However, we have shown recently that the synthesis of the trichohyalin is not affected by a severe highly selective arginine deficiency (28), indicating that hair protein synthesis is not affected by reduced arginine availability.

A striking result of the present study was that phenylalanine hydoxylation to tyrosine was decreased in OTC-deficient mice. Interestingly, phenylalanine hydroxylation to tyrosine is the first step in melanin formation. Thus, the decrease of phenylalanine to tyrosine conversion may explain the sparse fur phenotype observed in OTCD mice. In patients with phenylketonuria (PKU), who have a reduction of $\left[{ }^{2} \mathrm{H}_{5}\right.$ ]phenylalanine to $\left[{ }^{2} \mathrm{H}_{4}\right]$ tyrosine conversion (29), and a $50 \%$ reduction in plasma arginine (30), reduced melanin formation causes lighter skin and hair. In a mouse model of PKU, hypopigmentation was reversed by gene transfer of phenylalanine hydroxylase (31).

The mechanism by which OTC deficiency causes reduced phenylalanine hydroxylation is unclear at present. Reduced phenylalanine hydroxylation occurred concomitant to reduced cNOS-mediated NO production. We may hypothesize that reduced cNOS-mediated NO production causes reduced phenylalanine hydroxylation. It is known that NO produced by keratinocytes stimulates tyrosinase and melanogenesis (32). It was also shown that cNOS, not iNOS was involved in the stimulation of tyrosinase and melanogenesis (32). In our study, LPS treatment caused an increase in iNOS-mediated NO production. Phenylalanine hydroxylation was however not increased in this condition. In a previous study, acute reduction of circulating arginine in male mice tended to reduce phenylalanine hydroxylation (unpublished data). However, systemic eNOS-mediated NO production was not compromised (33). These data provide evidence against direct involvement of NO in phenylalanine hydroxylation. In addition, NOS knockout mice do not share the sparse fur phenotype.

The link between reduced arginine availability and phenylalanine hydroxylation is tetrahydrobiopterin, because tetrahydrobiopterin is a cofactor of both NOS and 
phenylalanine hydroxylase. Recent studies have indicated that the mechanism of stimulation of phenylalanine hydroxylase and NOS by tetrabiopterin is fundamentally different (34). Our previous results regarding phenylalanine hydroxylation and NO production in mice suffering an acute reduction of circulating arginine were in agreement with earlier results indicating that NOS is stimulated by much lower concentrations of the cofactor than phenylalanine hydroxylase (35).

In conclusion, circulating arginine determines the rate of NO production. A chronic reduction in circulating arginine due to OTCD causes a reduction in cNOSmediated NO production, but does not reduce the capacity for NO production. Our data also indicate that a change in circulating arginine causes a larger change in NO production in male than in female mice. In addition, the present study provides evidence that phenylalanine hydroxylation is decreased in OTCD. Reduction of cNOS-mediated NO production and phenylalanine hydroxylation may be related to phenotypic characteristics like hypopigmentation.

\section{Acknowledgments}

The authors wish to thank Mr. JLJM Scheyen, BSc and Mr. HMH van Eijk, PhD for LC-MS measurements. We also like to thank Mrs. GAM Ten Have, B.Sc. for assistance with the animal experiments, and Mr. JM Ruijter, Ph.D. for assistance with the statistical analysis. This study was supported by grants 902-23-098 and 902-23239 from the Dutch Association for Scientific Research (NWO).

\section{References}

1. Wu G, Morris SM, Jr. Arginine metabolism: nitric oxide and beyond. Biochem.J. 1998;336/Pt 1):1-17.

2. Cynober L, Le Boucher J, Vasson MP. Arginine metabolism in mammals. J.Nutr. Biochem. 1995;6:402-412.

3. Dejong CHC, Welters CFM, Deutz NEP, Heineman E, Soeters PB. Renal arginine metabolism in fasted rats with subacute short bowel syndrome. Clin Sci 1998;95:409-418.

4. Ricciuti F, Gelehrter TD, Rosenberg LE. X-Chromosome inactivation in human liver: confirmation of X-linkage of ornithine transcarbamylase. Am J Hum Genet 1976;28:332-338. 
5. Nagata N. Matsuda I, Oyanagi K. Estimated frequency of urea cycle enzymopathies in Japan. Am J Med Genet 1991;39:228-229.

6. Morris SMj. Regulation of enzymes of urea and arginine synthesis. Annu.Rev.Nutr. 1992;12:81-101.

7. Yudkoff $M$, Daikhin $Y$, Nissim I, Jawad A, Wilson J, Batshaw M. In vivo nitrogen metabolism in ornithine transcarbamylase deficiency. J Clin Invest 1996;98:2167-2173.

8. Batshaw ML, Yudkoff M, McLaughlin BA, Gorry E, Anegawa NJ, Smith IA, et al. The sparse fur mouse as a model for gene therapy in ornithine carbamoyltransferase deficiency. Gene Ther 1995;2:743-9.

9. Knowles RG, Moncada S. Nitric oxide synthases in mammals. Biochem J 1994:298:249-258.

10. Forstermann U, Closs El, Pollock JS, Nakane M, Schwartz P, Gath I, et al. Nitric oxide synthase isozymes. Characterization, purification, molecular cloning, and functions. Hypertension 1994;23:1121-1131.

11. Morris SMj, Billiar TR. New insights into the regulation of inducible nitric oxide synthesis. Am.J.Physiol. 1994;266:E829-E839.

12. Spector EB, Mazzocchi RA. The sparse fur mouse: an animal model for a human inborn error of metabolism of the urea cycle. Prog Clin Biol Res 1983;127:85-96.

13. Hallemeesch MM, Ten Have GAM, Deutz NEP. Measurement of metabolic fluxes across PDV, liver, kidney and hindquarter in mice. Lab Anim 2001;35:101-110.

14. Waldegrave W. Guide for the care and use of laboratory animals. Brussels. 1986. Report No.: Publication 86/609

15. Hallemeesch MM, Lamers WH, Meijer AJ, Soeters PB, Deutz NEP. In vivo rate of NO synthesis is increased during mouse endotoxemia. Chapter 3.1 thesis 2001.

16. Hallemeesch MM, Soeters PB, Deutz NEP. Tracer methodology in whole body and organ balance metabolic studies: plasma sampling is required. Clin Nutr 2000;19:157-163.

17. Van Eijk HMH, Rooyakkers DR, Deutz NEP. Rapid routine determination of amino acids in plasma by high-performance liquid chromatography with a 2-3 $\mu \mathrm{M}$ Spherisorb ODS II column. J.Chromatogr. 1993;620:143-148.

18. Van Eijk HMH, Rooyakkers DR, Deutz NEP. Determination of amino acid isotope enrichment using liquid chromatography-mass spectrometry. Anal.Biochem. 1999;271:8-17.

19. Dejong $\mathrm{CHC}$, Deutz NEP, Soeters PB. Renal ammonia and glutamine metabolism during liver insufficiency-induced hyperammonemia in the rat. J.Clin.Invest. 1993;92:2834-2840.

20. Wolfe RR. Radioactive and stable isotope tracers in biomedicine. Principles and practice of kinetic analysis. New York: Wiley-Liss; 1992.

21. Castillo L, Beaumier L, Ajami AM, Young VR. Whole body nitric oxide synthesis in healthy men determined from [15N]-arginine-to-[15N]citrulline labeling. Proc.Natl.Acad.Sci.USA 1996;93:11460-11465.

22. Yu YM, Burke JF, Tompkins RG, Martin R, Young VR. Quantitative effects of interorgan relationships among arginine and citrulline metabolism. Am.J.Physiol. 1996;271:E1098-E1109. 
23. Moldawer LL, Kawamura I, Bistrian BR, Blackburn GL. The contribution of phenylalanine to tyrosine metabolism in vivo. Studies in the post-absorptive and phenylalanine-loaded rat. Biochem J 1983;210:811-7.

24. DeMars R, Le Van SL, Trend BL, Russell L8. Abnormal ornithine carbamoyltransferase in mice having the sparse-fur mutation. Proc Natl Acad Sci USA 1976;73:1693.

25. White MF. The transport of cationic amino acids across the plasma membrane of mammalian cells. Biochim Biophys Acta 1985;822(3-4):355-74.

26. Devés $R$, Boyd CAR. Transporters for cationic amino acids in animal cells: discovery, structure and function. Physiol Rev 1998;78:487-545.

27. Losonczy G, Kriston T, Szabo A, Muller V, Harvey J, Hamar P, et al. Male gender predisposes to development of endotoxin shock in the rat. Cardiovasc Res 2000;47:183-191.

28. De Jonge WJ, Hallemeesch MM, Kwikkers KL, Ruijter JM, De Gier-de Vries C, Van Roon MA, et al. Overexpression of arginase $\mathrm{l}$ in enterocytes of transgenic mice elicits a selective arginine deficiency and affects skin, muscle and lymphoid development. Am J Clin Nutr 2001; accepted.

29. Van Spronsen FJ, D.-J. R, Smit GPA, Nagel GT, Stellaard F, Berger R, et al. Phenylketonuria. The hydroxylation rate of phenylalanine to tyrosine is decreased. J Clin Invest 1998;101:28752880 .

30. Linneweh F, Ehrlich M. Zur Pathogenese des Schwachsinns beim Phenolketonurie. Klin Wschr 1962;40:225.

31. Nagasaki Y, Matsubara Y, Takano H, Fujii K, Senoo M, Akanuma J, et al. Reversal of hypopigmentation in phenylketonuria mice by adenovirus-mediated gene transfer. Pediatr Res 1999;45:465-473.

32. Romero-Graillet $C$, Aberdam E, Clement M, Ortonne J.P, Ballotti R. Nitric oxide produced by ultraviolet-irradiated keratinocytes stimulates melanogenesis. J Clin Invest 1997;99:635-642.

33. Hallemeesch MM, Vissers YLJ, Soeters PB, Deutz NEP. Acute reduction of circulating arginine in mice does not compromise cNOS or iNOS-mediated NO production. Chapter 4.1 thesis 2001.

34. Werner ER, Habisch H-J, Gorren ACF, Schmidt K, Canevari L, Werner-Felmayer G, et al. Contrasting effects of N5-substituted tetrahydrobiopterin derivatives on phenylalanine hydroxylase, dihydropteridine reductase and nitric oxide synthase. Biochem J 2000;348:579583.

35. Kwon NS, Nathan CF, Stuehr DJ. Reduced biopterin as a cofactor in the generation of nitrogen oxides by murine macrophages. J Biol Chem 1989;264:20496-20501. 
Chapter 4 
4.3

Chronic reduction of circulating arginine by transgenic arginase expression causes a reduction of iNOS-mediated NO production

Marcella M. Hallemeesch ${ }^{1}$, Wouter J. de Jonge ${ }^{2}$, Peter B. Soeters' ${ }^{1}$, Wouter $H$. Lamers $^{2}$, and Nicolaas E.P. Deutz ${ }^{1}$

${ }^{1}$ Dept. of Surgery, Maastricht University, Maastricht, and ${ }^{2}$ Dept. of Anatomy and Embryology, University of Amsterdam, Amsterdam, The Netherlands 


\section{Abstract}

Background The amino acid arginine is the sole precursor for nitric oxide (NO) synthesis. We have recently engineered mice that express different levels of arginase $I$ in their enterocytes (F/A mice). In these mice circulating arginine levels are chronically reduced by $\sim 30 \%$.

Methods We now studied the effect of reduced circulating arginine on CNOS and iNOS-mediated NO production, and systemic arginine and protein turnover in male mice. NO production by cNOS was measured under baseline conditions and iNOSmediated NO production was measured after endotoxin treatment (LPS $10 \mathrm{mg} / \mathrm{kg}$ i.p.). NO production was measured as the in vivo conversion of $\left[{ }^{15} \mathrm{~N}_{2}\right]$ arginine to $\left[{ }^{15} \mathrm{~N}\right]$ citrulline.

Results In wildtype mice, de novo arginine production equaled $18 \%$ of systemic arginine turnover. In transgenic F/A-1 mice, the contribution of de novo arginine production to systemic arginine flux increased to $29 \%$. Transgenic arginase expression caused a tendency towards reduced protein turnover and decreased BCAA levels. Baseline NO production was not changed by reduced arginine availability. In response to endotoxin treatment, circulating arginine levels were not changed in wildtype or F/A-1 mice. In response to LPS administration NO production increased with $180 \%$ and $80 \%$ in wildtype and F/A-1 mice respectively.

Conclusion In transgenic F/A-1 mice, reduced protein turnover may have an argininesparing effect. In this model, a $30 \%$ reduction of circulating arginine impairs the iNOS-mediated increase in NO production, but does not change cNOS-mediated NO production.

\section{Introduction}

The amino acid arginine plays a pivotal role in the biosynthesis of various products, including proteins, nitric oxide (NO), urea, creatine, and indirectly proline and polyamines. The systemic level of arginine is maintained by dietary intake and de novo production from citrulline, mainly in the kidney $(1,2)$. Although arginine is not an essential amino acid in adults, the endogenous de novo arginine synthetic capacity is only $10 \%$ of arginine flux (3). In conditions of reduced dietary intake, or increased 
demand, such as growth, tissue repair and sepsis, the availability of arginine may be insufficient. Arginine has therefore been termed a conditionally essential amino acid $(4,5)$.

Arginine must be taken up by cells to exert its biological functions. Arginine transport is mediated by several transporter systems, and the kinetic constants $V_{\max }$ and $K_{m}$ of the individual transporters are different. Although the $K_{m}$ of NOS for arginine is only $2-20 \mu \mathrm{M}(6)$, several lines of evidence indicate that the endogenous production of NO by NOS is dependent on extracellular arginine and cellular arginine transport (7-9). In healthy volunteers the rate of NO production was $0.96 \mu \mathrm{mol} / \mathrm{kg} / \mathrm{hr}$, and equaled $1.2 \%$ of arginine flux (10). Although the percentage of arginine turnover involved in NO production was low, the plasma arginine compartment served as a significant precursor pool (54\%) for whole body NO formation (10). Thus, circulating arginine may regulate NO production.

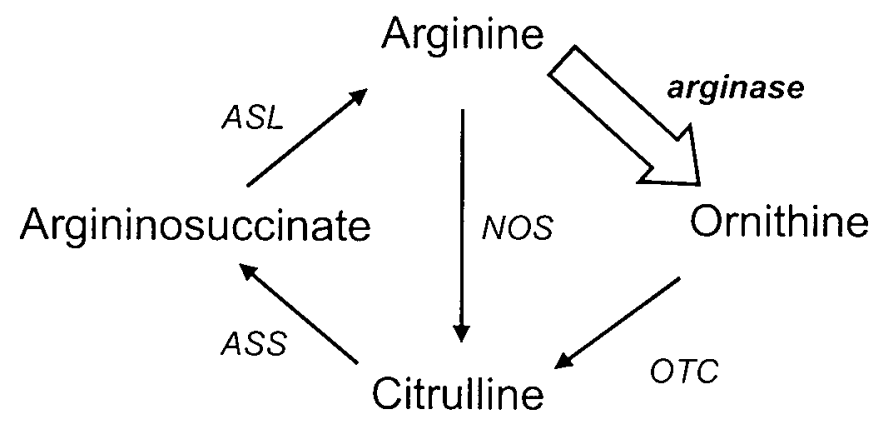

Figure 1. Mechanism of reduced arginine availability. The F/A-1 transgenic mice overexpress arginase I in their enterocytes, causing a reduction of circulating arginine. Detailed information regarding the generation of these transgenic mice was given before (11).

We have recently engineered transgenic mice that express different levels of arginase $I$ in their enterocytes (F/A transgenes) (11). Expression of arginase I causes a specific reduction of circulating arginine (Figure 1). In sepsis and experimental endotoxemia, a condition of increased demand for arginine, induction of iNOS causes increased NO production from arginine (12-15). Because increased NO production depends on extracellular arginine (7), it is conceivable that reduced arginine availability limits NO production during sepsis or endotoxemia. The goal of 
the present study therefore was to quantify cNOS and iNOS-mediated production in a condition of reduced arginine availability.

\section{Materials and Methods}

\section{Animals}

Male FVB and F/A-1 transgenic (11) mice (22-26 g, 2-3 months old) were bred at the Department of Anatomy and Embryology (AMC, Amsterdam, The Netherlands) and transported to the Centralized Animal Facilities of Maastricht University. The mice were fed standard lab chow and were subject to standard 12-hour light-dark cycle periods (7:30 A.M. to 7:30 P.M.). Room temperature was maintained at $25^{\circ} \mathrm{C}$.

Experiments were performed in accordance with the recommendations of the Guide for the Care and Use of Laboratory Animals (16), and were approved by the Ethical Committee of Animal Research of the Maastricht University.

\section{Generation of transgenics}

Intestinal fatty-acid binding protein (FABPi)/arginase I transgenic mice (F/A) were generated in the FVB-strain. Generation of the transgenics is described in detail elsewhere (11). Briefly, arginase I was specifically expressed in enterocytes by coupling the arginase I structural gene to the FABPi promoter/enhancer element.

\section{Experimental protocol}

The mice were randomly assigned to receive LPS ( $E$ coli O55:B5, $250 \mu \mathrm{g}$ in $0.5 \mathrm{ml}$ saline, Sigma, St. Louis, MO) or a corresponding volume of saline. Drinking water was provided but food was withheld after the injection of endotoxin or saline to avoid influences of differences in food intake. Mice injected with LPS were put under a heating lamp.

Five hours after LPS treatment, anesthesia was induced in the mice by an intraperitoneal injection followed by a subcutaneous infusion of ketamine and medetomidine (17). Catheters were inserted in the jugular vein and the carotid artery. During the surgical procedures the mice were kept at $37^{\circ} \mathrm{C}$ using a temperature controller (Technical Service, Maastricht University) and heat pads (17). 
A primed-constant infusion of L-[guanidino- ${ }^{15} \mathrm{~N}_{2}$ ]arginine, L-[ureido- ${ }^{13} \mathrm{C}$ ${ }^{2} \mathrm{H}_{2}$ ]citrulline, L-[ring- ${ }^{2} \mathrm{H}_{5}$ ]phenylalanine, and L-[ring- ${ }^{2} \mathrm{H}_{2}$ ]tyrosine (Mass Trace, Woburn, MA) was given in the jugular vein (per mouse: prime $\left[{ }^{15} \mathrm{~N}_{2}\right]$ arginine: 850 nmol, $\left[{ }^{13} \mathrm{C}_{-}{ }^{2} \mathrm{H}_{2}\right]$ citrulline: $215 \mathrm{nmol},{ }^{2} \mathrm{H}_{5}$-phenylalanine: $340 \mathrm{nmol},{ }^{2} \mathrm{H}_{2}$-tyrosine: 215 $\mathrm{nmol}$, infusion $\left[{ }^{15} \mathrm{~N}_{2}\right.$ ] arginine: $1700 \mathrm{nmol} / \mathrm{hr},\left[{ }^{13} \mathrm{C}^{2} \mathrm{H}_{2}\right]$ citrulline: $430 \mathrm{nmol} / \mathrm{hr}$, $\left[{ }^{2} \mathrm{H}_{5}\right]$ phenylalanine: $680 \mathrm{nmol} / \mathrm{hr},\left[{ }^{2} \mathrm{H}_{2}\right]$ tyrosine $430 \mathrm{nmol} / \mathrm{hr}$ ). Steady state of tracers and metabolites was reached within 20 minutes (18). Blood was sampled from the carotid artery (17), and collected in heparinized cups (Sarstedt, Nümbrecht, Germany) on ice.

Blood was centrifuged to obtain plasma, because we have shown recently that plasma sampling is required in organ balance metabolic studies using amino acid tracers that do not equilibrate well with blood cell cytoplasm (19). For determination of amino acid concentrations and tracer to tracee ratios (TTRs) $80 \mu \mathrm{l}$ plasma was added to $7 \mathrm{mg}$ dry sulfosalicylic acid, vortexed, frozen in liquid nitrogen and stored at $-80^{\circ} \mathrm{C}$. Plasma amino acid concentrations were measured as described (20). Amino acid TTRs were measured using a fully automated LC-MS system (21), using FMOC as amino acid derivative. BCAA is the sum of the Branched Chain Amino Acids: valine, leucine and isoleucine. SUMAA is the SUM of the Amino Acids glutamate, asparagine, serine, glutamine, glycine, threonine, histidine, citrulline, alanine, taurine, arginine, tyrosine, valine, methionine, isoleucine, phenylalanine, tryptophan, leucine, ornithine and lysine. For determination of plasma urea and ammonia, $20 \mu \mathrm{l} \mathrm{plasma}$ was added to $80 \mu \mathrm{l} 1 \%$ trichloroacetic acid. Plasma urea and ammonia were determined using commercially available kits on a Cobas Mira S (Roche Diagnostica, Hoffman La Roche, Basel, Switzerland), as described previously (22). For plasma $\mathrm{NO}_{2}{ }^{-}$and $\mathrm{NO}_{3}{ }^{-}$determinations, $50 \mu \mathrm{l}$ plasma was deproteinized by adding it to $100 \mu \mathrm{l}$ acetonitrile (Biosolve LTD, Valkenswaard, The Netherlands) to avoid artificially high $\mathrm{NO}_{2}{ }^{-}$and $\mathrm{NO}_{3}{ }^{-}$levels (23). After centrifugation, $60 \mu \mathrm{l}$ was transferred to a $250 \mu \mathrm{l}$ polypropylene conical insert mounted in a $4 \mathrm{mI}$ WISP vial, containing already $140 \mu \mathrm{l}$ Super$Q$ water, mixed and sealed with a Teflon ${ }^{R}$ seal. From the resulting solution $100 \mu$ l was injected on an IC-PackHR 75mm*4.6mm (all from Waters, Etten-Leur Netherlands). The column effluent was monitored using a Model UV-975 intelligent UV-VIS detector, set at $205 \mathrm{~nm}$ (Jasco, B\&L-systems, Wassenaar, The Netherlands). Anions 
were isocratically eluted from the column within 20 minutes using a $6 \mathrm{mM}$ sodium chloride solution containing $1 \mathrm{mM}$ potassium dihydrogenphosphate $(\mathrm{pH}=6)$.

\section{Calculations}

Whole body arginine and protein metabolism

Plasma arginine, citrulline, phenylalanine and tyrosine fluxes were calculated from the arterial isotopic enrichment values of respectively L-[guanidino- ${ }^{15} \mathrm{~N}_{2}$ ]arginine, L[ureido- ${ }^{13} \mathrm{C} ;{ }^{2} \mathrm{H}_{2}$ ]citrulline, L-[ring- ${ }^{2} \mathrm{H}_{5}$ ]phenylalanine and $\mathrm{L}$-[ring- ${ }^{2} \mathrm{H}_{2}$ ]tyrosine, using the standard steady state isotope dilution equation:

$Q=I / T T R(24)$,

where TTR is the tracer to tracee ratio, and I is the rate of infusion of the tracer.

Calculation of the plasma arginine to citrulline flux (NO production) was performed as follows:

$\mathrm{Q}_{\mathrm{Arg} \rightarrow \mathrm{Cll}}=\mathrm{Q}_{\mathrm{Cit}} \times \operatorname{TTR}_{\mathrm{Cit}(\mathrm{M}+1)} / \operatorname{TTR}_{\mathrm{Arg}(\mathrm{M}+2)}(10)$,

where $Q_{\mathrm{cit}}$ is the plasma citrulline flux (nmol $/ 10 \mathrm{~g} / \mathrm{min}$ ), estimated from the primed constant infusions of $\mathrm{L}-\left[\right.$ ureido- $\left.{ }^{13} \mathrm{C} ;{ }^{2} \mathrm{H}_{2}\right]$ citrulline; TTR $\mathrm{Cit}_{\mathrm{it}}$ and $\mathrm{TTR}_{\mathrm{Arg}}$ are the respective TTRs of [ureido- ${ }^{15} \mathrm{~N}$ ]citrulline and [guanidino- ${ }^{15} \mathrm{~N}_{2}$ ] arginine.

Calculation of the plasma citrulline to arginine flux (de novo arginine production) was performed as follows:

$\mathrm{Q}_{\mathrm{Cit} \rightarrow \mathrm{Arg}}=\mathrm{Q}_{\mathrm{Arg}} \times \mathrm{TTR}_{\mathrm{Arg}(\mathrm{M}+3)} / \mathrm{TTR}_{\mathrm{Cit}(\mathrm{M}+3)}(25)$,

where $Q_{\mathrm{Arg}}$ is the plasma arginine flux (nmol $/ 10 \mathrm{~g} / \mathrm{min}$ ), estimated from the primed constant infusions of $\mathrm{L}$-[guanidino- ${ }^{15} \mathrm{~N}_{2}$ ] ]arginine; $\operatorname{TTR}_{\mathrm{Arg}}$ and $T \mathrm{TR}_{\mathrm{Cit}}$ are the respective TTRs of L-[guanidino- ${ }^{13} \mathrm{C} ;{ }^{2} \mathrm{H}_{2}$ ] arginine and L-[ureido- ${ }^{13} \mathrm{C} ;{ }^{2} \mathrm{H}_{2}$ ]citrulline.

\section{Statistics}

Comparisons were made between FVB-Control and F/A-1-Control to test the effect of arginase overexpression. The FVB-Control and F/A-1-Control groups were compared to the FVB-LPS and F/A-1-LPS groups respectively to test the effect of LPS administration. The Mann-Whitney $U$ non-parametric test was used to test for differences, $P<0.05$ was considered significant. Data are presented as means \pm SEM. 


\section{Results}

\section{Effects of arginase / expression}

In F/A-1 transgenic mice, the expression of arginase I in the enterocytes causes a $27 \%$ reduction of circulating arginine levels under baseline conditions (Figure 2 ). The reduction of plasma arginine was accompanied by a decrease in plasma ammonia and plasma ornithine (Table 1). Arginase overexpression also caused a reduction of glycine, alanine, phenylalanine, tyrosine, lysine and the branched chain amino acids, but did not change plasma glutamine, glutamate, and urea (Table 1).

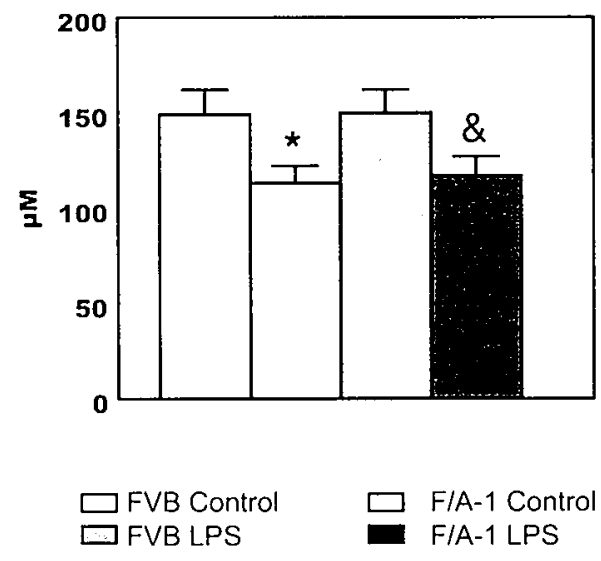

Figure 2. Circulating arginine levels in FVB and F/A-1 mice under basal and LPS-stimulated conditions. ${ }^{*} p<0.05$ vs. FVB-Control. ${ }^{\&} p<0.05$ vs. F/A-1 Control.

Under baseline conditions, plasma arginine flux was $39 \pm 3 \mathrm{nmol} / 10 \mathrm{~g} \mathrm{bw} / \mathrm{min}$ in wildtype mice (Table 2, Figure 3). De novo arginine production was $7 \pm 1 \mathrm{nmol} / 10 \mathrm{~g}$ bw/min (Table 2), and equaled $18 \%$ of plasma arginine flux. Transgenic arginase expression did not significantly change plasma arginine flux and de novo arginine synthesis (Table 2, Figure 3). The contribution of de novo arginine production to plasma arginine turnover was $29 \%$ in these animals. These figures indicate that the contribution of de novo arginine production in comparison with remaining arginine flux increased. In the F/A-1 mice, plasma phenylalanine and tyrosine turnover rates, indicators of protein turnover, were $83 \%$ and $81 \%$ of the value in the FVB control 
mice, although in absolute terms the reduction of phenylalanine $(p<0.10)$ and tyrosine $(p=0.11)$ turnover did not reach significance (Table 2). Nevertheless, the concentrations of the branched chain amino acids and the sum of amino acids were reduced in the F/A-1 transgenic mice.

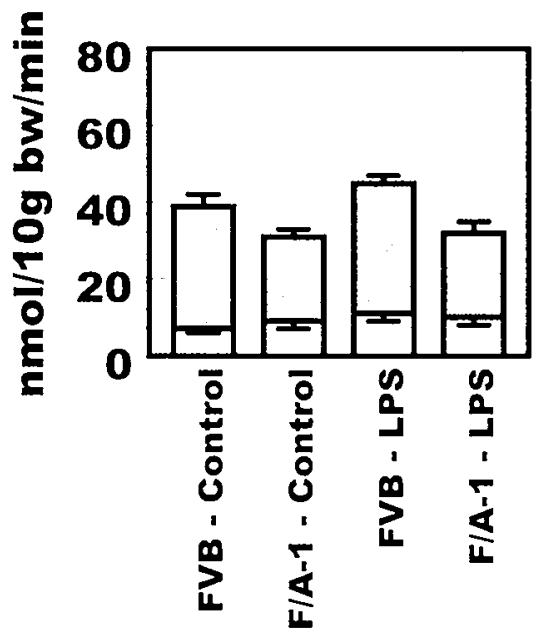

Figure 3. Systemic arginine flux in FVB and F/A-1 mice under basal and LPS-stimulated conditions. Systemic arginine flux is divided in de novo arginine production (white bars) and remaining arginine flux (grey bars).

The reduction of plasma arginine did not compromise the NO production rate, measured from $\left[{ }^{15} \mathrm{~N}_{2}\right]$ arginine to $\left[{ }^{15} \mathrm{~N}\right]$ citrulline conversion, under baseline conditions (Figure 4). In agreement with these results, plasma citrulline and the stable endproducts nitrite and nitrate were not changed by the reduction of arginine availability in F/A-1 mice (Table 1). 
Table 1. Arterial substrate concentrations. Values are mean $\pm S E M$ in $\mu M$. Urea in $m M . ~{ }^{*} p<0.05$ vs. FVB-Control, "p<0.05 vs. F/A-1-Control, ${ }^{\&} \mathrm{p}<0.05$ vs. FVB-LPS.

\begin{tabular}{|c|c|c|c|c|c|c|c|c|c|c|c|c|}
\hline & FVB & 1 & Control & F/A-1 & 1 & Control & FVB & 1 & LPS & F/A-1 & 1 & LPS \\
\hline $\mathrm{NO}_{2}$ & 4.5 & \pm & 1.2 & 5.6 & \pm & 2.3 & 9.2 & \pm & 3.0 & 7.1 & \pm & 2.1 \\
\hline $\mathrm{NO}_{3}^{-}$ & 21 & \pm & 3 & 28 & \pm & 5 & 99 & \pm & $20^{*}$ & 122 & \pm & $15^{\#}$ \\
\hline Amm & 221 & \pm & 18 & 98 & \pm & $10^{*}$ & 343 & \pm & $25^{\star}$ & 242 & \pm & $52^{\prime \prime}$ \\
\hline Urea & 8.6 & \pm & 0.8 & 7.0 & \pm & 0.6 & 16.4 & \pm & $1.7^{\star}$ & 16.1 & \pm & $0.9^{\#}$ \\
\hline GLU & 51 & \pm & 3 & 45 & \pm & 4 & 57 & \pm & 10 & 41 & \pm & 4 \\
\hline GLN & 451 & \pm & 34 & 448 & \pm & 17 & 543 & \pm & 43 & 466 & \pm & 59 \\
\hline GLY & 253 & \pm & 20 & 214 & \pm & $9^{*}$ & 219 & \pm & 18 & 190 & \pm & 12 \\
\hline CIT & 105 & \pm & 11 & 87 & \pm & 6 & 107 & \pm & 5 & 103 & \pm & 10 \\
\hline ALA & 330 & \pm & 27 & 230 & \pm & $13^{*}$ & 408 & \pm & $45^{\star}$ & 252 & \pm & $43^{8}$ \\
\hline TAU & 221 & \pm & 25 & 172 & \pm & 9 & 295 & \pm & 37 & 266 & \pm & $24^{\#}$ \\
\hline ARG & 149 & \pm & 13 & 113 & \pm & $9^{*}$ & 150 & \pm & 12 & 117 & \pm & $10^{\&}$ \\
\hline TYR & 95 & \pm & 5 & 65 & \pm & $5^{\star}$ & 134 & \pm & $10^{*}$ & 96 & \pm & 15 \\
\hline VAL & 212 & \pm & 22 & 157 & \pm & $15^{*}$ & 233 & \pm & 18 & 208 & \pm & $10^{\#}$ \\
\hline ILE & 76 & \pm & 7 & 59 & \pm & $5^{\star}$ & 86 & \pm & 9 & 84 & \pm & $8^{\# \prime}$ \\
\hline PHE & 109 & \pm & 9 & 75 & \pm & $5^{\star}$ & 148 & \pm & $9^{*}$ & 124 & \pm & $13^{*}$ \\
\hline LEU & 149 & \pm & 13 & 107 & \pm & $12^{\star}$ & 171 & \pm & 14 & 152 & \pm & $7^{\#}$ \\
\hline ORN & 111 & \pm & 10 & 78 & \pm & $7^{\star}$ & 128 & \pm & 10 & 109 & \pm & 20 \\
\hline LYS & 245 & \pm & 19 & 169 & \pm & $8^{*}$ & 451 & \pm & $28^{*}$ & 341 & \pm & $49^{\#}$ \\
\hline$B C A A$ & 437 & \pm & 41 & 323 & \pm & $32^{\star}$ & 491 & \pm & 39 & 444 & \pm & $24^{\#}$ \\
\hline SUM & 3042 & \pm & 142 & 2440 & \pm & $83^{*}$ & 3580 & \pm & $178^{*}$ & 2941 & \pm & $237^{8}$ \\
\hline
\end{tabular}

Table 2. Plasma fluxes. Values are mean $\pm \mathrm{SEM}$ in $\mathrm{nmol} / 10 \mathrm{~g}$ body wt. per minute. $\mathrm{ClT} \rightarrow \mathrm{ARG}=$ de novo arginine production from citrulline. ${ }^{*} p<0.05$ vs. FVB-Control, ${ }^{8} p<0.05$ vs. FVB-LPS.

\begin{tabular}{|c|c|c|c|c|c|c|c|c|c|c|c|c|}
\hline & FVB & 1 & Control & F/A-1 & I & Control & FVB & 1 & LPS & F/A-1 & 1 & LPS \\
\hline PHE & 41 & \pm & 3 & 34 & \pm & 2 & 48 & \pm & 2 & 42 & \pm & 4 \\
\hline TYR & 32 & \pm & 3 & 25 & \pm & 3 & 33 & \pm & 3 & 30 & \pm & 3 \\
\hline ARG & 39 & \pm & 3 & 31 & 1 & 2 & 45 & $I$ & 2 & 32 & \pm & $3^{8}$ \\
\hline CIT & 18 & \pm & 1 & 18 & \pm & 2 & 21 & \pm & $1^{\star}$ & 19 & \pm & 1 \\
\hline $\mathrm{CIT} \rightarrow \mathrm{ARG}$ & 7 & \pm & 1 & 9 & \pm & 2 & 11 & \pm & 2 & 10 & \pm & 2 \\
\hline
\end{tabular}




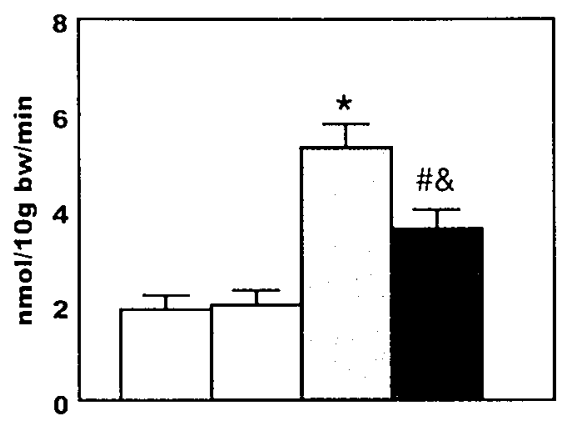

Figure 4. In vivo NO production rate in FVB and F/A-1 mice under basal and LPS-stimulated conditions. NO production rate was measured as $\left[{ }^{15} \mathrm{~N}_{2}\right]$ arginine-to- $\left[{ }^{15} \mathrm{~N}\right]$ citrulline conversion as detailed in the materials and methods section. ${ }^{*} p<0.05$ vs. FVB-Control. $p<0.05$ vs. F/A-1-Control. ${ }^{\&} p<0.05$ vs. FVB-LPS.

\section{Effects of LPS-treatment}

The animals were treated with bacterial endotoxin to investigate whether reduced arginine availability limits iNOS-mediated NO production rates. In response to treatment with LPS, circulating arginine was not changed (Figure 2). Thus also in endotoxin treated animals, circulating arginine was lower in the F/A-1 mice than in the FVB wildtype mice. LPS treatment caused a $180 \%$ increase in the systemic NO production rate in FVB mice (Figure 4). The increase in systemic NO production was accompanied by an increase in systemic citrulline flux (Table 2). Arginine deficiency did not prevent an increase in the NO production rate (Figure 4). In the F/A-1 mice, the NO production rate increased with $80 \%$. Thus, although the F/A-1 mice and the FVB mice both responded to LPS treatment by increasing the NO production rate, the increase was blunted by arginine deficiency. In addition, systemic citrulline turnover was not increased by LPS treatment in F/A-1 mice. The increase in NO production by LPS treatment was reflected in an increase in plasma nitrate, but not in plasma nitrite or citrulline (Table 1). The increase in plasma nitrate was similar in FVB and F/A-1 mice. Interestingly, in F/A-1 mice, but not in FVB mice, the concentrations of the branched chain amino acids valine, leucine and isoleucine were significantly increased in response to treatment with bacterial endotoxin (Table 1). 


\section{Discussion}

In the present study, the effects of reduced arginine availability on cNOS and iNOSmediated systemic NO production were studied. A $27 \%$ reduction of circulating arginine was caused by transgenic overexpession of hepatic arginase in the enterocytes. The present study suggests that reduced arginine availability causes a blunted iNOS-mediated response to endotoxin treatment, despite physiological cNOS-mediated NO production.

\section{Relationship plasma arginine - systemic NO production}

Recent experiments in eNOS ${ }^{-1 /}$ and $\mathrm{NOS}^{-/}$mice have shown that eNOS and nNOS both contribute $50 \%$ to baseline NO production, and that iNOS is not active under baseline conditions (15). Stimulation with bacterial endotoxin causes a down regulation of eNOS-mediated NO production, which implies that the LPS-stimulated increase in NO production is solely mediated by iNOS (15).

Although the $K_{m}$ of NOS for arginine is only $2-20 \mu M(6)$, several lines of evidence indicate that the endogenous production of NO by NOS is dependent on extracellular arginine and cellular arginine transport. The CAT1 and CAT2B transporters have a $\mathrm{K}_{\mathrm{m}}$ of 100-150 $\mu \mathrm{M}(26)$. In the present study, plasma arginine was reduced from $149 \pm 13 \mu \mathrm{M}$ to $113 \pm 9 \mu \mathrm{M}$, indicating that if circulating arginine and arginine transport are the main regulator of NO production, we should have detected changes in NO production. Basal NO production, mediated by eNOS and nNOS, was not compromised by the reduction of circulating arginine, indicating that under baseline, non-stimulated conditions, reduced circulating arginine does not compromise the systemic NO production rate. It has been suggested that decreased constitutive NO production in diseases such as atherosclerosis, may (partly) be attributed to reduced arginine availability (27), but our present data do not support any effect of reduced arginine availability on cNOS-mediated NO production.

In contrast, the iNOS-mediated increase in systemic NO production induced by LPS treatment was compromised in the F/A-1 mice. The present data thus support studies indicating that iNOS-mediated NO production is dependent on extracellular arginine. In addition, the present data may therefore support the supplementation of arginine in conditions of reduced arginine availability in conditions which normally iNOS-mediated NO production is stimulated. 
Ornithine transcarbamylase deficient (OTCD) mice are of a different genetic background (C57BL6 mouse strain) and have only 5-10\% of normal OTC activity. This leads to a $40-45 \%$ reduction of circulating citrulline and a $30 \%$ reduction of circulating arginine. The reduction of circulating arginine is similar in OTCD and F/A-1 mice. In OTCD mice, the NO production rate was linearly related to circulating arginine. The main difference between the two models of reduced arginine availability is the mechanism leading to the reduction of arginine availability. Our data therefore may indicate that the mechanism leading to the reduction of circulating arginine, rather than the decrease in circulating arginine per se, determines the relationship between circulating arginine and the systemic NO production rate.

In conclusion, a 30\% decrease in circulating arginine impairs the iNOS-mediated increase in NO production, but does not change cNOS-mediated NO production.

\section{Acknowledgments}

The authors thank J.L.J.M. Scheyen, B.Sc. and H.M.H. van Eijk, Ph.D. for the LC-MS measurements. We also thank G.A.M. Ten Have, B.Sc. for assistance with the animal experiments. This study was supported by grants 902-23-098 and 902-23-239 from the Dutch Association for Scientific Research (NWO).

\section{References}

1. Tangphao O, Chalon S, Coulston AM, Moreno HJ, Chan JR, Cooke JP, et al. L-arginine and nitric oxide related compounds in plasma: comparison of normal and arginine-free diets in a 24-h crossover study. Vasc Med 1999;4:27-32.

2. Tizianello A, De Ferrari G, Garibotto G, Gurreri G, Robaudo C. Renal metabolism of amino acids and ammonia in subjects with normal renal function and in patients with chronic renal insufficiency. J.Clin.Invest. 1980;65:1162-1173.

3. Castillo L, Chapman TE, Sanchez M, Yu YM, Burke JF, Ajami AM, et al. Plasma arginine and citrulline kinetics in adults given adequate and arginine-free diets. Proc.Natl.Acad.Sci.USA 1993;90:7749-7753.

4. Grimble GK. Essential and conditionally-essential nutrients in clinical nutrition. Nutr.Res.Rev. 1993;6:97-119.

5. Wu G, Meininger CJ, Knabe DA, Bazer FW, Rhoads JM. Arginine nutrition in development, health and disease. Curr Opin Clin Nutr Metab Care 2000;3(1):59-66.

6. Stuehr DJ. Mammalian nitric oxide synthases. Biochim Biophys Acta 1999;1411(2-3):217-30. 
7. Bune AJ, Shergill JK, Cammack R, Cook HT. L-Arginine depletion by arginase reduces nitric oxide production in endotoxic shock: an electron paramagnetic resonance study. FEBS Lett. 1995;366:127-130.

8. Bogle RG, Baydoun AR, Pearson JD, Moncada S, Mann GE. L-Arginine transport is increased in macrophage generating nitric oxide. Biochem.J. 1992;284:15-18.

9. Hammermann R, Hirschmann J, Hey C, Moessner J, Folkerts G, Nijkamp FP, et al. Cationic proteins inhibit $L$-arginine uptake in rat alveolar macrophages and tracheal epithelial cells. Implications for nitric oxide synthesis. Am J Respir Cell Mol Biol 1999;21:155-162.

10. Castillo L, Beaumier L, Ajami AM, Young VR. Whole body nitric oxide synthesis in healthy men determined from [15N]-arginine-to-[15N]citrulline labeling. Proc.Natl.Acad.Sci.USA 1996;93:11460-11465.

11. De Jonge WJ, Hallemeesch MM, Kwikkers KL, Ruijter JM, De Gier-de Vries C, Van Roon MA, et al. Overexpression of arginase $I$ in enterocytes of transgenic mice elicits a selective arginine deficiency and affects skin, muscle and lymphoid development. Am J Clin Nutr 2001;accepted.

12. Ter Steege JCA, Van de Ven WCM, Forget PP, Brouckaert $P$, Buurman WA. The role of endogenous IFN-gamma, TNF-alpha and IL-10 in LPS-induced nitric oxide release in a mouse model. Cytokine 1998;10:115-123.

13. Thiemermann C, Wu CC, Szabo C, Perretti M, Vane JR. Role of tumour necrosis factor in the induction of nitric oxide synthase in a rat model of endotoxin shock. Br.J.Pharmacol. 1993;110:177-182.

14. Szabo C, Salzman AL, Ischiropoulos H. Endotoxin triggers the expression of an inducible isoform of nitric oxide synthase and the formation of peroxynitrite in the rat aorta in vivo. FEBS Lett. 1995;363:235-238.

15. Hallemeesch MM, Janssen BJA, De Jonge WJ, Soeters PB, Lamers WH, Deutz NEP. Increased iNOS-mediated and decreased cNOS-mediated NO production rates reflect blood pressure changes in LPS-challenged mice. Thesis Chapter 3.42001.

16. Waldegrave W, Chairman Council of the European Community. Guide for the care and use of laboratory animals. Brussels, Belgium: European Community; 1986. Report No.: Publication $86 / 609$.

17. Hallemeesch MM, Ten Have GAM, Deutz NEP. Measurement of metabolic fluxes across PDV, liver, kidney and hindquarter in mice. Lab Anim 2001;35:101-110.

18. Hallemeesch MM, Lamers WH, Meijer AJ, Soeters PB, Deutz NEP. In vivo rate of NO synthesis is increased during mouse endotoxemia. Chapter 3.1 thesis 2001.

19. Hallemeesch MM, Soeters PB, Deutz NEP. Tracer methodology in whole body and organ balance metabolic studies: plasma sampling is required. Clin Nutr 2000;19:157-163.

20. Van Eijk HMH, Rooyakkers DR, Deutz NEP. Rapid routine determination of amino acids in plasma by high-performance liquid chromatography with a 2-3 $\mu \mathrm{M}$ Spherisorb ODS II column. J.Chromatogr. 1993;620:143-148.

21. Van Eijk HMH, Rooyakkers DR, Deutz NEP. Determination of amino acid isotope enrichment using liquid chromatography-mass spectrometry. Anal.Biochem. 1999;271:8-17. 
22. Dejong $\mathrm{CHC}$, Deutz NEP, Soeters PB. Renal ammonia and glutamine metabolism during liver insufficiency-induced hyperammonemia in the rat. J.Clin. Invest. 1993:92:2834-2840.

23. Moshage $H$, Kok $B$, Huizenga JR, Jansen PLM. Nitrite and nitrate determinations in plasma: a critical evaluation. Clin.Chem. 1995;41(6):892-896.

24. Wolfe RR. Radioactive and stable isotope tracers in biomedicine. Principles and practice of kinetic analysis. New York: Wiley-Liss; 1992

25. Yu YM, Burke JF, Tompkins RG, Martin R, Young VR. Quantitative effects of interorgan relationships among arginine and citrulline metabolism. Am.J.Physiol. 1996;271:E1098-E1109.

26. Devés R, Boyd CAR. Transporters for cationic amino acids in animal cells: discovery, structure and function. Physiol Rev 1998;78:487-545.

27. Cooke JP. Is atherosclerosis an arginine deficiency disease? J Investig Med 1998;46:377-80. 


\section{Chapter 5}

Summary and discussion 
In this thesis the effects of a reduction of circulating arginine levels on the in vivo rate of NO production were investigated. The experiments described were all performed in mice. Mice were chosen because of the availability of knockout and transgenic mice. Mice were not previously used for metabolic flux studies in the Department of Surgery, Maastricht University. The stable isotope measurements that were carried out in these animals require steady state conditions in the experimental animal. Therefore, methodology was developed to perform measurements in mice.

\section{Methodology}

The method used to measure metabolic fluxes in mice is described in Chapter 2.1. The chapter offers a description of the anesthetic regime, catheterization of vessels supplying and draining the organ of interest, the measurement of blood flow and strategies to limit the waste of blood during blood sampling. Because of the limited size of mice, it is not possible to obtain a large volume of blood. Metabolic parameters should therefore preferably be measured in whole blood. It was, however, not known whether whole blood could be used for measurements involving isotopes. Chapter 2.2 is a methodological chapter dealing with the possibility to quantify metabolic pathways using radioactive isotopes after whole blood sampling. From the data presented in this chapter it is clear that in case amino acid tracers are used plasma sampling is required in metabolic studies.

\section{Stable isotope measurement of NO production}

In Chapter 3.1 the use of the stable isotope $\left[{ }^{15} \mathrm{~N}_{2}\right]$ arginine to measure the rate of NO synthesis was first described in mice. This method to quantify NO synthesis was previously used in healthy subjects (1), and at present is the only method to give quantitative information on the in vivo rate of NO production. NO production has also been assessed on the basis of the levels of the end products nitrite and nitrate, NOS mRNA or protein levels, and $\left[{ }^{3} \mathrm{H}\right]$ arginine to $\left[{ }^{3} \mathrm{H}\right]$ citrulline assays in vitro, but none of these measurements truly measure flux. Measurement of NOS mRNA or protein 
levels, as well as in vitro NOS activity assays, give information on the potential for NO production, not on the actual rate of NO production. Stable isotope technology is therefore the method of choice. A disadvantage of the stable isotope measurement of the rate of NO production is that is does not give information to what extent the newly produced NO activates guanylyl cyclase. The availability of NO is determined by the production and disposal rates of NO. Several routes of NO disposal are known, including the reaction with superoxide to peroxynitrite (2), and oxidation to nitrite and nitrate.

The rate of NO production was measured under baseline conditions, in which the mice were treated with normal saline. It was assumed that basal NO production reflected cNOS-mediated NO production. A separate group of mice was treated with an intraperitoneal injection of LPS. In response to treatment with LPS, the rate of NO production was doubled, and it was assumed that the increase in NO production was mediated by iNOS. It is known that the amount of iNOS mRNA and protein induced by activation varies with species and strain, the host organism of LPS, the serotype and dose of LPS, and the co-administration of pro-inflammatory cytokines all determine the expression level of INOS. A standardized LPS regime was given throughout the studies.

In earlier studies NOS inhibitors were used to obtain information regarding the NOS isoform involved. Several NOS inhibitors have been described since the discovery of the production of NO from arginine, and much research has focussed on optimal selectivity towards NOS isoforms (3-7). In the present thesis, eNOS ${ }^{-1-}$ and iNOS $^{-1}$ mice were used to establish the NOS isoform mediating NO production under baseline and endotoxemic conditions. It was shown that eNOS and nNOS both contribute approximately $50 \%$ to systemic NO production under baseline, unstimulated, conditions. In response to endotoxemia, iNOS-mediated NO production is increased, whereas cNOS-mediated NO production is down-regulated. It has been shown that eNOS-mediated NO production is downregulated by NO (8), suggesting that excess iNOS-mediated NO production may reduce eNOS-mediated NO production. In the present experiments, CNOS-mediated NO production was reduced in LPS-treated NOS $^{-1}$ mice. It thus appears that LPS treatment causes a reduction in cNOS-mediated NO production independent of iNOS activation. The increase in NO production observed after endotoxemia is solely mediated by iNOS. This information 
is obviously important to understand the effects of reduced arginine availability on cNOS and iNOS-mediated NO production.

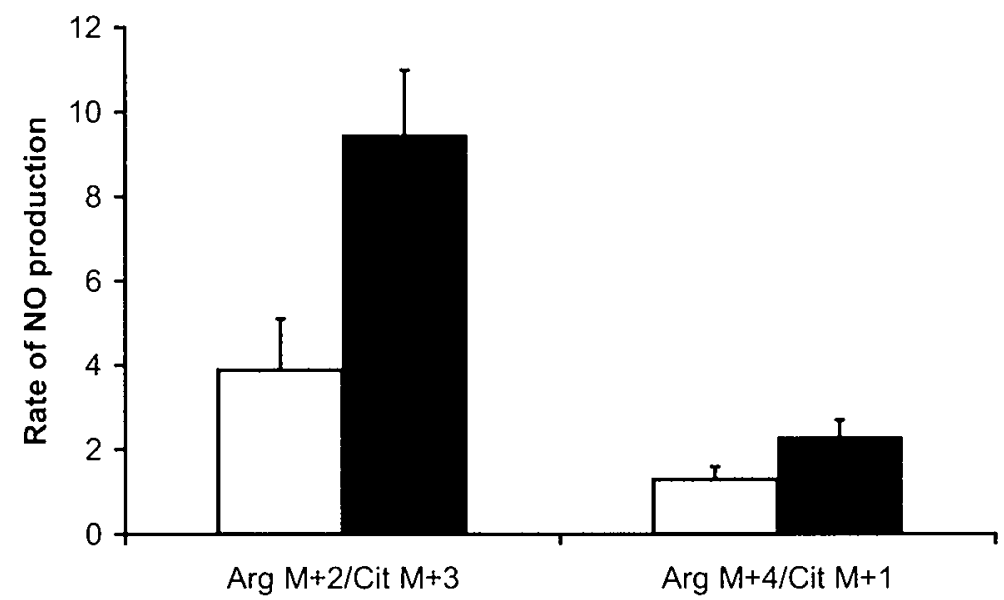

Figure 1. NO production rate using two tracer combinations in male Swiss mice. Grey bars: Control animals, Black bars: LPS-treated animals.

In the thesis two combinations of stable isotope tracers were used to quantify systemic NO production in male Swiss mice. The first combination of tracers was $\left[{ }^{15} \mathrm{~N}_{2}\right]$ arginine $(M+2)$ and $\left[{ }^{13} \mathrm{C}^{2} \mathrm{H}_{2}\right]$ citrulline $(M+3)($ Chapter 3.1). The second combination of tracers was $\left[{ }^{15} \mathrm{~N}_{2}{ }^{2} \mathrm{H}_{2}\right]$ arginine $(M+4)$ and $\left[{ }^{13} \mathrm{C}\right]$ citrulline $(\mathrm{M}+1)$ (Chapter 4.1). These two tracer combinations yielded different results with respect to NO synthesis (Figure 1). Baseline NO synthesis was much higher when measured using the $\operatorname{Arg} M+2 / C i t M+3$ tracer combination compared to the $\operatorname{Arg} M+4 / C$ it $M+1$ tracer combination, so that either the $\operatorname{Arg} M+2 / C i t ~ M+3$ tracer combination overestimated NO production, or that the $\operatorname{Arg} M+4 / C$ it $M+1$ tracer combination underestimated NO production. The most important difference between these two tracer combinations is the mass of the citrulline produced by NOS. In the Arg M+2/Cit M+3 tracer protocol, NOS activity causes $M+1$ citrulline to be produced, whereas in the $\operatorname{Arg} M+4 / C$ it $M+1$ tracer protocol $M+3$ citrulline is produced by NOS. The flux through NOS is low, and thus the enrichment in citrulline from labeled arginine is also low. The background enrichment of $M+1$ citrulline is much higher than that of $M+3$ citrulline. As a result it is easier to detect a small enrichment above background in $M+3$ citrulline than in $M+1$ citrulline. It thus appears that the measurements using the $\operatorname{Arg} M+4 / C$ it $M+1$ tracers 
are more sensitive with respect to NO synthesis rates and, hence, probably more accurate. The $\operatorname{Arg} \mathrm{M}+2 / \mathrm{Cit} \mathrm{M}+3$ protocol probably yielded an overestimation of $\mathrm{NO}$ production in the experiment described in Chapter 3.1, because citrulline $M+1$ appearance was overestimated.

Chapter 3.1 was the first study in which NO synthesis rates were measured in mice, using the $\operatorname{Arg} M+2 / C i t ~ M+1$ protocol. In Chapter 4.1, the Arg M+4/Cit M+1 tracer protocol yielded more accurate results. In the following chapters, the technique to measure the enrichment of $M+1$ citrulline was further optimized, and the basal NO synthesis rates were measured in a variety of strains using the $A r g M+2 / C i t M+1$ protocol. The results were quite comparable with the results obtained in Swiss mice in Chapter 4.1 using the $\operatorname{Arg} M+4 / C i t M+1$. It seems that $N O$ production was overestimated in Chapter 3.1.

\section{Are nitrite and nitrate representative for systemic NO production?}

Nitrite and nitrate are relatively stable end-products of NO in vitro and in vivo, and measurement of plasma nitrite and/or nitrate, or the sum of plasma nitrite and nitrate $\left(\mathrm{NO}_{\mathrm{x}}\right)$ have been considered useful to estimate NO production. In the presence of oxygen, NO is rapidly oxidized, via dinitrogen trioxide, to nitrite following pseudo-first order kinetics, with a strict 1:1 stoichiometry (9). In aqueous solutions, nitric oxide is oxidised to nitrite, but not to nitrate (10). Oxidation of nitrite to nitrate requires the presence of additional oxidizing species such as oxyhemoglobin (10). In mouse plasma, basal circulating nitrite is approximately $1-10 \mu \mathrm{M}$. The concentration of nitrate is much higher $(20-40 \mu \mathrm{M})$. In young women ( $<40 \mathrm{y})$, plasma NOx is lower than in men of the same age group (11), whereas in men and women of the older age group there is no significant difference (11).

One percent of plasma arginine flux is NO production (1), and approximately $0.5 \%$ of arginine flux enters nitrate (12). Thus, approximately $50 \%$ of NO is not oxidized to nitrate. The only source of nitrite in the body is arginine via NO, as shown using stable isotopes. Labeled arginine was given to volunteers and the enrichment in nitrite and nitrate was measured (13). The enrichment of nitrite was almost equal to the enrichment of arginine, but the enrichment in nitrate was much lower than the enrichment in arginine (13). These results indicate that nitrate derived from arginine 
is diluted with nitrate not originating from arginine. Possible sources of this nitrate may include bacteria in the gastrointestinal tract.

In response to treatment with LPS, the rate of NO production is increased. The increase in the rate of NO production coincides with an increase in plasma nitrite and nitrate. The increase in plasma nitrite is of a similar magnitude as the increase in the rate of NO production. These results led us to conclude that plasma nitrite is a better parameter to detect the magnitude of increased NO production in response to endotoxemia than plasma nitrate. In the following experiments, plasma nitrite did not always predict the increase in the rate of NO production.

Plasma nitrate was found to correlate well with the rate of NO production in LPS-treated animals. There was no correlation between the rate of NO production and nitrate under baseline conditions. In all studies undertaken, the increase in plasma nitrate was far greater than the increase in the rate of NO synthesis after endotoxin challenge.

The elimination half life of nitrite was estimated to be approximately $0.5 \mathrm{~h}$ in dog, sheep and pony (14). The plasma half life of nitrate was much longer, and reached $1.5 \mathrm{~h}$ in mice (15), $3.8 \mathrm{~h}$ in dogs (16), $4.2 \mathrm{~h}$ in sheep (14), $4.8 \mathrm{~h}$ in pony (14), and $5 \mathrm{~h}$ in young adults (17). These figures probably indicate that nitrite is a better parameter of NO production in short-term studies, whereas nitrate may be a better parameter in long-term studies.

Serum $\mathrm{NO}_{x}$ values inversely correlated with renal function (18). The effect of renal function on nitrate concentration should be accounted for in making any consideration on a given pathological condition and NO production as reflected in the nitrate concentration. $\mathrm{NO}_{\mathrm{x}}$ concentrations corrected for the effect of renal failure, were significantly higher in patients with septic shock than in patients without septic shock (19).

\section{Strain differences in NO production}

The basal rate of NO production differed between males of different mouse strains (Figure 2). The basal rate of NO production was higher in male FVB mice than in male C57BL6/J mice $(p<0.10)$. Basal NO synthesis was similar in male Swiss and C57BL6/J mice. In females, strain differences in constitutive NO production were less 
obvious. The fact that basal NO synthesis was different between strains was not obvious from the baseline nitrate concentration (FVB: $21 \pm 3$, Swiss: $26 \pm 3$, C57BL6/J: $36 \pm 7 \mu \mathrm{M}$ ), in line with the previous section.

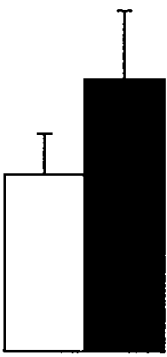

Swiss

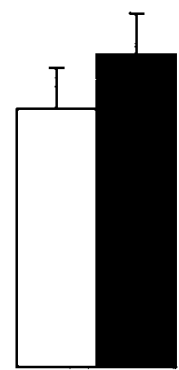

FVB

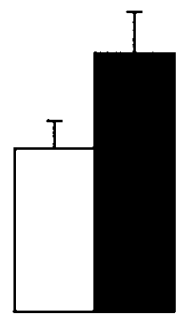

C57BL6/J

Figure 2. NO production rate in male and female Swiss, FVB and C57BL6/J mice under baseline conditions. White bars: male; black bars: female.

The differences in basal NO synthesis may be caused by differences in flux through cNOS, which may be related to polymorphisms in eNOS or nNOS. In human populations, polymorphisms in the NOS genes exist $(20,21)$. In addition, differences in allele frequencies exist between different ethnic populations (20). Possibly, differences in the rate of nitric oxide synthesis also exist between different human populations. As discussed in the previous section it is not possible to detect a difference in basal NO production by plasma nitrite or nitrate differences. The stable isotope method as employed in the present thesis may be useful in this respect. Alternatively, differences in baseline NO production may be caused by differences in the expression level of eNOS or nNOS.

Besides strain differences in baseline cNOS-mediated NO production also the iNOS-mediated response is different between mouse strains. In vivo, we found a 1.8, 2.8, and 2.3-fold increase in systemic NO production in response to treatment with LPS in Swiss, FVB and C57BL/6J mice, respectively. These results are in agreement with the fact that large genetic variation in interferon- $\gamma$ induced NO production by peritoneal macrophages of eight inbred strains of mice were observed in vitro (22). 
These differences in interferon- $y$ induced NO production were tightly associated with differential expression of iNOS mRNA (22). Thus, the expression level of iNOS in response to LPS challenge may be different between mouse strains. $\mathrm{C} 3 \mathrm{H} / \mathrm{HeJ}$ mice are hyporesponsive to LPS, because of a missence mutation in murine TOLL-like receptor 4, the LPS receptor (23). In contrast, Balb/c mice are very sensitive to LPS. Supplementation of arginine or tetrahydrobiopterin did not influence strain related NO production (22).

\section{The arginine:nitric oxide pathway and gender}

In the present thesis male and female mice were used. In general, the basal rate of NO production was higher in female than male mice $(p=0.03)$ (Figure 2). Similar results were obtained in healthy women and men using $\left[{ }^{15} \mathrm{~N}\right]$ arginine to $\left[{ }^{15} \mathrm{~N}\right]$ nitrate conversion (24). In addition, basal release of nitric oxide from aortic rings was greater in female rabbits than in male rabbits (25). The sex difference in basal NO production was the strongest in C57BL6/J mice, and the weakest in FVB mice. This difference in baseline NO synthesis may partly explain why the incidence of cardiovascular disease is lower in women before the menopause compared with men.

The sex difference in basal NO production may theoretically be related to a difference in cNOS activity, or a difference in arginine availability. In the present thesis experiments using intravenous arginase administration and transgenic arginase expression have shown that a reduction of circulating arginine does not limit basal NO production. In OTC-deficient mice, that are not capable of intracellular citrulline synthesis, basal NO production was reduced. The sex difference in basal NO production possibly arises from a difference in cNOS activity or a difference in intracellular citrulline cycling.

NO production is regulated by steroid hormones. Both eNOS and nNOS are upregulated by estrogen (26), and nitric oxide production is stimulated during pregnancy, a high estrogen state. The effect of androgen is opposite to that of estrogen. nNOS activity, mRNA expression or stabilization, and the number of NOScontaining neurons are down-regulated by testosterone, or its metabolite dihydrotestosterone (27). Estrogens provide protection against the development of 
proteinuria caused by chronic mild NOS inhibition, whereas androgens are responsible for the increased sensitivity of male rats (28).

Table 1. Proportional increase in NO production in response to LPS treatment in male and female mice.

\begin{tabular}{lcc}
\hline & Male & Female \\
\hline Swiss & 1.8 & 2.5 \\
FVB & 2.8 & 1.4 \\
C57BL6/J & 2.3 & 1.4 \\
\hline
\end{tabular}

In response to LPS treatment NO production was increased in all groups of mice evaluated. In Swiss mice, the increase in NO production was 1.8-fold in males and 2.5-fold in females (Table 1). In contrast, in FVB and C57BL6/J mice the increase in NO production after LPS injection was more pronounced in male than female animals (Table 1). Female BALB/c mice were found to produce two-fold higher levels of IFN-beta and TNF-alpha than male BALB/c mice (29).

In females, stimulatory and inhibitory effects of hormones on iNOS gene expression have been described. Estrogen receptor stimulation induces iNOS gene expression (30). The promotor region of the iNOS gene contains a sequence partly resembling an estrogen responsive element (31). Moreover, female but not male iNOS-deficient mice have a higher mortality due to endotoxemia than their wildtype counterparts, suggesting that estrogen modulates iNOS-mediated protection (32). In contrast, progesterone (which is comparable to androgen) inhibits inducible nitric oxide synthase gene expression and nitric oxide production in murine macrophages (33), suggesting that progesterone-mediated inhibition of NO may be an important gender-based difference between females and males that relates to macrophagemediated host defense.

In chapter 4.3, mice expressing an arginase transgene in enterocytes were used. In these mice, circulating arginine levels are reduced throughout development (34). When adulthood is reached, circulating arginine levels remain reduced in male animals, whereas they reach wild type levels in female animals (female adults: FVB: $174 \pm 22 \mu \mathrm{M}, \mathrm{F} / \mathrm{A}-1: 150 \pm 9 \mu \mathrm{M}, \mathrm{NS})$. It was shown that the transgene expressed 
arginase during early development (34). We did not measure the arginase activity in intestinal tissue of adult transgenic animals. The arginase transgene is under the control of the fatty acid binding protein promoter, which is specifically expressed in the intestines. Possibly, the expression of genes controlled by the fatty acid binding protein promoter is regulated in a gender-specific manner. It has been suggested that estrogens suppress FABP expression, whereas androgens stimulate FABP expression (35). These data imply higher arginase expression in adult male than female F/A-1 animals. In another line of transgenic animals, F/A-2, transgenic arginase activity is higher and the reduction of plasma arginine is aggravated (34). In addition, the F/A-2 mice have a retardation of body growth compared to wild type and F/A-1 mice. Adult male and female F/A-2 animals have $50 \%$ and $25 \%$ reduction of circulating arginine.

\section{Importance of de novo arginine production for NO synthesis}

In chapter 3.3 it was demonstrated that during endotoxemia renal citrulline uptake and arginine release were increased, and the stable isotope measurements confirmed that indeed de novo arginine production from citrulline was increased. In these animals renal protein synthesis was increased, since phenylalanine disposal and the net uptake of total amino acids were increased.

In an earlier study, similar measurements were performed $16 \mathrm{~h}$ after the first injection with LPS, in rats that received a double hit with LPS (36). In this study, renal arginine release was increased, but renal citrulline uptake was not, indicating that the increase in arginine production by the kidney did not originate from citrulline. Possibly, during late endotoxemia in rats, the increase in arginine release was caused by an increase in renal protein breakdown, since the net uptake of total amino acids by the kidney was decreased in these animals. The fact that glutamine uptake was decreased in the rat study without any effect on ammonia kinetics, may also indicate all glutamine metabolized was derived from protein degradation.

Although LPS administration caused an increase in de novo arginine production, reduced circulating arginine levels failed to stimulate de novo arginine production. Our results therefore differ from those obtained by Prins et al who reported that reduced arginine levels are the drive for arginine synthesis (37). Our 
study confirms the studies of Castillo et al and Dhanakoti et al, showing that de novo arginine synthesis is not increased in response to a reduction in dietary arginine intake $(38,39)$. In contrast, oxidation of arginine to ornithine was reduced $(40)$. A 7day arginine-free diet did not influence protein turnover in healthy volunteers (38). In contrast, in male and female F/A-1 mice phenylalanine and tyrosine plasma fluxes were decreased by $20 \%$, indicating a reduction of systemic protein turnover. Reduced protein turnover may have an arginine-sparing effect.

\section{Is circulating arginine the main determinant of NO production?}

From the experiments on eNOS ${ }^{-1-}$ and $\mathrm{iNOS}^{-1-}$ mice in chapter 3 it appears that iNOSmediated NO production is linearly related to circulating arginine. Mice expressing iNOS showed a linear relation between circulating arginine and the rate of NO production. When the iNOS gene was disrupted, the relationship between circulating arginine and the rate of NO production was lost.

In chapter 4 of the thesis three distinct methods to reduce circulating arginine were employed. Of these three models, one model resulted in an acute reduction of circulating arginine, and two models resulted in a chronic reduction of circulating arginine. Acute reduction of circulating arginine was accomplished by injection with bovine arginase into the circulation. The results of the study indicate that although circulating arginine was reduced by $50 \%$, cNOS and iNOS-mediated NO production were not compromised (Table 2). The two chronic models of reduced circulating arginine yielded different results (Table 2). In ornithine transcarbamylase deficient (OTCD) mice circulating arginine was reduced by approximately $30-40 \%$. In these mice, basal cNOS-mediated NO production was compromised. In response to endotoxin treatment, the rate of NO production was increased, indicating that iNOSmediated NO production was not compromised. In another model of reduced arginine availability, the F/A-1 transgenic mice, circulating arginine was reduced by $25 \%$. In these mice, basal cNOS-mediated NO production was unaffected, whereas the increase in iNOS mediated NO production in response to endotoxin treatment was severely compromised. 
Table 2. Effect on cNOS and iNOS-mediated NO production in three models of reduced arginine availability.

\begin{tabular}{ccccc}
\hline Model & $\begin{array}{c}\text { Mechanism of } \\
\text { arginine reduction }\end{array}$ & $\begin{array}{c}\text { Arginine } \\
\text { reduction }\end{array}$ & $\begin{array}{c}\text { Effect on cNOS- } \\
\text { mediated NO } \\
\text { production }\end{array}$ & $\begin{array}{c}\text { Effect on iNOS- } \\
\text { mediated NO } \\
\text { production }\end{array}$ \\
\hline Acute & Arginase injection & $57 \%$ & - & - \\
Chronic & OTC-deficiency & $30-40 \%$ & Reduced & - \\
Chronic & Arginase transgene & $25 \%$ & - & Reduced \\
\hline
\end{tabular}

The decrease in circulating arginine was the largest in the model of acute reduction of arginine by intravenous administration of arginase. Both cNOS and iNOS-mediated NO production were, however, not compromised. Analysis of tissue amino acid concentrations showed that tissue arginine was not reduced in jejunum and kidney. In contrast, the arginine concentration in ileum was reduced by $20 \%$. These results indicate that an acute reduction of circulating arginine compromised arginine availability in a limited number of tissues. At the whole body level, cNOS and iNOS-mediated NO production were not compromised by the decrease in circulating arginine. Intestinal NO production values tended to show a decrease in iNOSmedated NO production, which may be related to the decreased arginine concentration in ileum.

The studies in which circulating arginine was reduced in a chronic fashion yielded different results. The difference between the models is the mechanism leading to reduced arginine availability. OTC deficiency is a urea cycle enzyme defect. Reduced circulating arginine is not the sole manifestation in patients and animals with this genetic defect. In contrast, the arginase transgenic F/A mice were engineered to reduced circulating arginine.

Certain cells expressing cNOS are capable of citrulline synthesis from ornithine and $\mathrm{NH}_{4}{ }^{+}$. This capacity is compromised in OTC-deficient animals, but not in F/A transgenic animals. This difference could explain why cNOS-mediated NO production was compromised in OTC-deficient mice, but not in F/A transgenic mice. iNOS-mediated NO production appears dependent on circulating arginine. In OTCdeficient mice, LPS-treatment caused an increase in circulating arginine and an increase in iNOS-mediated NO production. Circulating arginine and NO production were however still lower than in wild type animals. 
Regardless of the differences between the two models of reduced circulating arginine, the studies described in the thesis indicate that a chronic reduction of circulating arginine can lead to a reduction of the rate of NO production in vivo.

\section{Future directions}

Conversely, on the basis of the considerations as described above, supplementation of arginine may increase the rate of NO production. Although supplemented arginine may predominantly be metabolized by arginase, nitric oxide production could also increase. For some years already, enteral and parenteral nutrition enriched with arginine are available. Arginine supplementation has been associated with positive effects on the immune status of immune-depressed patients, improved wound healing, nitrogen retention, and reduced length of hospital stay, and survival (41-43). Surprisingly, not one study mentioned baseline circulating arginine. It is therefore largely unknown whether circulating arginine was deficient or not. In addition, the effect of arginine supplementation on arginine metabolism and the rate of NO production is seldom reported. It would obviously be interesting to study the effects of arginine supplementation on systemic NO production in F/A and OTC-deficient mice. Arginine supplementation may normalise cNOS-mediated NO production in OTCdeficient mice. In F/A mice arginine supplementation could lift iNOS-mediated NO production to wild type levels. In addition, it may be interesting to measure arginine metabolism and the rate of nitric oxide production in patients with reduced circulating arginine. Circulating arginine is reduced in a number of conditions, including after aortic surgery (44). In a clinical setting it would also be possible to relate the effect of reduced arginine availability, and the effects of arginine supplementation to arginine metabolism, the rate of NO production and clinical end-points.

Many NOS inhibitors have been manufactured in order to reduce NO production (3-7). Again, the effects of these inhibitors on clinical end-points have been evaluated, but the effects on the rate of NO production have not been measured. The effects of most inhibitors in clinical studies have mostly been disappointing and often not understood (45). In the future it may thus be critical to first evaluate the effects on the rate of NO production and correlate these to clinical end-points. 
In the F/A transgenic mice, baseline NO production was not reduced despite a $25 \%$ reduction of circulating arginine. Nevertheless, the vascular relaxation response to acetylcholine was severely compromised in these animals [Hallemeesch, Schiffers, Lamers, Deutz, De Mey, unpublished data]. To the best of our knowledge this is the first direct support that a reduction of circulating arginine causes malfunction of blood vessels. This may suggest a relationship with atherosclerosis, possibly an arginine deficiency disease (46). Atherosclerosis develops and progresses spontaneously in apolipoprotein E-deficient $\left(A p o E^{-/}\right)$mice (47). Arginine treatment did not affect lesion formation $(48,49)$ or endothelial function $(48)$ in these animals. Circulating arginine levels under baseline conditions, after treatment and in the wild type animals were, however, not reported $(48,49)$. In conditions of reduced arginine availability, NOS may produce superoxide (50). Increased vascular superoxide production could result in decreased nitric oxide (NO) bioactivity. Superoxide and NO may form peroxynitrite, which in turn may cause nitrotyrosine to be formed. It could be interesting to obtain direct support of an increase in superoxide production in vessels of F/A mice. The importance of arginine in this respect may be further characterized by measuring the vascular relaxation response in F/A mice supplemented with arginine.

Hypercholesterolemia, an established risk factor for cardiovascular disease, causes endothelial dysfunction at a very early stage. Arginine supplementation improved endothelium-dependent forearm vasodilution $(51,52)$, and this improvement was similar to that after treatment with lipid-lowering medication (53). In a pilot experiment, F/A transgenic mice had a tendency towards higher lipid levels (Table 3 ), suggesting that the reduction of circulating arginine caused an increase in circulating lipids. This observation deserves some more attention.

Table 3. Arterial cholesterol and triglycerides in FVB and F/A-2 mice.

\begin{tabular}{lccccccc}
\hline & \multicolumn{3}{c}{ FVB } & \multicolumn{4}{c}{ F/A-2 } \\
\hline Cholesterol $(\mu \mathrm{M})$ & 70 & \pm & 20 & 90 & \pm & 20 \\
Triglycerides $(\mathrm{mM})$ & 1.7 & \pm & 0.2 & & 1.9 & \pm & 0.5 \\
\hline
\end{tabular}

In conclusion, in the present thesis a methodology to measure metabolic parameters in mice was developed. Using this methodology arginine metabolism was 
explored under baseline conditions and during endotoxemia, and the contribution of the NOS isoforms to the rate of NO production during baseline and LPS-stimulated conditions was determined. In addition, the effect of reduced circulating arginine levels on cNOS and iNOS-mediated NO production was measured in three different models. The mechanism by which the reduction of arginine was caused determined the effect on the rate of NO production.

\section{References}

1. Castillo L, Beaumier L, Ajami AM, Young VR. Whole body nitric oxide synthesis in healthy men determined from [15N]-arginine-to-[15N]citrulline labeling. Proc.Natl.Acad.Sci.USA 1996;93:11460-11465.

2. Pryor WA, Squadrito GL. The chemistry of peroxynitrite: a product from the reaction of nitric oxide with superoxide. Am.J.Physiol. 1995;268:L699-L722.

3. Rees DD, Palmer RMJ, Hodson HF, Moncada S. A specific inhibitor of nitric oxide formation from L-arginine attenuates endothelium-dependent relaxation. Br.J.Pharmacol. 1989;96:418424.

4. Southan GJ, Szabo C. Selective pharmalogical inhibition of distinct nitric oxide synthase isoforms. Biochem.Pharmacol. 1996;51:383-394.

5. Southan GJ, Szabo C, Thiemermann C. Isothioureas: potent inhibitors of nitric oxide synthases with variable isoform selectivity. Br.J.Pharmacol. 1995;114:510-516.

6. Liaudet L, Feihl F, Rosselet A, Markert M, Hurni J-M, Perret C. Beneficial effects of Lcanavaline, a selective inhibitor of inducible nitric oxide synthase, during rodent endotoxaemia. Clin.Sci. 1996;90:369-377.

7. Narayanan K, Spack L, McMillan K, Kilbourn RC, Hayward MA, Siler Masters BS, et al. SAlkyl-L-thiocitrullines. Potent stereoselective inhibitors of nitric oxide synthase with strong pressor activity in vivo. J.Biol.Chem. 1995;270(19):11103-11110.

8. Ravichandran LV, Johns RA, Rengasamy A. Direct and reversible inhibition of endothelial nitric oxide synthase by nitric oxide. Am.J.Physiol. 1995;268:H2216-H2223.

9. Kelm M, Feelisch M, Spahr R. Quantitative and kinetic characterization of nitric oxide and EDRF release from cultured endothelial cells. Biochem Biophys Res Commun 1988;154:236244.

10. Ignarro LJ, Fukuto JM, Griscavage JM, Rogers NE, Byrns RE. Oxidation of nitric oxide in aqueous solutions to nitrite but not nitrate: Comparison with enzymatically formed nitric oxide from L-arginine. Proc.Natl.Acad.Sci.USA 1993;90:8103-8107.

11. Watanabe $T$, Akishita $M$, Toba $K$, Kozaki $K$, Eto $M$, Sugimoto $N$, et al. Influence of sex and age on serum nitrite/nitrate concentration in healthy subjects. Clin Chim Acta 2000;301:169-179. 
12. Castillo L, Sanchez M, Vogt J, Chapman TE, DeRojas-Walker TC, Tannenbaum SR, et al. Plasma arginine, citrulline, and ornithine kinetics in adults, with observations on nitric oxide synthesis. Am.J.Physiol. 1995;268:E360-E367.

13. Rhodes PM, Leone AM, Francis PL, Struthers AD, Moncada S. The L-arginine:nitric oxide pathway is the major source of plasma nitrite in fasted humans. Biochem.Biophys.Res.Comm. 1995;209(2):590-596.

14. Schneider NR, Yeary RA. Nitrite and nitrate pharmacokinetics in the dog, sheep, and pony. Am J Vet Res 1975;36:941-947.

15. Veszelovszky E, Holford NHG, Thomsen LL, Knowles RG, Baguley BC. Plasma nitrate clearance in mice: modelling of the systemic production of nitrate following the induction of nitric oxide synthesis. CancerChemother.Pharmacol. 1995;36:155-159.

16. Zeballos GA, Bernstein RD, Thompson Cl, Forfia PR, Seyedi N, Shen W, et al. Pharmacokinetics of plasma nitrate/nitrite as an indicator of nitric oxide formation in conscious dogs. Circulation 1995;91:2982-2988.

17. Wagner DA, Schultz DS, Deen WM, Young VR, Tannenbaum SR. Metabolic fate of an oral dose of $15 \mathrm{~N}$-labeled nitrate in humans: effect of diet supplementation of ascorbic acid. Cancer Res 1983;43:1921-1925.

18. Mackenzie IM, Ekangaki A, Young JD, Garrard CS. Effect of renal function on serum nitrogen oxide concentrations. Clin Chem 1996;42(3):440-4.

19. Mackenzie IM, Garrard CS, Young JD. Indices of nitric oxide synthesis and outcome in critically ill patients. Anaesthesia 2001;56:326-330.

20. Grasemann H, Drazen JM, Deykin A, Israel E, De Sanctis GT, Pillari A, et al. Simple tandem repeat polymorphisms in the neuronal nitric oxide synthase gene in different enthnic populations. Hum Hered 1999;49:139-141.

21. Yoon $Y$, Song J, Hong SH, Kim JQ. Plasma nitric oxide concentrations and nitric oxide synthase gene polymorphisms in coronary heart disease. Clin Chem 2000;46:1626-1630.

22. Zidek Z, Frankova D, Boubelik M. Genetic variation in in-vitro cytokine-induced production of nitric oxide by murine peritoneal macrophages. Pharmacogenetics 2000;10:493-501.

23. Poltorak A, He X, Smirnova 1, Liu MY, Huffel CV, Du X, et al. Defective LPS signaling in C3H/HeJ and C57BL/10ScCr mice: mutations in TIr4 gene. Science 1998;282:2085-2088.

24. Forte P, Kneale BJ, Milne E, Chowienczyk PJ, Johnston A, Benjamin N, et al. Evidence for a difference in nitric oxide biosynthesis between healthy women and men. Hypertension 1998;32:730-734.

25. Hayashi T, Fukuto JM, Ignarro LJ, Chaudhuri G. Basal release of nitric oxide from aortic rings is greater in female rabbits than in male rabbits: implications for atherosclerosis. Proc Natl Acad Sci USA 1992;89:11259-11263.

26. Weiner CP, Lizasoain I, Baylis SA, Knowles RG, Charles IG, Moncada S. Induction of calciumdependent nitric oxide synthases by sex hormones. Proc Natl Acad Sci 1994;91:5212-5216. 
27. Singh R, Pervin S, Shryne J, Gorski R, Chaudhuri G. Castration increases and androgens decrease nitric oxide synthase activity in the brain: physiologic implications. Proc Natl Acad Sci 2000;97:3672-3677.

28. Verhagen AMG, Attia DMA, Koomans HA, Joles JA. Male gender increases sensitivity to proteinuria induced by mild NOS inhibition in rats: role of sex hormones. Am J Physiol: Renal Physiol. 2000;279:F664-F670.

29. Zaczynska E, Broniarek E, Blach-Olszewska Z. Spontaneous and lipopolysaccharide-induced tumor necrosis factor alpha and interferon beta production by resident peritoneal cells of mice: effects of sex, age and strain. Arch Immunol Ther Exp 1993;41:67-71.

30. Grohe C, Kahlert S, Lobbert K. Expression of oestrogen receptor alpha and beta in rat heart: role of local oestrogen synthesis. J Endocrinol 1998;156:R1-R7.

31. Chartrain NA, Geller DA, Koty PP. Molecular cloning, structure, and chromosomal localization of the human inducible nitric oxide synthase gene. J Biol Chem 1994;269:6765-6772.

32. Laubach VE, Foley PL, Shockey KS, Tribble CG, Kron IL. Protective roles of nitric oxide and testosterone in endotoxemia: evidence from NOS-2 deficient mice. Am J Physiol 1998;275:H2211-H2218.

33. Miller L, Alley EW, Murphy WJ, Russell SW, Hunt JS. Progesterone inhibits inducible nitric oxide synthase gene expression and nitric oxide production in murine macrophages. $J$ Leukocyte Biol 1996;59:442-450.

34. De Jonge WJ, Hallemeesch MM, Kwikkers KL, Ruijter JM, De Gier-de Vries C, Van Roon MA, et al. Overexpression of arginase $I$ in enterocytes of transgenic mice elicits a selective arginine deficiency and affects skin, muscle and lymphoid development. Am J Clin Nutr 2001; accepted.

35. Bogdarin YA. Effect of estrogen-receptor interaction on the levels of fatty-acid binding proteins and spectra of free acids in small intestinal mucosa of rabbits. Exp Clin Endocrinol 1990;96:177-184.

36. Hallemeesch MM, Cobben DCP, Dejong CHC, Soeters PB, Deutz NEP. Renal amino acid metabolism during endotoxemia in the rat. J Surg Res 2000;92:193-200.

37. Prins HA, Houdijk AP, Wiezer MJ, Teerlink T, van Lambalgen AA, Thijs LG, et al. Reduced arginine plasma levels are the drive for arginine production by the kidney in the rat. Shock 1999;11(3):199-204.

38. Castillo L, Ajami A, Branch S, Chapman TE, Yu YM, Burke JF, et al. Plasma arginine kinetics in adult man: response to an arginine-free diet. Metabolism 1994;43(1):114-122.

39. Dhanakoti SN, Brosnan JT, Brosnan ME, Herzberg GR. Net renal flux in rats is not affected by dietary arginine or dietary protein intake. J Nutr 1992;122:1127-1134.

40. Castillo L, Sanchez M, Chapman TE, Ajami A, Burke JF, Young VR. The plasma flux and oxidation rate of ornithine adaptively decline with restricted arginine intake.

Proc.Natl.Acad.Sci.USA 1994;91:6393-6397.

41. Barbul A, Sisto DA, Wasserkrug HL, Efron G. Arginine stimulates lymphocyte immune response in healthy human beings. Surgery 1981;90:244-251. 
42. Barbul A, Lazarou SA, Efron DT, Wasserkrug HL, Efron G. Arginine enhances wound healing and lymphocyte immune responses in humans. Surgery 1990;108:331-337.

43. Van Bokhorst-de van der Schueren MAE, Quak JJ, Von Blomberg-Van der Flier BME, Kuik DJ, Langendoen SI, Snow GB, et al. Effect of perioperative nutrition, with and without arginine supplementation, on nutritional status, immune function, postoperative mordibity, and survival in severely malnourished head and neck cancer patients. Am J Clin Nutr 2001;73:323-332.

44. Nijveldt RJ, Prins HA, Siroen MP, Rauwerda JA, Teerlink T, Van Leeuwen PA. Low arginine plasma levels in patients after thoracoabdominal aortic surgery. Eur $\mathrm{J}$ Clin Nutr 2000;54:615617.

45. Grover R, Zaccardelli D, Colice G, Guntupalli K, Watson D, Vincent JL. An open-label dose escalation study of the nitric oxide synthase inhibitor, $\mathrm{Ng}$-methyl-L-arginine hydrochloride (546C88), in patients with septic shock. Crit Care Med 1999;27:913-922.

46. Cooke JP. Is atherosclerosis an arginine deficiency disease? J Investig Med 1998;46:377-80.

47. Bonthu S, Heistad DD, Chappell DA, Lamping KG, Faraci FM. Atheroscierosis, vascular remodeling, and impairment of endothelium-dependent relaxation in genetically altered hyperlipidemic mice. Atheroscler Thromb Vasc Biol 1997;17:2333-2340.

48. Kauser K, Da Cunha V, Fitch R, Mallari C, Rubanyi GM. Role of endogenous nitric oxide in progression of atherosclerosis in apolipoprotein E-deficient mice. Am J Physiol Heart Circ Physiol 2000;278:H1679-H1685.

49. Kuhlencordt PJ, Chen J, Han F, Astern J, Huang PL. Genetic deficiency of inducible nitric oxide synthase reduces atherosclerosis and lowers plasma lipid peroxides in apolipoprotein $\mathrm{E}$ knockout mice. Circulation 2001;103:3099-3104.

50. Xia Y, Dawson VL, Dawson TM, Snyder SH, Zweier JL. Nitric oxide synthase generates superoxide and nitric oxide in arginine-depleted cells leading to peroxynitrite-mediated cellular injury. Proc.Natl.Acad.Sci.USA 1996;93:6770-6774.

51. Creager MA, Gallagher SJ, Girerd XJ, Coleman SM, Dzau VJ, Cooke JP. L-arginine improves endothelium dependent vasodilation in hypercholesterolemic humans. $\mathrm{J}$ Clin Invest 1992;90:1248-1253.

52. Casino PR, Kilcoyne CM, Quyyumi AA, Hoeg JM, Panza JA. Investigation on decreased availability of nitric oxide precursor as the mechanism responsible for impaired endothelium dependent vasodilation in hypercholesterolemic patients. J Am Coll Cardiol 1994;23:844-850.

53. Stroes ESG, Koomans HA, DeBruin TWA, Rabelink TJ. Vascular function in the forearm of hypercholesterolemic patients off and on lipid-lowering medication. Lancet 1995;346:467-471. 
Samenvatting 
Het aminozuur arginine is de enige precursor voor stikstof oxide in het lichaam. De vorming van stikstof oxide uit arginine wordt gemedieerd door het enzym stikstof oxide synthase. Van dit enzym bestaan twee varianten: het constitutieve stikstof oxide synthase, wat verder onder te verdelen is in het endotheliaal stikstof oxide synthase en het neuronaal stikstof oxide synthase, en het induceerbare stikstof oxide synthase. Het constitutieve enzym heeft een belangrijke functie in bijvoorbeeld de bloedvattonus en in zenuwgeleiding. Het induceerbare enzym wordt aangemaakt tijdens sepsis. Doel van de experimenten beschreven in dit proefschrift was om het effect van verminderde aanwezigheid van arginine op de vorming van stikstof oxide door constitutief en induceerbaar stikstof oxide synthase te bepalen.

Het proefschrift bestaat uit drie delen. Eerst wordt een model geïntroduceerd om in verdoofde levende muizen stofwisseling te meten in verschillende organen (darm, lever, nier en spier). Ook wordt in het eerste deel uitgezocht of de metingen in de volgende hoofdstukken van het proefschrift moeten worden gedaan in volbloed of in bloedplasma. In het tweede deel van het proefschrift worden de effecten van het toedienen van bacteriële endotoxinen op de vorming van stikstof oxide en de arginine stofwisseling bestudeerd. Tot slot wordt het effect van een verlaagde arginine spiegel op de vorming van stikstof oxide bestudeerd.

Hoofdstuk 1 van het proefschrift vormt een algemene introductie tot de stofwisseling van arginine. De beschikbaarheid van arginine in cellen wordt bepaald door het transport van arginine over de celmembraan, het gebruik van arginine door arginase en de nieuwvorming van arginine uit citrulline.

In het laboratorium zijn nog niet eerder muizen gebruikt voor dit soort metingen. In hoofdstuk 2 wordt de ontwikkeling van een model om stofwisseling in darm, lever, nier en spier te meten beschreven. $E r$ is aandacht voor stabiele verdoving, de afname van bloed en het meten van bloedflow in muizen. Het blijkt mogelijk om met behulp van dit model aminozuur stofwisseling van aminozuren in organen te meten in muizen. Ook wordt in hoofdstuk 2 bekeken of metingen aan de stofwisseling met behulp van isotopen moeten worden gedaan in volbloed of bloedplasma. Er worden grote fouten gemaakt indien metingen in volbloed worden gedaan en in volgende hoofdstukken van het proefschrift worden de metingen daarom verricht in bloedplasma. 
In hoofdstuk 3 is het effect van het geven van bacteriële endotoxinen (een benadering voor sepsis) op het metabolisme van arginine en stikstof oxide bestudeerd. Als endotoxinen worden gegeven neemt de productie van stikstof oxide toe. Ook neemt de nieuwvorming van arginine in de nier toe. In de darm neemt de eiwitsynthese toe en neemt het verbruik van arginine door arginase af. In de lever was er geen significant effect op de eiwitturnover, en was er een duidelijke toename van het verbruik van arginine door arginase. In dit hoofdstuk wordt ook gekeken naar de bijdrage van de verschillende stikstof oxide synthase enzymen aan de vorming van stikstof oxide. Endotheliaal stikstof oxide synthase en neuronaal stikstof oxide synthase dragen beide $50 \%$ bij aan de basale vorming van stikstof oxide. Er is geen basale stikstof oxide productie door induceerbaar stikstof oxide synthase. Na het behandelen van muizen met bacteriële endotoxinen, neemt de productie van stikstof oxide toe. Deze toename is volledig toe te schrijven aan induceerbaar stikstof oxide synthase. De vorming van stikstof oxide door constitutief stikstof oxide synthase is zelfs afgenomen.

In hoofdstuk 4 wordt in drie verschillende modellen gekeken naar het effect van verlaagde arginine spiegels in het bloedplasma op de vorming van stikstof oxide. Allereerst is een kortdurende verlaging van de arginine spiegel bereikt door het injecteren van arginase. Hoewel de arginine spiegel daalt met bijna $60 \%$, is er geen effect op de vorming van stikstof oxide door constitutief en/of induceerbaar stikstof oxide synthase. Daarna wordt onderzoek verricht naar het effect van een chronische verlaging van de arginine spiegel. Er worden 2 verschillende genetisch veranderde muizen gebruikt: de ornithine transcarbamylase (OTC)-deficiënte muis, en een transgene muis die levertype arginine tot expressie brengt in de darm. In deze verschillende modellen van verlaging van de arginine spiegel wordt ook een verschillend effect op de vorming van stikstof oxide waargenomen. OTC-deficiënte muizen hebben een 30-40\% lagere arginine spiegel dan controle muizen. Dit leidt tot een duidelijke daling van de basale stikstof oxide productie. De verlaagde arginine spiegel kan echter niet de toename in induceerbaar stikstof oxide synthase gemedieerde stikstof oxide productie tijdens endotoxine behandeling verhinderen. In de transgene muis is de arginine spiegel $30 \%$ lager dan in een normale (wild type) muis. Het blijkt dat de constitutieve stikstof oxide productie normaal was en dat de stikstof oxide productie door induceerbaar stikstof oxide synthase lager was dan in de controle muis. Er is in dit model geen duidelijk verband tussen de plasma arginine 
concentratie en de vorming van stikstof oxide. De samenvatting van dit proefschrift luidt daarom: verlaging van circulerend arginine leidt niet zonder meer tot verlaagde stikstof oxide productie (stelling 1). 
Publications 
Presented in the thesis

- Hallemeesch MM, Lamers WH, Deutz NEP. Reduced arginine availability and nitric oxide production. Clin Nutr 2001; In Press.

- Hallemeesch MM, Soeters PB, Deutz NEP. Tracer methodology in whole body and organ balance metabolic studies: plasma sampling is required. A study in post-absorptive rats using isotopically labeled arginine, phenylalanine, valine and leucine. Clin Nutr 2000; 19(3): 157-163.

- Hallemeesch MM, Ten Have GAM, Deutz NEP. Measurement of metabolic fluxes across PDV, liver, kidney and hindquarter in mice. Lab Anim 2001; 35: 101-110.

- Hallemeesch MM, Lamers WH, Meijer AJ, Soeters PB, Deutz NEP. In vivo rate of NO synthesis is increased during mouse endotoxemia. Submitted.

- Hallemeesch MM, Soeters PB, Deutz NEP. Renal arginine and protein synthesis are increased during early endotoxemia in mice. Am J Physiol: Renal Physiol 2001; In Press.

- Hallemeesch MM, Lamers WH, Soeters PB, Deutz NEP. Endotoxemia differentially affects arginine and protein metabolism in intestine and liver of mice. Submitted.

- Hallemeesch MM, Vissers YLJ, Soeters PB, Deutz NEP. Acute reduction of circulating arginine in mice does not compromise cNOS or iNOS-mediated NO production. Submitted.

- Hallemeesch MM, Janssen BJA, De Jonge WJ, Soeters PB, Lamers WH, Deutz NEP. Increased iNOS-mediated and decreased cNOS-mediated NO production rates reflect blood pressure changes in LPS-challenged mice. Submitted. 
Other publications

- Van Raaij MT, van den Thillart GE, Hallemeesch M, Balm PH, Steffens AB. Effect of arterially infused catecholamines and insulin on plasma glucose and free fatty acids in carp. Am J Physiol 1995; 268: R1163-70.

- Hallemeesch MM, Lamers WH, Soeters PB, Deutz NEP. Increased lactulose rhamnose ratio during fluid load is caused by increased urinary lactulose excretion. Am J Physiol 2000; 278: G83-88.

- Hallemeesch MM, Cobben DCP, Dejong CHC, Soeters PB, Deutz NEP. Renal amino acid metabolism during endotoxemia in the rat. J Surg Res 2000; 92: 193200.

- De Jonge WJ, Marescau B, D'Hooge R, De Deyn PP, Hallemeesch MM, Deutz NEP, Ruijter JM, Lamers WH. Effect of arginine deficiency on circulating and tissue amino acids and guanidino compounds, and on behavioral development. J Nutr 2001; 131(10): 2732-2740.

- Hallemeesch MM, Cobben DCP, Soeters PB, Deutz NEP. Differential effects of selective and non-selective NOS inhibition on renal arginine metabolism during endotoxemia in rats. Clin Nutr 2001; In Press.

- Soeters PB, Hallemeesch MM, Bruins MJ, Van Eijk HMH, Deutz NEP. Quantitative in vivo assessment of arginine utilization and nitric oxide production in endotoxemic mice and pigs. Am J Surg 2001, In Press.

- De Jonge WJ, Hallemeesch MM, Kwikkers KL, Ruijter JM, De Gier-de Vries C, Van Roon MA, Meijer AJ, Marescau B, D'Hooge R, DeDeijn PP, Deutz NEP, Lamers WH. Overexpression of arginase I in enterocytes of transgenic mice elicits a selective arginine deficiency and affects skin, muscle and lymphoid development. Submitted. 
Publications 
Dankwoord 
Hoewel het schrijven van een proefschrift een individuele sport is, staan er toch een heleboel begeleiders, verzorgers en supporters aan de zijlijn.

Allereerst bedank ik mijn ouders. Jullie moedigen mij steeds aan nieuwe dingen te ondernemen en jullie hebben altijd vertrouwen in een goede afloop. ... Pa en ma, bedankt voor alles!

Professor Soeters. Beste Peter, je hebt regelmatig geprobeerd de experimenten wat medischer te maken. Hoewel dat niet altijd gewaardeerd werd heb ik er wel van geleerd.

Professor Lamers. Beste Wout, vooral in de laatste fase, toen de afstand een stuk korter was geworden, hebben we veel contact gehad. Ik wil je hartelijk bedanken voor het enthousiasme en de altijd snelle reacties op vragen, problemen en ideeen.

Dr. Deutz. Beste Mick, er klonk her en der wat hoon gelach toen we besloten hadden om over te stappen van de rat naar de muis als proefdier. Metabole experimenten in muizen zijn mogelijk en dit proefschrift bewijst dat! Bedankt voor alle hulp bij de uitvoering van de experimenten.

Dr. Meijer. Beste Fred, in de oorspronkelijke projectaanvraag was een duidelijkere samenwerking met je voorzien. De in vivo experimenten duurden langer dan verwacht en daardoor is het er niet meer van gekomen. Dit is eigenlijk heel jammer.

Maaike Bruins. Beste Maaike, samen hebben we vanuit het Leidse de overstap naar Maastricht gemaakt. Het was niet altijd makkelijk en ik heb erg veel steun aan je gehad. Geweldig dat we de periode nu samen kunnen afsluiten met onze promoties op dezelfde dag! Een betere paranimf kan ik me niet voorstellen!

De Amsterdammers van het arginine project: Wout Lamers, Wouter de Jonge, Karin Kwikkers en Fred Meijer. Jullie kwamen steevast te vroeg opdraven voor arginine meetings in Maastricht. Wat een inzet! Wouter en Karin wil ik in het bijzonder bedanken voor het fokken van muizen met allerlei genetische afwijkingen.

De vaste bevolking van het aminozuur lab, inmiddels Metabolic Research Centre: Hans van Eijk, Jean Scheyen en Gabrie ten Have. Hans, jij was de eerste enige echte Limburger van het lab. Bedankt voor de talloze bepalingen en zeker ook voor de vele serieuze gesprekken! Jean, jij bent de opkomende MS-MS-MS-MS koning. Wat? Moet je een kopstoot! Bedankt voor de gezelligheid en het altijd bereid zijn nog 
eens naar een integratie te kijken. Gabrie, jij hebt de meeste rotzooi gesignaleerd van iedereen. Vaak was ik daar de oorzaak van. Bedankt voor de hulp bij de eerste stappen in muizenland en het overnemen van experimenten. In dit rijtje hoort natuurlijk ook Dennis Rooyakkers thuis. Dennis, samen hebben we met 6 verschillende derivaten, maar zonder succes, geprobeerd nitrotyrosine te detecteren. Als je het er niet in stopt kan je het ook niet meten! Ik vond het erg jammer dat je weg ging uit Maastricht.

De kamergenoten: Maaike Bruins, Jessica ter Steege, Juanita Vernooy, Steven Olde Damink, Martin Jäkel, Karel Hulsewé, Stephanie Breitfeld en Yvonne Vissers.

Sommigen daarvan ook bedankt voor hun bijdrage aan de borrels in de stad waarop de nodige kIOlO problemen verdronken werden. Jessica, bedankt voor je gezelligheid en interesse, en voor de pogingen om nitrotyrosine te meten met behulp van ELISA. Altijd weer dat nitrotyrosine! Yvonne, ook bedankt voor het oefenen van opereren in de vorm van de acute arginine verlagingsproef. Steffi, thanks for guarding my room while I was away and for friendship while I was there! De post-doc, Bernadette van Acker, bedankt voor gezellige etentjes. Binnenkort weer? Kees Dejong is altijd bereid om wat hopeloze verhalen uit het slop te trekken. Een aanrader voor iedereen! Kees, bedankt. Ben Janssen wil ik bedanken voor zijn belangrijke bijdrage in de vorm van bloeddruk en hartslagmetingen.

Ook veel dank aan Ton van de Bogaard en de medewerkers van de Centrale Proefdiervoorzieningen voor de verzorging van de proefdieren, en aan Heleen Erkens en Jos Kop van het RNL.

De leden van de beoordelingscommissie, Professor Ramsay, Dr. Ajami, Professor De Mey, Professor Jacobs en Professor Rabelink wil ik bedanken voor hun bereidheid het proefschrift te beoordelen. Dr. Ajami, dear Alfred, thank you very much for your interest in my work and for many stimulating conversations.

De uitgever, Ferdy Weisz, bedankt voor het uitgeven van dit geheel.

De andere paranimf, Tamara van Heel. We hebben al verschillende fases samen doorlopen. Ik ben blij dat je er nu ook weer bij bent!

Verder wil ik mijn VU-collega's van het vaatlab en het metabole lab bedanken, in het bijzonder Mariska Lieuw-A-Fa, Wim Kulik en Hanneke van den Akker.

Tenslotte, lieve Paul, een regel is natuurlijk te weinig om te zeggen wat ik voor je voel. Bedankt voor alle hulp tijdens het schrijven. Nu is het af! Het feest kan beginnen! 
Dankwoord 
Curriculum vitae

Curriculum vitae 
Curriculum vitae

Marcella M. Hallemeesch werd op 23 februari 1971 geboren te Den Haag. In 1989 behaalde zij het diploma Atheneum B aan het Rijnlands Lyceum te Wassenaar. In datzelfde jaar begon zij aan de studie Biologie aan de Universiteit Leiden. Na stages Dierfysiologie (Universiteit Leiden), Parasitologie (Universitas Indonesia, Jakarta, Indonesië), en Biochemie (Universite Libre de Bruxelles, België) werd in 1995 het doctoraal examen Biologie gehaald. In november 1995 begon zij aan het promotieonderzoek bij de afdeling Algemene Heelkunde van de Universiteit Maastricht, wat leidde tot dit proefschrift. Sinds juli 2000 is zij werkzaam bij de afdeling Klinische Chemie van de Vrije Universiteit te Amsterdam. 